UNIVERSIDADE DE BRASÍLIA

FACULDADE DE CIÊNCIAS DA SAÚDE

PATRÍCIA DINIZ ANDRADE

MICOTOXINAS EM CEREAIS E SEUS PRODUTOS: DESENVOLVIMENTO DE MÉTODO ANALÍTICO E AVALIAÇÃO DO RISCO DA EXPOSIÇÃO NA DIETA 
PATRÍCIA DINIZ ANDRADE

MICOTOXINAS EM CEREAIS E SEUS PRODUTOS: DESENVOLVIMENTO DE MÉTODO ANALÍTICO E AVALIAÇÃO DO RISCO DA EXPOSIÇÃO NA DIETA

Tese de Doutorado apresentada ao Programa de PósGraduação em Ciências Farmacêuticas da Faculdade de Ciências da Saúde, Universidade de Brasília, como requisito parcial à obtenção do título de Doutora em Ciências Farmacêuticas.

Orientadora: Eloisa Dutra Caldas

Brasília

2016 


\title{
MICOTOXINAS EM CEREAIS E SEUS PRODUTOS: DESENVOLVIMENTO DE MÉTODO ANALÍTICO E AVALIAÇÃO DO RISCO DA EXPOSIÇÃO NA DIETA
}

Tese de Doutorado apresentada ao Programa de Pós-Graduação em Ciências Farmacêuticas da Faculdade de Ciências da Saúde, Universidade de Brasília, como requisito parcial à obtenção do título de Doutora em Ciências Farmacêuticas.

Aprovada em 12 de Agosto de 2016.

\section{Banca examinadora}

\author{
Prof $^{\mathrm{a}}$. Dr ${ }^{\mathrm{a}}$. Eloisa Dutra Caldas - Universidade de Brasília
}

Prof $^{\mathrm{a}}$. Dr ${ }^{\mathrm{a}}$. Adriana Pavesi Arisseto Bragotto - Universidade Estadual de Campinas

Prof. Dr. Fernando Fabriz Sodré - Universidade de Brasília

Prof $^{\mathrm{a}}$. Dr ${ }^{\mathrm{a}}$. Marta Hiromi Taniwaki - Instituto de Tecnologia de Alimentos

Prof. Dr. Carlos Martín Infante Córdova - Universidade de Brasília 


\section{AGRADECIMENTOS}

Aos meus pais, Vander e Silvana, pelas palavras de incentivo, amor e por me desafiarem a buscar sempre meus objetivos. Aos meus irmãos, Dudu e Gum, por fazerem parte da minha caminhada, me apoiando e acolhendo. Ao Peter, pelo amor e companheirismo.

À professora Eloisa pela orientação, confiança, apoio e disponibilidade em todas as etapas deste trabalho. Sou muita grata pelos ensinamentos e oportunidades recebidos.

Ao CNPq e CAPES pelo auxílio financeiro.

Ao Dr. Philippe Verger (OMS) pelo auxílio na extração dos dados do GEMS/Food e ao Grupo Técnico de Contaminantes em Alimentos por todas as sugestões.

Aos professores Dr ${ }^{\mathrm{a}}$. Adriana Pavesi Arisseto Bragotto, Dr. Fernando Fabriz Sodré, Dr ${ }^{\mathrm{a}}$. Marta Hiromi Taniwaki e Dr. Carlos Martín Infante Córdova por aceitarem o convite de participação na banca.

À Rebecca, Tati, Nathalya e Gabriel pela grande ajuda na análise das amostras.

À Diana e Jéssica França pela ajuda no desenvolvimento e validação do método e à Alessandra pela colaboração na estimativa dos dados de consumo da POF.

À Denise, Jéssica Pinheiro, Jose e demais colegas do Labtox pela amizade e companheirismo.

Às colegas do Instituto Federal de Brasília, pela compreensão e apoio.

À Mari Abreu pelo convívio diário, apoio e paciência. À Ju Pasiani pela amizade e por se fazer sempre presente.

À Cacá, Gabi e Mari Rocha pelo carinho. 


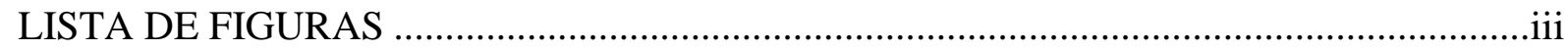

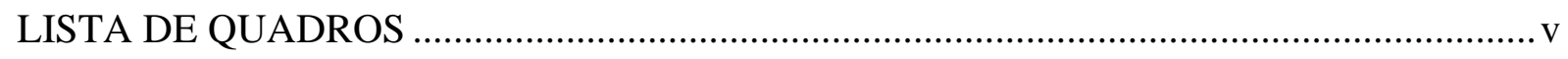

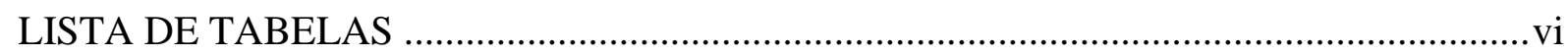

LISTA DE ABREVIATURAS E SIGLAS ................................................................... viii

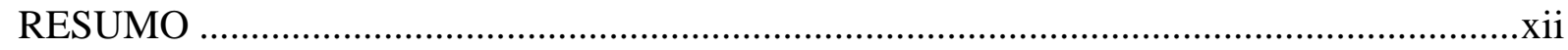

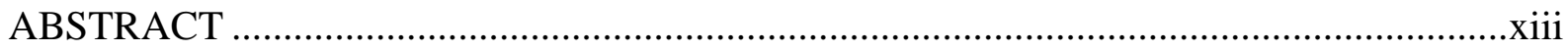

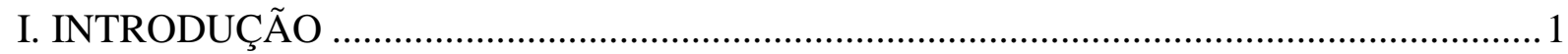

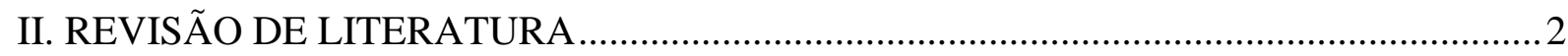

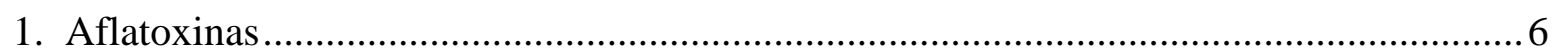

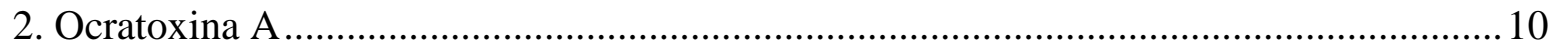

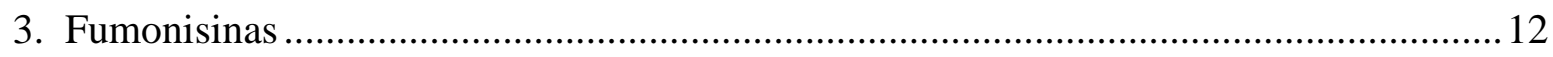

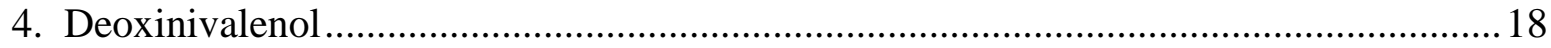

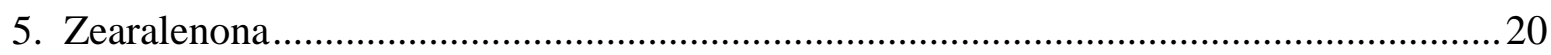

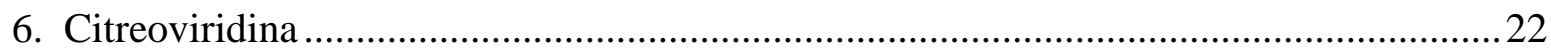

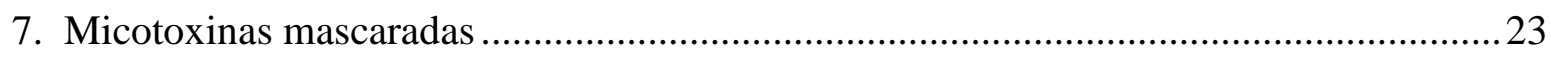

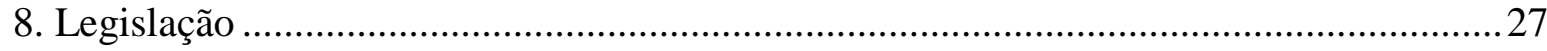

9. Métodos de análise e ocorrência de micotoxinas nos alimentos.....................................29

10. Avaliação de risco da exposição humana a micotoxinas na dieta .................................54

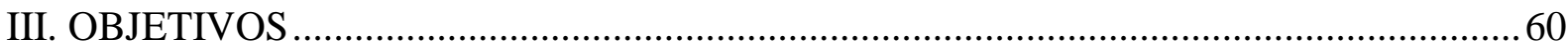

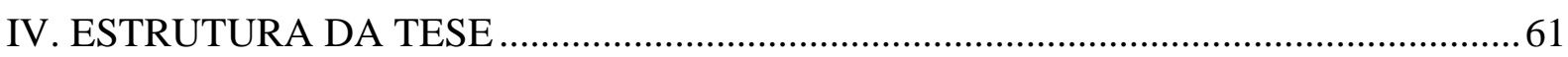

1. Aflatoxins in cereals: worldwide occurrence and dietary risk assessment ....................62

2. Analysis of multi-mycotoxins in cereals and determining total fumonisins in maize products using isotope labeled internal standard and LC-MS/MS ...................................63

3. Mycotoxins in cereals and derived products: occurrence and preliminary risk

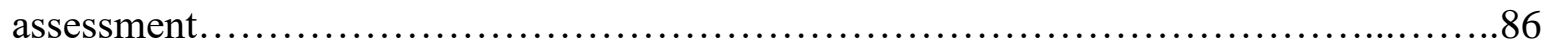

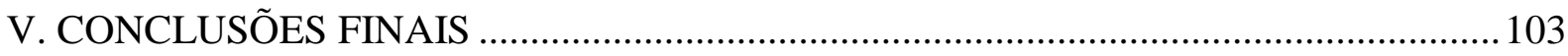

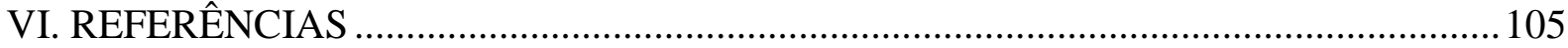

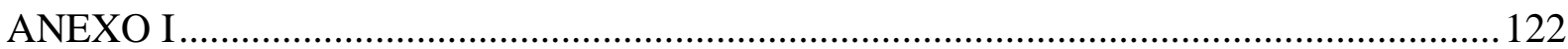




\section{LISTA DE FIGURAS}

\section{REVISÃO DE LITERATURA}

Figura 1. Fungos envolvidos na produção de micotoxinas nas commodities mais susceptíveis em locais de clima quente e úmido. Grãos pequenos: arroz, trigo, aveia, cevada, etc.

Figura 2. Estruturas químicas das aflatoxinas B1, B2, G1 e G2 ...................................... 7

Figura 3. Alguns metabólitos da aflatoxina $\mathrm{B} 1$.............................................................. 8

Figura 4. Estrutura química da ocratoxina A.......................................................... 10

Figura 5. Estruturas químicas das fumonisinas B1, B2 e B3 ........................................ 13

Figura 6. Via biossintética da formação de esfingolipídeos e possível mecanismo de ação das fumonisinas

Figura 7. Estruturas dos produtos da fumonisina B1 formados sob condições de processamento térmico.

Figura 8. Estrutura química do deoxinivalenol

Figura 9. Estrutura química da zearalenona.

Figura 10. Estrutura química da citreoviridina.

Figura 11. Esquema da proposta de harmonização dos termos utilizados para designar micotoxinas e seus potenciais compostos derivados.

Figura 12. Etapas da avaliação de risco

\section{ESTRUTURA DA TESE}

1. Analysis of multi-mycotoxins in cereals and determining total fumonisins in maize products using isotope labeled internal standard and LC-MS/MS

Figure 1. Chemical structures of AFB1, AFG1, OTA, DON, FB1, HFB1, ZON and CTV, some of the mycotoxins evaluated in this study.

Figure 2. Intensity of selected transitions (quantifier and qualifier) after direct infusion into the mass spectrometer using different additives $(0.1 \%$ Formic acid; $0.1 \%$ Acetic acid; $5 \mathrm{mM}$ Ammonium formate; $5 \mathrm{mM}$ Ammonium acetate). 
Figure 3. LC-MS/MS analysis of maize flour naturally contaminated with fumonisins submitted or not to hydrolysis procedure $(n=6)$.

Figure 4. LC-MS/MS chromatograms of naturally contaminated maize flour submitted to the total fumonisin extraction procedure. (A) non-hydrolyzed maize flour; (B) hydrolyzed maize flour

2. Mycotoxins in cereals and derived products: occurrence and risk assessment

Figure 1. LC-MS/MS chromatograms of naturally contaminated samples. (A) rice pasta, AFB1 $=0.6 \mu \mathrm{g} / \mathrm{kg}$; (B) cracker, CTV=8640 $\mu \mathrm{g} / \mathrm{kg}$; (C) snacks, ZON=102.8 $\mu \mathrm{g} / \mathrm{kg}$; (D) pasta, $\mathrm{D} 3 \mathrm{G}=54.8 \mu \mathrm{g} / \mathrm{kg}$; (E) wheat flour, $\mathrm{DON}=326.4 \mu \mathrm{g} / \mathrm{kg}$; (F) maize meal, total fumonisins $633.3 \mu \mathrm{g} / \mathrm{kg}$. 


\section{LISTA DE QUADROS}

\section{REVISÃO DE LITERATURA}

Quadro 1. Micotoxinas modificadas que serão analisadas neste trabalho, segundo a classificação proposta por Rychlik et al. (2014)

Quadro 2. Classificação e parâmetros de ingestão segura, exposição crônica e aguda (DON). 


\section{LISTA DE TABELAS}

\section{REVISÃO DE LITERATURA}

Tabela 1. Condições de crescimento fúngico e produção de micotoxinas para algumas espécies de Aspergillus, Penicillium e Fusarium.

Tabela 2. Limites máximos (LM) para AFs, OTA, DON, fumonisinas e ZON em alimentos destinados ao consumo humano no Brasil.

Tabela 3. Métodos de análise de aflatoxinas e corrência nos alimentos.

Tabela 4. Métodos de análise de ocratoxinas e corrência nos alimentos.

Tabela 5. Métodos de análise de fumonisinas e ocorrência nos alimentos.

Tabela 6. Métodos de análise de deoxinivalenol e compostos relacionados e ocorrência nos alimentos.

Tabela 7. Métodos de análise de zearalenona e compostos relacionados e ocorrência nos alimentos.

Tabela 8. Métodos de análise de citreoviridina e ocorrência nos alimentos.

\section{ESTRUTURA DA TESE}

1. Analysis of multi-mycotoxins in cereals and determining total fumonisins in maize products using isotope labeled internal standard and LC-MS/MS

Table 1. Parameters used to check mycotoxins concentration

Table 2. Optimized ESI ${ }^{+}-\mathrm{MS} / \mathrm{MS}$ parameters and chromatographic retention times used for the multi-mycotoxin LC-MS/MS analysis of cereals and derived products.

Table 3. Validation parameters obtained in five different concentration levels for maize meal

Table 4. Validation parameters obtained in five different concentration levels for rice.

Table 5. Validation parameters obtained in five different concentration levels for wheat flour

Table 6. Analysis of maize reference material for aflatoxins, fumonisins, deoxynivalenol, ochratoxin A e zearalenone.

Table S1. Recoveries (\%) and relative standard deviations (RSD;\%) obtained in five different concentration levels for maize meal. 
Table S2. Recoveries (\%) and relative standard deviations (RSD;\%) obtained in five different concentration levels for rice.

Table S3. Recoveries (\%) and relative standard deviations (RSD; \%) obtained in five different concentration levels for wheat flour.

2. Mycotoxins in cereals and derived products: occurrence and risk assessment

Table 1. Mycotoxins occurrence in maize, wheat, and rice product samples. Number of positive samples/Mean of positive samples (range), $\mu \mathrm{g} / \mathrm{kg}$.

Table 2. Total fumonisins (free + bound/hidden, $F B 1+F B 2+F B 3$ ) in maize-based products, and \% of bound/hidden*

Table 3. Consumption of maize, rice and wheat-based products obtained from 2008/2009 POF, estimated both for chronic exposure and acute exposure (g/bw day)

Table 4. Chronic dietary exposure assessment of deoxynivalenol from the consumption of maize and wheat-based products

Table 5. Acute dietary exposure assessment of deoxynivalenol from the consumption of maize and wheat-based products

Table 6. Chronic dietary exposure assessment of total fumonisins from the consumption of maize and wheat-based products

Table 7. Chronic dietary exposure assessment of zearalenone from the consumption of maize and wheat-based products 


\section{LISTA DE ABREVIATURAS E SIGLAS}

\begin{tabular}{|c|c|}
\hline $15 \mathrm{AcDON}$ & 15-acetil-deoxinivalenol \\
\hline $3 \mathrm{AcDON}$ & 3-acetil-deoxinivalenol \\
\hline A & Absorbância \\
\hline $\mathrm{ACN}$ & Acetonitrila \\
\hline $\mathrm{AcOH}$ & Ácido acético \\
\hline AFB1 & Aflatoxina B1 \\
\hline AFB2 & Aflatoxina B2 \\
\hline AFBO & AFB1-8,9-exo-epóxido \\
\hline AFG1 & Aflatoxina G1 \\
\hline AFG2 & Aflatoxina G2 \\
\hline AFM1 & Aflatoxina M1 \\
\hline AFP1 & Aflatoxina P1 \\
\hline AFQ1 & Aflatoxina Q1 \\
\hline AFs & Aflatoxinas \\
\hline ALARA & As low as reasonably achievable \\
\hline ANVISA & Agência Nacional de Vigilância Sanitária \\
\hline APPCC & Análise de Perigos e Pontos Críticos de Controle \\
\hline ARfD & Dose de referência aguda \\
\hline$a_{w}$ & Atividade de água \\
\hline BEN & Nefropatia endêmica dos Bálcãs \\
\hline BMDL & Benchmark dose lower confidence limit \\
\hline BPA & Boas Práticas Agrícolas \\
\hline $\mathrm{BPF}$ & Boas Práticas de Fabricação \\
\hline CAST & Council for Agriculture, Science and Tecnology \\
\hline $\mathrm{CCD}$ & Cromatografia em camada delgada \\
\hline $\mathrm{CDC}$ & Centers for Disease Control and Prevention \\
\hline $\mathrm{CE}$ & Collision energy \\
\hline CG-FID & Cromatografia gasosa acoplada a detector de chamas \\
\hline CG-MS & Cromatografia gasosa acoplada a espectrômetro de massas \\
\hline $\mathrm{CH}_{2} \mathrm{O}_{2}$ & Ácido fórmico \\
\hline CTV & Citreoviridina \\
\hline $\mathrm{CV}$ & Coeficiente de variação \\
\hline
\end{tabular}




\begin{tabular}{|c|c|}
\hline CXP & Collision cell exit potential \\
\hline D3G & Deoxinivalenol-3- $\beta$-(D)-glicosídeo \\
\hline DLLME & Microextração líquido-líquido dispersiva \\
\hline DNA & Ácido desoxirribonucleico \\
\hline DOM-1 & Deepoxi-deoxinevalenol \\
\hline DON & Deoxinivalenol \\
\hline $\mathrm{DP}$ & Declustering potential \\
\hline EFSA & European Food Safety Authority \\
\hline ELISA & Teste imunoenzimático \\
\hline ESI & Ionização por eletrospray \\
\hline $\mathrm{EtOH}$ & Etanol \\
\hline FAO & Food and Agriculture Organization of the United Nations \\
\hline FB1 & Fumonisina B1 \\
\hline FB2 & Fumonisina B2 \\
\hline FB3 & Fumonisina B3 \\
\hline FB4 & Fumonisina B4 \\
\hline $\mathrm{FC}$ & Fator de correção \\
\hline $\mathrm{FP}$ & Fator de processamento \\
\hline FUMO & Fumonisinas \\
\hline GEMS/Food & $\begin{array}{l}\text { Global Environment Monitoring System/Food Contamination } \\
\text { Monitoring and Assessment Programme }\end{array}$ \\
\hline GSH & Glutationa reduzida \\
\hline $\mathrm{HBsAg}^{-}$ & Não portadores do vírus da hepatite B \\
\hline $\mathrm{HBsAg}^{+}$ & Portadores do vírus da hepatite B \\
\hline HBV & Vírus da hepatite B \\
\hline HFB 1 & Fumonisina hidrolisada B1 \\
\hline HFB2 & Fumonisina hidrolisada B2 \\
\hline HFB3 & Fumonisina hidrolisada B3 \\
\hline HFBx & fumonisinas hidrolisadas \\
\hline HPLC-FD & Cromatografia líquida de alta eficiência com detector de fluorescência \\
\hline HPLC-UV & Cromatografia líquida acoplada a detector de UV \\
\hline IAC & Colunas de imunoafinidade \\
\hline IARC & Internation Agency for Research on Cancer \\
\hline IBGE & Instituto Brasileiro de Geografia e Estatística \\
\hline IEDI & International Estimated Daily Intake \\
\hline
\end{tabular}


ILSI International Life Science Institute

IPCS International Programme on Chemical Safety

JECFA Joint FAO/WHO Expert Committee on Food Additives

LACEN-DF Laboratório Central de Saúde Pública do Distrito Federal

LB Lower bound

LC-HRMS Cromatografia líquida de alta eficiência acoplada a espectrômetro de massas de alta resolução

LC-MS/MS Cromatografia líquida acoplada a espectrômetro de massas sequencial

LMR Limite máximo de resíduo

LM Limites máximos

LOD Limite de detecção

LOQ Limite de quantificação

MAPA Ministério da Agricultura, Pecuária e Abastecimento

$\mathrm{MeOH} \quad$ Metanol

MM Massa molar

MOE Margem de exposição

MRM Multiple reaction monitoring

MSPD Dispersão de matriz em fase sólida

NCM-FB1 N-caboximetil-FB1

ND Não detectado

NDA Naftaleno 2,3-dicarboxaldeído

NDF-FB1 $\quad N$-(1-deoxi-D-frutos-1-il)-FB1

NI Não informado

OTA Ocratoxina A

OTB Ocratoxina B

PMTDI Provisional Maximum Tolerable Daily Intake

POF Pesquisa de Orçamentos Familiares

RBC Rede Brasileira de Calibração

RE Recuperação

RNA Ácido ribonucleico

SAR Relação estrutura molecular e atividade

SPE Extração em fase sólida

SUA Food Supply Utilisation Account

TCAs Ácidos tricarboxílicos

TFMSA Ácido trifluormetanossulfônico 
TLC

TOL

UB

USFDA

UV

WHO

Z4G

$\mathrm{Z} 4 \mathrm{~S}$

$\mathrm{ZON}$

$\alpha-\mathrm{ZOL}$

$\alpha-\mathrm{ZOL}-4 \mathrm{G}$

$\beta$-ZOL

$\beta$-ZOL-4G
Thin-layer chromatography

Tolueno

Upper bound

U.S. Food and Drug Administration

Ultravioleta

World Health Organization

Zearalenona 4- $\beta$-(D)-glicopiranosídeo

Zeralenona-4-sulfato

Zearalenona

$\alpha$-zearalenol

$\alpha$-zearalenol-4- $\beta$-(D)-glicopiranosídeo

$\beta$-zearalenol

$\beta$-zearalenol-4- $\beta$-(D)-glicopiranosídeo 


\section{RESUMO}

ANDRADE, Patrícia Diniz. Micotoxinas em cereais e seus produtos: desenvolvimento de método analítico e avaliação do risco da exposição na dieta. Brasília, 2016. Tese de Doutorado em Ciências Farmacêuticas - Faculdade de Ciências da Saúde, Universidade de Brasília, Brasília 2016.

A dieta da população mundial é baseada no consumo de cereais como o arroz, milho, trigo e seus derivados, alimentos que podem estar contaminados por micotoxinas, metabólitos secundários potencialmente tóxicos ao homem e animais. $\mathrm{O}$ presente estudo teve como objetivos: 1) Avaliar a situação mundial da contaminação de cereais por aflatoxinas (AFs) e conduzir uma avaliação de risco da exposição na dieta; 2) Desenvolver e validar um método multi-micotoxinas para determinar aflatoxinas, ocratoxina A, fumonisinas, deoxinivalenol, zearalenona e citreoviridina em arroz, produtos de milho e produtos de trigo; 3 ) Otimizar um método para análise de fumonisinas totais (formas livres e ligadas/ocultas) em produtos de milho; 4) Analisar amostras de arroz, produtos de milho e produtos de trigo quanto ao teor das micotoxinas; 5) Conduzir uma avaliação de risco da exposição brasileira a estas micotoxinas pela dieta. Os dados da ocorrência mundial de AFs em cereais in natura (arroz, milho, trigo e sorgo) foram obtidos de artigos publicados e do banco de dados do GEMS/Food. Consumo de alimentos e peso corpóreo foram obtidos das 17 dietas Cluster do GEMS/Food. Os resultados indicaram alta incidência de aflaltoxinas em cereais, principalmente do arroz, com potencial risco à saúde em todos os clusters avaliados. $\mathrm{O}$ método multi-micotoxinas otimizado inlcui extração com acetonitrila acidificada e análise por LC-MS/MS, com LOQs entre 0,5 e 121 $\mu \mathrm{g} / \mathrm{kg}$. As fumonisinas ligadas/escondidas foram determinadas após a extração das formas livres (multi-micotoxinas) por meio de hidrólise básica. No total, foram analisadas 196 amostras de arroz, produtos de milho e trigo adquiridas no comércio de Brasília. Todas as amostras de produtos de trigo estavam contaminadas com pelo menos uma micotoxina, 90,7 \% das amostras de produto de milho e $16 \%$ das amostras de arroz também estavam contaminadas. As micotoxinas mais prevalentes foram fumonisinas (produtos de milho), DON e ZON (produtos de trigo). As formas ligadas/ocultas foram encontradas em todas as amostras de produtos de milho, principalmente em alimentos que passaram por tratamento térmico, como massas, cereais matinais e salgadinhos. A ingestão crônica total de DON pela população total e consumidores de produtos de milho e trigo representou 31 e $107 \%$ do PMTDI, respectivamente; a ingestão aguda representou $117 \%$ da $\mathrm{ARfD}$, indicando um potencial risco para a saúde. A ingestão total de fumonisinas correspondeu a 8 e $85 \%$ do PMTDI para população total e consumidores, e a de ZON 10 e 37\% do PMTDI, respectivamente. Os alimentos que mais contribuíram para a ingestão de fumonisinas foi o fubá, e para a ingestão de DON e ZON, as massas. Os resultados deste estudo indicam a necessidade do monitoramento constante de micotoxinas em cereais, particularmente DON, pois devido ao seu elevado consumo, qualquer nível de contaminação pode impactar fortemente na exposição.

Palavras chave: micotoxinas, cereais, LC-MS/MS, avaliação da exposição pela dieta, risco. 


\section{ABSTRACT}

ANDRADE, Patrícia Diniz. Mycotoxins in cereals and derived products: method development and dietary risk assessment. Brasília, 2016. Doctoral Thesis in Pharmaceutical Sciences - Faculty of Health Sciences, University of Brasília, Brasília 2016.

Cereals such as maize, rice, wheat and derived products are staple foods in diets around the world. They can be contaminated with mycotoxins, secondary fungi metabolites which are potentially toxic for humans and animals. The objectives of this study were: 1) to evaluate the worldwide occurrence of aflatoxins (AFs) in cereals and conduct a dietary risk assessment; 2) to develop and validate a multi-mycotoxin method to determine the presence of aflatoxins, ochratoxin A, fumonisins, deoxynivalenol, zearalenone and citreoviridin in rice, maize-based products and wheat-based products; 3 ) to optimize a method to determine total fumonisins (free and bound/hidden forms) in maize-based products; 4) to evaluate the occurrence of these mycotoxins in rice, maize-based products and wheat-based products; and 5) to conduct a dietary risk assessment of these mycotoxins for the Brazilian population. Data on the worldwide occurrence of AFs in raw cereals (rice, maize, wheat and sorghum) were obtained from published papers and from the GEMS/Food database; food consumption and body weight data were obtained from the 17 Cluster Diets. Results indicated a high incidence of aflatoxins in cereals, mainly rice, and a potential health risk for all clusters evaluated. The validated multimycotoxin method was based on extraction with acidified acetonitrile and LC-MS/MS analysis, with LOQs ranging from 0.5 to $121 \mu \mathrm{g} / \mathrm{kg}$. Bound/hidden fumonisins were determined after extraction of the free forms (multi-mycotoxin), using a basic hydrolysis procedure. A total of 196 samples of rice, maize and wheat-based products were analyzed. All samples of wheatbased products were contaminated with at least one mycotoxin; $90.7 \%$ of maize-based products and $16 \%$ of rice samples were also contaminated. The most prevalent mycotoxins were fumonisins in maize-based products, and DON and ZON in wheat-based products. Bound/hidden forms were found in all maize products, mainly in samples submitted to heat treatments such as pasta, breakfast cereals and maize snacks. The total DON chronic intake estimated for total population and for consumers of maize and wheat-based products represented 31 and $107 \%$ of the PMTDI, respectively; acute intake represented $117 \%$ of the ARfD, indicating a potential health risk. Total fumonisin intake for the total population and consumers represented 8 and $85 \%$ of the PMTDI, and ZON intake represented 10 and $37 \%$ of the PMTDI, respectively. Foods that most contributed to total intakes were maize meal for fumonisins and pasta for DON and ZON exposure. Results indicate that the occurrence of mycotoxins should be continuously monitored for cereals, particularly DON, since their occurrence in highly consumed products have a significant impact on dietary exposure estimates.

Keywords: mycotoxins, cereals, LC-MS/MS, dietary risk assessment, risk. 


\section{INTRODUÇÃ̃O}

A alimentação da população humana fundamenta-se, tradicionalmente, no consumo de cereais como o arroz, milho, trigo e seus derivados (BRASIL, 2008; FAO, 2014). Entretanto, estes cereais, assim como outras commodities agrícolas, não estão livres da presença de contaminantes. As micotoxinas, metabólitos secundários produzidos por fungos (FRISVAD; THRANE; SAMSON, 2007), estão entre os contaminantes de alimentos de maior relevância para a saúde humana (DESPHANDE, 2002; KOTSONIS \& BURDOCK, 2008).

A contaminação de alimentos por fungos produtores de micotoxinas pode ocorrer no campo, nas diversas fases de produção, durante o processamento dos produtos e no armazenamento (KUIPER-GOODMAN, 2004). A toxicidade das micotoxinas está relacionada principalmente às propriedades genotóxicas, carcinogênicas, imunotóxicas e nefrotóxicas (BRERA et al., 2008).

Embora sejam conhecidos mais de 300 tipos de micotoxinas, relativamente poucas são de grande preocupação no que diz respeito à saúde humana e animal (NICHOLSON, 2004). Dentre as principais classes de micotoxinas encontram-se as aflatoxinas, os tricotecenos, as fumonisinas, a zearalenona e a ocratoxina A (CAST, 2003). As micotoxinas são relativamente estáveis durante as condições usuais empregadas no processamento de alimentos (inclusive ao tratamento térmico), podendo ser transferidas para o produto final na sua forma original ou modificadas (BULLERMAN; BIANCHINI, 2007).

Não é possível eliminar completamente a presença das micotoxinas nos cereais e, portanto, sua presença em alimentos deve ser reduzida ao nível mais baixo possível (CODEX ALIMENTARIUS, 1995). Considerando a dificuldade de eliminação das micotoxinas em cereais e derivados e a importância destes alimentos na dieta brasileira, faz-se necessário uma contínua avaliação da exposição humana na dieta para que seja possível identificar potenciais prejuízos à saúde humana.

A realização de um estudo mais completo com relação à contaminação de cereais que constituem a base da dieta brasileira é de extrema importância, pois além de ser uma ferramenta de vigilância sanitária (verificação da adequação dos níveis de contaminação à legislação vigente), fornecerá dados relacionados à presença de fumonisina-ligada/escondida nos alimentos, informações já solicitadas por comitês internacionais (FAO/WHO, 2011). 


\section{REVISÃO DE LITERATURA}

Micotoxinas são metabólitos secundários produzidos por fungos que, ao serem ingeridos, inalados ou entrarem em contato com a pele, causam diminuição de desempenho, doenças ou até mesmo morte de animais e seres humanos expostos (PITT, 1996). Uma pequena proporção dos fungos comuns são toxigênicos e a presença de certo fungo em uma commodity não implica necessariamente na presença da toxina (PITT, 1996). Por outro lado, a ausência de sinais visíveis da colonização também não é sinônimo da inexistência de micotoxinas, pois estas podem permanecer no alimento mesmo após a eliminação do microrganismo produtor (TANIWAKI; IAMANAKA; SILVA, 2013).

Acredita-se que os metabólitos secundários de fungos, inclusive as micotoxinas, conferem alguma vantagem seletiva ao microrganismo produtor, sendo produzidas como resposta às alterações ambientais, geralmente em função do desencadeamento de condições de estresse (MAGAN; ALDRED, 2007). A hipótese mais provável é que muitos desses metabólitos não sejam produzidos aleatoriamente, mas sim com a intenção de alterar a ecologia do meio, causando inibição do crescimento de microrganismos competidores, insetos, etc (PITT et al., 2012).

Assim como no crescimento fúngico, a produção de micotoxinas é governada por uma série de fatores, entre eles (TANIWAKI; IAMANAKA; SILVA, 2013):

- Fungo: apenas alguns gêneros são toxigênicos, embora nem todas as espécies desses gêneros sejam produtores de micotoxinas;

- Substrato: alimentos com alto teor de carboidratos e algumas sementes oleaginosas são mais susceptíveis à produção de micotoxinas quando comparados a outros tipos de alimentos;

- Umidade relativa e atividade de água $\left(\mathrm{a}_{\mathrm{w}}\right)$ : grande parte dos fungos necessita de umidade relativa acima de $80 \%$ e valores de $a_{w}$ entre 0,6 e 0,9 para a produção de micotoxinas;

- Temperatura: a temperatura ótima de produção de micotoxinas geralmente encontrase na faixa de temperatura de crescimento fúngico (mínima-máxima). Climas tropicais e sub-tropicais favorecem o crescimento da maioria dos fungos toxigênicos;

- Atmosfera: são aeróbios, em sua maioria;

- Interação microbiana: a presença de outros microrganismos pode alterar a produção de micotoxinas de diferentes maneiras, ou seja, a produção pode ser estimulada ou 
mesmo inibida. Além disso, alguns microrganismos são capazes de remover ou degradar as micotoxinas presentes no meio.

Os fungos podem estar associados às plantas durante o seu crescimento (pré-colheita) como comensais, simbióticos ou patógenos ou não ter afinidade alguma pela cultura, no caso da infecção da planta e produção de micotoxinas ocorrerem pós-colheita (secagem, transporte e armazenamento), como acontece com a maioria dos fungos produtores de micotoxinas (PITT, 1996). Os gêneros Aspergillus, Penicillium e Fusarium são os mais importantes quando consideramos a ocorrência mundial de fungos e sua capacidade em produzir micotoxinas (PITT; HOCKING, 2009). Espécies de Fusarium são patógenos destrutivos em culturas de cereais e outras commodities, produzindo micotoxinas antes, ou imediatamente após a colheita. Algumas espécies de Aspergillus e Penicillium também são patógenos de plantas ou comensais (crescem no vegetal sem afetá-lo), mas esses gêneros são mais comumente associados a commodities e alimentos durante os processos de secagem e armazenamento. O Aspergillus flavus é uma exceção, podendo ser patógeno, comensal ou fungo de armazenamento, produzindo micotoxinas nas três condições (PITT et al., 2012). Fumonisinas, tricotecenos e zearalenona são bons exemplos de micotoxinas formadas na pré-colheita, ocratoxina A é formada tipicamente na pós-colheita (PITT, 1996) e aflatoxina pode ser formada ao longo de toda a cadeia produtiva (PITT; TANIWAKI; COLE, 2013).

São conhecidos mais de 300 tipos de micotoxinas, de estruturas químicas extremamente variáveis e efeitos tóxicos diversos (NICHOLSON, 2004). Porém, muitos desses compostos são de baixa relevância, pois são produzidos por fungos raramente encontrados em alimentos e ração animal, ou por apresentarem toxicidade somente em condições de teste (não apresentam toxicidade quando expostos por via natural) ou ainda por serem encontrados em concentrações tão baixas que não apresentam um risco real em condições normais (seus efeitos, quando manifestados, não são mensuráveis) (PITT et al., 2012). As micotoxinas de maior importância no contexto mundial são: aflatoxinas, ocratoxina A, fumonisinas, alguns tricotecenos (deoxinivalenol e nivalenol) e zearalenona (MILLER, 1995).

A Tabela 1 mostra as condições de crescimento e produção de micotoxinas para algumas das espécies fúngicas de maior relevância. É possível observar que a maioria dos fungos produtores de micotoxinas necessita de temperaturas altas para atingirem o máximo de crescimento (acima de $25^{\circ} \mathrm{C}$ ), além da necessidade de elevada disponibilidade de água livre 
$\left(a_{w}>0,85\right)$. As condições para produção de micotoxinas estão, geralmente, dentro daquelas necessárias para o crescimento fúngico.

Tabela 1 - Condições de crescimento fúngico e produção de micotoxinas para algumas espécies de Aspergillus, Penicillium e Fusarium.

\begin{tabular}{|c|c|c|c|c|c|}
\hline \multirow[b]{2}{*}{ Fungo } & \multirow[b]{2}{*}{ Micotoxina } & \multicolumn{2}{|c|}{ Crescimento fúngico } & \multicolumn{2}{|c|}{ Produção de micotoxina } \\
\hline & & $\begin{array}{c}\mathbf{T}^{\circ} \mathbf{C} \\
\text { (ótima) }\end{array}$ & $\mathbf{a}_{\mathbf{w}}$ & $\mathbf{T}{ }^{\circ} \mathbf{C}$ & $\mathbf{a}_{\mathbf{w}}$ \\
\hline A. flavus & AFs & $10-48(33)$ & $0,82^{\mathrm{a}}$ & $13-37$ & 0,82 (mín.) \\
\hline A. parasiticus & AFs & $12-42(32)$ & $0,82^{\mathrm{a}}$ & $12-40$ & 0,86 (mín.) \\
\hline P. citreonigrum & CTV & $(27-30)$ & $0,8^{\mathrm{b}}$ & $10-37$ & - \\
\hline F. graminearum & $\mathrm{DON}$ & $(24-26)$ & $0,9^{c}$ & 25 & $0,95-0,995^{\mathrm{c}}$ \\
\hline F. culmorum & DON & $0-31(21)$ & $0,87^{\mathrm{d}}$ & 25 & $0,96-0,995$ \\
\hline F. verticillioides & FUMO & $2,5-37(25)$ & $0,87^{\mathrm{a}}$ & - & 0,92 (mín.) \\
\hline F. proliferatum & FUMO & $(25)$ & 0,88 & 25 & 0,92 \\
\hline P. verrucosum & OTA & $0-31(20)$ & 0,8 & $0-31$ & 0,86 (mín.) \\
\hline A. carbonarius & OTA & $10-41(30)$ & $0,96-0,98$ & $15-20$ & $0,95-0,98$ \\
\hline F. graminearum & $\mathrm{ZON}$ & $(24-26)$ & 0,9 & 20 & - \\
\hline
\end{tabular}

AFs: aflatoxinas B1, B2, G1 e G2; CTV: citreoviridina; DON: deoxinivalenol: FUMO: fumonisinas B1, B2 e B3; OTA: ocratoxina A; ZON: zeralenona; ${ }^{a} a_{w}$ mínima a $25^{\circ} \mathrm{C}$; ${ }^{b} a_{w}$ mínima em 20,25 e $30^{\circ} \mathrm{C} ;{ }^{\mathrm{c}} \mathrm{a}_{\mathrm{w}}$ mínima para crescimento entre $15-25^{\circ} ;{ }^{\mathrm{d}} \mathrm{a}_{\mathrm{w}}$ mínima entre 20$25^{\circ} \mathrm{C}$; Adaptado de CX/CF 14/8/14 (CODEX ALIMENTARIUS, 2014).

Assim, dependendo da espécie do fungo produtor, as micotoxinas podem ser encontradas em alimentos produzidos tanto em regiões de clima temperado como clima tropical. Os principais alimentos afetados são cereais, nozes, frutas secas, café, cacau, pimentas, óleos vegetais, ervilhas secas, feijão e frutas, especialmente maçã e uva. Elas também podem ser encontradas em cervejas e vinhos em função da utilização de matérias-primas contaminadas. Além disso, as micotoxinas podem entrar na cadeia alimentar pelo consumo de carne e/ou outros produtos de origem animal como ovos, leite e derivados, provenientes de animais tratados com ração contaminada (TURNER; SUBRAHMANYAM; PILETSKY, 2009).

A Figura 1 resume os principais alimentos susceptíveis à formação de micotoxinas e os respectivos fungos produtores em regiões de clima quente e úmido, como no Brasil. Adicionalmente, em locais de clima frio a temperado, tem-se o favorecimento da produção de 
ocratoxina A em grãos pequenos ( $P$. verrucosum), uvas (A. carbonarius), café (A. ochraceus, A. carbonarius e A. westerdijkiae) e cacau (A. ochraceus e A. carbonarius).

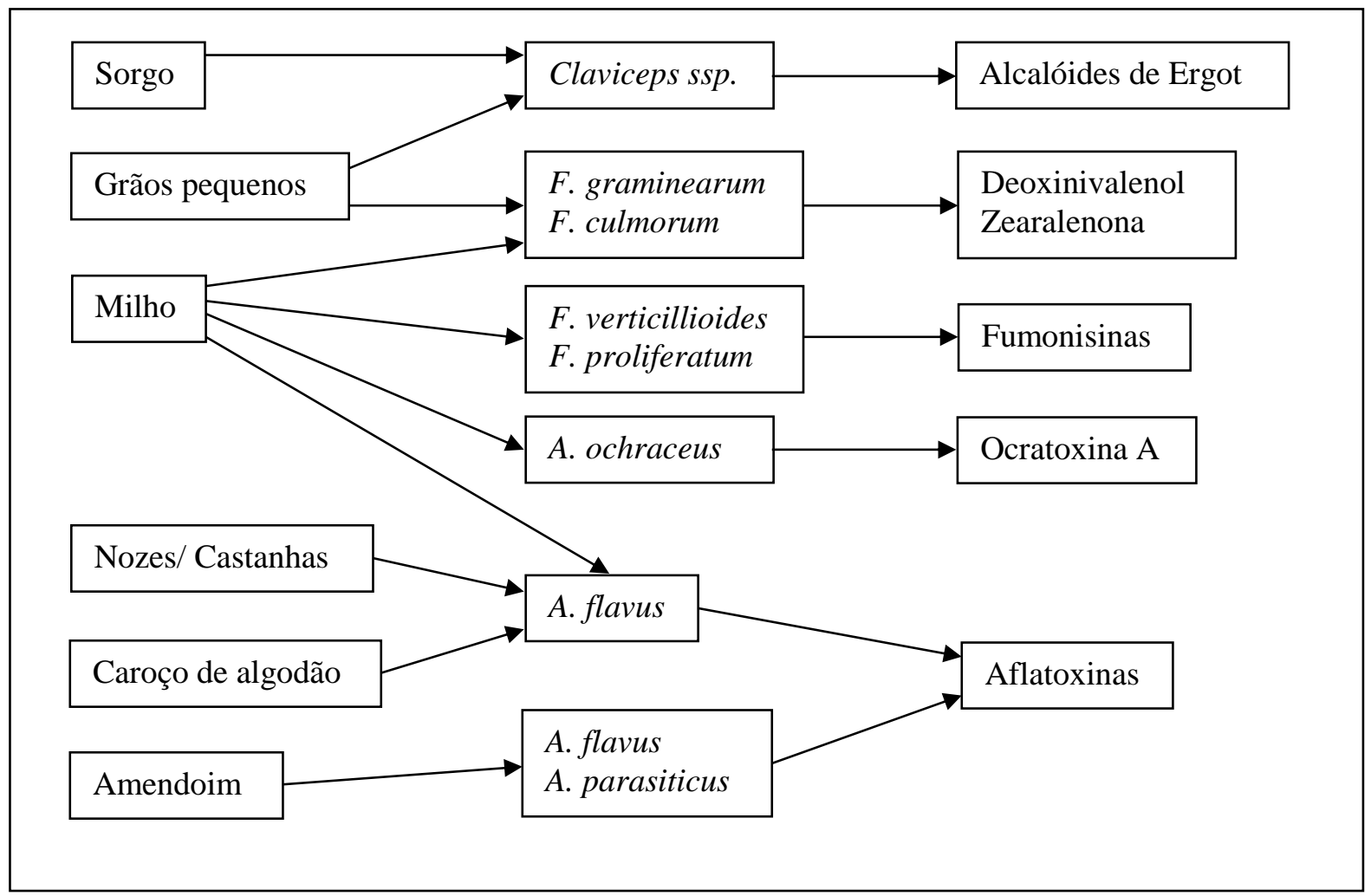

Figura 1 - Fungos envolvidos na produção de micotoxinas nas commodities mais susceptíveis em locais de clima quente e úmido. Grãos pequenos: arroz, trigo, aveia, cevada, etc. Adaptado de Pitt et al. (2012).

As micotoxinas não são completamente eliminadas durante o processamento de alimentos e, portanto, a melhor estratégia para seu controle ainda é a prevenção. Para prevenir a formação desses metabólitos tóxicos é importante conhecer o tipo de associação que o fungo exerce com o alimento, ou seja, se as micotoxinas serão formadas antes ou depois da colheita. Conhecendo o mecanismo de produção das micotoxinas é possível direcionar as ações de controle de acordo com o tipo de fungos produtores, pré ou pós-colheita, uma vez que as estratégias utilizadas são bem diferentes (PITT, 1996).

Controlar a formação de micotoxinas na pré-colheita é uma tarefa mais difícil, uma vez que fatores ambientais (como clima e temperatura) determinam o crescimento do fungo e a produção de micotoxinas. Segundo Pitt (2006), é possível fazer duas generalizações quanto à produção de micotoxinas na pré-colheita: o crescimento de fungos toxigênicos ocorre apenas em culturas específicas, onde há uma nítida associação fungo-planta e os fungos que produzem micotoxinas crescem apenas em elevada atividade de água (aw) e, desta maneira, as toxinas formadas na pré-colheita raramente serão formadas durante o armazenamento. 
As Boas Práticas Agrícolas (BPA), as Boas Práticas de Fabricação (BPF), além de sistemas de qualidade complementares como o APPCC (Análise de Perigos e Pontos Críticos de Controle), são ferramentas importantes na tentativa de controlar e manejar a contaminação dos alimentos por micotoxinas (CODEX ALIMENTARIUS, 2003). Rotação de culturas, cultivo de variedades de sementes resistentes ao ataque de fungos e insetos, uso de pesticidas e secagem rápida dos grãos são recomendações contidas no Código Práticas para prevenção e redução da contaminação por micotoxinas em cereais (CODEX ALIMENTARIUS, 2003).

\section{AFLATOXINAS}

As aflatoxinas (AFs) são produzidas por pelo menos 10 espécies de Aspergillus, sendo o A. flavus e o A. parasiticus os maiores produtores em alimentos (PITT et al., 2012). Em torno de $50 \%$ das cepas de ocorrência natural de A. flavus são produtoras de AFs enquanto quase todos os isolados conhecidos de A. parasiticus são toxigênicos (PITT, 2006). Na Figura 2 estão as principais aflatoxinas produzidas naturalmente, as aflatoxinas B1 (AFB1), B2 (AFB2), G1 (AFG1) e G2 (AFG2) (PITT; HOCKING, 2009). O A. flavus produz apenas aflatoxinas B, enquanto o A. parasiticus produz aflatoxinas B e G (PITT, 2006).

O A. flavus é ubíquo em culturas de zonas tropicais e subtropicais, já o A. parasiticus tem uma distribuição mais limitada (PITT et al., 2012). O A. flavus é comensal no algodão (KLICH; THOMAS; MELLON, 1984) e, provavelmente também no milho (LILLEHOJ et al., 1980), permitindo que o fungo cresça na planta, em sementes e grãos em desenvolvimento antes da colheita, fornecendo uma grande vantagem ecológica sobre fungos competidores. Como comensal, a planta não reage à presença do A. flavus e este não produz dano visível à planta ou a semente (PITT, 2006).

A. flavus e, em menor grau, A. parasiticus, tem sido isolados de uma ampla variedade de alimentos (PITT; HOCKING, 2009). Culturas susceptíveis à formação de aflatoxinas são em sua maioria nozes e oleaginosas, nas quais o teor de sólidos solúveis (açúcares) é baixo nas commodities secas e o conteúdo de óleo é alto. Os produtos de maior risco de contaminação por AFs no comércio internacional incluem amendoim, milho e caroço de algodão, seguidos de todos os tipos de frutos de casca rija (castanha do Brasil, pistache e produtos semiprocessados do coco), pimentas (provenientes de países tropicais), figos secos e, ocasionalmente, nozes, avelãs e castanha de caju (PITT et al., 2012). 


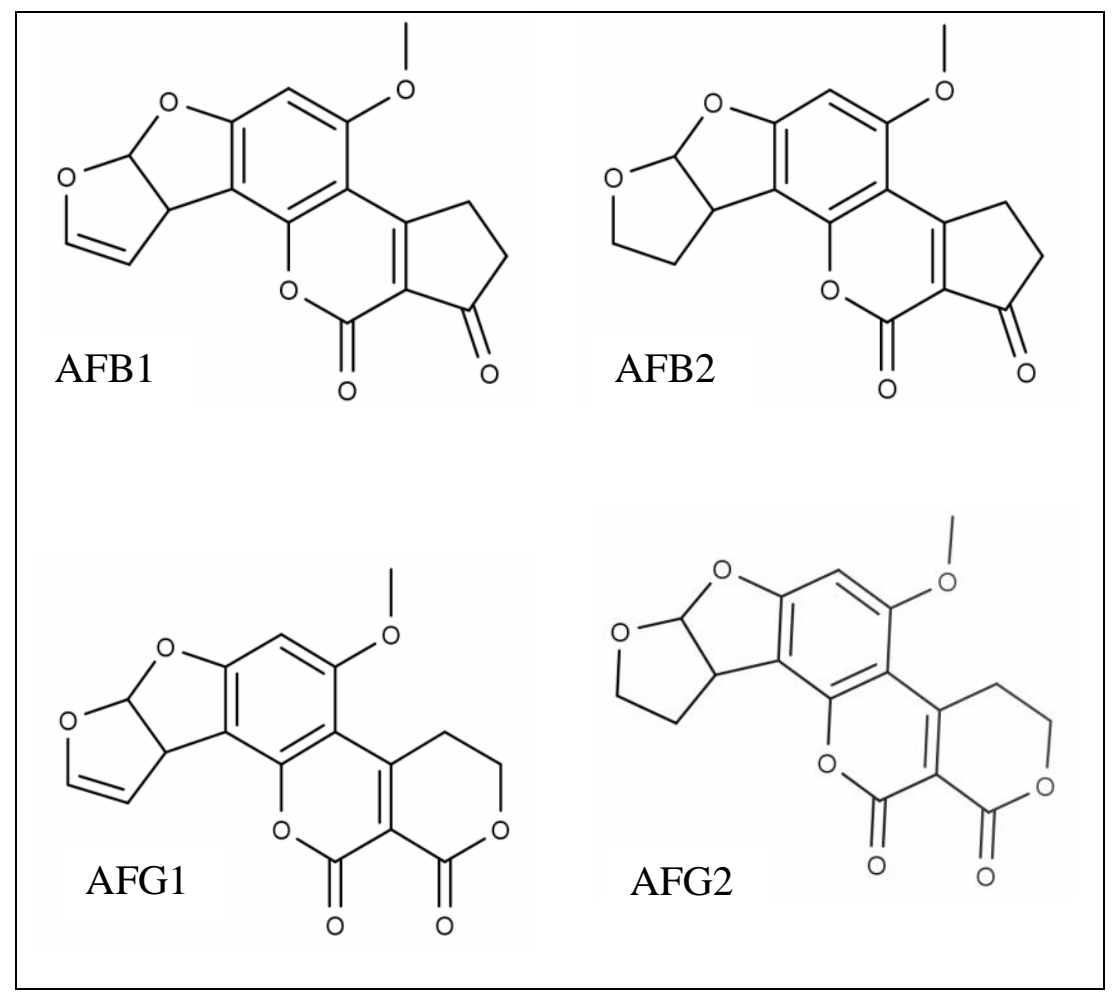

Figura 2 - Estruturas químicas das aflatoxinas B1, B2, G1 e G2.

A produção de aflatoxinas em milho, algodão e amendoim pode ocorrer na pré-colheita, entretanto para outras culturas como nozes, castanha do Brasil, noz-pecã, pistache, oleaginosas e pequenos grãos (trigo e cevada) as aflatoxinas são formadas essencialmente na pós-colheita, como resultado da secagem inadequada e/ou armazenamento incorreto (PITT, 2006). Estes dois fungos são capazes de crescer em até $0,8 \mathrm{a}_{\mathrm{w}} \mathrm{e}$ em temperaturas de até $37^{\circ} \mathrm{C}$ ou mais, o que os torna capaz de produzir toxinas em culturas armazenadas inadequadamente, o que ocorre principalmente nos trópicos úmidos (PITT, 2006).

O potencial tóxico das aflatoxinas em homens e animais pode ser tanto agudo como crônico, produzindo efeitos distintos que vão de danos agudos ao fígado, cirrose hepática, indução de tumores, efeitos teratogênicos a efeitos imunossupressores e interferência com a absorção de proteínas (CHAYTOR et al., 2011; GURSOY-YUZUGULLU et al., 2011; KUNIHOLM et al., 2008; WILLIAMS et al., 2004; WOO et al., 2011). As quatro aflatoxinas de ocorrência natural são classificadas como carcinógenos humanos (IARC, 1993).

A AFB1 é a mais tóxica entre as quatro aflatoxinas de ocorrência natural e sua toxicidade está associada ao processo de biotransformação que ocorre principalmente no fígado após a absorção (BENNETT; ESSIGMANN; WOGAN, 1981; IARC, 2002). A AFB1 é transformada pela ação de enzimas a um epóxido (AFBO) capaz de formar adutos covalentes 
com DNA, RNA e proteínas. Adutos com DNA em regiões transcricionalmente ativas, se não removidos por enzimas de reparação, podem levar a alterações somáticas (BEDARD; MASSEY, 2006). Entretanto, a formação de adutos pode ser prevenida se o AFBO for conjugado com glutationa reduzida $(\mathrm{GSH})$ e excretado como ácido mercaptúrico na urina (GROSS-STEINMEYER; EATON, 2012). As enzimas do citocromo P450, além de mediar à formação do AFBO, também atuam nas vias de detoxificação da AFB1, levando à formação de metabólitos menos tóxicos como a AFM1 (originalmente identificada no leite), AFQ1 e AFP1 (Figura 3) (EATON; GALLAGHER, 1994; GROSS-STEINMEYER; EATON, 2012).

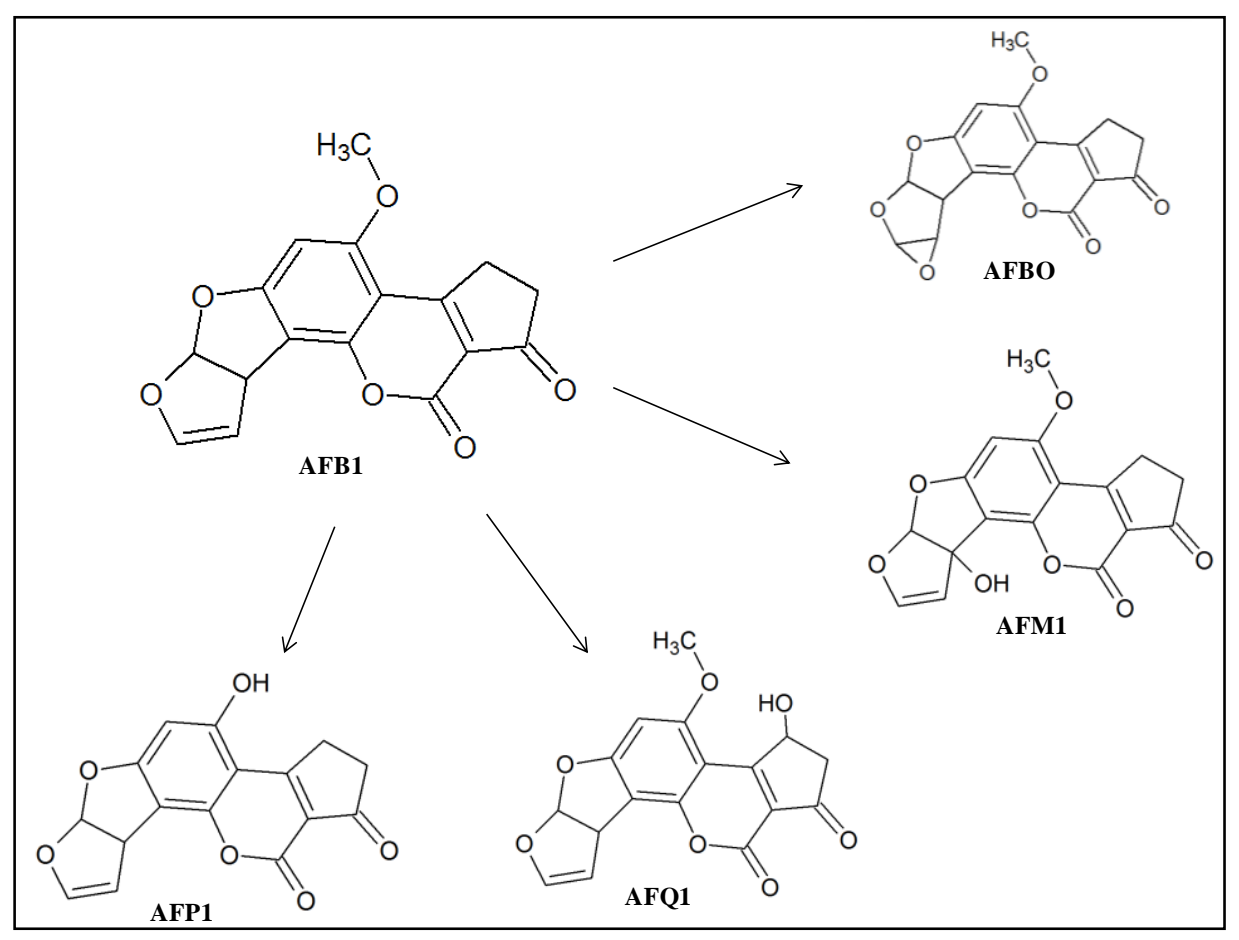

Figura 3 - Alguns metabólitos da aflatoxina B1.

Diferentes estratégias devem ser utilizadas para o controle de aflatoxinas nos alimentos. Na pré-colheita, por exemplo, o melhoramento de plantas está sendo empregado para aprimorar a resistência de cultivares de amendoim e milho à seca e ataque de insetos, fatores que predispõe à formação de AFs (PITT et al., 2012). Produtos de biocontrole, baseados no controle da produção de aflatoxinas pela exclusão competitiva entre cepas toxigênicas e não toxigênicas, estão disponíveis comercialmente (Afla-guard® e Aspergillus flavus AF36) para o milho, amendoim, algodão e pistache (MEDEIROS et al., 2012).

Além disso, a necessidade de garantir a qualidade microbiológica e a produção de alimentos seguros, estimulou o interesse no uso the modelos matemáticos para quantificar e 
predizer o comportamento microbiológico nos alimentos (GARCIA et al., 2009). O modelo preditivo é uma ferramenta utilizada para estimar a probabilidade da ocorrência de determinado fungo e/ou micotoxina em uma cultura, baseado em fatores ambientais da região avalida (BATTILANI et al., 2008; HOOKER; SCHAAFSMA; TAMBURIC-ILINCIC, 2002; PRANDINI et al., 2009). A aplicação de modelos preditivos possibilita novas oportunidades de gerenciamento, pois fornece informações que poderão auxiliar na redução da contaminação ou no re-direcionamento de alimentos altamente contaminados dentro do processo produtivo (SCHAAFSMA; HOOKER, 2007). O AfloMan é um modelo preditivo que pode ajudar na prevenção da formação de AFs no campo (PITT et al., 2012), pois auxilia o produtor a escolher o melhor momento para realizar determinadas práticas agrícolas (APSIM, 2014).

Os processos de separação e limpeza dos cereais, geralmente reduzem a concentração de AFs, pois eliminam os componentes de baixa qualidade (grãos quebrados, danificados e matéria estranha) onde normalmente encontra-se o maior nível de contaminação (JOHANSSON et al., 2006). No processo de moagem, as AFs podem ser redistribuídas e concentradas em certas frações obtidas no processamento, usualmente as partes externas dos grãos destinadas à fabricação de ração animal (CASTELLS et al., 2008; PIETRI; ZANETTI; BERTUZZI, 2009). Por exemplo, na produção de arroz polido e farinha de milho, a concentração de AFs foi reduzida em 92-97\% quando comparada aos grãos não processados (CASTELLS et al., 2007; SIWELA et al., 2005).

As AFs são compostos termorresistentes e, portanto, não são completamente eliminadas durante o processamento dos alimentos (CODEX ALIMENTARIUS, 2013). Entretanto, dependendo do teor de água, componentes da matriz e do binômio tempo-temperatura utilizado, alguma redução pode ser atingida com o tratamento térmico. O aquecimento de grãos úmidos de trigo $\left(100^{\circ} \mathrm{C} / 30 \mathrm{~min}\right)$ reduziu a concentração de $\mathrm{AFB} 1 \mathrm{em}$ até $47 \%$, enquanto o cozimento do arroz, em condições normais e sob pressão, diminui o teor de AFs em 37 e $78 \%$, respectivamente (HWANG; LEE, 2006; PARK; KIM, 2006). A redução de AFs após o processo de extrusão também foi avaliada, obtendo valores de redução entre 10-25\% para farinha de milho e 51-95\% em farinha de arroz (CASTELLS et al., 2006; CAZZANIGA et al., 2001). Até o momento, não foi relatada moléculas resultantes de modificações das AFs em decorrência do processamento de alimentos. 


\section{OCRATOXINA A}

O Penicillium verrucosum é o maior produtor de ocratoxina A (Figura 4) em cereais em países de clima temperado, enquanto em países de clima tropical os maiores produtores são espécies de Aspergillus, como A. carbonarius e A. westerdijkiae (PITT; HOCKING, 2009).

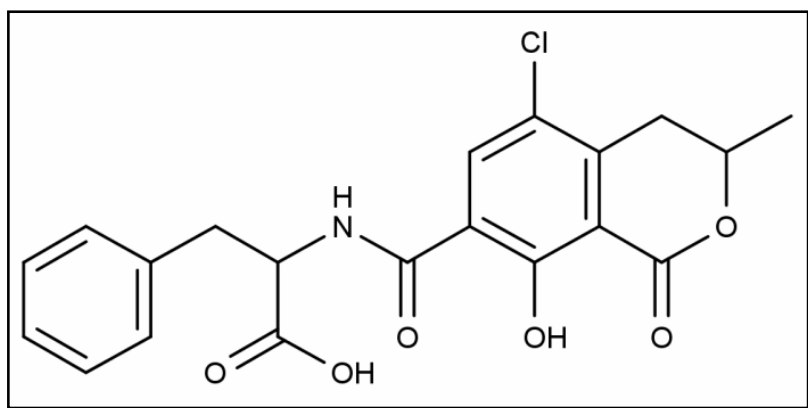

Figura 4 - Estrutura química da ocratoxina A.

A ecologia da formação de ocratoxina A (OTA) nos alimentos é um pouco mais complexa do que para as aflatoxinas, pois a OTA é produzida primordialmente por três espécies fúngicas distintas (e espécies relacionadas), provenientes de nichos ecológicos diferentes. Entretanto, por outro lado, a questão se torna mais fácil já que não existe evidência suficiente que essas espécies fúngicas estejam associadas a culturas específicas antes da colheita, ou seja, nenhum dos fungos produtores de OTA são conhecidos como invasores sistemáticos ou patógenos (PITT, 2006).

$P$. verrucosum cresce comumente em cereais cultivados em locais de clima temperado a frio, em regiões indo do norte ao centro da Europa, Canadá e norte da Ásia. OTA é encontrada em cereais e derivados, especialmente pão e derivados de farinha (PITT, 2006). Além dos cereais, principalmente trigo e cevada, a exposição à OTA também está relacionada ao consumo de cerveja, vinho, cacau e derivados, café, frutas secas, especiarias, produtos cárneos (principalmente suínos) e, em menor frequência, milho e sorgo (AISH et al., 2004; PITT et al., 2012).

O principal efeito da exposição humana à ocratoxina A é a nefrotoxicidade, embora também possua efeitos imunotóxicos, teratogênicos e genotóxicos em animais, sendo classificada como possível carcinógeno humano (IARC, 1993; LIU et al., 2012; PFOHLLESZKOWICZ, 2009; WILK-ZASADNA; MINTA, 2009). O nível de ingestão diária tolerável máxima (PMTDI - Provisional Maximum Tolerable Daily Intake) estabelecido para OTA é de 100ng/kg pc/dia (JECFA, 2001). 
A exposição à OTA já foi considerada agente causal do desenvolvimento da nefropatia endêmica dos Bálcãs (BEN) e aparecimento de tumores uroteliais (O’BRIEN; DIETRICH, 2005). BEN é uma doença renal crônica e progressiva que atinge a população da Bósnia, Bulgária, Croácia, Romênia e Sérvia, ocorrendo em vilarejos rurais situados à margem do rio Danúbio (TATU et al., 1998). Embora tenha sido bastante estudada nos últimos 50 anos, sua etiologia exata ainda é desconhecida (BATUMAN, 2006). Entretanto, estudos mais recentes forneceram evidências fortes de que, na verdade, o fator etiológico principal para o desenvolvimento de BEN seja o ácido aristolóquico, presente em ervas daninhas de plantações da região afetada pela doença (GROLLMAN et al., 2007). Desta maneira, a toxicidade renal da OTA em humanos tem sido questionada.

Em mamíferos, a OTA é absorvida do trato gastrointestinal, ligando-se às proteínas plasmáticas do sangue (principalmente a albumina), de onde é direcionada principalmente para os rins e, em menores quantidades, para o fígado, músculo e tecido adiposo (JECFA, 2001; PITT et al., 2012). A ocratoxina $\alpha$, metabólito consideravelmente menos tóxico que a OTA, é frequente encontrada nas diversas espécies analisadas (JECFA, 2001). Pela sua semelhança estrutural com a fenilalanina, a OTA inibe competitivamente a fenilalanina-tRNA ligase, restringindo a síntese de proteínas, RNA e DNA (PITT et al., 2012). Além disso, existem outros mecanismos moleculares pelos quais a OTA pode exercer seus efeitos tóxicos, como a formação de adutos com DNA, interferência na peroxidação lipídica e inibição da respiração mitocondrial (BAYMAN; BAKER, 2006; O’BRIEN; DIETRICH, 2005).

Já que a OTA é produzida principalmente na pós-colheita, a melhor ferramenta de controle da contaminação dos cereais é pela secagem rápida e eficiente dos grãos (PITT et al., 2012). Geralmente as práticas de limpeza e seleção não são de grande importância na redução da contaminação por OTA, uma vez que os valores obtidos são baixos (<3\% para cevada), porém isso depende muito da contaminação inicial do cereal (CODEX ALIMENTARIUS, 2014; SCUDAMORE; BANKS; MACDONALD, 2003). Assim como para as AFs, o teor de OTA é maior em produtos obtidos de farinha integral, considerando que a toxina se concentra na parte externa dos grãos (gérmen e farelo), removida para a obtenção das farinhas comuns (SCUDAMORE; BANKS; MACDONALD, 2003).

Os efeitos do processamento dos alimentos nos níveis de OTA são variáveis. Por exemplo, não houve redução durante a produção de pães, enquanto para biscoitos assados a diminuição atingiu 60\% (SCUDAMORE; BANKS; MACDONALD, 2003; SUBIRADE, 1996). A torrefação de grãos de café de diferentes origens produziu resultados heterogêneos, 
com média de redução de 66\% (13-93\%), enquanto a extrusão de farinha integral de trigo diminui em, no máximo, $40 \%$ o teor de OTA (OBANOS; CERAIN; GONZÁLEZ-PEÑAS, 2005; SCUDAMORE; BANKS; GUY, 2004).

Cramer et al. (2008) identificaram os dois principais produtos da degradação térmica da OTA durante a torrefação de café, o 14-(R)-OTA e o 14-decarboxi-OTA. Durante a análise de amostras de café, encontraram o 14-(R)-OTA em quantidades até 25,6\% da concentração de OTA, enquanto o 14-decarboxi-OTA foi encontrado em níveis traço. Os autores ainda avaliaram a toxicidade dos produtos de degradação, concluindo que estes são menos citotóxicos (células epiteliais dos rins) que a OTA. Uma vez que a baixa formação dos compostos 14-(R)OTA e 14-decarboxi-OTA não explica completamente a redução de OTA durante a torrefação de café, Bittner et al. (2013), recentemente comprovaram a formação de ésteres de OTA com polissacarídeos do café durante o processamento térmico de amostras contaminadas artificialmente. $\mathrm{O}$ estudo utilizou, primeiramente, um modelo experimental com o $\alpha$-(D)glicopiranosídeo de metila representando os polissacarídeos e, após confirmar a ligação com as moléculas de OTA, também confirmou sua ligação em modelos utilizando celulose, bem como utilizando o próprio grão de café.

\section{FUMONISINAS}

O maior grupo das toxinas de Fusarium, as fumonisinas, são produzidas por $F$. verticillioides (anteriormente chamado de $F$. moniliforme) e $F$. proliferatum (PITT, 2006). Essas espécies são sistêmicas no milho cultivado no mundo todo, estando sempre presente nas plantas e até mesmo nos grãos saudáveis (MILLER, 1995). Alguns estudos sugerem que o $F$. verticillioides pode ter papel importante no cultivo de milho (PITT, 2006), pois indicam que este fungo é capaz de suprimir o crescimento de outros fungos da espiga (REID et al., 1999) e que sua ausência no grão (decorrente de prévio tratamento térmico do grão) pode alterar o crescimento do vegetal (germinam, porém não crescem) (FOLEY, 1962). Entretanto, o $F$. verticillioides e $F$. proliferatum também são responsáveis pela podridão rosa da espiga, doença recorrente em anos secos e quentes em plantações com elevado dano por insetos (LOGRIECO et al., 2002).

Recentemente, estudos mostraram que o Aspergillus niger também é capaz de produzir fumonisina B2 (FRISVAD et al., 2007). Esse achado pode alterar o panorama de contaminação por fumonisinas, pois este fungo, além de também ser produtor de OTA, é frequentemente isolado de alimentos como uvas, uvas passas, vinho, café, frutas frescas e cebola, alimentos até 
pouco tempo considerados de baixa relevância para a contaminação por fumonisinas (PITT; HOCKING, 2009; PITT; TANIWAKI; COLE, 2013).

As fumonisinas são encontradas principalmente em milho e derivados e no sorgo (CALDAS; SILVA, 2007; PITT, 2006). Aparentemente, são produzidas apenas quando a planta sofre estresse hídrico ou em outras condições desfavoráveis em que ocorre um distúrbio do equilíbrio entre fungo e planta (PITT, 2006). A principal observação que pode ser feita sobre as toxinas de Fusarium é que todas as espécies desse gênero crescem exclusivamente em situações de elevada atividade de água, acima de 0,9 (PITT; HOCKING, 2009), e a produção da toxina ocorre apenas na pré-colheita ou nos primeiros estágios da secagem, ocorrendo no armazenamento somente em condições muito precárias (JACKSON; JABLONSKI, 2004; MARIN et al., 1995).

Em 1988, as fumonisinas foram isoladas pela primeira vez, a partir de culturas de Fusarium verticillioides e denominadas fumonisinas B1 (FB1) e B2 (FB2) (GELDERBLOM et al., 1988). Posteriormente, as fumonisinas B3 (FB3) e B4 (FB4) foram descritas por Cawood et al. (1991). Os análogos de fumonisinas até então caracterizados, 28 no total, foram divididos em quatro grupos principais: fumonisinas das séries A, B, C e P (RHEEDER; MARASAS; VISMER, 2002). As fumonisinas do grupo B, especialmente FB1, FB2 e FB3 (Figura 5), são os compostos de ocorrência natural encontrados com maior frequência nas amostras de milho contaminadas (NELSON; DESJARDINS; PLATTNER, 1993). Entretanto, pesquisa mais

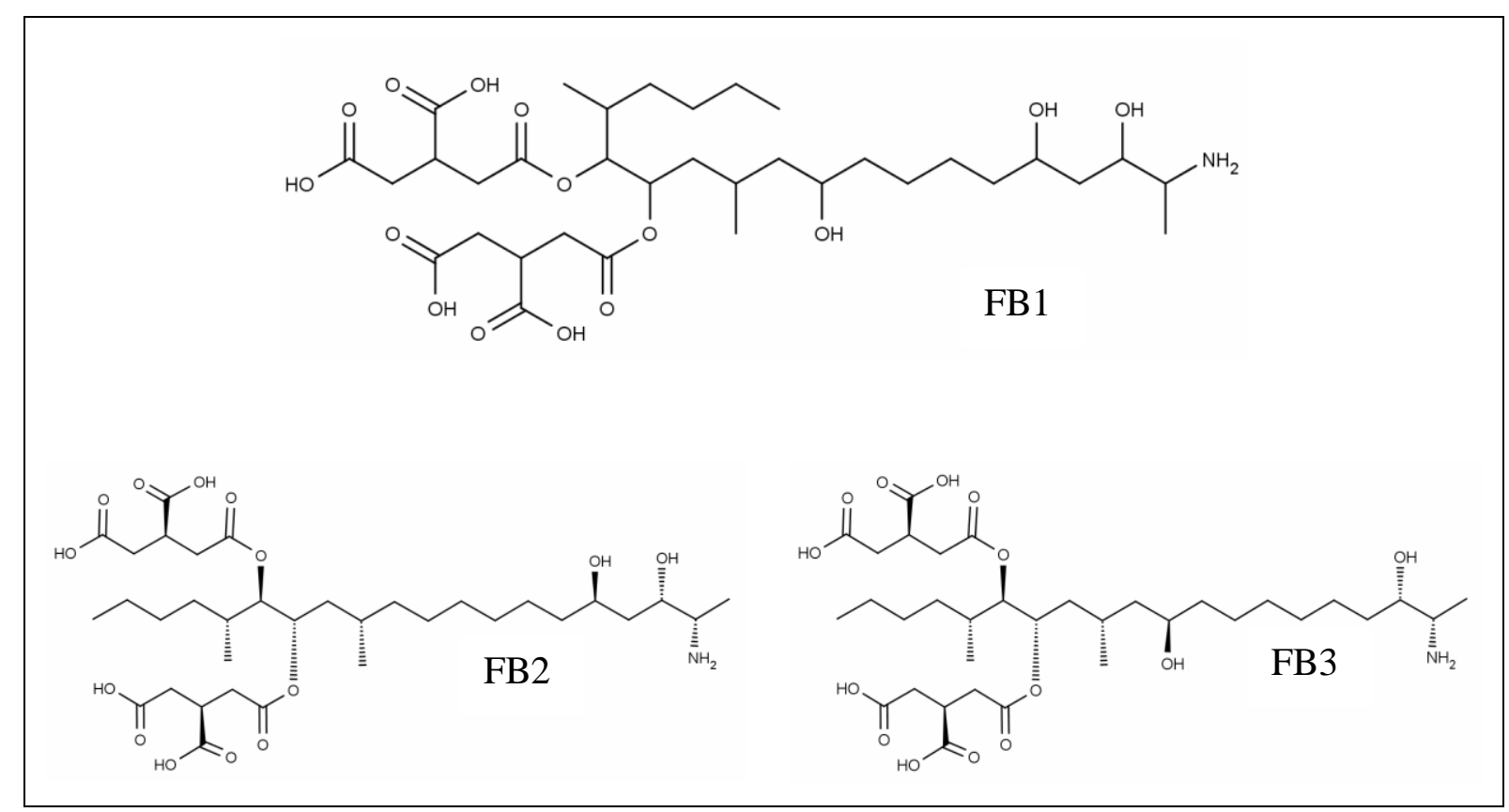

Figura 5 - Estruturas químicas das fumonisinas B1, B2 e B3. 
recente, sugere a existência de pelo menos mais 23 compostos relacionados, incluindo duas novas séries, FD (possui menor número de átomos de carbono, provável precursor das fumonisinas já bem conhecidas) e FX (1 ou 2 grupamentos hidroxilas ligados à estrutura conhecida das fumonisinas foram esterificados) (BARTÓK et al., 2006).

A exposição humana a fumonisinas pelo consumo de milho e derivados altamente contaminados tem sido associada ao aparecimento de câncer no esôfago, no fígado, defeitos do tubo neural e problemas cardiovasculares (MISSMER et al., 2006; SYDENHAM et al., 1995; UENO et al., 1997; WAES et al., 2005). O PMTDI para fumonisinas B1, B2 e B3, sozinhas ou combinadas é de $2 \mu \mathrm{g} / \mathrm{kg}$ pc/dia (JECFA, 2001) e a fumonisina B1 foi classificada como um provável carcinógeno humano (IARC, 2002). A fumonisina B1 foi identificada como um potente inibidor da enzima ceramida sintase (Figura 6), e seus efeitos tóxicos podem estar relacionados ao comprometimento da biossíntese e metabolismo de esfingolipídios (VOSS et al., 2009; WANG et al., 1991).

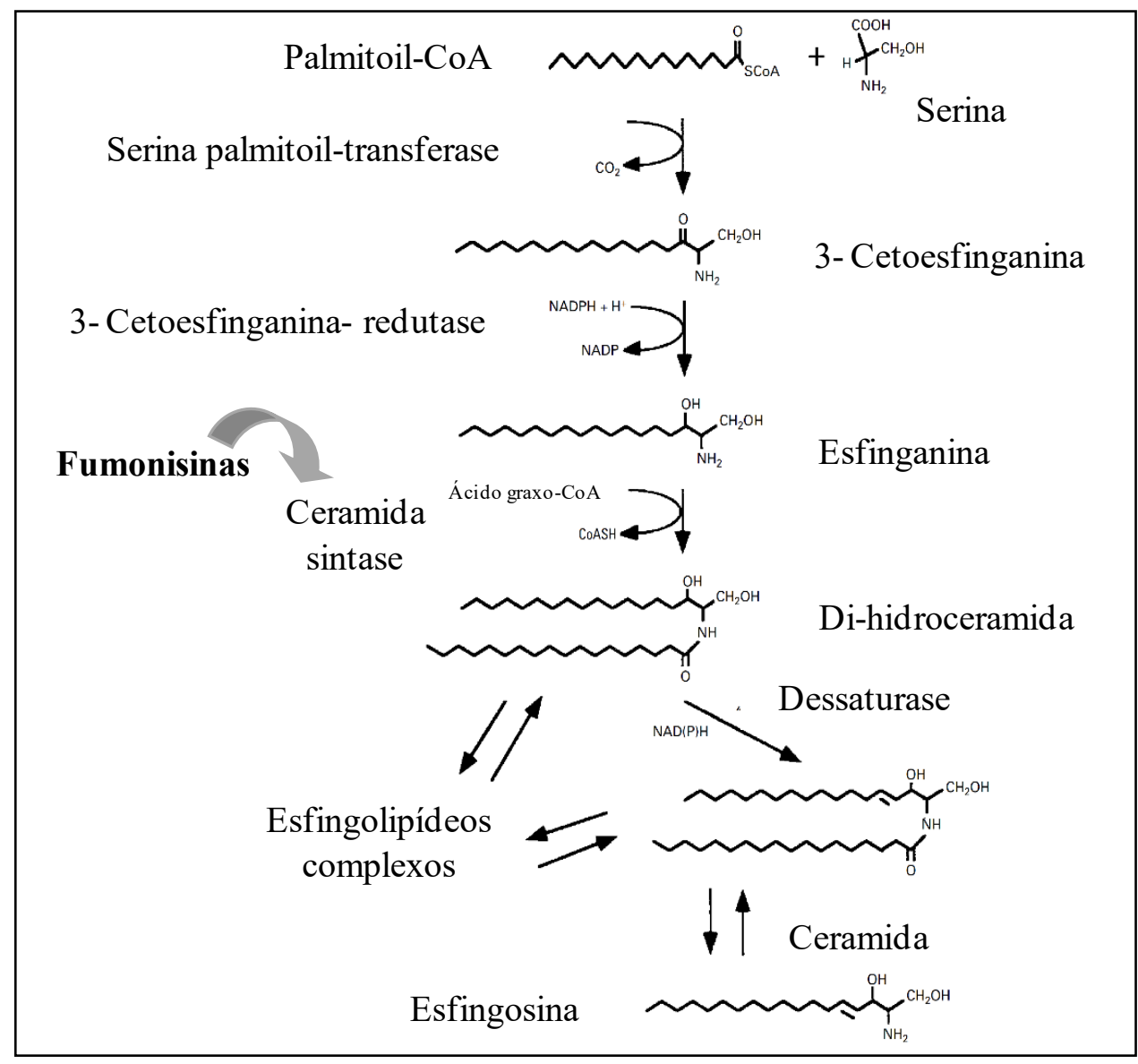

Figura 6 - Via biossintética da formação de esfingolipídeos e possível mecanismo de ação das fumonisinas. Adaptado de Merril et al. (2001). 
Como dito anteriormente, estresse hídrico e ataque de insetos propiciam o desenvolvimento das espécies fúngicas produtoras de fumonisinas e, desta maneira, a irrigação, utilização de grãos transgênicos (cultivares Bt) e de cultivares adaptadas ao clima da região produtora são ferramentas importantes no controle da contaminação por esta micotoxina (PITT; TANIWAKI; COLE, 2013; VISCONTI, 1996). Além disso, modelos preditivos como o FUMAgrain ajudam a prever a contaminação do milho por fumonisinas em função da combinação dos dados de plantio, condições meteorológicas (temperatura, umidade relativa, intensidade de chuvas, velocidade do vento) e uso de fungicidas, possibilitando a tomada de ações que evitem que os níveis da toxina ultrapassem o limite permitido nos grãos (MAIORANO et al., 2009).

A limpeza e seleção dos grãos removem grande parte do material contaminado, reduzindo em até $84 \%$ os níveis de fumonisinas nos cereais (AFOLABI et al., 2006; FIRRAO et al., 2010; PIETRI; ZANETTI; BERTUZZI, 2009; PITT et al., 2012; VAN DER WESTHUIZEN et al., 2011). Assim como as AFs, as fumonisinas se concentram no gérmen e farelo do milho após a moagem e, portanto, a contaminação no produto processado dependerá da fração utilizada para sua obtenção (BRERA et al., 2004; PIETRI; ZANETTI; BERTUZZI, 2009; SCUDAMORE; PATEL, 2009; VANARA; REYNERI; BLANDINO, 2009).

As fumonisinas são relativamente termorresistentes (suportam temperaturas de até 100$120^{\circ} \mathrm{C}$ ), podendo ser encontradas após o processamento e preparo dos alimentos (HUMPF; VOSS, 2004). A maioria dos estudos relata reduções significativas nos níveis de fumonisinas nos alimentos submetidos a tratamento térmico acima de $150^{\circ} \mathrm{C}$, como ocorreu com farinha de milho $\left(190^{\circ} \mathrm{C}\right.$; redução de 40\%) (SCOTT; LAWRENCE, 1994), muffins (175-200 ${ }^{\circ} \mathrm{C}$; redução de até 84\%) (JACKSON et al., 1997) e milho em conserva, farinha de milho e creme de milho (9- 100\% de redução) (CASTELO; SUMNER; BULLERMAN, 1998). O cozimento do arroz pelo método convencional levou a uma redução de $80 \%$ para arroz polido parboilizado, $68 \%$ para arroz polido e 70\% para arroz integral (BECKER-ALGERI et al., 2013).

O efeito da extrusão na estabilidade das fumonisinas depende dos parâmetros utilizados no processo, ou seja, da temperatura, velocidade da rosca e presença de açúcares redutores no meio. Os valores de redução obtidos na extrusão de flocos de milho podem variam entre 4594\%, dependendo das condições escolhidas (CASTELO et al., 2001; JACKSON et al., 2011; KATTA et al., 1999). A nixtamalização, cozimento alcalino do milho para obtenção de tortilhas, também pode reduzir a contaminação por fumonisinas em até 80\% (DE LA CAMPA; MILLER; HENDRICKS, 2004; DOMBRINK-KURTZMAN et al., 2000). 
Alguns produtos de degradação das fumonisinas já foram descritos na literatura. Durante o processo de nixtamalização (cozimento do milho em meio alcalino - fabricação de tortillas), ocorre a remoção das cadeias laterais de ácidos tricarboxílicos (TCA) das moléculas de fumonisinas (Figura 7), formando as fumonisinas hidrolisadas (HFBx) (HOPMANS; MURPHY, 1993; SYDENHAM et al., 1995). A significância toxicológica das fumonisinas hidrolisadas ainda não é bem clara, embora testes revelem menor toxicidade in vivo e maior citotoxicidade quando comparada a FB1 (GELDERBLOM et al., 1993; HUMPF; VOSS, 2004).

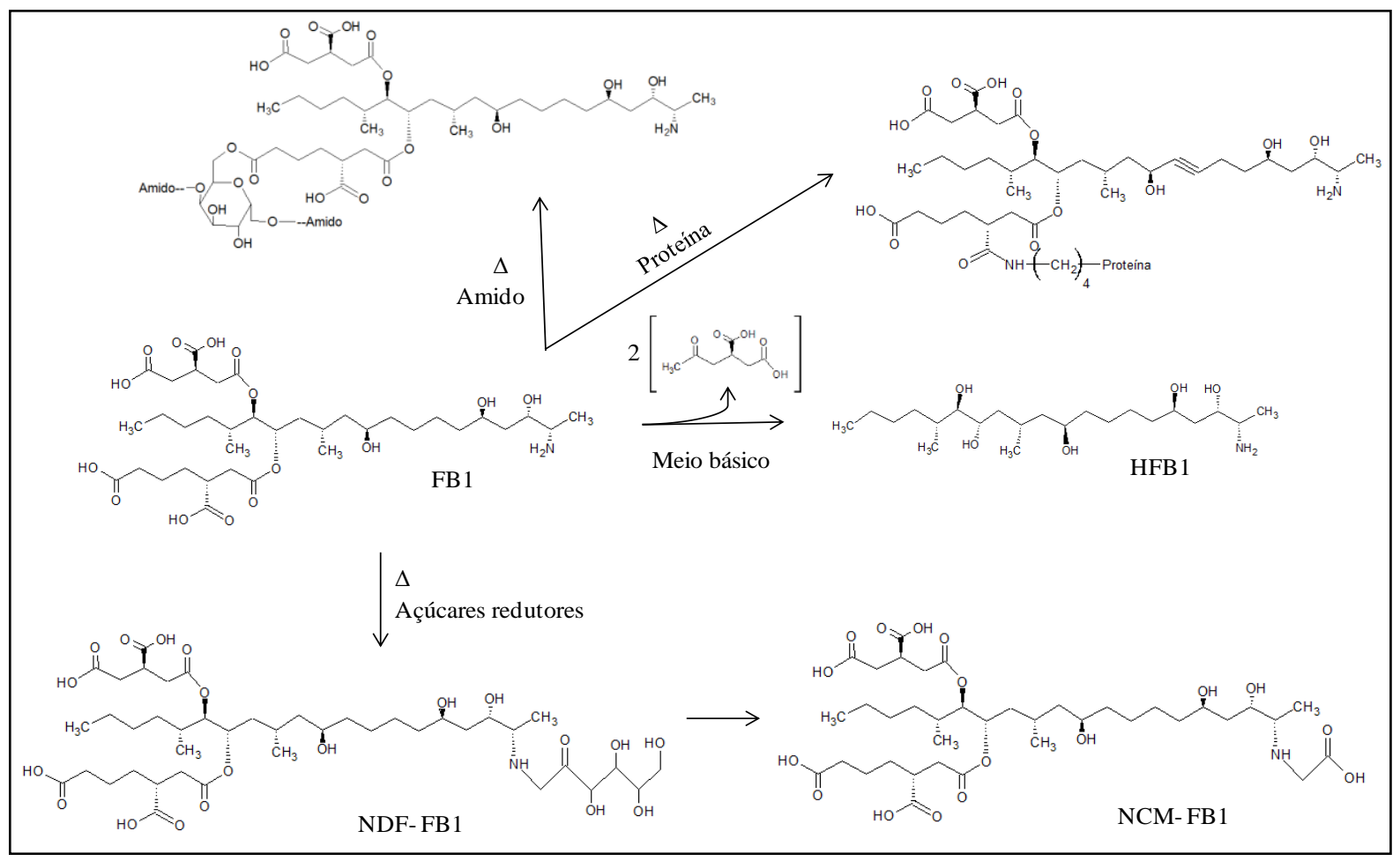

Figura 7 - Estruturas dos produtos da fumonisina B1 formados sob condições de processamento térmico. Adaptado de Humpf e Voss (2004).

O processamento dos alimentos também pode levar a formação de complexos entre as fumonisinas e componentes da matriz, ou mesmo a reação com outros ingredientes do alimento (HUMPF; VOSS, 2004). Por exemplo, quando a FB1 é aquecida na presença de açúcares ocorre uma reação entre o grupamento amina da toxina e o açúcar redutor, nos moldes da reação de Maillard (Figura 7), levando à formação de produtos como o $N$-(1-deoxi-D-frutos-1-il)-FB1 (NDF-FB1) e $N$-caboximetil-FB1 (NCM-FB1) (HOWARD et al., 1998; LU et al., 2002). Dados toxicológicos referentes às fumonisinas $\mathrm{N}$-substituídas são limitados, mas o estudo feito utilizando derivados $N$-acetilados de FB1 e FB2 mostrou que o bloqueio do grupamento amina 
previne a toxicidade em culturas de hepatócitos de ratos, bem como em testes in vivo (GELDERBLOM et al., 1993).

Além disso, testes de digestão realizados in vitro mostraram que estes compostos não eram clivados e, portanto, a fumonisina primária não era liberada no trato digestivo, embora esta hidrólise ocorra sob condições alcalinas (FALAVIGNA et al., 2012). A ocorrência de NDF-FB1 e NCM-FB1 nos alimentos submetidos ao tratamento térmico, extrusão e nixtamalização, é extremamente baixa e, portanto, apenas sua formação não explica adequadamente a redução da contaminação por fumonisinas obtidas com este tipo de processamento (SEEFELDER; HARTL; HUMPF, 2001; VOSS et al., 2001).

Além do grupamento amina, as moléculas de fumonisinas possuem cadeias laterais de ácidos tricarboxílicos (TCA) que podem reagir com componentes do alimento (HUMPF; VOSS, 2004). Shier et al. (2000) propuseram que as fumonisinas seriam capazes de se ligar covalentemente ao amido e proteínas presentes no alimento, o que foi posteriormente confirmado por Seefelder et al. (2003). Os modelos experimentais utilizados mostraram que as fumonisinas eram capazes de se ligar aos grupamentos funcionais de polissacarídeos e proteínas por meio das cadeias laterais de TCA, após tratamento térmico, levando à formação de conjugados alcila (Figura 7).

Acredita-se que a hidrólise em condições básicas nos alimentos rompe a ligação entre o amido e as proteínas ligadas às moléculas de fumonisinas, liberando os análogos hidrolisados da micotoxina (FALAVIGNA et al., 2012; SEEFELDER; KNECHT; HUMPF, 2003). Kim et al. (2003) encontraram em amostras de cereais matinais submetidos à hidrólise alcalina uma quantidade de fumonisinas equivalente a quase 3 vezes o valor inicial. Entretanto, testes de digestão realizados in vitro mostraram que estes conjugados alcila também não são liberados nessas condições, assim como acontece com os conjugados alquila (NDF-FB1 e NCM-FB1) (FALAVIGNA et al., 2012).

Além disso, ainda no campo, pode ocorrer associação entre as moléculas de fumonisina e os macroconstituintes das plantas, como uma resposta da planta à infecção fúngica, permitindo a compartimentalização do analito na estrutura do vegetal. Assim, esses compostos podem ser encontrados em milho in natura, pois não necessitam de tratamento térmico para sua formação (DALL'ASTA et al., 2009a). Diferentemente dos compostos formados durante o tratamento térmico, essas formas associativas de fumonisinas são clivadas em testes de digestão in vitro, podendo liberar o composto original no trato gastrointestinal (FALAVIGNA et al., 2012; SEEFELDER; KNECHT; HUMPF, 2003). 


\section{DEOXINIVALENOL}

Os tricotecenos são as toxinas de maior ocorrência entre aquelas produzidas por espécies de Fusarium, largamente presentes em vários cereais, principalmente trigo. Os tricotecenos são uma família de micotoxinas quimicamente relacionadas, mas o deoxinivalenol (DON) é considerado o tricoteceno de maior relevância. DON pode ser produzido por $F$. graminearum (comumente listado com Gibberella zeae, seu estágio sexual), F. culmorum e espécies relacionadas (PITT; HOCKING, 2009; PITT, 2006). F. graminearum é frequentemente encontrado no milho e em grãos pequenos (especialmente trigo e cevada), enquanto o $F$. culmorum é mais comuns nos grãos pequenos (PITT, 2006). Essas duas espécies de Fusarium são patógenos de plantas, invadindo vegetais e grãos e causando doenças, conhecidas como Giberela e Fusariose, prevalentes em locais de clima temperado, especialmente em anos chuvosos (PITT, 2006). Diferentemente das micotoxinas relacionadas anteriormente, o DON não é formado em condições de estresse hídrico, mas sim como resultado da chuva, principalmente na antese (florescimento) (SCHAAFSMA; HOOKER, 2007; VAN DER FELSKLERX et al., 2012).

Os tricotecenos podem ser divididos em quatro grupos, A-D, de acordo com seus grupamentos funcionais. O DON (Figura 8) pertence ao grupo B, compostos que possuem uma carbonila no C8 (JECFA, 2001). Em condições naturais, seus dois derivados acetilados, o 3acetil-deoxinivalenol (3AcDON) e o 15-acetil-deoxinivalenol (15AcDON), também podem ser excretados pelas espécies de Fusarium acima relacionadas e, embora produzidos em menor quantidade, sua ocorrência concomitantemente com o DON nos alimentos tem sido relatada (BERTHILLER et al., 2009, 2013).

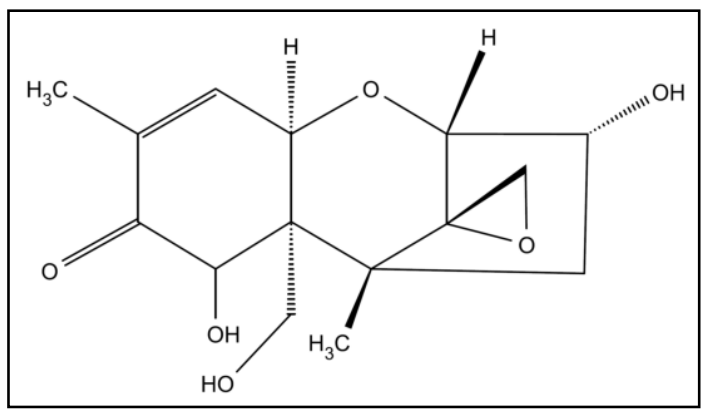

Figura 8 - Estrutura química do deoxinivalenol.

Cereais infectados com fungos produtores de DON são capazes de detoxificar essa micotoxina por meio dos mecanismos de biotransformação (BERTHILLER et al., 2013). A maior via de detoxificação do DON em vegetais se dá pela conjugação da micotoxina a 
moléculas de glicose, formando o deoxinivalenol-3- $\beta$-(D)-glicosídeo (D3G), composto isolado de culturas de milho tratadas com DON, e também de milho e trigo naturalmente contaminados (BERTHILLER et al., 2005, 2013; POPPENBERGER et al., 2003).

Como todas as micotoxinas do grupo dos tricotecenos, o DON é inibidor de síntese proteica (COSTA et al., 2011; ROBBANA-BARNAT et al., 1987; WALLE et al., 2010) e em altas doses pode causar dores abdominais, tontura, dores de cabeça, náusea, vômitos e outros efeitos no homem (PESTKA; SMOLINSKI, 2005; PESTKA, 2010). Casos de intoxicação aguda são raros, mas surtos já foram reportados na Índia, Japão e China (JECFA, 2001; PESTKA, 2010). O DON possui um grupo epóxido (Figura 8), altamente reativo, não precisando de ativação metabólica para exercer seus efeitos biológicos (PITT et al., 2012). O metabolismo de DON varia entre as espécies, podendo ser metabolizado pela microflora intestinal, levando a formação do deepoxi-deoxinivalenol (DOM-1) que, posteriormente, é conjugado com ácido glicurônico (ERIKSEN et al., 2002; GRATZ; DUNCAN; RICHARDSON, 2013).

Estudos in vitro e de toxicidade oral aguda mostraram similaridade ou toxicidade pouco menor para os compostos acetilados $(3 \mathrm{AcDON}$ e $15 \mathrm{AcDON})$ quando comparados à molécula de DON (DAENICKE et al., 2011; ERIKSEN; PETTERSSON; LUNDH, 2004; FORSELL et al., 1987). O JECFA, em sua mais recente avaliação do DON, considerando que os derivados acetilados contribuem para a toxicidade total induzida pela exposição ao DON, determinou o PMTDI de $1 \mu \mathrm{g} / \mathrm{kg}$ pc e ARfD (dose de referência aguda) de $8 \mu \mathrm{g} / \mathrm{kg}$ pc para a combinação de DON, 3AcDON e 15AcDON (JECFA, 2011). Estudos recentes também mostraram que o D3G pode ser clivado por bactérias intestinais, se tornando biodisponível e contribuindo para a exposição total por DON (BERTHILLER et al., 2011; NAGL et al., 2012).

O controle da produção de DON nos cereais tem sido feito utilizando cultivares mais resistentes à infecção fúngica (adaptados a cada região), grãos transgênicos (menor dano por insetos) e aplicação de fungicidas, principalmente na antese (PITT et al., 2012). Além disso, modelos preditivos também estão sendo utilizados no Canadá, Uruguai e alguns países Europeus para prever a contaminação por DON em trigo (PITT et al., 2012; SCHAAFSMA; HOOKER, 2007; VAN DER FELS-KLERX et al., 2009).

Os processos de seleção e limpeza podem reduzir os níveis de contaminação por DON em cereais, embora os valores de redução obtidos variem consideravelmente entre os estudos conduzidos (6-78\%; trigo) (ABBAS et al., 1985; NEAGU et al., 2012; SCUDAMORE; PATEL, 2008; VISCONTI et al., 2004). Tkachuk et al. (1991) mostrou que grãos altamente 
infectados por Fusarium se tornavam murchos e perdiam massa e, consequentemente, podiam ser separados de grãos não contaminados utilizando mesas gravitacionais. Assim como para as demais micotoxinas, o DON é distribuído entre as frações obtidas pela moagem dos grãos, concentrando-se, principalmente no gérmen e farelo (LANCOVA et al., 2008; VISCONTI et al., 2004).

A influência do processamento térmico no conteúdo de DON nos alimentos tem sido frequentemente avaliada. Durante a produção de pães, a redução varia bastante, indo de efeitos não significativos a 63\% de redução (LANCOVA et al., 2008; VIDAL et al., 2014; VOSS; SNOOK, 2010). Os resultados obtidos após o processo de extrusão também são bem diversificados. Cazzaniga et al. (2001) relatou uma redução de até 95\% (dependendo das condições escolhidas) na extrusão de farinha de milho artificialmente contaminada, enquanto Scudamore \& Patel (2008) não encontraram grandes efeitos na quantidade de DON durante a fabricação de cereais matinais a partir de farinha de trigo. $\mathrm{O}$ efeito da fabricação de dois tipos de macarrão asiáticos (amarelo alcalino e instantâneo) a base de farinha de trigo também foi avaliado por Farahany \& Jinap (2011), obtendo reduções de 43,2\% e 55,4\%, respectivamente.

Os produtos da degradação do DON hoje conhecidos foram obtidos após intenso tratamento térmico ou sob condições moderadamente alcalinas, são eles: isoDON, norDON-A, norDON-B, norDON-C, norDON-D, norDON-E, norDON-F, 9-hidroximetil-DON-lactona e DON-lactonas (BRETZ et al., 2006; GREENHALGH et al., 1984; GROVE, 1985; YOUNG; BLACKWELL; APSIMON, 1986). Os produtos de degradação norDON-A, nor-DON-B e norDON-C já foram encontrados em amostras de produtos a base de cereais (29-66\%; 3-15 $\mu \mathrm{g} / \mathrm{kg})$, comprovando a significância destes produtos de degradação (BRETZ et al., 2006). DONoligossacarídeos foram descritos recentemente por Zachariasova et al. (2012) e encontrados em $67-80 \%$ das amostras de malte, cerveja e produtos de panificação analisados.

\section{ZEARALENONA}

A zearalenona (ZON) também é produzida por várias espécies de Fusarium, sendo encontrada em todos os cereais, principalmente no milho e trigo (CAST, 2003). A ZON (Figura 9) é produzida pelos mesmos fungos que produzem deoxinivalenol e, geralmente, nas mesmas condições. Portanto, a ecologia da produção de zearalenona se espelha na de DON (PITT, 2006). 


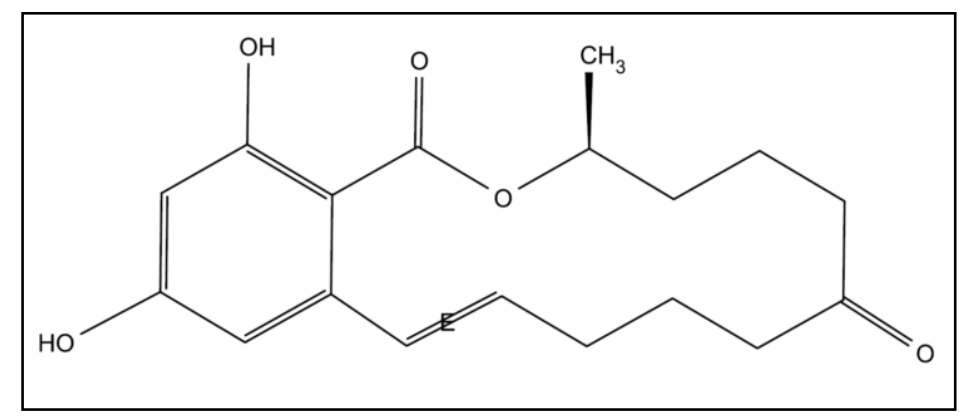

Figura 9 - Estrutura química da zearalenona. E= ligantes de maiores números atômicos em lados opostos.

A zearalenona causa síndrome estrogênica em suínos, efeito que pode potencialmente ocorrer no homem (SHERIF; SALAMA; ABDEL-WAHHAB, 2009). O PMTDI para zearalenona é de $0,5 \mu \mathrm{g} / \mathrm{kg}$ pc (JECFA, 2000). Em animais, a ZON é metabolizada durante a absorção pelos tecidos intestinais ao $\alpha$-zearalenol ( $\alpha$-ZOL) e $\beta$-zearalenol ( $\beta$-ZOL) e, após uma nova redução, ao $\alpha$ e $\beta$-zearalanol (JECFA, 2000). O $\alpha$-ZOL possui maior potencial estrogênico quando comparado à ZON, sendo o principal metabólito produzido em estudos in vitro (FINKGREMMELS; MALEKINEJAD, 2007).

A ZON e seus metabólitos podem se ligar aos receptores de estrogênio, embora também seja um substrato competitivo para enzimas envolvidas na síntese e metabolismo de esteroides, o que a torna um potencial desregulador endócrino (PITT et al., 2012). Ding et al. (2006) demonstraram que a ZON é um ligante eficaz do receptor de pregnano X (regula a expressão de inúmeras enzimas responsáveis pelo metabolismo hepático de drogas), ou seja, a ZON pode ter efeitos generalizados sobre a expressão genética, como resultado da modificação da atividade desse fator de transcrição nuclear (PITT et al., 2012).

Espécies de Fusarium também são capazes de produzir conjugados, como a zeralenona4-sulfato (Z4S), composto que mantém a capacidade estrogênica do composto original e já foi encontrado em amostras de milho em concentrações de 0,1-50 $\mu \mathrm{g} / \mathrm{kg}$ (BERTHILLER et al., 2009; PLASENCIA; MIROCHA, 1991). A Z4S é facilmente convertida à forma original (ZON), por sulfatases ou hidrólises químicas durante a o processo de extração (BERTHILLER et al., 2009).

Outros microrganismos, quando incubados com a ZON, também são capazes de produzir conjugados. O Rhizopus arrhizus é capaz de catalisar a sulfatação de ZON à 4- $\beta$-(D)glicopiranosídeo (Z4G), enquanto espécies de Rhizopus, Mucor bainieri e Thamnidium elegans tem a habilidade de converter ZON a Z4G e zearalenona 2,4-(O)- $\beta$-diglicosíedo (apenas 
Thamnidium elegans) (EL-SHARKAWAY et al., 1991; EL-SHARKAWY; ABUL-HAJJ, 1987; KAMIMURA, 1986).

As plantas também se protegem contra a presença de xenobióticos, convertendo-os a compostos mais polares que, posteriormente, podem ser armazenados nos vacúolos ou conjugados com biopolímeros, como os componentes da parede celular (BERTHILLER et al., 2009). Os produtos resultantes da biotransformação da ZON em plantas foram elucidados por um modelo utilizando a Arabidopsis thaliana. O modelo mostrou que a ZON se transforma rapidamente em 17 compostos diferentes, incluindo glicosídeos, malonil glicosídeos, dihexosídeos e pentosil-hexosídeos de ZON, alem de seus metabólitos de fase I, o $\alpha$-ZOL e $\beta$ ZOL (BERTHILLER et al., 2006). Assim como o D3G, a ZON ainda pode ser glicosilada por enzimas presentes nos vegetais (UDP glicosiltransferases), produzindo a zearalenona-4-(O)glicosídeo e prevenindo a ligação entre ZON e receptores estrogênicos (POPPENBERGER et al., 2006).

Uma vez que a ZON é produzida pelas mesmas espécies produtoras de DON, as estratégias utilizadas no controle dessas micotoxins são similares, ou seja, utilização de cultivares resistentes e transgênicos, aplicação de fungicidas e uso de modelos preditivos (PITT et al., 2012). Brera et al. (2006) mostraram que durante a moagem de milho a ZON também se concentra no farelo e no gérmen.

O processamento térmico de trigo e cevada, em temperaturas entre $140-220^{\circ} \mathrm{C} /$ forno convencional, levou a uma redução máxima de $85 \%$ no teor de $\mathrm{ZON}\left(220^{\circ} \mathrm{C} / 60 \mathrm{~min}\right.$ ) (YUMBEGUEVARA; IMOTO; YOSHIZAWA, 2003). Cetin \& Bullerman (2005) avaliaram o processo de extrusão de produtos de milho como uma potencial técnica de detoxificação para a ZON. Os resultados encontrados demonstraram uma redução de 60-81\% nos níveis de ZON, dependendo das condições escolhidas (temperatura e velocidade da rosca), além da diminuição da toxicidade (testes in vitro).

\section{CITREOVIRIDINA}

O Penicillium citreonigrum é o principal produtor de citreoviridina (CTV) e, embora não seja uma espécie comumente isolada, é amplamente distribuído (EL-BANNA; PITT; LEISTNER, 1987; PITT; HOCKING, 2009), sendo encontrado no arroz, milho e ocasionalmente em trigo e derivados, feijão e pimentas (PITT; HOCKING, 2009; ROSA et al., 2010). A CTV (Figura 10) é produzida em ampla faixa de temperatura $\left(10-37^{\circ} \mathrm{C}\right)$, porém o máximo de produção é obtido próximo a $20^{\circ} \mathrm{C}$ (UENO, 1972). 


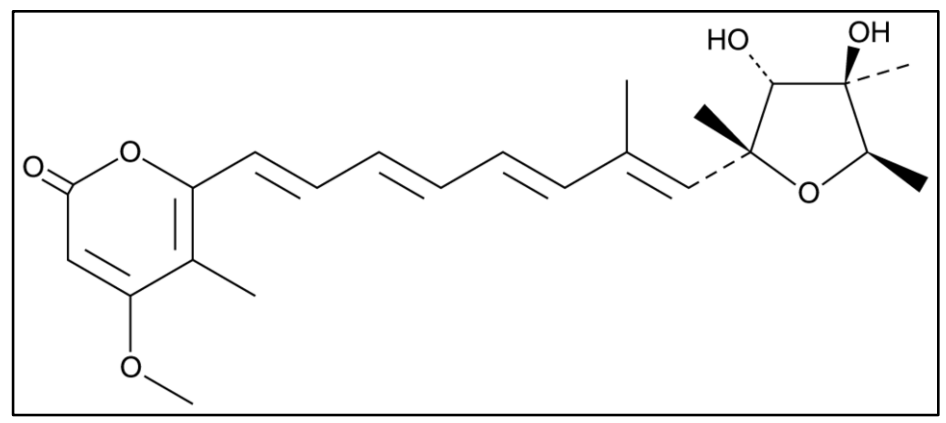

Figura 10 - Estrutura química da citreoviridina.

A CTV foi considerada a causa do beribéri cardíaco agudo, doença prevalente por muito tempo na Ásia, que ficou conhecida como doença do "arroz amarelo" (PITT; HOCKING, 2009; UENO, 1971; URAGUCHI, 1969). O beribéri é causado pela deficiência de vitamina B1 (tiamina), decorrente de deficiência nutricional, alcoolismo, aumento da demanda ou da eliminação de tiamina. Pode manifestar-se como beribéri úmido ou beribéri Shoshin, afetando principalmente o sistema cardiovascular, ou beribéri seco e Síndrome de Wernick-Korsakoff, atuando sobre o sistema nervoso (THURNHAM, 2009). Quando se trata de beribéri induzido pela exposição à CTV, acredita-se que a toxina possua um efeito anti-tiamina, inibindo a adenosina trifosfato e a tiamina difosfato (DATTA; GHOSH, 1981).

No Brasil, em 2006, houve um surto de beribéri no Maranhão, totalizando 1207 casos e 40 óbitos até o final de 2008 (PADILHA et al., 2011). Amostras de arroz coletadas na região dos surtos foram analisadas e diversas espécies de fungos foram encontradas, inclusive Peniclillium citreonigrum. Além disso, cinco amostras estavam contaminadas com CTV (ROSA et al., 2010). Entretanto, um estudo de caso-controle conduzido no Maranhão não foi capaz de estabelecer uma associação entre o consumo de arroz contaminado com CTV e os casos de beribéri apresentados, pois não encontraram amostras contaminadas com CTV e nem isolaram fungos produtores desta toxina. Apesar disso, encontraram uma associação entre a doença e o consumo de arroz de subsistência, além dos fatores de risco tradicionais para o beribéri (LIMA et al., 2010). Atualmente, o beribéri associado à CTV tem apenas interesse histórico no Japão (PITT; HOCKING, 2009), porém, com o surto ocorrido no Brasil, a exposição à CTV se tornou importante no contexto da saúde pública brasileira.

\section{MICOTOXINAS MASCARADAS}

O termo micotoxina mascarada foi introduzido na década de 90 (GAREIS et al., 1990) para descrever a presença em cereais do composto zearalenona-glicosídeo, micotoxina não detectada pelos métodos convencionais de análise até então utilizados, mas que era hidrolisada 
durante o processo digestivo ao composto original, a zearalenona. Desde então, o termo foi utilizado para descrever uma grande variedade de compostos oriundos de algum tipo de modificação da molécula original da micotoxina e que não poderiam ser detectados por métodos de rotina (CIRLINI; DALL'ASTA; GALAVERNA, 2012; PARK et al., 2004a).

Posteriormente, o termo micotoxina conjugada também passou a ser utilizado, considerando que as alterações sofridas pelas substâncias poderiam ser resultantes do metabolismo de plantas, animais ou mamíferos ou ainda decorrentes do processamento de alimentos (BERTHILLER et al., 2009). As formas conjugadas foram divididas conforme eram encontradas nos alimentos: solúveis (masked mycotoxins) ou ligadas às macromoléculas (bound mycotoxins). Em 2011, o ILSI (International Life Science Institute) definiu que o termo micotoxinas mascaradas deveria ser utilizado apenas para designar micotoxinas metabolizadas por plantas (BERTHILLER et al., 2013), o que não resolveu o problema da falta de harmonização entre as definições dos compostos resultantes de alterações das micotoxinas "originais".

Buscando incluir todos os potenciais compostos derivados das micotoxinas e visando a conciliação dos termos utilizados, um novo esquema foi proposto por Rychlik et al. (2014). A Figura 11 mostra a estrutura proposta pelos autores, de acordo com os três grupos criados: micotoxinas livres, associadas à matriz e modificadas. No primeiro grupo, micotoxinas livres ou não modificadas, encontram-se as micotoxinas primárias, ou seja, os metabólitos secundários tóxicos produzidos por vários fungos em vias biossintéticas bem conhecidas, como a aflatoxina B1 (AFB1), ocratoxina A (OTA), fumonisina B1 (FB1), zearalenona (ZON), deoxinivalenol (DON), 3-acetil-deoxinivalenol (3AcDON) e 15-acetil-deoxinivalenol (15AcDON).

No grupo das micotoxinas associadas à matriz estão os compostos que formam complexos com os componentes da matriz, são fisicamente dissolvidos ou compartimentalizados e os que se ligam covalentemente aos elementos da matriz, como acontece com as fumonisinas ligadas ao amido ou proteínas presentes no alimento.

O terceiro grupo, das micotoxinas modificadas, inclui as substâncias que sofreram qualquer tipo de modificação, seja química ou biológica, em sua estrutura básica. No grupo das micotoxinas biologicamente modificadas estão os compostos resultantes do processo de biotransformação, tanto de reações de fase I (adição ou exposição de grupos funcionais) como de fase II (conjugação com substâncias endógenas), além de outros tipos de modificações biológicas. Entre os metabólitos de fase I, temos a formação da AFB1-8,9-exo-epóxido, 
composto responsável pelos efeitos tóxicos da AFB1 através da ligação covalente com moléculas de DNA. As micotoxinas conjugadas, metabólitos de fase II, incluem as substâncias resultantes de reações de conjugação realizada por plantas (deoxinivalenol-3-glicosídeo), animais (DON-glicuronídeos) e fungos (ZON-4-sulfato). O terceiro grupo dos modificados biologicamente compreende todos os outros tipos de alterações biológicas, como por exemplo, a formação de deepoxi-deoxinevalenol (DOM-1) pela microbiota intestinal de animais e humanos.

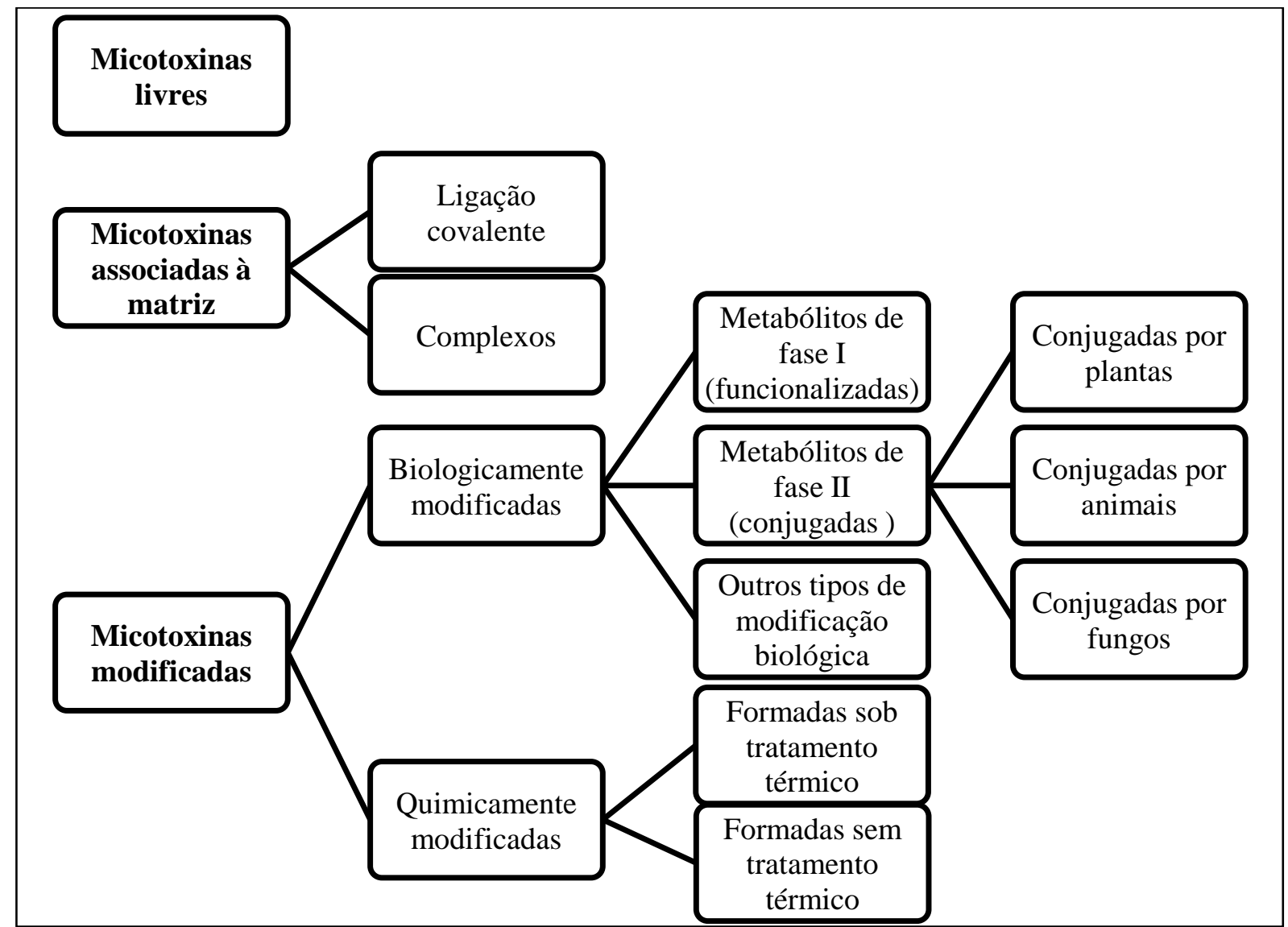

Figura 11 - Esquema da proposta de harmonização dos termos utilizados para designar micotoxinas e seus potenciais compostos derivados (RYCHLIK et al., 2014).

Os compostos quimicamente modificados abrangem os compostos formados tanto na presença de tratamento térmico quanto na sua ausência. Degradações e modificações térmicas podem ocorrer durante o processamento de alimentos, nos processos de cozimento, torrefação, frituras ou extrusão. A reação da FB1 com açúcares redutores formando o $N$-1-deoxi-(D)frutose-FB1 e o $N$-carboximetil-FB1 são exemplos de modificação térmica enquanto a formação de hidrolisados de fumonisina $\left(\mathrm{HFB}_{\mathrm{x}}\right)$ em condições alcalinas é um tipo de modificação não térmica (HOPMANS; MURPHY, 1993; HOWARD et al., 1998). 
Rychlik et al. (2014) concordam com a definição do ILSI para micotoxinas mascaradas (exclusivo para metabólitos produzidos por plantas) e ressaltam que alguns compostos podem ser gerados de diferentes maneiras, ou seja, a mesma substância poderá pertencer a diferentes categorias. Entretanto, destacam que com essa divisão, todas as formas potencialmente relevantes das micotoxinas seriam incluídas nas novas definições (Figura 11). Independente da definição adotada, homens e animais que consomem alimentos contaminados por micotoxinas não estão expostos apenas ao composto nativo, mas também às substâncias modificadas. Como o conhecimento sobre a ocorrência, biodisponibilidade e metabolismo subsequente desses compostos modificados ainda é pequeno, faz-se necessário desenvolver métodos analíticos que sejam capazes de identificar e quantificar esses compostos para que estes possam ser incluídos no processo de avaliação do risco, garantindo proteção à saúde do consumidor. O Quadro 1 mostra os compostos derivados de micotoxinas que serão analisados neste trabalho.

Quadro 1 - Micotoxinas modificadas que serão analisadas neste trabalho, segundo a classificação proposta por Rychlik et al. (2014)

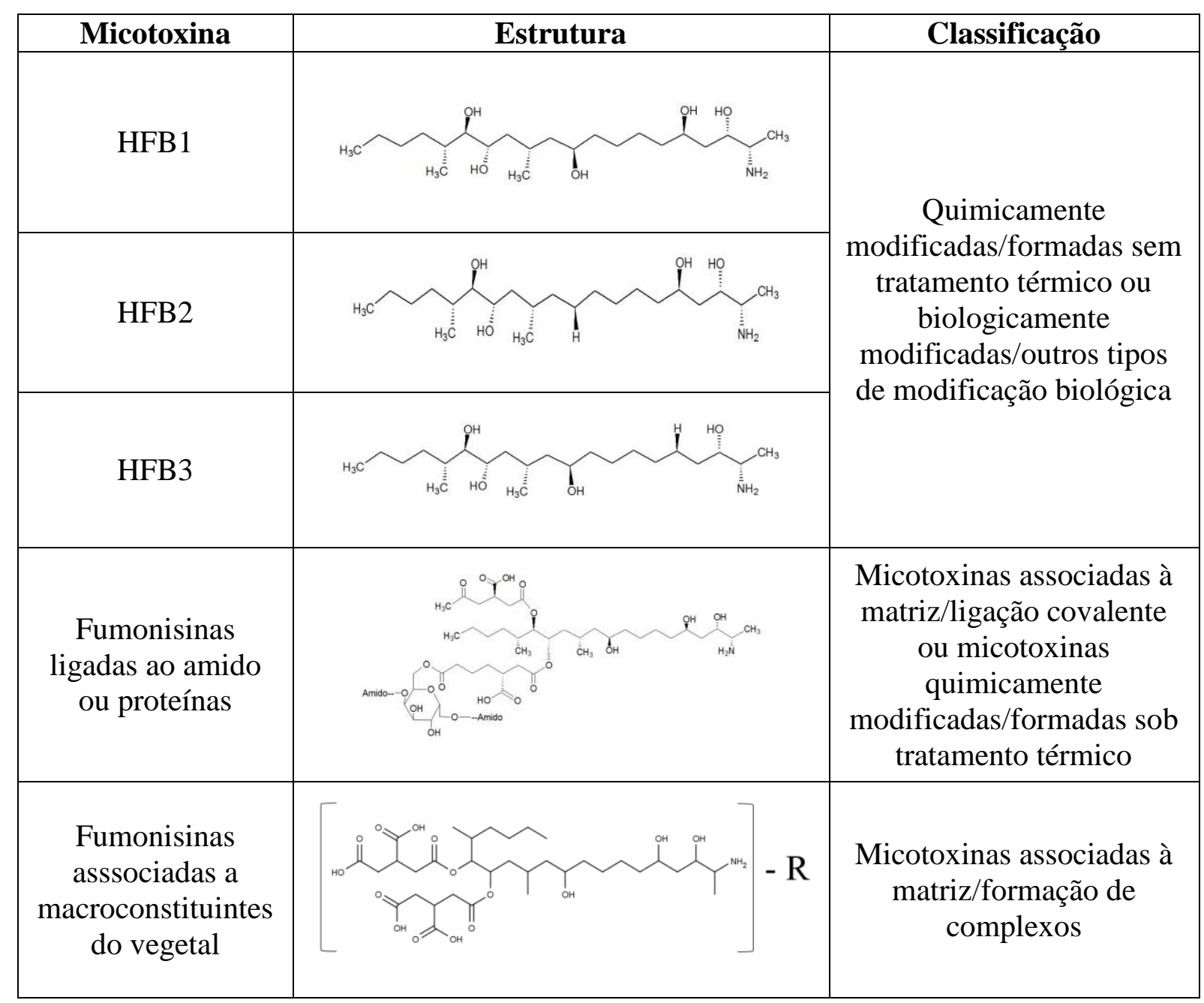




\begin{tabular}{|c|c|c|}
\hline Micotoxina & Estrutura & Classificação \\
\hline $3 \mathrm{AcDON}$ & & $\begin{array}{l}\text { Livres ou biologicamente } \\
\text { modificados/metabólitos } \\
\text { de fase II/conjugados por } \\
\text { plantas }\end{array}$ \\
\hline 15 AcDON & & $\begin{array}{c}\text { Livres ou biologicamente } \\
\text { modificados/metabólitos } \\
\text { de fase II/conjugados por } \\
\text { plantas }\end{array}$ \\
\hline D3G & & $\begin{array}{c}\text { Biologicamente } \\
\text { modificados/metabólitos } \\
\text { de fase II/conjugados por } \\
\text { plantas } \\
\end{array}$ \\
\hline DOM-1 & & $\begin{array}{c}\text { Biologicamente } \\
\text { modificadas/outros tipos } \\
\text { de modificação biológica }\end{array}$ \\
\hline$\alpha-Z O L$ & & $\begin{array}{c}\text { Biologicamente } \\
\text { modificados/metabólitos } \\
\text { de fase I }\end{array}$ \\
\hline
\end{tabular}

\section{LEGISLAÇÃO}

Como mostrado anteriormente, o processamento e preparo dos alimentos não são suficientes para eliminar completamente as micotoxinas, além de poder causar modificações em sua estrutura, dificultando sua detecção no produto final. Sendo assim, a melhor maneira de diminuir a exposição humana às micotoxinas é diminuir seus níveis nos alimentos não processados, como os cereais in natura, com ações de manejo e controle no campo, armazenamento e transporte. Adicionalmente, o estabelecimento de limite máximo (LM) é uma estratégia de gestão importante para retirar do comércio alimentos altamente contaminados e diminuir a exposição humana (CODEX ALIMENTARIUS, 1995).

A primeira legislação brasileira sobre micotoxinas entrou em vigor em 1977 e estabeleceu LM de $30 \mu \mathrm{g} / \mathrm{kg}$ para o somatório de AFB1 e AFG1 em alimentos destinados ao consumo humano (CNNPA, 1977). Em 2002, a RDC n 274 (BRASIL, 2002) incluiu LM para AFM1 em leite fluido e leite em pó $(0,5 \mu \mathrm{g} / \mathrm{L}$ e $5,0 \mu \mathrm{g} / \mathrm{kg}$, respectivamente) e AFs (AFB1+AFB2+AFG1+AFG2) em amendoim, pasta de amendoim, milho em grão e farinha ou sêmola de milho para consumo humano $(20 \mu \mathrm{g} / \mathrm{kg})$, revogando parcialmente a resolução do CNNPA (Comissão Nacional de Normas e Padrões para Alimentos). Como as legislações brasileiras anteriores estabeleciam LM apenas para AFs (BRASIL, 2002; CNNPA, 1977), a RDC $n^{\circ} 7$ (BRASIL, 2011) incluiu LM para OTA, DON, fumonisinas (FB1+FB2), patulina e 
ZON e expandiu a lista de alimentos para os quais os LM de AFs se aplicam. A RDC $\mathrm{n}^{\circ} 7$ escalonou os prazos para a aplicação dos LM para que o setor produtivo tomasse as medidas necessárias para atender à nova legislação. Os limites estabelecidos foram divididos entre os de vigência imediata (2011) e os de aplicação nos anos de 2012, 2014 e 2016 (OTA, DON, fumonisinas e ZON). No entanto, atendendo às solicitações do setor produtivo, os LM com prazos de adequação para 2014 e 2016 foram prorrogados até janeiro de 2017 (BRASIL, 2013). A Tabela 2 mostra alguns dos LM vigentes para AFs, OTA, DON, fumonisinas e ZON em alimentos destinados ao consumo humano no Brasil.

Tabela 2 - Limites máximos (LM) para AFs, OTA, DON, fumonisinas e ZON em alimentos destinados ao consumo humano no Brasil.

\begin{tabular}{|c|c|c|}
\hline Micotoxina & Alimento & LM $(\mu \mathrm{g} / \mathrm{kg})$ \\
\hline \multirow[t]{3}{*}{$\begin{array}{l}\mathrm{AFB} 1+\mathrm{AFB} 2+ \\
\mathrm{AFG} 1+\mathrm{AFG} 2\end{array}$} & $\begin{array}{l}\text { Alimentos à base de cereais para alimentação infantil, } \\
\text { fórmulas infantis }\end{array}$ & 1 \\
\hline & Cereais e derivados (exceto milho), feijão & 5 \\
\hline & $\begin{array}{l}\text { Milho, milho em grão (inteiro, partido, amassado, moído), } \\
\text { farinhas ou sêmolas de milho }\end{array}$ & 20 \\
\hline \multirow[t]{2}{*}{ OTA } & Alimentos à base de cereais para alimentação infantil & 2 \\
\hline & $\begin{array}{l}\text { Cereais e derivados, feijão, café torrado (moído ou em } \\
\text { grão), café solúvel }\end{array}$ & 10 \\
\hline \multirow[t]{4}{*}{ DON } & Alimentos à base de cereais para alimentação infantil & 200 \\
\hline & Arroz beneficiado e derivados & 750 \\
\hline & $\begin{array}{l}\text { Farinha de trigo, massas, crackers, biscoitos de água e sal, } \\
\text { produtos de panificação, cereais e derivados (exceto trigo) }\end{array}$ & 1750 \\
\hline & $\begin{array}{l}\text { Trigo integral, trigo para quibe, farinha de trigo integral, } \\
\text { farelo de trigo, farelo de arroz, grão de cevada }\end{array}$ & 2000 \\
\hline \multirow[t]{3}{*}{$\mathrm{FB} 1+\mathrm{FB} 2$} & Alimentos à base de milho para alimentação infantil & 200 \\
\hline & $\begin{array}{l}\text { Milho de pipoca, amido de milho e outros produtos à base } \\
\qquad \text { de milho }\end{array}$ & 2000 \\
\hline & $\begin{array}{l}\text { Farinha de milho, creme de milho, fubá, flocos de milho, } \\
\text { canjica, canjiquinha }\end{array}$ & 2500 \\
\hline \multirow[t]{3}{*}{$\mathrm{ZON}$} & Alimentos à base de cereais para alimentação infantil & 20 \\
\hline & $\begin{array}{c}\text { Farinha de trigo, massas, crackers, produtos de panificação, } \\
\text { cereais e derivados (exceto trigo), arroz beneficiado e } \\
\text { derivados }\end{array}$ & 200 \\
\hline & Arroz integral & 800 \\
\hline
\end{tabular}




\begin{tabular}{ccc}
\hline Micotoxina & Alimento & LM $(\boldsymbol{\mu g} / \mathbf{k g})$ \\
\hline & Milho de pipoca, canjiquinha, canjica, derivados de milho & 300 \\
& Trigo integral, farinha de trigo integral, farelo de trigo & 400 \\
\hline
\end{tabular}

Fonte: RDC $\mathrm{n}^{\circ} 7$ de 18 de fevereiro de 2011 (BRASIL, 2011).

$\mathrm{Na}$ União Europeia existem limites para AFs em diversos produtos, como nozes, castanhas, frutas secas, cereais e derivados, pimentas e alimentos infantis, com LM variando entre $0,1 \mu \mathrm{g} / \mathrm{kg}$ e $12 \mu \mathrm{g} / \mathrm{kg}$, além de limites para AFM1 em leite e derivados $(0,025-0,05$ $\mu \mathrm{g} / \mathrm{kg}$ ). Para DON e ZON existem limites para cereais e seus produtos, com valores de LM entre $200-1750 \mu \mathrm{g} / \mathrm{kg}$ e $20-400 \mu \mathrm{g} / \mathrm{kg}$, respectivamente. A presença de fumonisinas (B1+B2) é regulada em milho e derivados $(200-4000 \mu \mathrm{g} / \mathrm{kg})$ e a OTA em cereais e seus produtos, frutas secas, café, cacau, vinho, suco de uva e produtos destinados à alimentação infantil, entre outros $(0,5-30 \mu \mathrm{g} / \mathrm{kg})$. A legislação Europeia ainda prevê o controle de patulina e das toxinas T-2 e HT-2 (EC, 2006). Nos Estados Unidos, existe limite para aflatoxinas em alimentos de maneira geral $(20 \mu \mathrm{g} / \mathrm{kg}$ ) (USFDA, 2000) e recomendações para DON em produtos finalizados de trigo $(1000 \mu \mathrm{g} / \mathrm{kg})$ e fumonisinas (FB1+FB2+FB3) em milho e derivados $(2000-4000 \mu \mathrm{g} / \mathrm{kg})$ (NGFA, 2011).

No âmbito internacional, o Codex Alimentarius estabelece limites para AFs em amendoim, amêndoa, avelã, castanha do Brasil, figos secos e pistache (10-15 $\mu \mathrm{g} / \mathrm{kg})$ e para OTA em trigo cru, cevada e centeio (5 $\mu \mathrm{g} / \mathrm{kg}$ ) (CODEX ALIMENTARIUS, 1995). Em 2014, o Comitê de Contaminantes do Codex aprovou limites para fumonisinas (FB1+FB2) em grãos de cereais crus $(4000 \mu \mathrm{g} / \mathrm{kg})$ e em fubá e farinha de milho $(2000 \mu \mathrm{g} / \mathrm{kg})$. O estabelecimento de limites para DON (cereais crus, produtos processados e cereais para alimentação infantil) e AFs em arroz, milho, sorgo e trigo ainda está em discussão (FAO/WHO, 2014).

\section{MÉTODOS DE ANÁLISE E OCORRÊNCIA DE MICOTOXINAS NOS ALIMENTOS}

Nas Tabelas 3 a 8 são mostrados alguns dos métodos frequentemente utilizados para a determinação de micotoxinas em cereais. De maneira geral, os procedimentos analíticos envolvem etapas de amostragem, homogeneização, extração, clean up (purificação), concentração ou diluição do extrato. A separação e a detecção dos analitos são efetuadas, geralmente, por técnicas cromatográficas (com diferentes detectores) ou por métodos imunoquímicos.

A cromatografia líquida acoplada à espectrometria de massas sequencial (LC-MS/MS) tem se tornado a ferramenta analítica mais utilizada na determinação de multi-micotoxinas e 
seus metabólitos (BERTHILLER et al., 2007; CAPRIOTTI et al., 2012). Ao contrário dos métodos baseados em cromatografia gasosa, os compostos polares são facilmente analisados, sem a necessidade de derivatização. Outras vantanges da utilização de LC-MS/MS incluem os baixos limites de detecção atingidos, a confirmação da identidade dos analitos, baixo requerimento de tratamento de amostra e a possibilidade de cobrir uma vasta gama de analitos de diferentes polaridades (BERTHILLER et al., 2007; CAPRIOTTI et al., 2012; MALACHOVÁ et al., 2014). Os espectrômetros de massas são detectores bem gerais, não tão dependentes das características químicas dos compostos como os detectores de UV e fluorescência (FD) (BERTHILLER et al., 2007).

Entretanto, os efeitos de matriz limitam o potencial do LC-MS/MS e, supressão e/ou aumento de sinal são observados em função da presença de componentes da matriz que coeluem com os analitos de interesse (GOSETTI et al., 2010; MATUSZEWSKI; CONSTANZER; CHAVEZ-ENG, 1998; VARGA et al., 2012). O efeito de matriz pode ser compensado pela diluição do extrato antes da injeção, pelo uso de curva em matriz, pela utilização de calibração interna ou ainda pela inclusão de mais etapas no preparo de amostras (BERTHILLER et al., 2007; MATUSZEWSKI; CONSTANZER; CHAVEZ-ENG, 1998; VARGA et al., 2012).

A calibração interna utilizando padrões analíticos isotópicos tem sido recomendada para o tratamento de efeito matriz, pois suas características químicas e físicas são praticamente idênticas aos compostos de interesse e, desta maneira, quando analisados juntamente com os respectivos analitos podem compensar a variabilidade observada nas respostas dos espectrômetros de massas (MALACHOVÁ et al., 2014; RYCHLIK; ASAM, 2008). A utilização de padrões internos isotópicos tem sido aplicada com sucesso na análise de mycotoxinas, como descrito por Rychlik \& Asam (2008), Häubl et al. (2006a), Varga et al. (2012) e Liao et al. (2013).

A Tabela 3 mostra os métodos normalmente utilizados na análise de AFs bem como sua ocorrência em cereais e derivados. A extração das AFs é comumente realizada utilizando misturas entre água e solventes orgânicos (acetonitrila e metanol), sendo que em métodos multimicotoxinas costuma-se acidificar a fase extratora (BELTRÁN et al., 2013; SULYOK; KRSKA; SCHUHMACHER, 2007). A purificação dos extratos é obtida principalmente pela utilização de colunas de extração em fase sólida (SPE), colunas de imunoafinidade (IAC) ou ainda pela adição de soluções clarificantes como o sulfato de cobre (ALMEIDA et al., 2012; CALDAS; SILVA, 2007; LATTANZIO et al., 2011), dependendo do método instrumental 
escolhido. A identificação e quantificação das AFs são conduzidas fundamentalmente por cromatografia em camada delgada (CCD), cromatografia líquida acoplada a detectores de fluorescência e espectrometria de massas sequencial (HPLC-FD; LC-MS/MS - modo positivo) (CARVALHO et al., 2010; LIAO et al., 2013; NUNES et al., 2003). Para aumentar a sensibilidade da AFB1 e AFG1 analisadas por fluorescência, é comum adotar técnicas de derivatização pré ou pós-coluna (Kobra-cell e fotoquímicas) (CAMPONE; PICCINELLI; RASTRELLI, 2011; KABAK, 2012).

Os métodos de análise de AFs (AFB1+AFB2+AFG1+AFG2) têm limites de quantificação (LOQs) variando de $0,06 \mu \mathrm{g} / \mathrm{kg}$ (HPLC-FD) (ALMEIDA et al., 2012) a $25 \mu \mathrm{g} / \mathrm{kg}$ (LC-MS/MS) (VISHWANATH et al., 2009) e valores de recuperação entre 32 (AFG1; LCMS/MS) (VISHWANATH et al., 2009) e 137\% (AFB2; CCD) (KAWASHIMA; VALENTE SOARES, 2006) (Tabela 3). As aflatoxinas foram analisadas principalmente em arroz (ALMEIDA et al., 2012; CARVALHO et al., 2010; DORS; BIERHALS; BADIALEFURLONG, 2011), milho e derivados (CAMPONE; PICCINELLI; RASTRELLI, 2011; KAWASHIMA; VALENTE SOARES, 2006; SEKIYAMA et al., 2005; WARTH et al., 2012) e farinha de trigo (RUBERT; SOLER; MAÑES, 2011), e detectadas em níveis entre 0,022 $\mu \mathrm{g} / \mathrm{kg}$ (AFB2; produtos de cereais) (KABAK, 2012) e $636 \mu \mathrm{g} / \mathrm{kg}$ (AFB1; milho) (WARTH et al., 2012).

Os métodos de determinação de OTA em cereais (Tabela 4) também se baseiam na extração com ACN/MeOH e água (geralmente $80 \%$ de fase orgânica), purificação, se necessário, por SPE, IAC ou soluções clarificantes (ALMEIDA et al., 2012; LATTANZIO et al., 2011; SEKIYAMA et al., 2005), seguido de análise por CCD, HPLC-FD e LC-MS/MS (modo positivo) (ALMEIDA et al., 2012; DORS; BIERHALS; BADIALE-FURLONG, 2011; VARGA et al., 2012). Os LOQs dos métodos variam entre 0,06 $\mu \mathrm{g} / \mathrm{kg}$ (UPLC-MS/MS) (BELTRÁN et al., 2013) e 10 g/kg (CCD) (KAWASHIMA; VALENTE SOARES, 2006) e os valores de recuperação obtidos vão de 38 a 105\% (UPLC-MS/MS) (BELTRÁN et al., 2013). A OTA foi encontrada principalmente em trigos e seus produtos (BELTRÁN et al., 2013; LIAO et al., 2013; RUBERT; SOLER; MAÑES, 2011) e também no arroz (DORS; BIERHALS; BADIALE-FURLONG, 2011; LIAO et al., 2013; NUNES et al., 2003), em níveis entre 0,2 $\mu \mathrm{g} / \mathrm{kg}$ (arroz) (ALMEIDA et al., 2012) e $128 \mu \mathrm{g} / \mathrm{kg}$ (arroz) (NUNES et al., 2003). As determinações de OTB foram realizadas utilizando métodos multi-micotoxinas, baseados na extração por solventes orgânicos e determinação por LC-MS/MS (SULYOK; KRSKA; 
SCHUHMACHER, 2007; VISHWANATH et al., 2009), porém nenhuma amostra positiva foi encontrada (WARTH et al., 2012).

As fumonisinas (Tabela 5) também são extraídas por misturas entre água e solventes orgânicos, porém, melhores resultados são obtidos quando se emprega misturas mais polares como, por exemplo, $\mathrm{MeOH}: \mathrm{H}_{2} \mathrm{O}$ (80:20) (QUEIROZ et al., 2012) e $\mathrm{H}_{2} 0: \mathrm{ACN}: \mathrm{MeOH}(50: 25: 25$ ) (DALL'ASTA et al., 2008; PARK et al., 2004a). Quando necessário, a purificação é feita com o auxílio de SPE (CASTRO et al., 2004; KAWASHIMA; VALENTE SOARES, 2006) ou IAC (PARK et al., 2004a; QUEIROZ et al., 2012) e a detecção principalmente por HPLC-FD (CALDAS; SILVA, 2007; KAWASHIMA; VALENTE SOARES, 2006) ou LC-MS/MS (DALL'ASTA et al., 2009b; RUBERT; SOLER; MAÑES, 2011; SULYOK; KRSKA; SCHUHMACHER, 2007). Os LOQs dos métodos variam entre $0,1 \mu \mathrm{g} / \mathrm{kg}$ (FB1; UPLCMS/MS) (BELTRÁN et al., 2013) e $125 \mu \mathrm{g} / \mathrm{kg}$ (FB1,FB2; LC-MS/MS) (OLIVEIRA et al., 2015) e as recuperações obtidas ficam entre 43\% (FB2) e 117\% (FB1; UPLC-MS/MS) (BELTRÁN et al., 2013). Os produtos com maior incidência de fumonisinas foram milho e seus derivados, com níveis de contaminação entre 3,5 $\mu \mathrm{g} / \mathrm{kg}$ (FB1; cereais matinais) (BELTRÁN et al., 2013)e $8600 \mu \mathrm{g} / \mathrm{kg}$ (FB1; produtos de milho) (KAWASHIMA; VALENTE SOARES, 2006).

Para a análise das fumonisinas associadas à matriz ou quimicamente modificadas (sob tratamento térmico), o resíduo da matriz já analisado para as formas livres é hidrolisado (meio alcalino e/ou dissolução de proteínas por detergentes) e depois determinado como fumonisinas hidrolisadas (DALL'ASTA et al., 2008, 2009b; PARK et al., 2004). Os LOQs estabelecidos para as formas hidrolisadas vão de $0,8 \mu \mathrm{g} / \mathrm{kg}$ (HFB1; LC-MS/MS) (VISHWANATH et al., 2009) a $125 \mu \mathrm{g} / \mathrm{kg}$ (HFB1, HFB2; LC-MS/MS) (OLIVEIRA et al., 2015), com níveis de recuperação entre 67\% (HFB1; LC-MS/MS) (SULYOK; KRSKA; SCHUHMACHER, 2007) e 98\% (HFB3; LC-MS/MS) (DALL'ASTA et al., 2008). As fumonisinas associadas à matriz ou quimicamente modificadas são encontradas principalmente em produtos de milho como flocos, farinha, salgadinhos extrusados, cereais matinais, chips, tortilhas, pães e bolos, em níveis que variam entre 22 (ligadas a proteínas) (PARK et al., 2004a) e $4740 \mu \mathrm{g} / \mathrm{kg}$ (DALL'ASTA et al., 2009b).

Os métodos utilizados na determinação de DON e seus conjugados (Tabela 6) consistem na extração com misturas entre água e solventes orgânicos como $\mathrm{ACN}: \mathrm{H}_{2} 0$ (84:16) (LATTANZIO et al., 2011; RASMUSSEN et al., 2012) ou misturas mais polares como MeOH:KCl 4\% (90:10) (DORS; BIERHALS; BADIALE-FURLONG, 2011; OLIVEIRA; 
SOARES; SAWAZAKI, 2001), seguida de purificação com SPE (LATTANZIO et al., 2011; OLIVEIRA; SOARES; SAWAZAKI, 2001), IAC (ALMEIDA et al., 2012) ou colunas multifuncionais (Mycosep) (RASMUSSEN et al., 2012; TRAN; SMITH; GIRGIS, 2012). A detecção tem sido realizada tanto por técnicas de cromatografia líquida (CCD, HPLC-UV, LCMS/MS) (ALMEIDA et al., 2012; DORS; BIERHALS; BADIALE-FURLONG, 2011; LIAO et al., 2013) quanto por cromatografia gasosa (CG-FID, CG-MS) (NUNES et al., 2003; TRAN; SMITH; GIRGIS, 2012). Os LOQs variam de 0,2 $\mu \mathrm{g} / \mathrm{kg}$ (DON; LC-HRMS) (LATTANZIO et al., 2011) a $250 \mu \mathrm{g} / \mathrm{kg}$ (DON; LC-MS/MS) (VENDL et al., 2010), com valores de recuperação entre 54\% (D3G; LC-MS/MS) (SULYOK; KRSKA; SCHUHMACHER, 2007) e 124\% (3AcDON; LC-MS/MS) (RASMUSSEN et al., 2012). DON e seus derivados foram encontrados principalmente em amostras de aveia, trigo e milho (incluindo seus produtos) (BOEVRE et al., 2012; RASMUSSEN et al., 2012; VENDL et al., 2010), em concentrações de $5 \mu \mathrm{g} / \mathrm{kg}$ (DON; milho) (BOEVRE et al., 2012) a $14000 \mu \mathrm{g} / \mathrm{kg}$ (DON; milho) (TRAN; SMITH; GIRGIS, 2012).

Alguns dos métodos adotados na análise de ZON e derivados em cereais e seus produtos são mostrados na Tabela 7. A extração é realizada com misturas mais polares, como $\mathrm{MeOH}: \mathrm{H}_{2} 0$ (75:25) (HEWITT et al., 2012) ou misturas frequentemente utilizadas em métodos multimicotoxinas, como ACN: $\mathrm{H}_{2} \mathrm{O}(85: 15)$ (LIAO et al., 2013). Os métodos de purificação utilizados para ZON, são os mesmos aplicados a DON, ou seja, SPE (DORS; BIERHALS; BADIALEFURLONG, 2011; LATTANZIO et al., 2011), colunas multifuncionais (ALMEIDA et al., 2012), IAC (HEWITT et al., 2012; QUEIROZ et al., 2012), ou soluções clarificantes (KAWASHIMA; VALENTE SOARES, 2006; SEKIYAMA et al., 2005). A separação e identificação dos compostos têm sido realizadas principalmente por LC-MS/MS (modo negativo) (BELTRÁN et al., 2013; RUBERT; SOLER; MAÑES, 2011; SULYOK; KRSKA; SCHUHMACHER, 2007; VARGA et al., 2012; VENDL et al., 2010), ou ainda por CCD seguido de confirmação por CG-FID (DORS; BIERHALS; BADIALE-FURLONG, 2011; NUNES et al., 2003) ou mesmo HPLC-FD (ALMEIDA et al., 2012; HEWITT et al., 2012).

Os LOQs dos métodos utilizados nas análises de ZON e derivados em cereais variam de 0,1 $\mu \mathrm{g} / \mathrm{kg}$ (ZON; UPLC-MS/MS) (BELTRÁN et al., 2013) a $195 \mu \mathrm{g} / \mathrm{kg}$ (ZON; CCD) (DORS; BIERHALS; BADIALE-FURLONG, 2011), com recuperações entre 39\% (ZON) (BELTRÁN et al., 2013) e 114\% (ZON) (HEWITT et al., 2012). ZON e seus derivados têm sido encontrados em amostras de aveia (BOEVRE et al., 2012), milho e derivados (BOEVRE et al., 2012; LIAO et al., 2013; QUEIROZ et al., 2012; SEKIYAMA et al., 2005; VENDL et 
al., 2010), trigo e derivados (BOEVRE et al., 2012; VENDL et al., 2010) e também no arroz (ALMEIDA et al., 2012; DORS; BIERHALS; BADIALE-FURLONG, 2011), em concentrações entre $1 \mu \mathrm{g} / \mathrm{kg}$ (produtos de milho, trigo e centeio) (VENDL et al., 2010) e 1071 $\mu \mathrm{g} / \mathrm{kg}$ (milho) (BOEVRE et al., 2012).

A citreoviridina é extraída principalmente com diclorometano (Tabela 8) (ALMEIDA et al., 2012; ROSA et al., 2010), o extrato purificado em SPE e a detecção realizada por CCD (WICKLOW; COLE, 1984); HPLC-FD (ROSA et al., 2010; STUBBLEFIELD; GREER; SHOTWELL, 1988), HPLC-UV (ALMEIDA, 2008; ALMEIDA et al., 2012) ou LC-MS/MS (VISHWANATH et al., 2009). Os LOQs variam de 0,9 $\mu \mathrm{g} / \mathrm{kg}$ (HPLC-UV) (ALMEIDA et al., 2012) a $25 \mu \mathrm{g} / \mathrm{kg}$ (LC-MS/MS) (VISHWANATH et al., 2009), com recuperações entre 86 e 103\% (ROSA et al., 2010; STUBBLEFIELD; GREER; SHOTWELL, 1988). A citreoviridina foi encontrada principalmente em arroz (ALMEIDA et al., 2012; ROSA et al., 2010), mas também já foi detectada em amostras de milho (WICKLOW; COLE, 1984; WICKLOW et al., 1988). As concentrações encontradas vão de $0,9 \mu \mathrm{g} / \mathrm{kg}$ (arroz) (ALMEIDA et al., 2012) a 2790 $\mu \mathrm{g} / \mathrm{kg}$ (milho) (WICKLOW et al., 1988).

Com a necessidade de analisar diversas classes de micotoxinas em uma mesma amostra se torna necessário, cada vez mais, o desenvolvimento de metodologias multi-resíduos. Entretanto, no Brasil, não foi encontrada publicação em que um método multi-micotoxinas tivesse sido desenvolvido e aplicado à análise de cereais. Além disso, com relação às micotoxinas modificadas, apenas a análise de fumonisinas escondidas (hidden) foi descrita no Brasil (OLIVEIRA et al., 2015). 
Tabela 3 - Métodos de análise de aflatoxinas e corrência nos alimentos.

\begin{tabular}{|c|c|c|c|c|c|}
\hline Aflatoxinas & Método & $\begin{array}{c}\text { LOQ } \\
(\mu \mathrm{g} / \mathrm{kg})\end{array}$ & $\begin{array}{l}\text { RE } \\
(\%)\end{array}$ & $\begin{array}{c}\text { Alimento analisado } \\
\left(\mathrm{n}^{\circ} \text { positivas / }{ }^{\circ} \text { analisadas; }\right. \\
\text { faixa de contaminação }-\mu \mathrm{g} / \mathrm{kg})\end{array}$ & $\begin{array}{c}\text { Local } \\
\text { Referência }\end{array}$ \\
\hline $\begin{array}{l}\text { AFB1 } \\
\text { AFB2 } \\
\text { AFG1 } \\
\text { AFG2 }\end{array}$ & $\begin{array}{l}\text { Extração: } \mathrm{ACN}: \mathrm{H}_{2} \mathrm{O}(80: 20), 0,1 \% \\
\mathrm{CH}_{2} \mathrm{O}_{2} ; \text { Diluição; LC-ESI }{ }^{+}-\mathrm{MS} / \mathrm{MS} ; \\
\text { Curva em matriz }\end{array}$ & $\begin{array}{l}0,03-0,43 \\
0,05-1,5 \\
0,03-0,77\end{array}$ & $\begin{array}{l}69-113 \\
58-112 \\
61-118\end{array}$ & $\begin{array}{l}\text { Arroz }(0 / 10 ; \text { ND), cereais matinais } \\
(0 / 10 ; \text { ND), cerveja }(0 / 10 ; \text { ND), } \\
\text { massas }(0 / 10 ; \text { ND), produtos de } \\
\text { panificação }(0 / 50 ; \text { ND) e produtos de } \\
\text { soja }(0 / 10 ; N D)\end{array}$ & $\begin{array}{l}\text { Espanha } \\
\text { (BELTRÁN et al., 2013) }\end{array}$ \\
\hline $\begin{array}{l}\text { AFB1 } \\
\text { AFB2 } \\
\text { AFG1 } \\
\text { AFG2 }\end{array}$ & $\begin{array}{l}\text { Extração: ACN: } \mathrm{H}_{2} \mathrm{O}(84: 16) ; \text { Clean } \\
\text { up: SPE; LC-HRMS (modo positivo); } \\
\text { Curva em matriz; Calibração interna }\end{array}$ & $\begin{array}{l}0,1-1,6^{\mathrm{a}} \\
0,1-0,7^{\mathrm{a}} \\
0,1-1,2^{\mathrm{a}} \\
0,1-1,5^{\mathrm{a}}\end{array}$ & $\begin{array}{l}73-108 \\
84-114 \\
77-109 \\
84-112\end{array}$ & Não analisou amostras reais & $\begin{array}{l}\text { Itália } \\
\text { (LATTANZIO et al., } \\
\text { 2011) }\end{array}$ \\
\hline AFB2 & & 1,5 & $69-76$ & $\begin{array}{l}\text { Farinha de aveia }(1 / 2 ; 1,6) \text {, farinha de } \\
\text { milho }(0 / 9 ; \mathrm{ND}) \text {, farinha de soja }(0 / 1 ; \\
\text { ND), farinha de trigo }(1 / 25 ; 2), \\
\text { produtos de panificação }(0 / 8 ; \mathrm{ND})\end{array}$ & \\
\hline AFG1 & & 0,25 & $71-80$ & $\begin{array}{l}\text { Farinha de aveia }(0 / 2 ; \mathrm{ND}) \text {, farinha } \\
\text { de milho }(0 / 9 ; \mathrm{ND}) \text {, farinha de soja } \\
(0 / 1 ; \mathrm{ND}) \text {, farinha de trigo }(2 / 25\end{array}$ & \\
\hline
\end{tabular}




\begin{tabular}{|c|c|c|c|c|c|}
\hline Aflatoxinas & Método & $\begin{array}{c}\mathrm{LOQ} \\
(\mu \mathrm{g} / \mathrm{kg})\end{array}$ & $\begin{array}{l}\text { RE } \\
(\%)\end{array}$ & $\begin{array}{c}\text { Alimento analisado } \\
\left(\mathrm{n}^{\circ} \text { positivas / } \mathrm{n}^{\circ} \text { analisadas; }\right. \\
\text { faixa de contaminação }-\mu \mathrm{g} / \mathrm{kg})\end{array}$ & $\begin{array}{c}\text { Local } \\
\text { Referência }\end{array}$ \\
\hline AFG2 & & 0,75 & $77-81$ & $\begin{array}{l}0,53-0,72), \text { produtos de panificação } \\
(0 / 8 ; \text { ND) } \\
\text { Farinha de aveia }(0 / 2 ; \text { ND), farinha } \\
\text { de milho }(0 / 9 ; \text { ND), farinha de soja } \\
(0 / 1 ; \text { ND), farinha de trigo }(1 / 25 ; \\
1,0) \text {, produtos de panificação }(2 / 8 \text {; } \\
\text { LOQ- } 1,2)\end{array}$ & \\
\hline AFB1 & $\begin{array}{l}\text { Extração: } \mathrm{MeOH}: \mathrm{H}_{2} 0 \text { (80:20); Clean } \\
\text { up: DLLME; HPLC-FD; } \\
\text { Derivatização fotoquímica pós-coluna }\end{array}$ & $0,11-0,15$ & $68-90$ & $\begin{array}{l}\text { Arroz e derivados }(0 / 12 ; \mathrm{ND}) \text {, milho } \\
\text { e derivados }(1 / 17 ; 0,5) \text {, trigo e } \\
\text { derivados }(0 / 15 ; \mathrm{ND})\end{array}$ & $\begin{array}{l}\text { Itália } \\
\text { (CAMPONE; } \\
\text { PICCINELLI; }\end{array}$ \\
\hline AFB2 & & $0,04-0,1$ & $74-88$ & Arroz e derivados $(0 / 12 ; \mathrm{ND})$, milho & RASTRELLI, 2011) \\
\hline AFG1 & & $0,19-0,57$ & $71-79$ & e derivados $(0 / 17$; ND), trigo e & \\
\hline AFG2 & & $0,29-0,33$ & $76-85$ & derivados $(0 / 15 ; \mathrm{ND})$ & \\
\hline AFB2 & AcOH (79:20:1); LC-ESI+-MS/MS; & $0,7^{\mathrm{a}}$ & 108 & & (SULYOK; KRSKA; \\
\hline AFG1 & Curva em matriz; Calibração externa & $0,5^{\mathrm{a}}$ & 102 & & SCHUHMACHER, \\
\hline $\mathrm{AFG} 2$ & & $1,0^{\mathrm{a}}$ & 104 & & 2007) \\
\hline AFs & $\begin{array}{l}\text { Extração: } \mathrm{MeOH}: \mathrm{KCl} 4 \%(90: 10) \\
\text { Clean up:solução clarificante e celite; } \\
\text { Partição: clorofórmio; CCD-UV }\end{array}$ & $2,5^{\mathrm{b}}$ & $90-97$ & $\begin{array}{l}\text { Arroz integral, polido e parboilizado } \\
(0 / 10 ; \text { ND) }\end{array}$ & $\begin{array}{l}\text { Brasil } \\
\text { (NUNES et al., 2003) }\end{array}$ \\
\hline AFB1 & $\begin{array}{l}\text { Extração: } \mathrm{MeOH}: \mathrm{KCl} 4 \%(90: 10) \\
\text { Clean up: solução clarificante e celite; } \\
\text { Partição: clorofórmio; CCD-UV }\end{array}$ & 2,6 & 86 & Arroz parboilizado $(3 / 32 ; 11-74)$ & $\begin{array}{l}\text { Brasil } \\
\text { (DORS; BIERHALS; } \\
\text { BADIALE-FURLONG, } \\
\text { 2011) }\end{array}$ \\
\hline AFB1 & $\begin{array}{l}\text { Extração: } \mathrm{MeOH}: \mathrm{KCl} 4 \%(90: 10) \\
\text { Clean up: solução clarificante e celite; }\end{array}$ & 0,07 & $65,4-99,8$ & $\begin{array}{l}\text { Arroz polido, parboilizado, integral, } \\
\text { orgânico }(1 / 36 ; 1,2)\end{array}$ & $\begin{array}{l}\text { Brasil } \\
\text { (CARVALHO et al., }\end{array}$ \\
\hline AFB2 & Partição: clorofórmio; HPLC-FD & 0,05 & & Arroz polido, parboilizado, integral, & 2010) \\
\hline AFG1 & & 0,11 & & orgânico $(0 / 36 ; 1,2)$ & \\
\hline AFG2 & & 0,16 & & & \\
\hline
\end{tabular}




\begin{tabular}{|c|c|c|c|c|c|}
\hline Aflatoxinas & Método & $\begin{array}{c}\text { LOQ } \\
(\mu \mathrm{g} / \mathrm{kg})\end{array}$ & $\begin{array}{l}\text { RE } \\
(\%)\end{array}$ & $\begin{array}{c}\text { Alimento analisado } \\
\left(\mathrm{n}^{\circ} \text { positivas } / \mathrm{n}^{\circ} \text { analisadas; }\right. \\
\text { faixa de contaminação }-\mu \mathrm{g} / \mathrm{kg})\end{array}$ & $\begin{array}{c}\text { Local } \\
\text { Referência }\end{array}$ \\
\hline AFs & $\begin{array}{l}\text { Extração: } \mathrm{MeOH}: \mathrm{H}_{2} \mathrm{O}(80: 20) ; \text { Clean } \\
\text { up: IAC; HPLC-FD }\end{array}$ & 0,06 & $88-102$ & Arroz $(75 / 166 ; 0,11->30)$ & $\begin{array}{l}\text { Brasil } \\
\text { (ALMEIDA et al., 2012) }\end{array}$ \\
\hline AFB1 & Extração: $\mathrm{MeOH}: \mathrm{KCl} 4 \%$ (90:10); & 1 & 110 & Produtos de milho $(5 / 74 ; \leq 20)$ & Brasil \\
\hline AFB2 & Clean up: solução clarificante e celite; & 1 & 137 & Produtos de milho $(3 / 74 ; \leq 3)$ & (KAWASHIMA; \\
\hline AFG1 & Partição: clorofórmio; CCD-UV & 1 & 96 & Produtos de milho $(0 / 74 ; \mathrm{ND})$ & VALENTE SOARES, \\
\hline AFB2 & Clean up: solução clarificante e celite; & 0,96 & 109 & Produtos de milho $(2 / 121 ; 2,4)$ & (SEKIYAMA et al., \\
\hline AFG1 & Partição: clorofórmio; CCD-UV & 2 & 106 & Produtos de milho $(0 / 121 ;$ ND) & 2005) \\
\hline AFG2 & & 0,48 & 109 & & \\
\hline AFs & $\begin{array}{l}\text { Extração: } \mathrm{MeOH}: \mathrm{KCl} 4 \%(90: 10) \text {; } \\
\text { Clean up: solução clarificante e celite; } \\
\text { Partição: clorofórmio; CCD-UV }\end{array}$ & $0,5-3,2$ & 109,5 & Produtos de milho $(7 / 123 ; 3,3-23,9)$ & $\begin{array}{l}\text { Brasil } \\
\text { (AMARAL et al., 2006) }\end{array}$ \\
\hline AFs & $\begin{array}{l}\text { Extração: } \mathrm{MeOH}: \mathrm{KCl} 4 \% \text { (90:10); } \\
\text { Clean up: solução clarificante e celite; } \\
\text { Partição: clorofórmio; CCD-UV }\end{array}$ & $2^{\mathrm{b}}$ & NI & Produtos de milho $(0 / 101 ;$ ND) & $\begin{array}{l}\text { Brasil } \\
\text { (CALDAS; SILVA, } \\
2007)\end{array}$ \\
\hline AFB2 & Kobra-Cell & 0,021 & $86,1-88,2$ & $\begin{array}{l}\text { Produtos de cereais } \\
(14 / 110 ; 0,022-0,044)\end{array}$ & \\
\hline AFG1 & & 0,046 & $88,6-90,3$ & $\begin{array}{l}\text { Produtos de cereais } \\
(7 / 110 ; 0,053-0,149)\end{array}$ & \\
\hline AFG2 & & 0,029 & $83,9-92,0$ & $\begin{array}{l}\text { Produtos de cereais } \\
(2 / 110 ; 0,033-1,125)\end{array}$ & \\
\hline AFB 1 & Extração: $\mathrm{ACN}: \mathrm{H}_{2} \mathrm{O}: \mathrm{CH}_{2} \mathrm{O}_{2}$ & 0,1 & 105 & Não analisou amostras reais & Áustria \\
\hline AFB2 & $(80: 19,9: 0,1) ;$ seguida de extração & 0,1 & 100 & & (VARGA et al., 2012) \\
\hline AFG1 & com ACN: $\mathrm{H}_{2} \mathrm{O}: \mathrm{CH}_{2} \mathrm{O}_{2}(20: 79,9: 0,1)$ & 0,1 & 101 & & \\
\hline AFG2 & & 0,4 & 101 & & \\
\hline
\end{tabular}




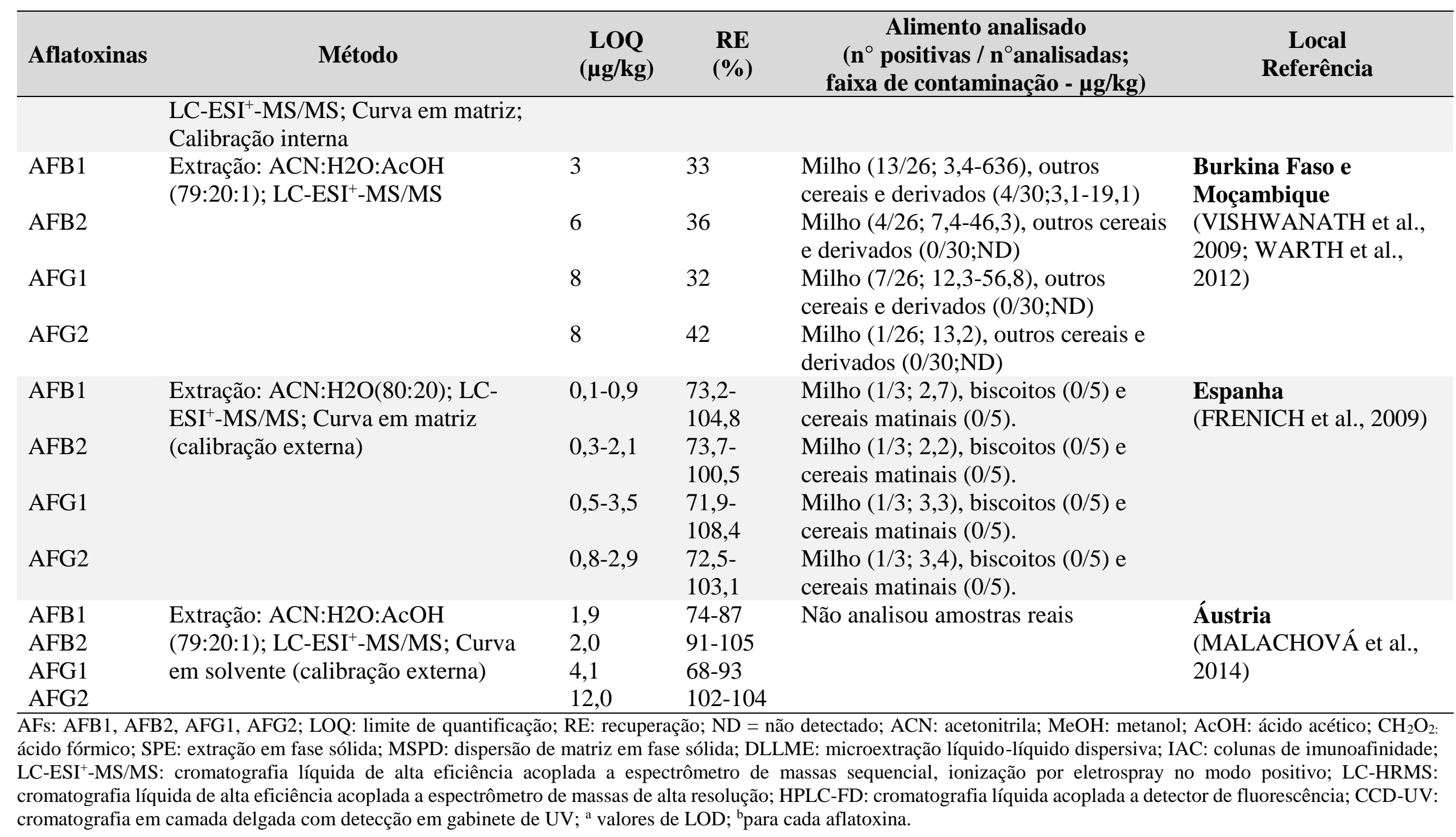


Tabela 4 - Métodos de análise de ocratoxinas e corrência nos alimentos.

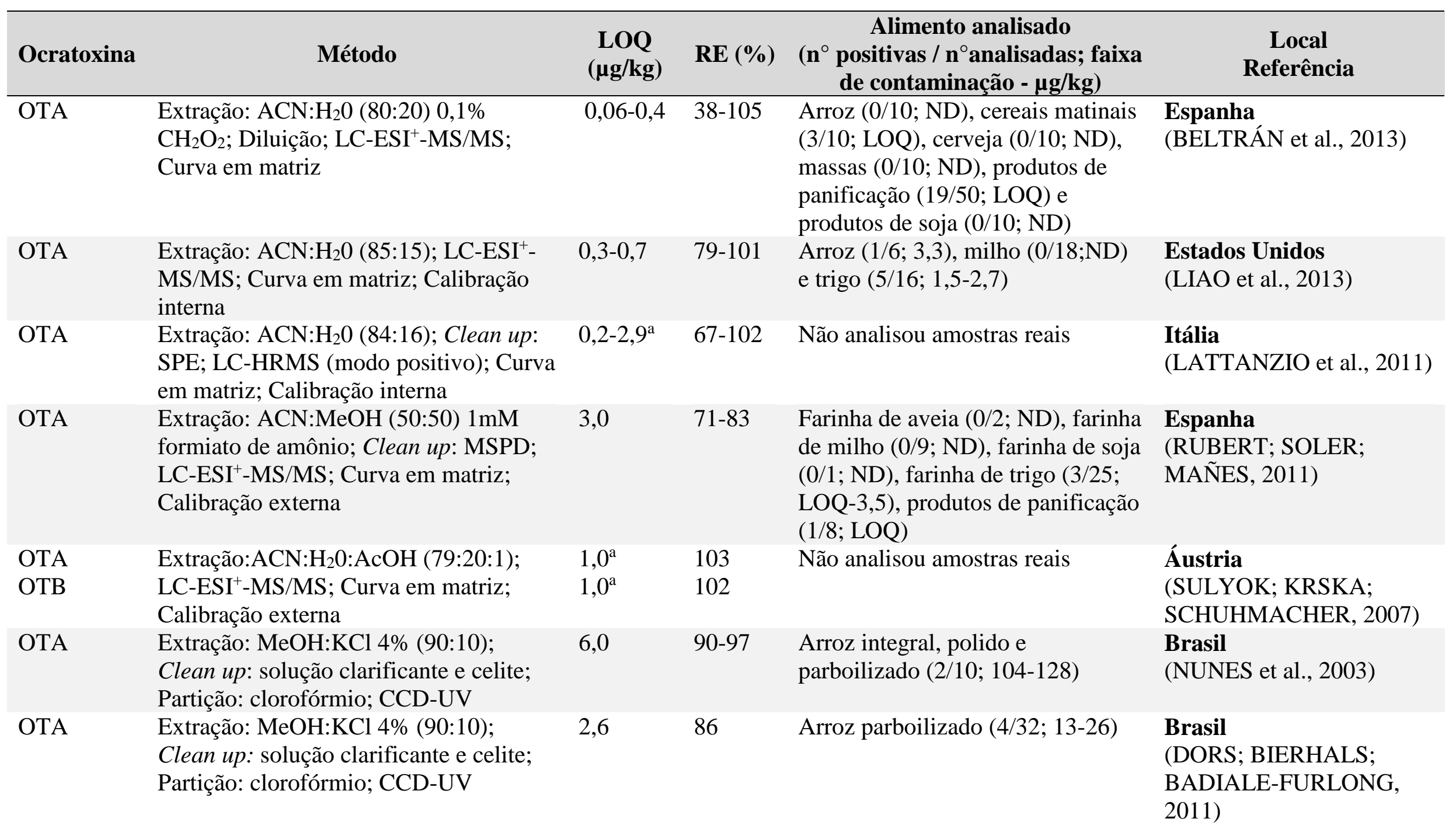




\begin{tabular}{|c|c|c|c|c|c|}
\hline Ocratoxina & Método & $\begin{array}{c}\text { LOQ } \\
(\mu \mathrm{g} / \mathrm{kg})\end{array}$ & $\operatorname{RE}(\%)$ & $\begin{array}{c}\text { Alimento analisado } \\
\left(\mathrm{n}^{\circ} \text { positivas } / \mathrm{n}^{\circ} \text { analisadas; faixa }\right. \\
\text { de contaminação }-\mu \mathrm{g} / \mathrm{kg})\end{array}$ & $\begin{array}{c}\text { Local } \\
\text { Referência }\end{array}$ \\
\hline OTA & $\begin{array}{l}\text { Extração: MeOH (3\% bicarbonato de } \\
\text { sódio); Clean up: IAC; HPLC-FD }\end{array}$ & 0,1 & 95 & Arroz $(46 / 165 ; 0,2->10)$ & $\begin{array}{l}\text { Brasil } \\
\text { (ALMEIDA et al., 2012) }\end{array}$ \\
\hline OTA & $\begin{array}{l}\text { Extração: } \mathrm{MeOH}: \mathrm{KCl} 4 \%(90: 10) \text {; } \\
\text { Clean up: solução clarificante e celite; } \\
\text { Partição: clorofórmio; CCD-UV }\end{array}$ & 10 & 54 & Produtos de milho $(0 / 74 ; \mathrm{ND})$ & $\begin{array}{l}\text { Brasil } \\
\text { (KAWASHIMA; } \\
\text { VALENTE SOARES, } \\
\text { 2006) }\end{array}$ \\
\hline OTA & $\begin{array}{l}\text { Extração: } \mathrm{MeOH}: \mathrm{KCl} 4 \%(90: 10) \\
\text { Clean up: solução clarificante e celite; } \\
\text { Partição: clorofórmio; CCD-UV }\end{array}$ & 6,4 & 102 & Produtos de milho $(1 / 121 ; 64)$ & $\begin{array}{l}\text { Brasil } \\
\text { (SEKIYAMA et al., 2005) }\end{array}$ \\
\hline OTA & $\begin{array}{l}\text { Extração: } \mathrm{ACN}: \mathrm{H}_{2} 0: \mathrm{CH}_{2} \mathrm{O}_{2} \\
(80: 19,9: 0,1) ; \text { seguida de extração com } \\
\text { ACN: } \mathrm{H}_{2} 0: \mathrm{CH}_{2} \mathrm{O}_{2}(20: 79,9: 0,1) ; \text { LC- } \\
\text { ESI'-MS/MS; Curva em matriz; } \\
\text { Calibração interna }\end{array}$ & 0,4 & 93 & Não analisou amostras reais & $\begin{array}{l}\text { Áustria } \\
\text { (VARGA et al., 2012) }\end{array}$ \\
\hline OTA & $\begin{array}{l}\text { Extração: ACN:H2O: AcOH (79:20:1); } \\
\text { LC-ESI+-MS/MS }^{+}\end{array}$ & 5,0 & 92 & $\begin{array}{l}\text { Milho }(1 / 26 ; 18,6) \text {, outros cereais e } \\
\text { derivados }(1 / 30 ; 13,8)\end{array}$ & $\begin{array}{l}\text { Burkina Faso e } \\
\text { Moçambique }\end{array}$ \\
\hline OTB & & 5,0 & 84 & $\begin{array}{l}\text { Milho }(0 / 26 ; \mathrm{ND}) \text {, outros cereais e } \\
\text { derivados }(0 / 30 ; \mathrm{ND})\end{array}$ & $\begin{array}{l}\text { (VISHWANATH et al., } \\
\text { 2009; WARTH et al., } \\
\text { 2012) }\end{array}$ \\
\hline OTA & $\begin{array}{l}\text { Extração: ACN:H2O(80:20); LC-ESI+ } \\
\text { MS/MS; Curva em matriz (calibração } \\
\text { externa) }\end{array}$ & $0,9-4,3$ & $\begin{array}{l}76,6- \\
103,5\end{array}$ & $\begin{array}{l}\text { Milho }(0 / 3) \text {, biscoitos }(0 / 5) \mathrm{e} \\
\text { cereais matinais }(0 / 5) \text {. }\end{array}$ & $\begin{array}{l}\text { Espanha } \\
\text { (FRENICH et al., 2009) }\end{array}$ \\
\hline OTA & $\begin{array}{l}\text { Extração: ACN:H2O:AcOH (79:20:1); } \\
\text { LC-ESI }{ }^{+} \text {-MS/MS; Curva em solvente } \\
\text { (calibração externa) }\end{array}$ & 2,2 & $70-88$ & Não analisou amostras reais & $\begin{array}{l}\text { Áustria } \\
\text { (MALACHOVÁ et al., } \\
\text { 2014) }\end{array}$ \\
\hline
\end{tabular}


Tabela 5. Métodos de análise de fumonisinas e ocorrência nos alimentos.

\begin{tabular}{|c|c|c|c|c|c|}
\hline Fumonisina & Método & $\begin{array}{c}\text { LOQ } \\
(\mu \mathrm{g} / \mathrm{kg})\end{array}$ & $\begin{array}{l}\mathbf{R E} \\
(\%)\end{array}$ & $\begin{array}{c}\text { Alimento analisado } \\
\left(n^{\circ} \text { positivas } / \mathrm{n}^{\circ} \text { analisadas; faixa de }\right. \\
\text { contaminação - } \mu \mathrm{g} / \mathrm{kg})\end{array}$ & $\begin{array}{c}\text { Local } \\
\text { Referência }\end{array}$ \\
\hline FB1 & \multirow[t]{2}{*}{$\begin{array}{l}\text { Extração: ACN: } \mathrm{H}_{2} \mathrm{O}(80: 20) 0,1 \% \\
\mathrm{CH}_{2} \mathrm{O}_{2} ; \text { diluição; LC-ESI }{ }^{+}-\mathrm{MS} / \mathrm{MS} ; \\
\text { Curva em matriz }\end{array}$} & $0,1-6$ & $65-117$ & $\begin{array}{l}\text { Arroz }(0 / 10 ; \mathrm{ND}) \text {, cereais matinais } \\
(6 / 10 ; 3,5) \text {, cerveja }(10 / 10 ; \mathrm{LOQ}-13), \\
\text { produtos de panificação }(0 / 50 ; \mathrm{ND}), \\
\text { produtos de soja }(0 / 10 ; \mathrm{ND})\end{array}$ & $\begin{array}{l}\text { Espanha } \\
\text { (BELTRÁN et al., } \\
\text { 2013) }\end{array}$ \\
\hline FB2 & & $0,1-3,7$ & $43-109$ & $\begin{array}{l}\text { Arroz }(0 / 10 ; \mathrm{ND}) \text {, cereais matinais } \\
(0 / 10 ; \mathrm{ND}) \text {, cerveja }(0 / 10 ; \mathrm{ND}) \text {, } \\
\text { produtos de panificação }(0 / 50 ; \mathrm{ND}) \text {, } \\
\text { produtos de soja }(0 / 10 ; \mathrm{ND})\end{array}$ & \\
\hline FB1 & \multirow{2}{*}{$\begin{array}{l}\left.\text { Extração: ACN: } \mathrm{H}_{2} 0 \text { ( } 85: 15\right) \text {; LC-ESI+- } \\
\text { MS/MS; Curva em matriz; Calibração } \\
\text { interna }\end{array}$} & $7,3-9,1$ & $66-86$ & $\begin{array}{l}\text { Arroz }(0 / 6 ; N D) \text {, milho }(11 / 18 ; 41-1.143) \\
\text { e trigo }(0 / 16 ; N D)\end{array}$ & \multirow[t]{2}{*}{$\begin{array}{l}\text { Estados Unidos } \\
\text { (LIAO et al., 2013) }\end{array}$} \\
\hline FB2 & & $7,4-9,6$ & $70-87$ & $\begin{array}{l}\text { Arroz }(0 / 6 ; \mathrm{ND}) \text {, milho }(8 / 18 ; 25-937) \text {, e } \\
\text { trigo }(0 / 16 ; \mathrm{ND})\end{array}$ & \\
\hline FB1 & $\begin{array}{l}\text { Extração: ACN:MeOH (50:50) 1mM } \\
\text { formiato de amônio; Clean up: MSPD; } \\
\text { LC-ESI }^{+}-\mathrm{MS} / \mathrm{MS} \text {; Curva em matriz; } \\
\text { Calibração externa }\end{array}$ & 83 & $77-84$ & $\begin{array}{l}\text { Farinha de aveia }(0 / 2 ; \mathrm{ND}) \text {; farinha de } \\
\text { milho }(0 / 9 ; \text { ND); farinha de soja }(0 / 1 ; \\
\text { ND); farinha de trigo }(0 / 25 ; \mathrm{ND}) ; \\
\text { produtos de panificação }(0 / 8 ; \mathrm{ND}) \text {. }\end{array}$ & $\begin{array}{l}\text { Espanha } \\
\text { (RUBERT; } \\
\text { SOLER; MANES, } \\
\text { 2011) }\end{array}$ \\
\hline FB1 & Extração: ACN:H ${ }_{2} 0: \mathrm{AcOH}(79: 20: 1)$; & $8,0^{\mathrm{a}}$ & 79 & \multirow[t]{4}{*}{ Não analisou amostras reais } & Áustria \\
\hline FB2 & LC-ESI ${ }^{+}-M S / M S ;$ Curva em matriz; & $7,0^{\mathrm{a}}$ & 96 & & (SULYOK; \\
\hline FB3 & Calibração externa & $4,0^{\mathrm{a}}$ & 88 & & KRSKA; \\
\hline HFB 1 & & $17^{\mathrm{a}}$ & 67 & & $\begin{array}{l}\text { SCHUHMACHER, } \\
\text { 2007) }\end{array}$ \\
\hline
\end{tabular}




\begin{tabular}{|c|c|c|c|c|c|}
\hline Fumonisina & Método & $\begin{array}{c}\text { LOQ } \\
(\mu g / k g)\end{array}$ & $\begin{array}{l}\text { RE } \\
(\%)\end{array}$ & $\begin{array}{c}\text { Alimento analisado } \\
\left(\mathrm{n}^{\circ} \text { positivas / } \mathrm{n}^{\circ} \text { analisadas; faixa de }\right. \\
\text { contaminação - } \mu \mathrm{g} / \mathrm{kg} \text { ) }\end{array}$ & $\begin{array}{c}\text { Local } \\
\text { Referência }\end{array}$ \\
\hline FB1 & $\begin{array}{l}\text { Extração } \mathrm{MeOH}: \mathrm{H}_{2} 0 \text { (3:1); Clean up: } \\
\text { SPE; Derivatização (OPA); HPLC-FD }\end{array}$ & 12 & 86 & Produtos de milho $(71 / 74 ; 20-8600)$ & $\begin{array}{l}\text { Brasil } \\
\text { (KAWASHIMA; } \\
\text { VALENTE } \\
\text { SOARES, 2006) }\end{array}$ \\
\hline FB1 & Extração: MeOH:H20 (3:1); Clean up: & 20 & $60-110$ & Produtos de milho (40/81; nd-4930) & Brasil \\
\hline FB2 & SPE; Derivatização (OPA); HPLC-FD & 20 & $58-102$ & Produtos de milho (44/81; nd-1380) & $\begin{array}{l}\text { (MACHINSKI } \\
\text { JUNIOR; } \\
\text { SOARES, 2000) }\end{array}$ \\
\hline FB1 & Extração: $\mathrm{MeOH}: \mathrm{H}_{2} \mathrm{O}$ (70:30); Clean & 20 & NI & Produtos de milho (117/196; 171-5825) & Brasil \\
\hline FB2 & up: SPE; Derivatização (ácido o- & 20 & NI & Produtos de milho (106/196; 28-1687) & (CASTRO et al., \\
\hline FB3 & fosfórico); HPLC-FD & 20 & NI & Produtos de milho $(106 / 196 ; 16-549)$ & 2004) \\
\hline FB1, FB2 & $\begin{array}{l}\text { Extração: MeOH:H20 (70:30); Clean } \\
\text { up: SPE; Derivatização (NDA); HPLC- } \\
\text { FD }\end{array}$ & $20^{\mathrm{b}}$ & $75-97$ & Produtos de milho $(168 / 208 ; 20-6170)$ & $\begin{array}{l}\text { Brasil } \\
\text { (CALDAS; } \\
\text { SILVA, 2007) }\end{array}$ \\
\hline FB1 & Extração: $\mathrm{H}_{2} 0: \mathrm{ACN}: \mathrm{MeOH}(50: 25: 25)$; & 5 & $95-97$ & Produtos de milho $(10 / 10 ; 50-450)$ & Itália \\
\hline FB2 & LC-ESI+-MS/MS & 5 & $96-98$ & NI & (DALL'ASTA et \\
\hline FB3 & & 12 & $95-96$ & NI & al., 2008) \\
\hline HFB 1 & & 70 & 93 & Produtos de milho $(10 / 10 ; 50-150)$ & \\
\hline HFB2 & & 70 & 93-94 & NI & \\
\hline HFB3 & & 70 & $95-98$ & NI & \\
\hline Total & $\begin{array}{l}\text { Liofilização do resíduo; Hidrólise } \\
\text { alcalina }\left(\mathrm{NaOH} ; 25^{\circ} \mathrm{C} ; 60 \mathrm{~min}\right) ; \\
\text { Extração: acetato de etila; LC-ESI+- } \\
\text { MS/MS }\end{array}$ & 70 & $93-98$ & Produtos de milho $(10 / 10 ; 50-300)$ & \\
\hline FB1 & Extração: $\mathrm{H}_{2} 0: \mathrm{MeOH}(30: 70)-2$ & 5 & $92-98$ & Produtos de milho (33/40; LOQ-3310) & Itália \\
\hline FB2 & vezes; Concentração; LC-ESI ${ }^{+}-\mathrm{MS} / \mathrm{MS}$ & 5 & & & (DALL'ASTA et \\
\hline FB3 & & 12 & & & al., 2009b) \\
\hline HFB1 & & 70 & & Produtos de milho (33/40; LOQ-621) & \\
\hline HFB2 & & 70 & & & \\
\hline
\end{tabular}




\begin{tabular}{|c|c|c|c|c|c|}
\hline Fumonisina & Método & $\begin{array}{c}\text { LOQ } \\
(\mu \mathrm{g} / \mathrm{kg})\end{array}$ & $\begin{array}{l}\text { RE } \\
(\%)\end{array}$ & $\begin{array}{c}\text { Alimento analisado } \\
\left(\mathrm{n}^{\circ} \text { positivas } / \mathrm{n}^{\circ} \text { analisadas; faixa de }\right. \\
\text { contaminação }-\mu \mathrm{g} / \mathrm{kg})\end{array}$ & $\begin{array}{c}\text { Local } \\
\text { Referência }\end{array}$ \\
\hline HFB3 & & 70 & & & \\
\hline Total & $\begin{array}{l}\text { Hidrólise alcalina da matriz (KOH; } \\
\text { 60min); Extração com ACN; LC-ESI }{ }^{+}- \\
\text {MS/MS }\end{array}$ & 70 & $92-98$ & Produtos de milho (21/21; LOQ-4740) & \\
\hline FB1 & Extração: $\mathrm{ACN}: \mathrm{H}_{2} 0: \mathrm{CH}_{2} \mathrm{O}_{2}$ & 4,3 & 101 & Não analisou amostras reais & Áustria \\
\hline FB2 & $\begin{array}{l}\text { (80:19,9:0,1); seguida de extração com } \\
\text { ACN:H } 20: \mathrm{CH}_{2} \mathrm{O}_{2}(20: 79,9: 0,1) ; \text { LC- } \\
\text { ESI+-MS/MS; Curva em matriz; } \\
\text { Calibração interna }\end{array}$ & 3,9 & 88 & & $\begin{array}{l}\text { (VARGA et al., } \\
\text { 2012) }\end{array}$ \\
\hline FB1 & Extração: $2 \mathrm{X}$ com MeOH:ACN: $\mathrm{H}_{2} \mathrm{O}$ & $8-10$ & $82-85$ & Produtos de milho $(21 / 30 ; 13-237)$ & Canadá \\
\hline FB2 & (25:25:50); Clean up IAC; HPLC-FD & & $82-90$ & Produtos de milho $(2 / 30 ; 21-23)$ & (PARK et al., \\
\hline HFB 1 & $\begin{array}{l}\text { Extração: } 2 \mathrm{X} \text { com MeOH:ACN: } \mathrm{H}_{2} \mathrm{O} \\
(25: 25: 50) ; \text { Clean up:SPE; HPLC-FD }\end{array}$ & & $76-83$ & Produtos de milho $(4 / 30 ; 7-47)$ & 2004a) \\
\hline Total & $\begin{array}{l}\text { Extrair matriz com SDS }(1 \%) \text {; Clean up } \\
\text { IAC; Hidrólise com KOH }\left(2 \mathrm{~N} ; 60^{\circ} \mathrm{C} \text {; }\right. \\
\text { 1h); Clean up SPE; HPLC-FD }\end{array}$ & $8-10$ & $76-83$ & Produtos de milho $(15 / 30 ; 22-176)$ & \\
\hline Total & $\begin{array}{l}\text { Hidrólise do resíduo sólido com KOH } \\
\left(2 \mathrm{~N} ; 60^{\circ} \mathrm{C} ; 1 \mathrm{~h}\right) \text {; Clean up SPE; HPLC- } \\
\text { FD }\end{array}$ & & & Produtos de milho $(20 / 30 ; 28-418)$ & \\
\hline Fumonisinas & $\begin{array}{l}\text { Extração: } \mathrm{MeOH}: \mathrm{H}_{2} \mathrm{O}(80: 20) ; \text { Clean } \\
\text { up: IAC; Fluorômetro }\end{array}$ & $\mathrm{NI}$ & $71,1-91,2$ & Milho (40/40; 230-6450) & $\begin{array}{l}\text { Brasil } \\
\text { (QUEIROZ et al., } \\
\text { 2012) }\end{array}$ \\
\hline FB1 & $\begin{array}{l}\text { Extração com ACN: } \mathrm{H}_{2} \mathrm{O}: \mathrm{AcOH} \\
(79: 20: 1) ; \text { LC-ESI }{ }^{+}-\mathrm{MS} / \mathrm{MS}\end{array}$ & 20 & 72 & $\begin{array}{l}\text { Milho }(21 / 26 ; 22,5-1343) \text { e outros } \\
\text { cereais e derivados }(1 / 30 ; 73,8)\end{array}$ & $\begin{array}{l}\text { Burkina Faso e } \\
\text { Moçambique }\end{array}$ \\
\hline FB2 & & 10 & 77 & $\begin{array}{l}\text { Milho }(18 / 26 ; 11,3-589) \text { e outros } \\
\text { cereais e derivados }(1 / 30 ; 28,2)\end{array}$ & $\begin{array}{l}\text { (VISHWANATH } \\
\text { et al., 2009; }\end{array}$ \\
\hline FB3 & & 20 & 94 & $\begin{array}{l}\text { Milho }(12 / 26 ; 23,2-274) \text { e outros } \\
\text { cereais e derivados }(0 / 30 ; \mathrm{ND})\end{array}$ & $\begin{array}{l}\text { WARTH et al., } \\
\text { 2012) }\end{array}$ \\
\hline
\end{tabular}




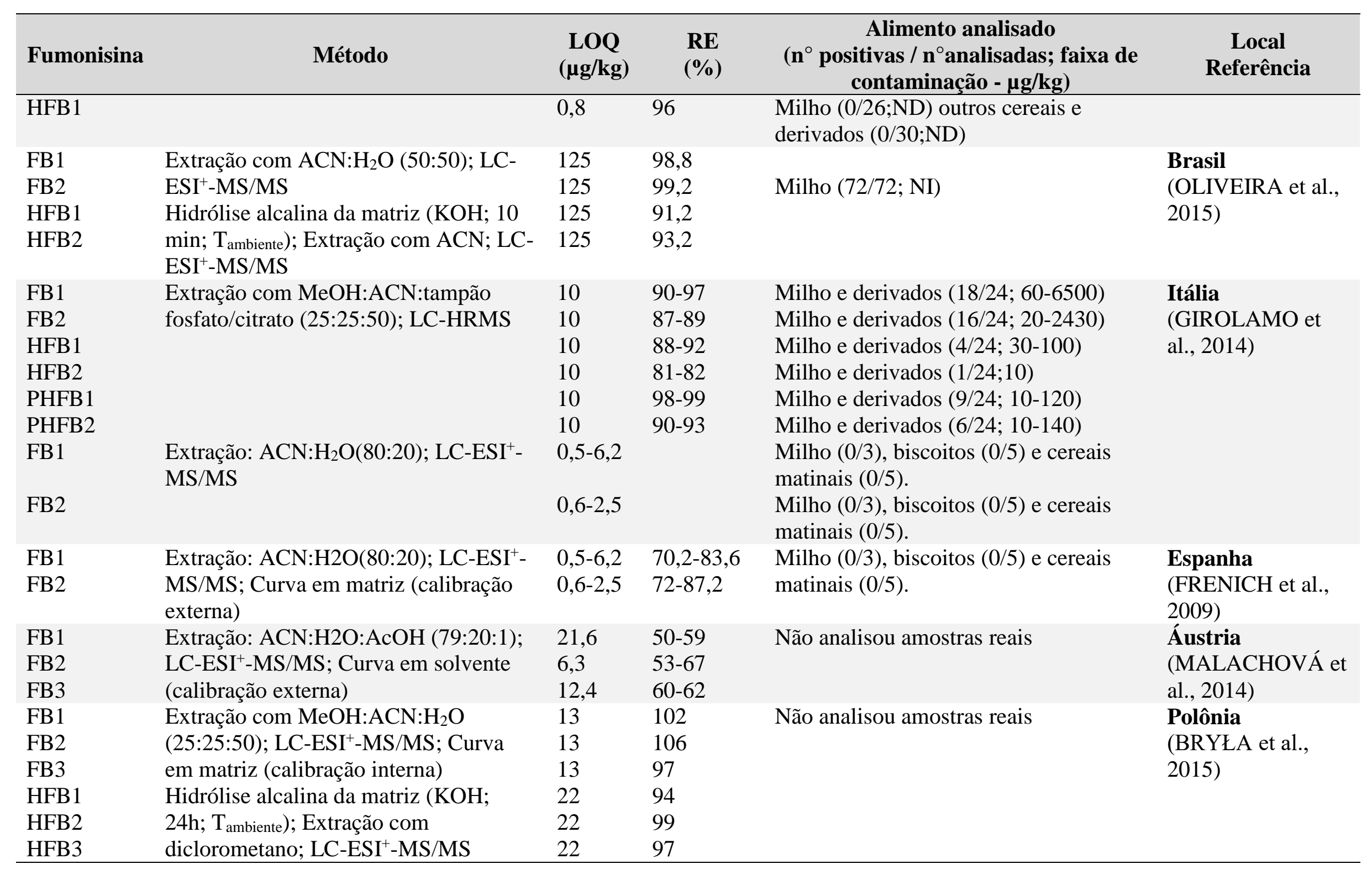


FB1: fumonisina B1; FB2: Fumonisina B2; FB3: fumonisina B3; HFB1: fumonisina hidrolisada B1; HFB2: fumonisina hidrolisada B2; HFB3: fumonisina hidrolisada B3; PHFB1: fumonisina parcialmente hidrolisada B1; PHFB2: fumonisina parcialmente hidrolisada B2; Total: fumonisinas livres + fumonisinas ligadas (bound) + fumonisinas escondidas (hidden). LOQ: limite de quantificação; $\mathrm{RE}$ : recuperação; $\mathrm{ND}=$ não detectado; NI: não informado $\mathrm{ACN}$ : acetonitrila; $\mathrm{MeOH}$ metanol; $\mathrm{AcOH}$ : ácido acético; $\mathrm{CH}_{2} \mathrm{O}_{2}$ ácido fórmico; NDA: naftaleno 2,3-dicarboxaldeido; SPE: extração em fase sólida; MSPD: dispersão de matriz em fase sólida; DLLME: microextração líquido-líquido dispersiva; IAC: colunas de imunoafinidade; LC-ESI+-MS/MS: cromatografia líquida de alta eficiência acoplada a espectrômetro de massas sequencial, ionização por eletrospray no modo positivo; LC-HRMS: cromatografia líquida de alta eficiência acoplada espectrômetro de massas de alta resolução; HPLC-FD: cromatografia líquida acoplada a detector

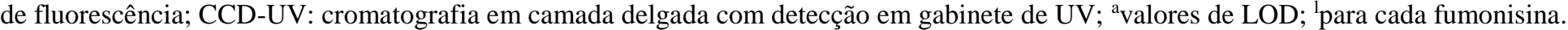

Tabela 6. Métodos de análise de deoxinivalenol e compostos relacionados e ocorrência nos alimentos

\begin{tabular}{|c|c|c|c|c|c|}
\hline Tipo & Método & $\begin{array}{c}\text { LOQ } \\
(\mu \mathrm{g} / \mathrm{kg})\end{array}$ & $\begin{array}{l}\text { RE } \\
(\%)\end{array}$ & $\begin{array}{l}\text { Alimento analisado ( }{ }^{\circ} \text { positivas / } \\
n^{\circ} \text { analisadas; faixa de contaminação - } \\
\mu \mathrm{g} / \mathrm{kg})\end{array}$ & $\begin{array}{c}\text { Local } \\
\text { Referência }\end{array}$ \\
\hline DON & $\begin{array}{l}\text { Extração: } \mathrm{ACN}: \mathrm{H}_{2} \mathrm{O}(80: 20) 0,1 \% \\
\mathrm{CH}_{2} \mathrm{O}_{2} \text {; Diluição; LC-ESI+- } \\
\text { MS/MS; Curva em matriz }\end{array}$ & $2,4-40$ & $71-110$ & $\begin{array}{l}\text { Arroz, }(0 / 10 ; \text { ND), cereais matinais } \\
(7 / 10 ; \text { LOQ-203), cerveja }(0 / 10 ; \text { ND), } \\
\text { massas }(0 / 10 ; \text { ND), produtos de } \\
\text { panificação }(40 / 50 ; \text { LOQ-203), produtos } \\
\text { de soja }(0 / 10 ; N D)\end{array}$ & $\begin{array}{l}\text { Espanha } \\
\text { (BELTRÁN et al., } \\
\text { 2013) }\end{array}$ \\
\hline 3AcDON & & $2-17$ & $77-112$ & $\mathrm{ND}^{\mathrm{a}}$ & \\
\hline 15AcDON & & $1,5-73$ & 70-109 & $\mathrm{ND}^{\mathrm{a}}$ & \\
\hline DON & $\begin{array}{l}\text { Extração: ACN:H } \mathrm{H}_{2} 0 \text { (85:15); LC- } \\
\mathrm{ESI}^{+} \text {-MS/MS; Curva em matriz; }\end{array}$ & $10,1-11,3$ & $76-97$ & $\begin{array}{l}\text { Arroz }(0 / 6 ; N D) \text {, milho }(3 / 18 ; 78-134) \text { e } \\
\text { trigo }(2 / 16 ; 63-88) \text {. }\end{array}$ & $\begin{array}{l}\text { Estados Unidos } \\
\text { (LIAO et al., 2013) }\end{array}$ \\
\hline $15 \mathrm{AcDON}$ & Calibração interna (isótopo) & $10,2-12,8$ & $77-116$ & ND & \\
\hline DON & $\begin{array}{l}\text { Extração: ACN:H } \mathrm{H}_{2} 0: \text { AcOH } \\
(79: 20: 1)+5 \mathrm{~mL} \text { hexano, } \\
\text { Concentração; LC-ESI+-MS/MS; }\end{array}$ & $10-26$ & 90 & $\begin{array}{l}\text { Aveia }(1 / 6 ; 46) \text {, flocos de milho }(1 / 6 \text {; } \\
\text { 207), milho }(6 / 6 ; 5-245) \text {, pão }(4 / 6 ; 20 \text { - } \\
\text { 102), trigo }(4 / 6 ; 16-150) \text {. }\end{array}$ & $\begin{array}{l}\text { Bélgica } \\
\text { (BOEVRE et al., } \\
\text { 2012) }\end{array}$ \\
\hline $3 \mathrm{AcDON}$ & $\begin{array}{l}\text { Curva em matriz; Calibração } \\
\text { interna }\end{array}$ & & 89 & $\begin{array}{l}\text { Aveia }(6 / 6 ; 34-116) \text {, flocos de milho } \\
(5 / 6 ; 29-52) \text {, milho }(6 / 6 ; 63-613) \text {, pão } \\
(6 / 6 ; 29-51) \text {, trigo }(1 / 6 ; 17)\end{array}$ & \\
\hline $15 \mathrm{AcDON}$ & & & 104 & $\begin{array}{l}\text { Aveia }(3 / 6 ; 15-27) \text {, flocos de milho } \\
(1 / 6 ; 17) \text {, milho }(6 / 6 ; 61-792) \text {, pão (1/6; } \\
\text { 18), trigo (ND). }\end{array}$ & \\
\hline
\end{tabular}




\begin{tabular}{|c|c|c|c|c|c|}
\hline Tipo & Método & $\begin{array}{l}\text { LOQ } \\
(\mu \mathrm{g} / \mathrm{kg})\end{array}$ & $\begin{array}{l}\text { RE } \\
(\%)\end{array}$ & $\begin{array}{c}\text { Alimento analisado ( }{ }^{\circ} \text { positivas / } \\
\mathbf{n}^{\circ} \text { analisadas; faixa de contaminação - } \\
\mu \mathrm{g} / \mathrm{kg})\end{array}$ & $\begin{array}{c}\text { Local } \\
\text { Referência }\end{array}$ \\
\hline $\mathrm{D} 3 \mathrm{G}$ & & & 90 & $\begin{array}{l}\text { Aveia (4/6; 28-97), flocos de milho } \\
(3 / 6 ; 24-28), \text { milho }(6 / 6 ; 36-1003), \text { pão } \\
(5 / 6 ; 26-29), \text { trigo }(2 / 6 ; 16-18) .\end{array}$ & \\
\hline DON & $\begin{array}{l}\text { Extração: } \mathrm{ACN}: \mathrm{H}_{2} 0 \text { (84:16); } \\
\text { Clean up: } \mathrm{SPE} \text {; LC-HRMS (modo } \\
\text { negativo); Curva em matriz; } \\
\text { Calibração interna }\end{array}$ & $0,2-3,4^{b}$ & $89-108$ & Não analisou amostras reais & $\begin{array}{l}\text { Itália } \\
\text { (LATTANZIO et al., } \\
\text { 2011) }\end{array}$ \\
\hline DON & $\begin{array}{l}\text { Extração: ACN:MeOH (50:50) } \\
1 \mathrm{mM} \text { formiato de amônio; Clean } \\
\text { up: MSPD; LC-ESI+-MS/MS; } \\
\text { Curva em matriz; Calibração } \\
\text { externa }\end{array}$ & 31 & $80-89$ & $\begin{array}{l}\text { Farinha de aveia }(1 / 2 ; 153) \text {; farinha de } \\
\text { milho }(0 / 9 ; \text { ND); farinha de soja }(0 / 1 ; \\
\text { ND); farinha de trigo }(5 / 25 ; 45-367) ; \\
\text { produtos de panificação }(2 / 8 ; 32,5-180) \text {. }\end{array}$ & $\begin{array}{l}\text { Espanha } \\
\text { (RUBERT; SOLER; } \\
\text { MAÑES, 2011) }\end{array}$ \\
\hline DON & Extração com ACN: $\mathrm{H}_{2} \mathrm{O}: \mathrm{AcOH}$ & $20^{\mathrm{b}}$ & 98 & Não analisou amostras reais & Áustria \\
\hline 3AcDON & (79:20:1); LC-ESI--MS/MS; & $20^{\mathrm{b}}$ & 109 & & (SULYOK; KRSKA; \\
\hline $15 \mathrm{AcDON}$ & Curva em matriz; Calibração & $50^{\mathrm{b}}$ & 101 & & SCHUHMACHER, \\
\hline DOM-1 & externa & $15^{\mathrm{b}}$ & 100 & & 2007) \\
\hline D3G & & $15^{\mathrm{b}}$ & 54 & & \\
\hline DON & $\begin{array}{l}\text { Extração: } \mathrm{MeOH}: \mathrm{KCl} 4 \% \text { (90:10); } \\
\text { Clean up: minicolunas de carvão } \\
\text { ativado:alumina:celite; } \\
\text { Derivatização; Padrão interno; } \\
\text { CCD; Confirmação: CG-FID }\end{array}$ & 120 & 80,5 & $\begin{array}{l}\text { Arroz integral, polido e parboilizado } \\
(1 / 10 ; 266)\end{array}$ & $\begin{array}{l}\text { Brasil } \\
\text { (NUNES et al., 2003) }\end{array}$ \\
\hline DON & $\begin{array}{l}\text { Extração com MeOH:KCl } 4 \% \\
\text { (90:10); clean up com minicolunas } \\
\text { de sílica:alumina:celite; } \\
\text { derivatização; padrão interno; } \\
\text { CCD; confirmação por CG-FID }\end{array}$ & $59-180$ & $82-90$ & Arroz parboilizado $(3 / 32 ; 11-74)$ & $\begin{array}{l}\text { Brasil } \\
\text { (DORS; BIERHALS; } \\
\text { BADIALE- } \\
\text { FURLONG, 2011) }\end{array}$ \\
\hline DON & $\begin{array}{l}\text { Extração: } \mathrm{H}_{2} 0+\text { polietileno glicol; } \\
\text { Clean up: IAC; HPLC-UV }\end{array}$ & 30 & 93 & Arroz $(15 / 65 ;>30)$ & Brasil \\
\hline
\end{tabular}




\begin{tabular}{|c|c|c|c|c|c|}
\hline Tipo & Método & $\begin{array}{c}\text { LOQ } \\
(\mu \mathrm{g} / \mathrm{kg})\end{array}$ & $\begin{array}{l}\text { RE } \\
(\%)\end{array}$ & $\begin{array}{c}\text { Alimento analisado ( }{ }^{\circ} \text { positivas / } \\
\mathbf{n}^{\circ} \text { analisadas; faixa de contaminação - } \\
\mu \mathrm{g} / \mathrm{kg})\end{array}$ & $\begin{array}{c}\text { Local } \\
\text { Referência }\end{array}$ \\
\hline & & & & & $\begin{array}{l}\text { (ALMEIDA et al., } \\
\text { 2012) }\end{array}$ \\
\hline DON & $\begin{array}{l}\text { Extração: } \mathrm{MeOH}: \mathrm{KCl} 4 \%(90: 10) \\
\text { Clean up: SPE; Derivatização; } \\
\text { CG-FID }\end{array}$ & 30 & NI & Milho de pipoca $(5 / 105 ; 32-770)$ & $\begin{array}{l}\text { Brasil } \\
\text { (OLIVEIRA; } \\
\text { SOARES; } \\
\text { SAWAZAKI, 2001) }\end{array}$ \\
\hline D3G & \multirow{2}{*}{$\begin{array}{l}\text { Extração: ACN:H }{ }_{2} 0: A c O H \\
(79: 20: 1) ; \text { LC-ESI--MS/MS }\end{array}$} & $100-250$ & 97 & $\begin{array}{l}\text { Produtos de milho, trigo e centeio }(2 / 25 \text {; } \\
100)\end{array}$ & \multirow{2}{*}{$\begin{array}{l}\text { Áustria } \\
\text { (VENDL et al., 2010) }\end{array}$} \\
\hline $3 \mathrm{AcDON}$ & & $25-50$ & 87 & $\begin{array}{l}\text { Produtos de milho, trigo e centeio }(0 / 25 \text {; } \\
\text { ND) }\end{array}$ & \\
\hline DON & $\begin{array}{l}\text { Extração: ACN:H20 (84:16); } \\
\text { Clean up: Mycosep; LC-ESI-- } \\
\text { MS/MS; Calibração interna }\end{array}$ & 18 & $85-118$ & $\begin{array}{l}\text { Aveia }(9 / 11 ; 62-2216) ; \text { milho }(10 / 10 ; \\
32-2246) ; \text { trigo }(6 / 6 ; 46-2638)\end{array}$ & $\begin{array}{l}\text { Dinamarca } \\
\text { (RASMUSSEN et al., } \\
\text { 2012) }\end{array}$ \\
\hline DON & $\begin{array}{l}\text { Extração; Clean up: Mycosep; } \\
\text { CG-MS }\end{array}$ & 120 & NI & Milho (62/86; 70-14.000) & \multirow{2}{*}{$\begin{array}{l}\text { Canadá } \\
\text { (TRAN; SMITH; } \\
\text { GIRGIS, 2012) }\end{array}$} \\
\hline Conjugados & $\begin{array}{l}\text { Extração com } \mathrm{H}_{2} \mathrm{O} \text { ( } 30 \text { min); } \\
\text { Hidrólise: TFMSA; Neutralização: } \\
\text { carbonato de sódio; ELISA }\end{array}$ & $\begin{array}{l}0,0125 \\
\mu \mathrm{g} / \mathrm{mL}\end{array}$ & NI & Milho (72/86; 100-340) & \\
\hline DON & $\begin{array}{l}\text { Extração: } \mathrm{ACN}: \mathrm{H}_{2} \mathrm{O}: \mathrm{CH}_{2} \mathrm{O}_{2} \\
\text { (80:19,9:0,1); seguida de extração } \\
\text { com ACN: } \mathrm{H}_{2} 0: \mathrm{CH}_{2} \mathrm{O}_{2} \\
\text { (20:79,9:0,1); UPLC-ESI+- } \\
\text { MS/MS; Curva em matriz; } \\
\text { Calibração interna }\end{array}$ & 2,9 & 103 & Não analisou amostras reais & $\begin{array}{l}\text { Áustria } \\
\text { (VARGA et al., 2012) }\end{array}$ \\
\hline
\end{tabular}




\begin{tabular}{|c|c|c|c|c|c|}
\hline Tipo & Método & $\begin{array}{c}\text { LOQ } \\
(\mu \mathrm{g} / \mathrm{kg})\end{array}$ & $\begin{array}{l}\text { RE } \\
(\%)\end{array}$ & $\begin{array}{c}\text { Alimento analisado ( }{ }^{\circ} \text { positivas / } \\
\mathrm{n}^{\circ} \text { analisadas; faixa de contaminação - } \\
\mu \mathrm{g} / \mathrm{kg})\end{array}$ & $\begin{array}{c}\text { Local } \\
\text { Referência }\end{array}$ \\
\hline$\overline{\mathrm{DON}}$ & \multirow[t]{2}{*}{$\begin{array}{l}\text { Extração: ACN:H2O: AcOH } \\
\text { (79:20:1); LC-ESI'-MS/MS }\end{array}$} & 20 & 75 & $\begin{array}{l}\text { Milho }(1 / 26 ; 31,4) \text { e outros cereais e } \\
\text { derivados }(10 / 30 ; 22,3-250)\end{array}$ & \multirow{2}{*}{$\begin{array}{l}\text { Burkina Faso e } \\
\text { Moçambique } \\
\text { (VISHWANATH et } \\
\text { al., 2009; WARTH et } \\
\text { al., 2012) }\end{array}$} \\
\hline D3G & & 10 & 105 & $\begin{array}{l}\text { Milho }(0 / 26 ; \mathrm{ND}) \text { e outros cereais e } \\
\text { derivados }(2 / 30 ; 23,6-39,7)\end{array}$ & \\
\hline DON & $\begin{array}{l}\text { Extração: ACN:H2O(80:20); } \\
\text { UPLC-ESI'-MS/MS; Curva em } \\
\text { matriz (calibração externa) }\end{array}$ & $3,7-5,9$ & $74,8-98,5$ & $\begin{array}{l}\text { Milho }(0 / 3) \text {, biscoitos }(0 / 5) \text { e cereais } \\
\text { matinais }(1 / 5 ; 42,1) .\end{array}$ & $\begin{array}{l}\text { Espanha } \\
\text { (FRENICH et al., } \\
\text { 2009) }\end{array}$ \\
\hline DON & $\begin{array}{l}\text { Extração: ACN:H2O(84:16); LC- } \\
\text { ESI--MS/MS; Curva em solvente } \\
\text { (calibração interna) }\end{array}$ & $8 \mu \mathrm{g} / \mathrm{L}$ & $95-99$ & Não analisou amostras reais & $\begin{array}{l}\text { Áustria } \\
\text { (HÄUBL et al., } \\
\text { 2006b) }\end{array}$ \\
\hline DON & $\begin{array}{l}\text { Extração: ACN:H2O:AcOH } \\
\text { (79:20:1); LC-ESI--MS/MS; } \\
\text { Curva em solvente (calibração } \\
\text { externa) }\end{array}$ & 18,2 & $93-95$ & Não analisou amostras reais & $\begin{array}{l}\text { Áustria } \\
\text { (MALACHOVÁ et } \\
\text { al., 2014) }\end{array}$ \\
\hline
\end{tabular}

DON: deoxinivalenol; 3AcDON; 3-acetildeoxinivalenol; 15AcDON: 15-acetildeoxinivalenol; DON-3G: deoxinivalenol-3-glicosídeo; DOM-1: deepoxi-deoxinivalenol; LOQ: limite de quantificação; RE: recuperação; ND: não detectado; NI: não informado; $\mathrm{ACN}$ : acetonitrila; $\mathrm{MeOH}_{\mathrm{O}}$ metanol; $\mathrm{AcOH}$ : ácido acético; CH $\mathrm{O}_{2:}$ ácido fórmico; TFMSA: ácido trifluormetanossulfônico; ELISA: teste imunoenzimático; SPE: extração em fase sólida; MSPD: dispersão de matriz em fase sólida; DLLME: microextração líquidolíquido dispersiva; IAC: colunas de imunoafinidade; UPLC-ESI+-MS/MS: cromatografia líquida de utraperformance acoplada a espectrômetro de massas sequencial, ionização por eletrospray no modo positivo; LC-ESI ${ }^{+}$-MS/MS: cromatografia líquida de alta eficiência acoplada a espectrômetro de massas sequencial, ionização por eletrospray no modo positivo; LC-ESI--MS/MS: cromatografia líquida de alta eficiência acoplada a espectrômetro de massas sequencial, ionização por eletrospray no modo negativo; LC-HRMS: cromatografia líquida de alta eficiência acoplada a espectrômetro de massas de alta resolução; HPLC-FD: cromatografia líquida acoplada a detector de fluorescência; HPLCUV: cromatografia líquida acoplada a detector de UV; CCD: cromatografia em camada delgada; CG-FID: cromatografia gasosa acoplada a detector de chamas; CG-MS: cromatografia gasosa acoplada espectrômetro de massas; ${ }^{a}$ mesmas amostras analisadas para DON; ${ }^{b}$ valores de LOD. 
Tabela 7. Métodos de análise de zearalenona e compostos relacionados e ocorrência nos alimentos.

\begin{tabular}{|c|c|c|c|c|c|}
\hline Tipo & Método & $\begin{array}{c}\text { LOQ } \\
(\mu \mathrm{g} / \mathrm{kg})\end{array}$ & $\begin{array}{l}\text { RE } \\
(\%)\end{array}$ & $\begin{array}{c}\text { Alimento analisado } \\
\left(\mathrm{n}^{\circ} \text { positivas } / \mathrm{n}^{\circ} \text { analisadas; }\right. \\
\text { faixa de contaminação - } \\
\mu \mathrm{g} / \mathrm{kg}) \\
\end{array}$ & $\begin{array}{c}\text { Local } \\
\text { Referência }\end{array}$ \\
\hline$\overline{\mathrm{ZON}}$ & $\begin{array}{l}\text { Extração: ACN: } \mathrm{H}_{2} \mathrm{O}(80: 20) 0,1 \% \\
\mathrm{CH}_{2} \mathrm{O}_{2} \text {; diluição; UPLC-ESI-MS/MS; } \\
\text { curva em matriz }\end{array}$ & $0,1-1,1$ & $39-106$ & $\begin{array}{l}\text { Arroz, }(0 / 10 ; \text { ND), cereais } \\
\text { matinais }(0 / 10 ; \mathrm{ND}) \text {, cerveja } \\
(0 / 10 ; \mathrm{ND}) \text {, massas }(0 / 10 ; \mathrm{ND}) \text {, } \\
\text { produtos de panificação }(6 / 50 ; \\
\text { <LOQ) e produtos de soja } \\
(0 / 10 ; \mathrm{ND})\end{array}$ & $\begin{array}{c}\text { Espanha } \\
\text { (BELTRÁN et al., 2013) }\end{array}$ \\
\hline $\mathrm{ZON}$ & $\begin{array}{l}\text { Extração: } \mathrm{ACN}: \mathrm{H}_{2} 0 \text { (85:15); LC-ESI+- } \\
\text { MS/MS; Curva em matriz; Calibração } \\
\text { interna }\end{array}$ & $7,3-9,8$ & $81-111$ & $\begin{array}{l}\text { Arroz }(0 / 6 ; N D) \text {, milho } \\
(4 / 18 ; 115-339) \text { e trigo } \\
(0 / 16 ; N D)\end{array}$ & $\begin{array}{l}\text { Estados Unidos } \\
\text { (LIAO et al., 2013) }\end{array}$ \\
\hline $\mathrm{ZON}$ & $\begin{array}{l}\text { Extração: } \mathrm{ACN}: \mathrm{H}_{2} 0: \mathrm{AcOH}(79: 20: 1)+ \\
\text { 5mL hexano; Concentração; LC-ESI+- } \\
\text { MS/MS; Curva em matriz e calibração } \\
\text { interna }\end{array}$ & $10-26$ & 74 & $\begin{array}{l}\text { Aveia }(4 / 6 ; 13-85), \text { flocos de } \\
\text { milho }(5 / 6 ; 31-90) \text {, milho }(5 / 6 ; \\
59-1071) \text {, pão }(5 / 6 ; 19-53), \\
\text { trigo }(5 / 6 ; 12-109)\end{array}$ & $\begin{array}{c}\text { Bélgica } \\
\text { (BOEVRE et al., 2012) }\end{array}$ \\
\hline$\alpha-Z O L$ & & & 77 & $\begin{array}{l}\text { Aveia }(2 / 6 ; 51-68), \text { flocos de } \\
\text { milho }(2 / 6 ; 26-34), \text { milho }(6 / 6 ; \\
\text { 22-262), pão }(2 / 6 ; 18-110), \\
\text { trigo }(2 / 6 ; 15-16)\end{array}$ & \\
\hline$\beta-Z O L$ & & & 79 & $\begin{array}{l}\text { Aveia }(1 / 6 ; 46), \text { flocos de } \\
\text { milho }(4 / 6 ; 44-63) \text {, milho }(6 / 6 ; \\
12-103) \text {, pão }(3 / 6 ; 55-96) \text {, trigo } \\
(1 / 6 ; 49)\end{array}$ & \\
\hline Z4G & & & 89 & $\begin{array}{l}\text { Aveia (ND), flocos de milho } \\
(\mathrm{ND}), \text { milho }(1 / 6 ; 274), \text { pão } \\
(2 / 6 ; 20) \text {, trigo (ND) }\end{array}$ & \\
\hline
\end{tabular}




\begin{tabular}{|c|c|c|c|c|c|}
\hline Tipo & Método & $\begin{array}{c}\mathrm{LOQ} \\
(\mu \mathrm{g} / \mathrm{kg})\end{array}$ & $\begin{array}{l}\text { RE } \\
(\%)\end{array}$ & $\begin{array}{c}\text { Alimento analisado } \\
\left(\mathrm{n}^{\circ} \text { positivas / }{ }^{\circ} \text { analisadas; }\right. \\
\text { faixa de contaminação - } \\
\mu \mathrm{g} / \mathrm{kg})\end{array}$ & $\begin{array}{c}\text { Local } \\
\text { Referência }\end{array}$ \\
\hline$\alpha-Z O L-4 G$ & & & 80 & $\begin{array}{l}\text { Aveia (ND), flocos de milho } \\
\text { (ND), milho (1/6; 283), pão } \\
\text { (ND), trigo (ND) }\end{array}$ & \\
\hline$\beta-Z O L-4 G$ & & & 81 & $\begin{array}{l}\text { Aveia }(1 / 6 ; 20) \text {, flocos de milho } \\
\text { (ND), milho (3/6; 92-193), pão } \\
\text { (ND), trigo (ND) }\end{array}$ & \\
\hline $\mathrm{Z} 4 \mathrm{~S}$ & & & 78 & $\begin{array}{l}\text { Aveia }(1 / 6 ; 12), \text { flocos de milho } \\
(\mathrm{ND}), \text { milho }(1 / 6 ; 51), \text { pão } \\
(1 / 6 ; 24), \text { trigo }(2 / 6 ; 11)\end{array}$ & \\
\hline $\mathrm{ZON}$ & $\begin{array}{l}\text { Extração: ACN: } \mathrm{H}_{2} 0 \text { (84:16); Clean up: } \\
\text { SPE; LC-HRMS (modo negativo); } \\
\text { Curva em matriz; Calibração interna }\end{array}$ & $0,3-2,3^{\mathrm{a}}$ & $64-97$ & Não analisou amostras reais & $\begin{array}{c}\text { Itália } \\
\text { (LATTANZIO et al., 2011) }\end{array}$ \\
\hline $\mathrm{ZON}$ & $\begin{array}{l}\text { Extração: ACN:MeOH (50:50) 1mM } \\
\text { formiato de amônio; Clean up: MSPD; } \\
\text { LC-ESI--MS/MS; Curva em matriz; } \\
\text { Calibração externa }\end{array}$ & 12,6 & $77-79$ & $\begin{array}{l}\text { Farinha de aveia }(0 / 2 ; \mathrm{ND}) ; \\
\text { farinha de milho }(1 / 9 ; 70,5) ; \\
\text { farinha de soja }(0 / 1 ; \mathrm{ND}) ; \\
\text { farinha de trigo }(1 / 25 ; 39,3) ; \\
\text { produtos de panificação }(0 / 8 ; \\
\text { ND) }\end{array}$ & $\begin{array}{c}\text { Espanha } \\
\text { (RUBERT; SOLER; } \\
\text { MAÑES, 2011) }\end{array}$ \\
\hline $\mathrm{ZON}$ & Extração com ACN: $\mathrm{H}_{2} 0: \mathrm{AcOH}$ & $0,4^{\mathrm{a}}$ & 106 & Não analisou amostras reais & Áustria \\
\hline$\alpha-\mathrm{ZOL}$ & (79:20:1); LC-ESI-MS/MS; Curva em & $3,0^{\mathrm{a}}$ & 110 & & (SULYOK; KRSKA; \\
\hline$\beta-Z O L$ & matriz; Calibração externa & $4,0^{\mathrm{a}}$ & 111 & & SCHUHMACHER, 2007) \\
\hline $\mathrm{Z} 4 \mathrm{G}$ & & $5,0^{\mathrm{a}}$ & 108 & & \\
\hline $\mathrm{Z} 4 \mathrm{~S}$ & & $0,3^{\mathrm{a}}$ & 111 & & \\
\hline $\mathrm{ZON}$ & $\begin{array}{l}\text { Extração: } \mathrm{MeOH}: \mathrm{KCl} 4 \% \text { (90:10); } \\
\text { Clean up: minicolunas de carvão } \\
\text { ativado:alumina:celite; Derivatização; } \\
\text { Padrão interno; CCD; Confirmação: } \\
\text { CG-FID }\end{array}$ & 45 & 90 & $\begin{array}{l}\text { Arroz integral, polido e } \\
\text { parboilizado }\end{array}$ & $\begin{array}{c}\text { Brasil } \\
\text { (NUNES et al., 2003) }\end{array}$ \\
\hline
\end{tabular}




\begin{tabular}{|c|c|c|c|c|c|}
\hline Tipo & Método & $\begin{array}{c}\text { LOQ } \\
(\mu \mathrm{g} / \mathrm{kg})\end{array}$ & $\begin{array}{l}\text { RE } \\
(\%)\end{array}$ & $\begin{array}{c}\text { Alimento analisado } \\
\left(\mathrm{n}^{\circ} \text { positivas / } \mathrm{n}^{\circ} \text { analisadas; }\right. \\
\text { faixa de contaminação - } \\
\mu \mathrm{g} / \mathrm{kg})\end{array}$ & $\begin{array}{c}\text { Local } \\
\text { Referência }\end{array}$ \\
\hline $\mathrm{ZON}$ & $\begin{array}{l}\text { Extração: } \mathrm{MeOH}: \mathrm{KCl} 4 \%(90: 10) ; \\
\text { Clean up: minicolunas de } \\
\text { sílica:alumina:celite; Derivatização; } \\
\text { Padrão interno; CCD; Confirmação: } \\
\text { CG-FID }\end{array}$ & $40-195$ & $61-75$ & $\begin{array}{l}\text { Arroz parboilizado }(6 / 32 ; 317- \\
396)\end{array}$ & $\begin{array}{c}\text { Brasil } \\
\text { (DORS; BIERHALS; } \\
\text { BADIALE-FURLONG, } \\
\text { 2011) }\end{array}$ \\
\hline $\mathrm{ZON}$ & $\begin{array}{l}\text { Extração: ACN:H20 (84:16); Clean } \\
\text { up: Mycosep; HPLC-FD }\end{array}$ & 3,6 & 94 & Arroz $(49 / 165 ; 3,6->400)$ & $\begin{array}{c}\text { Brasil } \\
\text { (ALMEIDA et al., 2012) }\end{array}$ \\
\hline $\mathrm{ZON}$ & $\begin{array}{l}\text { Extração: } \mathrm{MeOH}: \mathrm{KCl} 4 \%(90: 10) \text {; } \\
\text { Clean up: solução clarificante e celite; } \\
\text { Partição: clorofórmio; CCD-UV }\end{array}$ & 50 & 99 & Produtos de milho $(0 / 74 ;$ ND) & $\begin{array}{c}\text { Brasil } \\
\text { (KAWASHIMA; } \\
\text { VALENTE SOARES, } \\
\text { 2006) }\end{array}$ \\
\hline $\mathrm{ZON}$ & $\begin{array}{l}\text { Extração: } \mathrm{MeOH}: \mathrm{KCl} 4 \%(90: 10) \\
\text { Clean up: solução clarificante e celite; } \\
\text { Partição: clorofórmio; CCD-UV }\end{array}$ & 76,8 & 102 & $\begin{array}{l}\text { Produtos de milho (1/121; } \\
448)\end{array}$ & $\begin{array}{c}\text { Brasil } \\
\text { (SEKIYAMA et al., 2005) }\end{array}$ \\
\hline $\mathrm{ZON}$ & $\begin{array}{l}\text { Extração: ACN:H20:AcOH (79:20:1); } \\
\text { LC-ESI-MS/MS }\end{array}$ & 10 & 91 & $\begin{array}{l}\text { Produtos de milho, trigo e } \\
\text { centeio }(8 / 25 ; 10-44,2)\end{array}$ & $\begin{array}{c}\text { Áustria } \\
\text { (VENDL et al., 2010) }\end{array}$ \\
\hline$\alpha-Z O L$ & & $25-50$ & 89 & Produtos de milho, trigo e & \\
\hline$\beta-Z O L$ & & 25 & 89 & centeio $(0 / 25 ; \mathrm{ND})$ & \\
\hline $\mathrm{Z} 4 \mathrm{G}$ & & 10 & 73 & & \\
\hline $\mathrm{Z} 4 \mathrm{~S}$ & & $1-2,5$ & 43 & $\begin{array}{l}\text { Produtos de milho, trigo e } \\
\text { centeio }(13 / 25 ; 1-6,1)\end{array}$ & \\
\hline$\alpha-Z G$ & & $10-25$ & 80 & Produtos de milho, trigo e & \\
\hline$\beta-Z G$ & & $10-25$ & 75 & centeio $(0 / 25 ; \mathrm{ND})$ & \\
\hline $\mathrm{ZON}$ & $\begin{array}{l}\text { Extração: } \mathrm{MeOH}: \mathrm{H}_{2} \mathrm{O}(75: 25) ; \text { Clean } \\
\text { up: IAC; HPLC-FD }\end{array}$ & 2 & $76,4-114,4$ & $\begin{array}{l}\text { Milho e produtos de milho } \\
(13 / 35 ; \text { LOD-19,5) }\end{array}$ & $\begin{array}{c}\text { Estados Unidos } \\
\text { (HEWITT et al., 2012) }\end{array}$ \\
\hline $\mathrm{ZON}$ & $\begin{array}{l}\text { Extração: } \mathrm{ACN}: \mathrm{H}_{2} 0: \mathrm{CH}_{2} \mathrm{O}_{2} \\
\text { (80:19,9:0,1); seguida de extração com } \\
\text { ACN: } \mathrm{H}_{2} 0: \mathrm{CH}_{2} \mathrm{O}_{2}(20: 79,9: 0,1) ;\end{array}$ & 2,9 & 103 & Não analisou amostras reais & $\begin{array}{c}\text { Áustria } \\
\text { (VARGA et al., 2012) }\end{array}$ \\
\hline
\end{tabular}




\begin{tabular}{|c|c|c|c|c|c|}
\hline Tipo & Método & $\begin{array}{c}\text { LOQ } \\
(\mu \mathrm{g} / \mathrm{kg})\end{array}$ & $\begin{array}{l}\text { RE } \\
(\%)\end{array}$ & $\begin{array}{c}\text { Alimento analisado } \\
\left(\mathrm{n}^{\circ} \text { positivas / } \mathrm{n}^{\circ} \text { analisadas; }\right. \\
\text { faixa de contaminação - } \\
\mu \mathrm{g} / \mathrm{kg})\end{array}$ & $\begin{array}{c}\text { Local } \\
\text { Referência }\end{array}$ \\
\hline & $\begin{array}{l}\text { UPLC-ESI-MS/MS; Curva em matriz; } \\
\text { Calibração interna }\end{array}$ & & & & \\
\hline ZON & $\begin{array}{l}\text { Extração: MeOH:H2O (80:20); Clean } \\
\text { up: IAC; Fluorômetro }\end{array}$ & NI & $71-110$ & Milho (38/40; 1,8-99) & $\begin{array}{c}\text { Brasil } \\
\text { (QUEIROZ et al., 2012) }\end{array}$ \\
\hline $\mathrm{ZON}$ & $\begin{array}{l}\text { Extração: ACN:H2O: AcOH (79:20:1); } \\
\text { LC-ESI--MS/MS }\end{array}$ & 10 & 83 & $\begin{array}{l}\text { Milho }(2 / 26 ; 11-15,8) \text { e outros } \\
\text { cereais e derivados }(8 / 30 ; 12,3 \text { - } \\
\text { 17) }\end{array}$ & $\begin{array}{c}\text { Burkina Faso e } \\
\text { Moçambique } \\
\text { (VISHWANATH et al., } \\
\text { 2009; WARTH et al., 2012) }\end{array}$ \\
\hline ZON & $\begin{array}{l}\text { Extração: ACN:H2O(80:20); UPLC- } \\
\text { ESI }{ }^{+} \text {-MS/MS; Curva em matriz } \\
\text { (calibração externa) }\end{array}$ & $5,1-6,3$ & $74,3-102,9$ & $\begin{array}{l}\text { Milho }(0 / 3) \text {, biscoitos }(0 / 5) \mathrm{e} \\
\text { cereais matinais }(0 / 5) \text {. }\end{array}$ & $\begin{array}{c}\text { Espanha } \\
\text { (FRENICH et al., 2009) }\end{array}$ \\
\hline $\mathrm{ZON}$ & $\begin{array}{l}\text { Extração: ACN:H2O:AcOH (79:20:1); } \\
\text { LC-ESI-MS/MS; Curva em solvente } \\
\text { (calibração externa) }\end{array}$ & 0,7 & $87-109$ & Não analisou amostras reais & $\begin{array}{l}\text { Áustria } \\
\text { (MALACHOVÁ et al., } \\
\text { 2014) }\end{array}$ \\
\hline \multicolumn{6}{|c|}{ 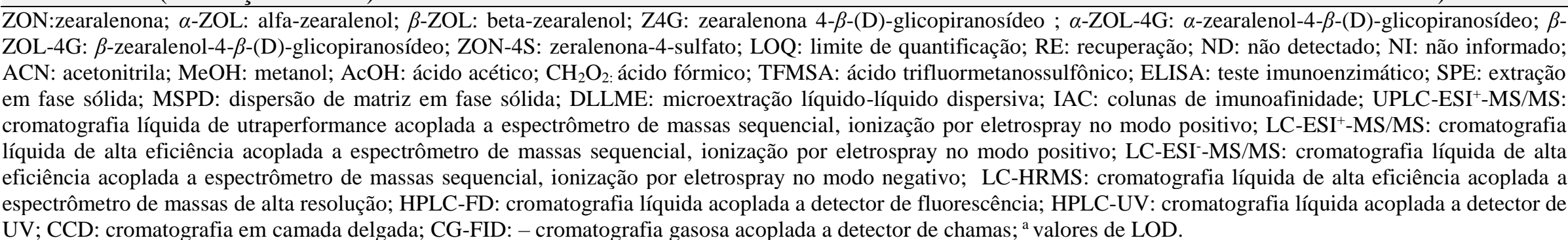 } \\
\hline
\end{tabular}


Tabela 8. Métodos de análise de citreoviridina e ocorrência nos alimentos.

\begin{tabular}{|c|c|c|c|c|}
\hline Método & $\begin{array}{c}\text { LOQ } \\
(\mu \mathrm{g} / \mathrm{kg})\end{array}$ & $\begin{array}{l}\text { RE } \\
(\%)\end{array}$ & $\begin{array}{c}\text { Alimento analisado } \\
\left(\mathrm{n}^{\circ} \text { positivas / }{ }^{\circ} \text { analisadas; }\right. \\
\text { faixa de contaminação }-\mu \mathrm{g} / \mathrm{kg})\end{array}$ & $\begin{array}{c}\text { Local } \\
\text { Referência }\end{array}$ \\
\hline $\begin{array}{l}\text { Extração: diclorometano; Clean up: SPE; } \\
\text { HPLC-FD }\end{array}$ & 1 & 86 & Arroz $(5 / 420 ; 12-254)$ & $\begin{array}{l}\text { Brasil } \\
\text { (ROSA et al., 2010) }\end{array}$ \\
\hline $\begin{array}{l}\text { Extração: ACN:H2O: AcOH (79:20:1); } \\
\text { LC-ESI+-MS/MS }\end{array}$ & 25 & 122 & $\begin{array}{l}\text { Milho }(0 / 26 ; \mathrm{ND}) \text { e outros cereais e } \\
\text { derivados }(0 / 30 ; \mathrm{ND})\end{array}$ & $\begin{array}{l}\text { Burkina Faso e } \\
\text { Moçambique } \\
\text { (VISHWANATH et al., } \\
\text { 2009; WARTH et al., 2012) }\end{array}$ \\
\hline $\begin{array}{l}\text { Extração com diclorometano; Clean up: } \\
\text { SPE; HPLC-FD }\end{array}$ & 2 & $\mathrm{NI}$ & Milho $(5 / 8 ; 19-2790)$ & $\begin{array}{l}\text { Estados Unidos } \\
\text { (WICKLOW et al., 1988) }\end{array}$ \\
\hline $\begin{array}{l}\text { Extração com diclorometano; Clean up: } \\
\text { SPE; HPLC-FD }\end{array}$ & 2 & $89-102,8$ & Não analisou amostras reais & $\begin{array}{l}\text { Estados Unidos } \\
\text { (STUBBLEFIELD; GREER; } \\
\text { SHOTWELL, 1988) }\end{array}$ \\
\hline $\begin{array}{l}\text { Extração com clorofórmio; Clean up: SPE; } \\
\text { CCD }\end{array}$ & NI & $\mathrm{NI}$ & $\begin{array}{l}\text { CTV foi detectada em milho ainda no } \\
\text { campo (NI) }\end{array}$ & $\begin{array}{l}\text { Estados Unidos } \\
\text { (WICKLOW; COLE, 1984) }\end{array}$ \\
\hline
\end{tabular}




\section{AVALIAÇÃO DE RISCO DA EXPOSIÇÃO HUMANA A MICOTOXINAS NA} DIETA

A avaliação de risco é um procedimento constituído por 4 etapas distintas e que tem como objetivo estimar a probabilidade da ocorrência de um efeito adverso após a exposição humana a substancias potencialmente tóxicas presentes na dieta, inclusive micotoxinas (IPCS, 2009). A Figura 12 ilustra as etapas do processo, que é função da toxicidade da substância e da exposição. Na primeira etapa, identificação do perigo (hazard identification), identifica-se a natureza do efeito adverso causado pela exposição humana a uma determinada substância (IPCS, 2009). Relação estrutura molecular e atividade (SAR), testes in vitro, experimentação animal e estudos epidemiológicos são fontes comumente utilizadas para obter este tipo de informação (JARDIM; CALDAS, 2009).

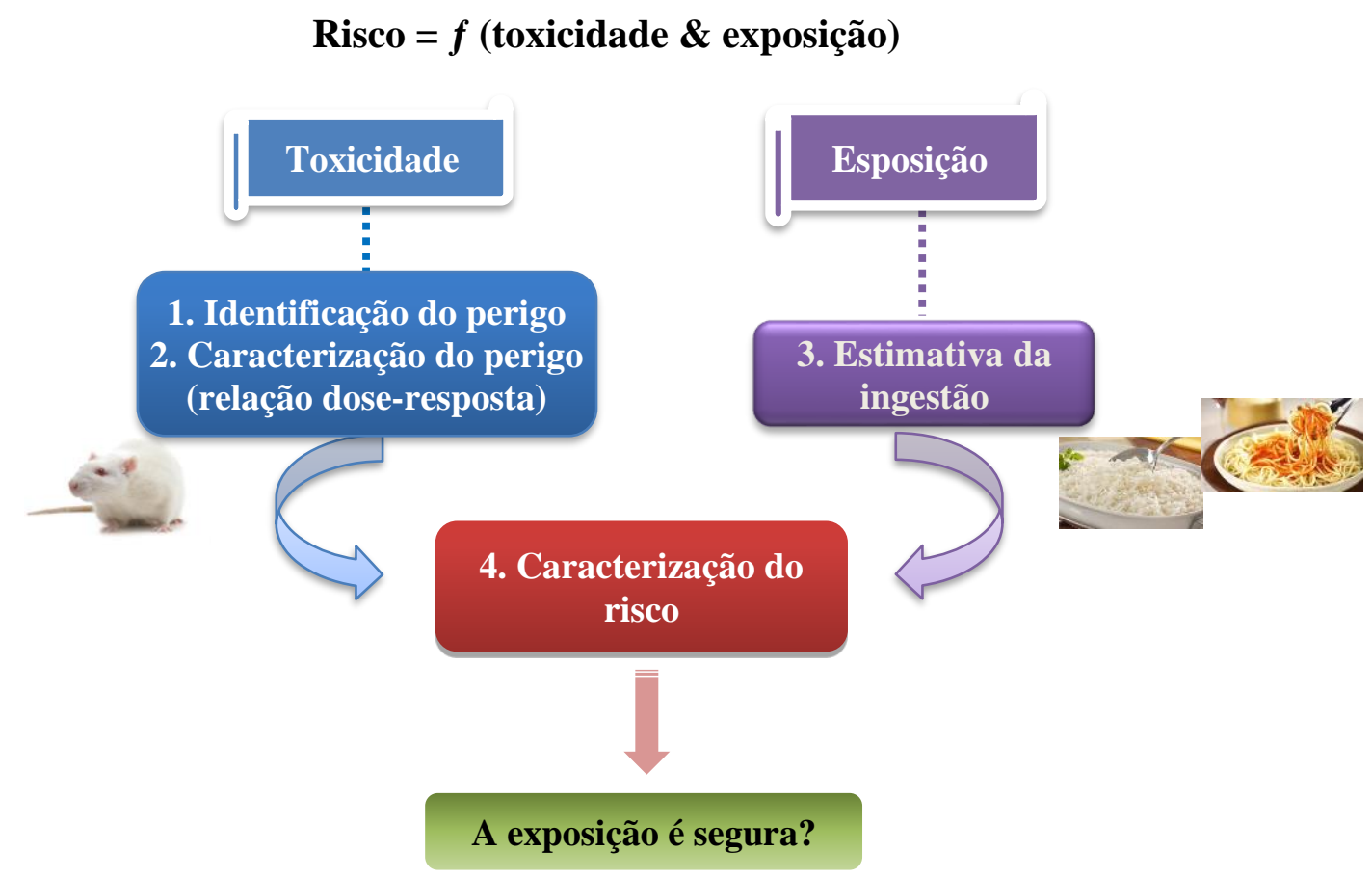

Figura 12 - Etapas da avaliação de risco.

$\mathrm{Na}$ segunda etapa (caracterização do perigo ou hazard characterization) tenta-se estabelecer uma relação quantitativa entre a exposição e o substância em estudo (relação dose/resposta) (IPCS, 2009; JARDIM; CALDAS, 2009). A partir desse tipo de dados é possível estimar parâmetros de ingestão segura, crônica e aguda, das substâncias. Para as micotoxinas, este parâmetro para exposição crônica é comumente denominado de Ingestão Diária Provisória 
Máxima Tolerável (Provisional Maximum Tolerable Daily Intake, ou PMTDI) (JECFA, 2000, 2001, 2011). O DON é a única micotoxina para qual existe uma dose segura de exposição aguda, a dose de referencia aguda (ARfD) (JECFA, 2011). Para substâncias genotóxicas, como as aflatoxinas, não é possível estabelecer doses de ingestão segura e, portanto, recomenda-se que a exposição seja mantida no nível mais baixo possível (ALARA - As low as reasonably achievable) (IPCS, 2009). Parâmetros toxicológicos para avaliação de risco quantitativo a aflatoxinas incluem a benchmark dose (BMDL, o limite inferior desta estimativa) ou o risco carcinogênico (JECFA, 1999, 2006).

Na terceira etapa, realiza-se avaliação da exposição ao contaminante na dieta (ingestão; Figura 12), levando em consideração a concentração da substância no alimento e o padrão de consumo dos alimentos. Os dados de concentração podem ser obtidos em estudos de monitoramento de alimentos ou, na ausência destes, utilizando limites legais (LM) (IPCS, 2009). Os dados de consumo de alimentos, quando possível, devem estar associados ao peso corpóreo de cada indivíduo, podendo ser obtidos de dados de suprimentos de alimentos (GEMS/Food Cluster diets), disponibilidade de alimentos no domicílio (POF - Pesquisa de Orçamentos Familiares - IBGE), consumo individual (questionário de frequência alimentar, recordatório 24 horas) ou por estudos de dieta duplicada (JARDIM; CALDAS, 2009). O cálculo da ingestão pode ser feito usando modelos determinísticos (valores pontuais de concentração e consumo, como médias ou percentis), ou modelos probabilísticos (curvas de distribuição de contaminação e consumo - modelos matemáticos) (IPCS, 2009).

$\mathrm{Na}$ etapa de caracterização do risco, estima-se a probabilidade da ocorrência do efeito adverso em uma população exposta (IPCS, 2009). No caso de substâncias não genotóxicas, compara-se a ingestão calculada com o parâmetro de ingestão segura estabelecido na etapa de caracterização da relação dose/resposta (o PMTDI para micotoxinas).

No caso de substâncias genotóxicas, como as aflatoxinas, algumas das opções para a caracterização do risco são a estimativa do risco de câncer e o cálculo da margem de exposição (MOE) (JARDIM; CALDAS, 2009). Para as aflatoxinas, o cálculo do risco de câncer pode ser realizado de acordo com o procedimento estabelecido pelo JECFA (1999). A estimativa considera a potência carcinogênica das aflatoxinas em indivíduos portadores de hepatite $\mathrm{B}$ $\left(\mathrm{HBsAg}^{+}\right)$e em não portadores $\left(\mathrm{HBsAg}^{-}\right)$, sendo a potência no primeiro grupo 30 vezes maior que no segundo. Assim o cálculo do risco de câncer para uma dada população advindo da exposição a aflatoxinas pode ser determinado de acordo com as equações 1 e 2 . 


$$
\begin{gathered}
P_{\text {estimada }}=\left[\text { PHBsAg } \mathrm{H}^{+} \% \text { População } \mathrm{HBsAg}^{+}\right]+ \\
{\left[\mathrm{PHBsAg}^{-} \times \% \text { População } \mathrm{HBsAg}^{-}\right]}
\end{gathered}
$$

$$
\text { Risco de câncer }=P_{\text {estimada }} \times \text { Ingestão }
$$

$\mathrm{O}$ risco resultante da exposição às aflatoxinas também pode ser caracterizado pelo cálculo da MOE (Eq. 3), onde a referencia toxicológica utilizada é normalmente a BMDL. O EFSA (European Food Safety Authority) estimou, baseado em dados da carcinogenicidade em ratos expostos a $\mathrm{AFB} 1$, uma $\mathrm{BMDL}_{10}$ de $0,17 \mu \mathrm{g} / \mathrm{kg}$ pc/dia. Quanto maior a MOE calculada, menor a preocupação e, geralmente, valores abaixo de 10000 podem indicar risco à saúde humana (EFSA, 2005).

$$
M O E=\frac{\text { Referência toxicológica }}{\text { Ingestão }}
$$

No quadro 2 temos a classificação e os parâmetros de ingestão segura crônica (PMTDI) e aguda (ARfD; apenas para DON) existentes para as micotoxinas que serão analisadas neste trabalho. Atualmente, o perfil toxicológico da citreoviridina ainda não foi definido pela OMS e a caracterização do risco desta micotoxina não pode ser finalizada.

A avaliação da exposição às micotoxinas pelo consumo de cereais tem sido conduzida no mundo todo. No Brasil, Caldas \& Silva (2007) realizaram uma avaliação da exposição da população à fumonisinas (FB1+FB2) a partir do consumo de produtos à base de milho. Foram analisadas amostras coletadas no Distrito Federal e, para avaliação da exposição da população brasileira, foram incluídos resultados descritos na literatura. A exposição foi avaliada tanto para os consumidores (indivíduos que relatarm consumo dos alimentos de interessse) quanto para população total (média de consumo calculada incluindo consumidores e não consumidores dos produtos avaliados). A média de contaminação das amostras variou entre $0,058 \mathrm{mg} / \mathrm{kg}$ (milho enlatado) e 3,32 mg/kg (fubá) para a soma das fumonisinas B1 e B2. O resultado da avaliação da exposição demonstrou que consumidores desta classe de produtos podem estar numa situação risco, pois a ingestão calculada de fumonisinas representou 355\% do PMTDI $(2 \mu \mathrm{g} / \mathrm{kg})$ enquanto que para a população total, este valor ficou em $24,1 \%$. O produto que contribuiu com a maior parte da ingestão foi o fubá, representando $74 \%$ da ingestão total. 
Quadro 2 - Classificação e parâmetros de ingestão segura, exposição crônica e aguda (DON).

\begin{tabular}{|c|c|c|c|}
\hline Micotoxinas & $\begin{array}{l}\text { Classificação } \\
\text { IARC }\end{array}$ & $\begin{array}{c}\text { Ingestão diária } \\
\text { tolerável máxima } \\
\text { (PMTDI) }\end{array}$ & Caracterização do risco \\
\hline AFs & $\begin{array}{l}\text { Carcinógenos }{ }^{\mathrm{a}} \\
\quad(\text { Grupo 1) }\end{array}$ & - & $\begin{array}{l}\text { 1. Risco de câncer } \\
\text { 2. MOE = BMDL } / \text { ingestao } \\
\text { MOE }<10.000 \text { pode } \\
\text { representar preocupaçao } \\
\text { para a saúde }\end{array}$ \\
\hline OTA & $\begin{array}{c}\text { Provável } \\
\text { carcinógeno }^{\text {a }} \\
(\text { Grupo 2B) }\end{array}$ & $0,1 \mu \mathrm{g} / \mathrm{kg} \mathrm{pc}{ }^{\mathrm{c}}$ & \multirow{4}{*}{$\begin{array}{c}\% \text { PMTDI }=\underline{(\text { Ingestão x }} \\
\frac{100)}{\text { PMTDI }} \\
\text { Risco pode existir quando } \\
\% \text { PMTDI }>100\end{array}$} \\
\hline Fumonisinas & $\begin{array}{c}\text { Provável } \\
\text { carcinógeno } \\
\text { (Grupo 2B) }\end{array}$ & $2 \mu \mathrm{g} / \mathrm{kg} \mathrm{pc}{ }^{\mathrm{c}}$ & \\
\hline DON & $\begin{array}{c}\text { Evidências } \\
\text { inadequadas }{ }^{\text {a }} \\
(\text { Grupo 3) }\end{array}$ & $\begin{array}{c}1 \mu \mathrm{g} / \mathrm{kg} \mathrm{pc}{ }^{\mathrm{c}} \\
\mathrm{ARfD}=8 \mu \mathrm{g} / \mathrm{kg} \mathrm{pc}^{\mathrm{e}}\end{array}$ & \\
\hline $\mathrm{ZON}$ & $\begin{array}{l}\text { Evidências } \\
\text { limitadas }^{\text {a }} \\
\text { (Grupo 3) }\end{array}$ & $0,5 \mu \mathrm{g} / \mathrm{kg} \mathrm{pc}{ }^{\mathrm{f}}$ & \\
\hline
\end{tabular}

Martins et al. (2012) avaliaram a ingestão de FB1+FB2 pelo consumo de produtos de milho pela população do Paraná, encontrando um valor médio de 120,6 ng/kg (6\% do PMTDI). O nível de contaminação das amostras analisadas por Martins et al. (2012) (média FB1+FB2 = $211 \mu \mathrm{g} / \mathrm{kg}$ ) foi bem menor do que o nível encontrado nas amostras analisadas por Caldas \& Silva (2007). Um estudo publicado recentemente estimou a ingestão de FB1 no estado de São Paulo a partir do consumo de produtos de milho, e o resultado obtido representou apenas $3 \%$ do PMTDI (BORDIN et al., 2014b). Diferentemente do estudo conduzido por Caldas \& Silva (2007), Bordin et al. (2014b) estimaram a ingestão apenas para FB1 e utilizaram dados de consumo obtidos com a aplicação de questionários de frequência alimentar. Além disso, a contaminação por FB1 nos produtos analisados nesse último estudo (média de contaminação do fubá $=476,4 \mu \mathrm{g} / \mathrm{kg}$ ) é consideravelmente menor do que a encontrada no trabalho anterior (FB1+FB2) (média de contaminação do fubá = 1,68 mg/kg).

A ingestão de DON pelo consumo de pão francês e massas alimentícias foi estimada pela análise de amostras de trigo coletadas no Paraná e Rio Grande do Sul (SANTOS et al., 2011). 72,2\% ( $\mathrm{n}=36)$ das amostras de trigo analisadas estavam contaminadas, com média de $321,6 \mu \mathrm{g} / \mathrm{kg}$. A ingestão de DON representou de 25 a 36,5\% do PMTDI ( $1 \mu \mathrm{g} / \mathrm{kg})$, dependendo 
da faixa etária avaliada. Embora tenham analisado grãos de trigo, os autores realizaram estimativas para obter valores equivalentes de contaminação nos produtos processados. Uma nova avaliação da exposição de DON pelo consumo de produtos de trigo (pães e massas) foi realizada pelo mesmo grupo, porém, desta vez as amostras de trigo foram coletadas apenas no Paraná. Foram analisadas 113 amostras, sendo 66,4\% positivas para DON. A média de contaminação nas amostras foi de $1894,9 \mu \mathrm{g} / \mathrm{kg}$ e avaliação da exposição mostrou que a ingestão estimada ultrapassava a PMTDI (113\%) (SANTOS et al., 2013).

Amaral et al. (2006) avaliaram a ingestão de AFB1 pelo consumo de produtos de milho no Brasil e obtiveram um valor médio de $0,34 \mathrm{ng} / \mathrm{kg}$ pc/dia. Ao avaliar apenas a ingestão de AFs pelo consumo de fubá, o valor médio obtido foi de $0,14 \mathrm{ng} / \mathrm{kg} \mathrm{pc} / \mathrm{dia}$, variando entre 0,04 ng/kg pc/dia (população de alta renda) e $0,21 \mathrm{ng} / \mathrm{kg}$ pc/dia (população de baixa renda).

Um estudo recente realizado pelo nosso grupo de pesquisa mostrou que a ingestão calculada de aflatoxinas pela população brasileira foi maior do que a encontrada na Europa e no Japão e menor que na maioria dos países africanos (ANDRADE et al., 2013). O trabalho incluiu avaliação do resultado de análise de amostras de amendoim e seus produtos, castanha do Brasil e outras castanhas, além de algus protutos de milho (fubá, canjica, pipoca, cereais matinais, etc) e amostras de arroz. Os dados foram coletados de laudos de análsie do LACENDF e obtidos da literatura. Assim como no trabalho conduzido para avaliação da exposição de fumonisinas por Caldas \& Silva (2007), a avaliação de aflatoxinas foi avaliada tanto para os consumidores quanto para população total. A ingestão de aflatoxinas para a população total foi de 6,6-6,8 ng/kg pc/dia, alcançando 16,3-27,6 ng/kg pc/dia para os consumidores. Para a população total, o arroz representou quase $100 \%$ da ingestão diária de aflatoxinas, enquanto que para os consumidores esse valor ficou em torno de 50\%. Os autores concluíram que o arroz também deveria ser incluído no monitoramento de micotoxinas, uma vez que é a base da dieta brasileira e qualquer valor de contaminação impacta fortemente na exposição.

A exposição simultânea a AFB1, OTA e ZON pelo consumo de massas e produtos de panificação foi avaliada recentemente por Bol et al. (BOL et al., 2016). Os níveis de concentração utilizados na estimativa foram obtidos após experimentos de determinação de fatores de processamento para massas e produtos de panificação (cozimento/assamento), a partir de amostras de farinha de trigo artificialmente contaminadas (no limite máximo da legislação brasileira). As maiores reduções nas concentrações de AFB1, OTA e ZON foram obtidas na produção de bolo, respectivamente, 70, 90 e 95\%, enquanto as menores reduções foram obtidas para massas (10\% para AFB1 - 75\% para ZON). Considerando estes fatores de 
processamento, as ingestões estimadas representaram 12.6\% do PMTDI estabelecido para ZON e 30.5\% do PTWI para OTA. Para a AFB1 a margem de exposição estimada foi de 24,6.

A exposição simultânea às micotoxinas é uma questão importante e deve ser monitorada, uma vez que podem ocorrer interações entre seus efeitos. Por exemplo, a exposição simultânea à AFB1 (genotóxica) e a FB1 (promotora da carcinogênese) em ratos demonstrou o efeito sinergístico entre estas micotoxinas (GELDERBLOM et al., 2002).

Portanto, considerando a predominância destes cereais na dieta e a co-ocorrência destas micotoxinas nestes grupos de alimentos, é de extrema importância realizar um monitoramento contínuo da presença de contaminantes como aflatoxinas, ocratoxina, fumonisinas, deoxinivalenol, zearalenona e citreoviridina em cereais e derivados e gerar dados para a realização de estudos de avaliação de risco na dieta. 


\section{OBJETIVOS}

\section{Geral}

Avaliar o risco da exposição às aflatoxinas, fumonisinas, deoxinivalenol, citreoviridina, ocratoxina A e zearalenona pelo consumo de cereais e seus produtos.

\section{Objetivos específicos}

1. Avaliar a situação mundial da contaminação de cereais por aflatoxinas e conduzir uma avaliação de risco da exposição a estas micotoxinas na dieta;

2. Desenvolver e validar um método multi-micotoxinas para analisar aflatoxinas (AFB1, AFB2, AFG1, AFG2), citreoviridina, deoxinivalenol (DON, 15AcDON, 3AcDON, D3G e DOM), fumonisinas (FB1, FB2, FB3 e HFB1), ocratoxina A e zearalenona (ZON e $\alpha$-ZOL) em arroz, produtos de milho e produtos de trigo;

3. Obter padrões das fumonisinas hidrolisadas HB1, HFB2 e HFB3 e realizar a determinação de fumonisinas totais (formas livres e ligadas/ocultas) em produtos de milho;

4. Coletar e analisar amostras de arroz, produtos de milho e produtos de trigo quanto ao teor das micotoxinas em estudo;

5. Estimar a ingestão diária e conduzir uma avaliação de risco da exposição brasileira a estas micotoxinas pela dieta. 


\section{ESTRUTURA DA TESE}

Os métodos utilizados e os resultados obtidos neste trabalho serão apresentados em formato de artigo, em três capítulos distintos. O primeiro capítulo (1. Aflatoxins in cereals: worldwide occurrence and dietary risk assessment) trata dos resultados relacionados ao primeiro objetivo deste estudo e foi publicado no periódico World Mycotoxin Journal em 2015 (ANDRADE; CALDAS, 2015).

O segundo capítulo (2. Multi-mycotoxins analysis in cereals and determination of total fumonisins in maize products using isotope labeled internal standard and LC-MS/MS) traz os resultados da otimização e validação do método de análise de micotoxinas em cereais, assim como o de determinação de fumonisinas totais em produtos de milho, atendendo aos objetivos 2 e 3 deste trabalho.

O terceiro capítulo (3. Mycotoxins in cereals and derived products: occurrence and risk assessment), contempla o quarto e quinto objetivos que incluem a coleta e análise das amostras de cereais, e uma avaliação preliminar da exposição da população brasileira a estas micotoxinas pela dieta. 


\section{AFLATOXINS IN CEREALS: WORLDWIDE OCCURRENCE AND DIETARY RISK ASSESSMENT}

Este estudo foi publicado na World Mycotoxin Journal 2015; 8 (4): 415-431 (Anexo I) e os objetivos, materiais e método, resultados e conclusões estão resumidos abaixo:

Objetivos: Avaliar a situação mundial da contaminação de aflatoxinas em cereais e conduzir uma avaliação de risco da exposição a estas micotoxinas na dieta.

Materiais e métodos: A ocorrência mundial de aflatoxinas (AFB1, AFB2, AFG1 e AFG2), micotoxinas genotóxicas, foi avaliada em amostras de arroz, milho, trigo e sorgo, coletadas a partir de 2000 e disponibilizadas no banco de dados do GEMS/Food ou publicadas na literatura científica. A avaliação da exposição a aflatoxinas pela dieta foi conduzida utilizando os dados de ocorrência extraídos do banco de dados do GEMS/Food e os dados de consumo das 17 dietas Cluster. A caracterização do risco da exposição às aflatoxinas foi realizada tanto pelo cálculo do risco de câncer quanto pela determinação da margem de exposição (MOE).

Resultados e discussão: No total, foram encontradas 89 publicações, relatando análise de 18097 amostras, sendo 37,6\% positivas para pelo menos uma aflatoxina. A média de contaminação no limite superior (LS) de todas as amostras analisadas foi 13,6 $\mu \mathrm{g} / \mathrm{kg}$, sendo as mais altas para arroz $(24,6 \mu \mathrm{g} / \mathrm{kg})$ e sorgo $(25,9 \mu \mathrm{g} / \mathrm{kg})$. Com relação aos dados obtidos do banco de dados do GEMS/Food, foram encontrados resultados referentes a 4536 amostra, sendo $12,7 \%$ delas positivas para pelo menos uma aflatoxina. A média do LS para todas as amostras foi $1,9 \mu \mathrm{g} / \mathrm{kg}$, sendo maior para arroz $(2,4 \mu \mathrm{g} / \mathrm{kg})$ e milho $(1,6 \mu \mathrm{g} / \mathrm{kg})$. As ingestões totais variaram de 3,0 ng/kg pc/dia (Cluster 11) a 17,1 ng/kg pc/dia (Cluster 09). Na média, o consumo de arroz contribuiu com $41,6 \%$ da ingestão total de aflatoxinas em todos os clusters, seguido de trigo $(35,4 \%)$, milho $(21,2 \%)$ e sorgo $(1,8 \%)$. O menor valor para o risco de câncer foi encontrado no cluster 11 (0,057 cancer/ano/105 indivíduos) e o maior no cluster 09 (0,467 cancer/ano/10 5 indivíduos). A MOE variou entre 56 (cluster 11) e 10 (cluster 9), indicando um potencial risco à saúde dos consumidores.

Os resultados encontrados ressaltaram a necessidade de ações contínuas pelas autoridades de saúde, visando a diminuição da contaminação dos cereais por afaltoxinas, uma vez que estes são considerados a base de dietas do mundo todo. Essas ações incluem a adoção de códigos de prática no nível nacional e o estabelecimento de níveis máximos de contaminação de aflatoxinas em cereais pelo Codex, no âmbito internacional. 
2. ANALYSIS OF MULTI-MYCOTOXINS IN CEREALS AND DETERMINING TOTAL FUMONISINS IN MAIZE PRODUCTS USING ISOTOPE LABELED INTERNAL STANDARD AND LC-MS/MS

Patrícia Diniz Andrade, Rebecca Rodrigues Dantas, Tatiana Loureiro da Silva de MouraAlves, Eloisa Dutra Caldas.

\section{Introduction}

Mycotoxins are secondary fungi metabolites that can contaminate a wide range of foods (FRISVAD; THRANE; SAMSON, 2007), and which may lead to the development of adverse effects, both in humans and animals (NICHOLSON, 2004; PITT, 1996). The most common classes of mycotoxins are aflatoxins, trichothecenes, and especially deoxinivalenol, fumonisins, zearalenone and ochratoxin A, produced mainly by the genera Aspergillus, Penicillium and Fusarium (CAST, 2003). Their chemical structures, as well as their toxic effects, are extremely variable, mainly due to their genotoxic, immunotoxic and nephrotoxic properties (BRERA et al., 2008; NICHOLSON, 2004). Cereals are staple foods in diets around the world, and can be a major source of dietary exposure to mycotoxins (ANDRADE; CALDAS, 2015; FAO, 2014; FRISVAD; THRANE; SAMSON, 2007). Small grains, such as rice and wheat, are susceptible to deoxynivalenol, ochratoxin A and zearalenone contamination, and fumonisins are the main mycotoxins found in maize and maize products (PITT et al., 2012).

In addition to the parental forms, food can also contain derivative/trasnformed compounds produced during food processing or as a result of plant/animal metabolism (RYCHLIK et al., 2014). For instance, fumonisins can covalently bind to matrix macroconstituents during food thermal processing (e.g., linkage between fumonisin tricarboxylic acids - TCA and starch, or proteins; Figure 1) (HUMPF; VOSS, 2004; SEEFELDER; KNECHT; HUMPF, 2003; SHIER et al., 2000). The bound-fumonisins are not detected by common analytical methods, which may lead fumonisin levels in food to be underestimated (DALL'ASTA et al., 2009a). The bound-fumonisin link can be broken under alkaline conditions, such as in nixtamalization processes (e.g. production of tortillas), releasing the hydrolyzed forms (HFB1; Figure 1) that can be analyzed by routine methods (FALAVIGNA et al., 2012; SEEFELDER; KNECHT; HUMPF, 2003). Fumonisins can also be linked to matrix macroconstituents that are not submitted to a heat treatment by an associative mechanism 
which, in this case, are known as hidden fumonisins or non-covalently bound fumonisins (DALL'ASTA et al., 2009a) .

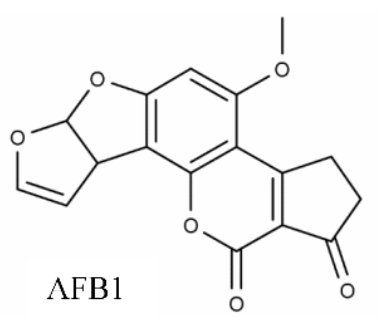<smiles>CCCCC(C)C(OC(=O)CC(CC(=O)O)C(=O)O)C(CC(C)CC(O)CCCCC(O)CC(O)C(C)N)OC(=O)CC(CC(=O)O)C(=O)O</smiles><smiles>COc1cc2c(c3oc(=O)c4c(c13)CCOC4=O)C1C=COC1O2</smiles><smiles>CCCCC(C)[C@H](O)[C@H](O)C[C@@H](C)C[C@@H](O)CCCC[C@H](O)C[C@@H](O)[C@H](C)N</smiles><smiles>CC1Cc2c(Cl)cc(C(=O)NC(Cc3ccccc3)C(=O)O)c(O)c2C(=O)O1</smiles><smiles></smiles>

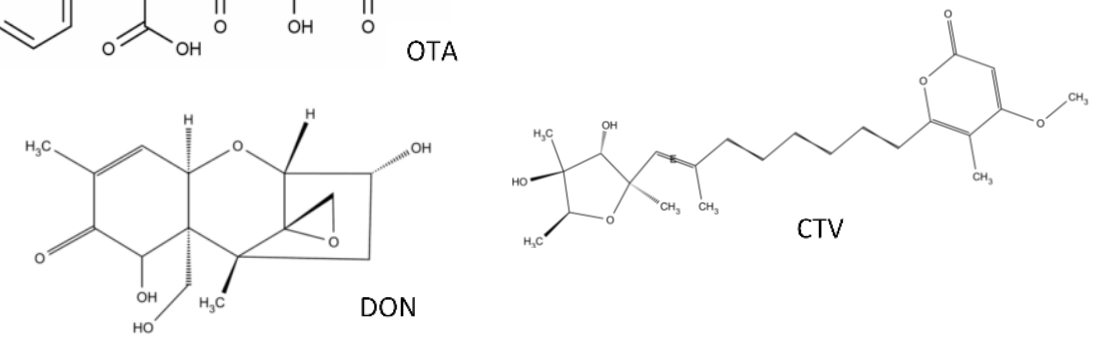

Figure 1 - Chemical structures of AFB1, AFG1, OTA, DON, FB1, HFB1, ZON and CTV, some of the mycotoxins evaluated in this study.

In general, methods used to analyze mycotoxins are based on extraction with organic solvents, clean-up (solid phase extraction, immunoaffinity columns), and followed by concentration/dilution steps (ALMEIDA et al., 2012; CAPRIOTTI et al., 2010; FRENICH et al., 2009; LIAO et al., 2013; SULYOK; KRSKA; SCHUHMACHER, 2007). Detection methods include HPLC-FD or UV, GC-FID, and LC-MS or MS/MS (ALMEIDA et al., 2012; DORS; BIERHALS; BADIALE-FURLONG, 2011; KAWASHIMA; VALENTE SOARES, 2006; SULYOK; KRSKA; SCHUHMACHER, 2007; TRAN; SMITH; GIRGIS, 2012).

Matrix matched calibration, internal calibration and sample dilution are procedures commonly used to compensate matrix effects observed in LC-MS/MS analyses (VARGA et al., 2012). The use of isotope labeled internal standards seems to be the best tool to cope with matrix effects and ensure reliable results. However, the high costs and limited availability of 
isotopically labeled internal standards restrict its application (MALACHOVÁ et al., 2014). Stable isotope dilution in mycotoxin analyses has been reviewed by Rychlik and Asam (2008), and successfully applied by several researchers (ASAM; RYCHLIK, 2007; HÄUBL et al., 2006; LIAO et al., 2013; VARGA et al., 2012).

The aim of this study was to optimize and validate a method for the simultaneous analysis of aflatoxins (AFB1, AFB2, AFG1 and AFG2), citreoviridin (CTV), deoxynivalenol (DON), 15-acetyldeoxynivalenol (15AcDON), 3-acetyldeoxynivalenol (3AcDON), deoxynivalenol-3-glucoside (D3G), deepoxydeoxynivalenol (DOM), fumonisins (FB1, FB2 and FB3) and their hydrolyzed forms (HFB1, HFB2 and HFB3), ochratoxin A (OTA), zearalenone $(\mathrm{ZON})$ and alfa-zearalenol $(\alpha-\mathrm{ZOL})$ in maize, rice and wheat-derived products, using isotope labeled internal standards, and LC-MS/MS.

\section{Materials and method}

\subsection{Chemicals and reagents}

HPLC-grade acetonitrile (ACN), ethyl acetate (AcOEt) and methanol $(\mathrm{MeOH})$ were purchased from Merck (Darmstadt, Germany); HPLC-grade toluene was obtained from Mallinckrodt Baker (Phillipsburg, USA); formic acid from Sigma-Aldrich (St. Louis, MO, USA); acetic acid from J.T Baker (Phillipsburg, USA); ammonium formate and ammonium acetate from Fluka (Buchs, Switzerland); anhydrous sodium sulphate, potassium hydroxide $(\mathrm{KOH})$ and hydrochloric acid $(\mathrm{HCl})$ from Vetec (Rio de Janeiro, Brazil); ultrapure water obtained through a Milli-Q purification system, and the syringe filters used were Millex ${ }^{\mathrm{TM}}$, both from Millipore (Millipore, Bedford, MA, USA).

Standards of AFB1 (99.0\%), AFB2 (99.0\%), AFG1 (99.0\%), AFG2 (99.5\%) and d1DON (97.5\%) were purchased from Sigma-Aldrich (St. Louis, MO, USA). CTV (97.0\%) was acquired from Enzo Life Sciences International Inc. (Farmingdale, NY, USA). 15AcDON (98.8\%), 3AcDON (99.4\%), D3G (96.0\%), DOM (98.0\%), DON (99.4\%), FB1 (97.6\%), FB2 (99.0\%), FB3 (98.5\%), HFB1 (98.4\%), ZON (99.4\%), $\alpha$-ZOL (98.7\%), $\left({ }^{13} \mathrm{C}_{17}\right)$-AFB1 (99.0\%), $\left({ }^{13} \mathrm{C}_{17}\right)$-AFG1 (99.0\%), $\left({ }^{13} \mathrm{C}_{18}\right)$-ZON $(99.2 \%),\left({ }^{13} \mathrm{C}_{20}\right)$-OTA $(98.7 \%)$ and $\left({ }^{13} \mathrm{C}_{34}\right)$-FB1 $(97.8 \%)$ were obtained from Biopure (Tulin, Austria). Stock solutions of aflatoxins were prepared in toluene-ACN (9:1), of CVT in ethyl acetate, of OTA in toluene-acetic acid (99:1), and of fumonisins in $\mathrm{ACN}$-water (50:50). Stock solutions of the remaining compounds were prepared in ACN. Concentrations of aflatoxins, OTA, ZON, DON, 3AcDON, 15AcDON and CTV solutions were checked monthly, using UV spectrophotometry. Wavelength and molar 
absorptivity used to check mycotoxins concentration are shown in Table 1 (MAPA, 2011). Parameters for 3AcDON and 15AcDON were obtained from Krska et al (2007), and for CTV from Rocha, Resck and Caldas (2015). Solutions were considered valid when a maximum of $3 \%$ variation was estimated in relation to the first check (MAPA, 2011).

Table 1 - Parameters used to check mycotoxins concentration.

\begin{tabular}{cccccc}
\hline Mycotoxin & $\begin{array}{c}\text { Molecular } \\
\text { weight }\end{array}$ & $\begin{array}{c}\text { Concentration } \\
(\boldsymbol{\mu g} / \mathbf{m L})\end{array}$ & Solvent & Wavelength & $\begin{array}{c}\text { Molar } \\
\text { absorptivity }\end{array}$ \\
\hline 15AcDON & 338.5 & 50 & ACN & 218.8 & 7033 \\
3AcDON & 338.3 & 50 & ACN & 219.8 & 7108 \\
AFB1 & 312.2 & $8-10$ & $\begin{array}{c}\text { TOL:ACN } \\
(9: 1)\end{array}$ & 350 & 19300 \\
AFB2 & 314.3 & $8-10$ & $\begin{array}{c}\text { TOL:ACN } \\
(9: 1)\end{array}$ & 350 & 21000 \\
AFG1 & 328.3 & $8-10$ & $\begin{array}{c}\text { TOL:ACN } \\
(9: 1)\end{array}$ & 350 & 16400 \\
AFG2 & 330.3 & $8-10$ & $\begin{array}{c}\text { TOL:ACN } \\
(9: 1)\end{array}$ & 350 & 18300 \\
CTV & 402.5 & $1-15$ & $\begin{array}{c}\text { MeOH } \\
\text { ACN }\end{array}$ & 294 & 21959 \\
DON & 296.6 & 50 & TOL:AcOH & 333 & 6400 \\
OTA & 403.8 & 40 & $(99: 1)$ & 208 & 5440 \\
ZON & 318.3 & 50 & MeOH & 274 & 13900 \\
\hline
\end{tabular}

Adapted from MAPA (2011). ACN: acetonitrile; TOL: toluene; $\mathrm{MeOH}$ : methanol; AcOH: acetic acid.

Maize multi-mycotoxin reference material TR-MT100 (MTC-9999E) containing aflatoxins, fumonisins, DON, OTA and ZON was purchased from Trilogy Analytical Laboratory (Washington, MO, USA).

\subsection{LC-MS/MS conditions}

LC-MS/MS analysis was performed using a Shimadzu LC system (Shimadzu, Kyoto, Japan) coupled to a 4000 Qtrap triple-quadrupole mass spectrometer (Sciex, Framingham, MA, USA), fitted with a Turbo Ion Spray electrospray ionization (ESI) source. System operation and data acquisition were controlled by Analyst ${ }^{\circledR}$ (V 1.5.2) software (Sciex).

The analyte-dependent MS/MS parameters were optimized by direct infusion of mycotoxin solutions $\left(200-800 \mathrm{ng} / \mathrm{mL}\right.$; dissolved in $\mathrm{MeOH} / \mathrm{H}_{2} \mathrm{O}$, containing the selected additive) into the mass spectrometer, at a flow rate of $10 \mu \mathrm{L} / \mathrm{min}$. The best mobile phase additive was chosen after testing the effects of acetic acid (0.1\%), formic acid (0.1\%), ammonium formate $(5 \mathrm{mM})$ or ammonium acetate $(5 \mathrm{mM})$ in the preparation of aflatoxins, fumonisins, OTA, 
CTV, HFB1, DON, 3AcDON, 15AcDON, DOM, D3G and ZON solutions. The additive that gave the best ionization results was also tested in different concentrations. ESI-MS/MS was performed in the multiple reaction monitoring (MRM) mode, and both positive and negative polarities were evaluated. Declustering potential (DP), collision energy (CE) and collision cell exit potential (CXP) were optimized for the three most abundant transitions for each analyte. In most cases, the two most abundant transitions were used in the method (quantifier and qualifier).

Ion source parameters were automatically optimized using flow injection analysis of 80 $\mathrm{ng} / \mathrm{mL}$ D3G standard solution $(0.8 \mathrm{~mL} / \mathrm{min})$, which was the less sensitive compound in the preliminary tests. The optimal conditions of the mass spectrometer ion source were: entrance potential at $10 \mathrm{~V}$, ion source at $500^{\circ} \mathrm{C}$, ion source gas 1 and 2 at 50 (GS1) and 40 psi (GS2), ion spray voltage at $5500 \mathrm{~V}$, curtain gas at $12 \mathrm{psi}$, and collision gas at medium.

Chromatographic separation was performed with a Gemini C18 analytical column $(150 \times 4.6 \mathrm{~mm}, 5 \mu \mathrm{m})$ preceded by a C18 security guard cartridge $(4.0 \times 3.0 \mathrm{~mm}, 5 \mu \mathrm{m})$, both from Phenomenex ${ }^{\circledR}$ (Torrance, CA, USA). The column was kept at $40^{\circ} \mathrm{C}$ and a flow rate of 0.8 $\mathrm{mL} / \mathrm{min}$ was used. The mobile phase consisted of a gradient of water (A) and methanol (B), both with the additive chosen in the analyte-dependent MS/MS parameters optimization procedure. The gradient started at $40 \% \mathrm{~B}$; held for $1 \mathrm{~min}$; increased to $86 \% \mathrm{~B}$ in $11 \mathrm{~min}$, held for $2 \mathrm{~min}$; increased to $95 \% \mathrm{~B}$ in $2 \mathrm{~min}$ and held for $4 \mathrm{~min}$. The system was equilibrated at the initial condition for 6 min between consecutive runs.

\subsection{Multi-mycotoxin extraction optimization}

Rice, maize meal and wheat flour were used as model matrix during the development and validation of the analysis procedure, and were obtained at retail stores in Brasília (Federal District). Cereals samples were quartered, ground (blender), homogenized, and sieved (18 mesh) to ensure the uniformity of processing. The homogenized samples were then transferred to polyethylene bags and stored at room temperature for further use. The analytical procedure was based on a solid-liquid extraction (SLE) using an ultrasonic bath, followed by centrifugation and filtration prior to injection, as described below. Five grams of the homogenized samples were weighted into a $50 \mathrm{~mL}$ falcon tube, and $20 \mathrm{~mL}$ of a solvent mixture were added. The mixture was agitated for 20 s (vortex), submitted to the ultrasonic bath for 15 min, and centrifuged at $3500 \mathrm{rpm} / 10 \mathrm{~min} / 18^{\circ} \mathrm{C} .1 \mathrm{~mL}$ of supernatant was evaporated (Centrivap 
Vacuum Concentrator System - LABCONCO/Germany), redissolved in 1mL methanol:water (40:60), and filtered through a syringe filter $(0.45 \mu \mathrm{m})$ before injection in the LC-MS/MS.

When isotope labeled internal standards were used, an aliquot of $180 \mu \mathrm{L}$ of the extract was transferred to an insert and combined with $20 \mu \mathrm{L}$ of the internal standard working solutions, at the following concentrations: $\left({ }^{13} \mathrm{C}_{17}\right)-\mathrm{AFB} 1=25.7 \mathrm{ng} / \mathrm{mL},\left({ }^{13} \mathrm{C}_{17}\right)-\mathrm{AFG} 1=25.9 \mathrm{ng} / \mathrm{mL}$, $\left({ }^{13} \mathrm{C}_{18}\right)-\mathrm{ZON}=2 \mu \mathrm{g} / \mathrm{mL},\left({ }^{13} \mathrm{C}_{20}\right)-\mathrm{OTA}=414 \mathrm{ng} / \mathrm{mL},\left({ }^{13} \mathrm{C}_{34}\right)-\mathrm{FB} 1=753 \mathrm{ng} / \mathrm{mL}$ and $\mathrm{d} 1-\mathrm{DON}=5$ $\mu \mathrm{g} / \mathrm{mL}$. Isotope dilution assay was used for internal calibration for all mycotoxins, except CTV (no isotope available). $\left({ }^{13} \mathrm{C}_{17}\right)$-AFB1 was used for quantification of AFB1 and AFB2; $\left({ }^{13} \mathrm{C}_{17}\right)$ AFG1 for AFG1 and AFG2; $\left({ }^{13} \mathrm{C}_{18}\right)$-ZON for ZON and $\alpha$-ZOL; $\left({ }^{13} \mathrm{C}_{20}\right)$-OTA for OTA; $\left({ }^{13} \mathrm{C}_{34}\right)$ FB1 for fumonisins and their hydrolyzed forms; d1-DON for D3G, DON, DOM, 15AcDON and $3 \mathrm{AcDON}$.

In order to select the best solvent mixture for the extraction procedure, three different compositions were tested: $\mathrm{A}=\mathrm{ACN}: \mathrm{H} 20$ (80:20 0.1\% formic acid), $\mathrm{B}=\mathrm{ACN}: \mathrm{H} 20$ (80:20), and $\mathrm{C}=\mathrm{MeOH}: \mathrm{H} 20$ (80:20). The SLE procedure was tested for maize meal, rice and wheat flour. Recovery tests were carried out in triplicate, for each solvent composition, at concentrations ranging from $2.2 \mu \mathrm{g} / \mathrm{kg}$ (AFB1, AFG1) to $224 \mu \mathrm{g} / \mathrm{kg}$ (15AcDON, 3AcDON). Matrix matched standard curves were prepared at concentrations between 0.96 and $1600 \mu \mathrm{g} / \mathrm{kg}$. The optimized method was submitted to validation.

\subsection{Multi-mycotoxin method validation}

For method validation, the extraction procedure was miniaturized, using $0.5 \mathrm{~g}$ of sample and the same sample/solvent ratio $(1 \mathrm{~g} / 4 \mathrm{~mL})$. Selectivity was evaluated by analyzing the LCMS/MS chromatograms of blank and fortified cereal samples, checking for interferences eluting at the same retention time as the mycotoxins of interest. Matrix effect was evaluated for each analyte at five different concentrations, six replicates at each level, using both internal and external calibration; \% matrix effect in each case was estimated by the ratio between the average instrument response (areas) of matrix matched standards and neat solution standards. Signal suppression/enhancement above $\pm 20 \%$ was considered a significant matrix effect.

Linearity was checked by analyzing the same set of samples used in the matrix effect evaluation. The linear parameters of the regression were estimated by the ordinary least squares method, the presence of outliers verified by the Grubbs test, the homogeneity of variances by Cochran test, and the coefficient of determination $\left(\mathrm{R}^{2}\right)$ and significance of the regression obtained using ANOVA. For heterocedastic data, different weighting factors were tested (1/x, 
$1 / \mathrm{x}^{2}, 1 / \mathrm{y}, 1 / \mathrm{y}^{2}, \ln \mathrm{x}$ and $\left.\ln \mathrm{y}\right)$ and the one that produced the lowest sum of relative errors was chosen for the regression. Calibration curves (five points) ranged from LOQ to 5xLOQ for D3G and $\alpha$-ZOL, from LOQ to 10xLOQ for DOM, FB3 and HFB1, and from LOQ to up 100xLOQ for 15AcDON, 3AcDON, AFB1, AFB2, AFG1, AFG2, CTV, DON, FB1, FB2, OTA and ZON. For isotope internal calibration, weighted/ordinary calibration curves were obtained for each analyte by plotting the compound concentrations versus the relative areas, which was the ratio between the analyte peak area and the corresponding isotope internal standard peak area.

Recoveries of the analytes in each matrix were evaluated by fortifying the samples at 5 different levels ( $n=3-6$ at each level) and comparing the areas of the spiked samples and the area of the matrix matched external standards, expressed as \%. The experiment was performed on the same day by the same analyst. For isotope internal calibration, recoveries were obtained by comparing relative areas of the spiked samples with relative areas of the matrix matched set, also expressed as \%. Repeatability was expressed as the relative standard deviations $\left(\% \mathrm{RSD}_{\mathrm{r}}\right.$, $\mathrm{n}=3-6$; each level). Intermediate precision was evaluated by analysis of samples fortified at five concentration levels, by the same analyst, on different days $\left(\% \mathrm{RSD}_{\mathrm{p}}, \mathrm{n}=3-6\right.$ each level; two days).

Trueness was evaluated by analyzing five replicates of the TR-MT100 multi-mycotoxin maize reference material. For each mycotoxin, the LOQ was defined as the lowest level for which the method was satisfactorily validated (recovery between 80 and $120 \%$ and $\mathrm{RSD}_{\mathrm{r}} \leq 20 \%$ and $\mathrm{RSD}_{\mathrm{p}} \leq 25 \%$ ). All replicates used for validation were prepared from independent working solutions. Spiked samples were left for 2 days at room temperature in the fumehood, protected from light, to allow solvent evaporation and analyte-sample equilibration.

\subsection{Hydrolyzed fumonisin preparation}

Since standards of hydrolyzed fumonisin B2 and B3 were not commercially available, they were prepared from pure fumonisins standards, based on the procedure of Dall'Asta et al. (2009b). Solutions of FB1, FB2 and FB3 were evaporated to dryness (Centrivap Vacuum Concentrator System - LABCONCO/Germany), redissolved in $\mathrm{KOH} 2 \mathrm{M}(1 \mathrm{~mL} / 50 \mu \mathrm{g}$ standard) and allowed to react in a thermal bath $\left(60^{\circ} \mathrm{C}\right)$ under constant agitation, during $0,15,30,60,120$ and $180 \mathrm{~min}$. After hydrolysis, the mixture was extracted three times with acetonitrile ( $1 \mathrm{~mL} / 50 \mu \mathrm{g}$ standard), agitated (vortex), and then centrifuged $\left(1500 \mathrm{rpm}, 15^{\circ} \mathrm{C}, 5 \mathrm{~min}\right)$. Organic phases were pooled, evaporated, redissolved in $\mathrm{ACN}: \mathrm{H}_{2} \mathrm{O}$ (50:50), filtered through a syringe 
filter $(0.45 \mu \mathrm{m})$, and injected in the LC-MS/MS to determine the yield of the reaction. The optimizing experiments were conducted in triplicate.

\subsection{Total fumonisin extraction procedure}

Total fumonisins concentrations were obtained by determining both free and bound/hidden fumonisin forms. Free fumonisins were extracted with the multi-mycotoxin procedure, described in Section 2.3. Bound/hidden forms were then obtained with the hydrolysis procedure described below, and determined as the hydrolyzed fumonisins (HFB1, HFB2 and HFB3). The hydrolysed forms were converted to FB1, FB2 and FB3 using molar mass ratios.

After the multi-mycotoxin extraction procedure, cereal solid residues were completely dried in the lyophilizer (Liobras/K105). A procedure based on the work of Dall'Asta et al. (2009b) was tested. In summary, $10 \mathrm{~mL} \mathrm{KOH} \mathrm{(2M)} \mathrm{was} \mathrm{added} \mathrm{under} \mathrm{stirring} \mathrm{(vortex)} \mathrm{to} 1 \mathrm{~g}$ of the residues, kept at $60^{\circ} \mathrm{C}$ under agitation for $60 \mathrm{~min}$, the mixture extracted three times with 10 $\mathrm{mL}$ of $\mathrm{ACN}$, vortex, centrifuged $\left(1500 \mathrm{rpm}, 15^{\circ} \mathrm{C}, 5 \mathrm{~min}\right)$ and the organic phases pooled and evaporated to dryness (Centrivap Vacuum Concentrator System - LABCONCO/Germany) for LC-MS/MS analysis. However, this procedure required a long time to evaporate the organic phase, which still contains some aqueous basic solution, and yielded low recoveries $(<50 \%$ for most analytes; data not shown).

In order to improve the extraction procedure, solid-liquid extraction with low temperature purification was used (SLE-LTP). After the hydrolysis step, $10 \mathrm{~mL}$ of ACN was added, the $\mathrm{pH}$ adjusted to $3.0 \pm 0.5$, tubes were taken to sonication for $15 \mathrm{~min}$, centrifuged $\left(3500 \mathrm{rpm} / 5 \mathrm{~min} / 12^{\circ} \mathrm{C}\right)$, and left in the freezer $\left(-18^{\circ} \mathrm{C}\right)$ for $12 \mathrm{~h}$. The liquid supernatant (organic phase) was filtered in anhydrous sodium sulfate and the extract evaporated under a vacuum concentrator system (Centrivap - LABCONCO/Germany). The residues were dissolved in 1 $\mathrm{mL} \mathrm{MeOH}: \mathrm{H}_{2} \mathrm{O}$ (40:60), filtered through a syringe filter $(0.45 \mu \mathrm{m})$, and injected in the LCMS/MS.

\section{Results and discussion}

\subsection{Optimization of LC-MS/MS}

Direct infusion of mycotoxins solutions in positive mode showed sufficient formation of the ammonium adducts $\left[\mathrm{M}+\mathrm{NH}_{4}\right]^{+}$for $15 \mathrm{AcDON}(5 \mathrm{mM}$ ammonium formate and $5 \mathrm{mM}$ ammonium acetate), DOM (5mM ammonium formate), D3G (5mM ammonium formate) and 
HFB1 (5mM ammonium formate). However, except for D3G, intensities were lower than those obtained for the protonated adducts $[\mathrm{M}+\mathrm{H}]^{+}$.

In the negative mode, only $3 \mathrm{AcDON}, \mathrm{DOM}, \mathrm{DON}$ and D3G yielded good responses when using $5 \mathrm{mM}$ ammonium acetate, while ZON was successfully ionized using all four additives tested. The formation of the acetate adduct was only observed for 3AcDON, DOM and DON. Responses of all product ions formed in negative mode were significantly lower than in positive mode using the same additives. These results agree with Boevre et al. (2012), who also observed better ionization results for DON, D3G, 3AcDON, 15AcDON, ZON, $\alpha-Z O L$ and DOM in positive mode. However, other studies reported higher ionization in negative mode, mainly for ZON (BELTRÁN et al., 2013; BERTHILLER et al., 2005; CAPRIOTTI et al., 2010; VARGA et al., 2012). Considering the overall intensities obtained in both polarities for all analytes, positive mode was chosen for the LC-MS/MS multi-mycotoxin method.

Figure 2 shows the responses obtained in positive mode for the two most intense transitions for each analyte, and the additive used in the mobile phase. Higher intensities were observed for all compounds using ammonium acetate, except for fumonisins, the major mycotoxin in maize products. Overall, the use of ammonium formate as additive produced reasonable responses for all analytes, and was selected by this study. Additionally, $0.1 \%$ formic acid was added to the mobile phase to improve the chromatography of fumonisins (CAVALIERE et al., 2005; SORENSEN; ELBAK, 2005; SULYOK et al., 2006).

The effect of different concentrations of ammonium formate in the analyte response was also evaluated. Mycotoxins solutions (AFB1, CTV, OTA, DON, FB1 and ZON) containing 0.1 $\%$ formic acid and $0.1,0.25,0.5,1$ and $5 \mathrm{mM}$ ammonium formate were infused into the mass spectrometer and ionization enhancement or suppression observed. Results showed that $5 \mathrm{mM}$ ammonium formate caused ionization suppression for all analytes, except AFB1, and $1 \mathrm{mM}$ ammonium formate gave the best overall results (data not shown).

Table 2 summarizes the optimized $\mathrm{ESI}^{+}$parameters for the mycotoxins and isotope internal standards obtained by direct infusion of the analyte solutions diluted in $\mathrm{MeOH}: \mathrm{H}_{2} 0$ (50:50), containing $0.1 \%$ formic acid and $1 \mathrm{mM}$ ammonium formate. For all analytes, the protonated forms $[\mathrm{M}+\mathrm{H}]^{+}$were monitored, except for $\mathrm{D} 3 \mathrm{G}$, for which the ammonium adduct $\left[\mathrm{M}+\mathrm{NH}_{4}\right]^{+}$was selected. The DON acetylated isomers (15AcDON and 3AcDON) coeluted under the chromatographic conditions used. Acetonitrile and methanol, both containing $0.1 \%$ formic acid and $1 \mathrm{mM}$ ammonium formate, were also tested as the organic component of the mobile phase. Although acetonitrile increased sensitivity for most compounds (aflatoxins, 
OTA, fumonisins), the presence of methanol was essential to improve the peak shapes of DON and its derivatives. Tests with different injection volumes (10 to $100 \mu \mathrm{L}, \mathrm{n}=5$ in each case) showed that peak areas increased proportionally with injection volumes up to $50 \mu \mathrm{L}$ and, from this point on, peak width began to increase. Thus, as a compromise between sensitivity and peak integration quality, $25 \mu \mathrm{L}$ was selected as injection volume.

\subsection{Multi-mycotoxin analysis - optimization and method validation}

In the optimization of the extraction procedure, the best results were obtained using acidified ACN as the extraction solvent, and was chosen for the validation procedures (data not shown). The chromatograms of blanks did not show any interfering peaks eluting in the same retention times of the analytes under evaluation, indicating satisfactory selectivity of the method. Validation results are shown in Tables 3 to 5. For maize meal (Table 3), matrix effects using external calibration showed ion suppression of over $30 \%$ for seven analytes, including aflatoxins (27.8 to $45.1 \%$ matrix effect), and a large ion enhancement for HFB1 (170.8\%) (Table 3). For the isotope internal standard, matrix effects were in the range of 76 to $122 \%$ for all analytes, except for HFB1 (141.4\%). The behavior of the residues of the analytical curves obtained by the least squares method showed heteroscedasticity $\left(\mathrm{C}_{\text {calculated }}<\mathrm{C}_{\text {critical }}\right.$ 5;6$)$ for all mycotoxins, except D3G and $\alpha$-ZOL (homoscedastic, ordinary least squares adjustment). For the heteroscedastic compounds, the best weighting factors found were 1/y (15AcDON and ZON), 1/x (3AcDON, DOM, DON, FB1 and FB3) and 1/x² (AFB1, AFB2, AFG1, AFG2, CTV, FB2, HFB1 and OTA). Coefficients of determination $\left(\mathrm{R}^{2}\right)$ were higher than 0.98 , regressions were significant $(\mathrm{p}<0.05)$, and there was no lack-of-fit for the regressions used in calibration procedures (data not shown). 

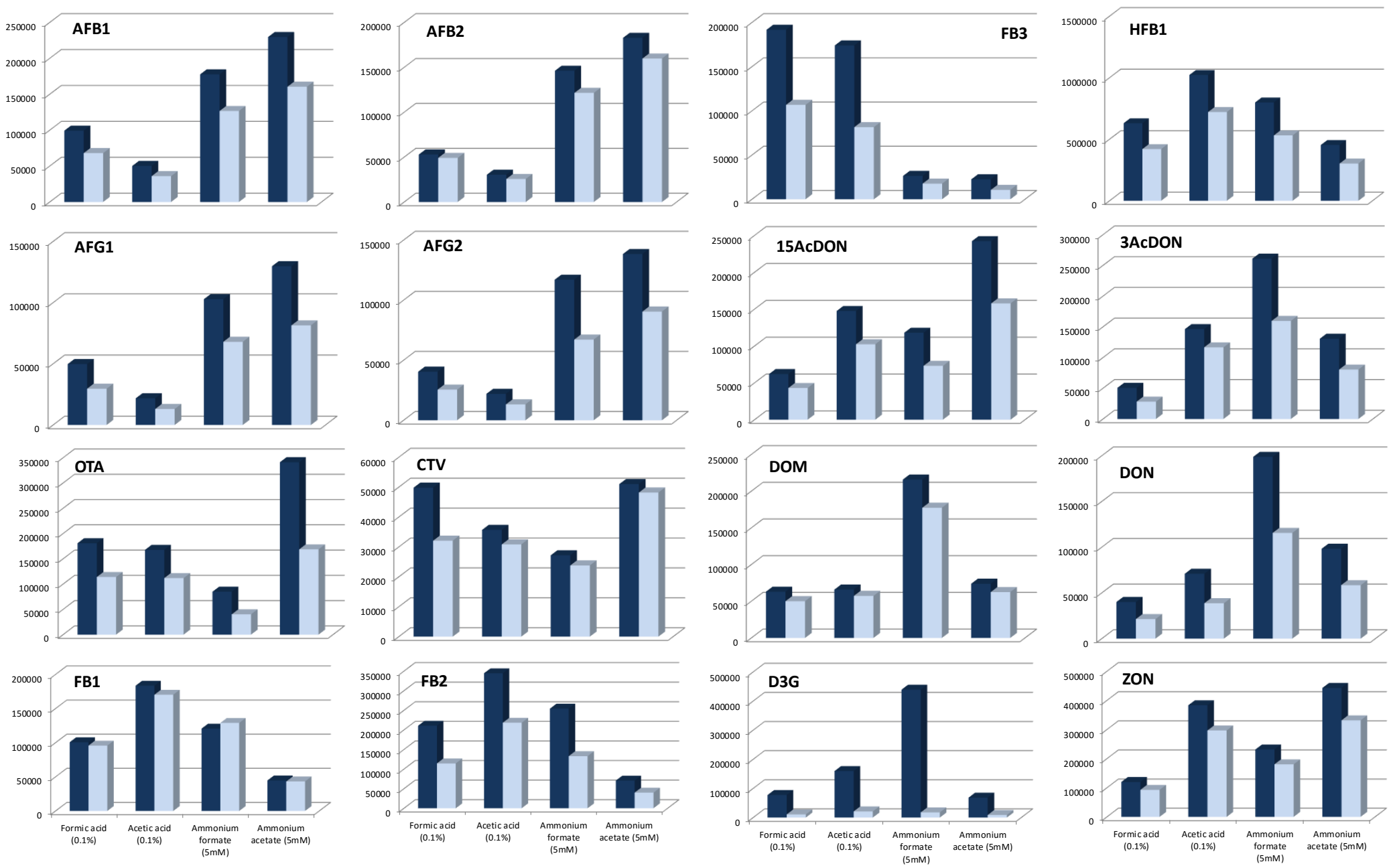

Figure 2 - Intensity of selected transitions (quantifier and qualifier) after direct infusion into the mass spectrometer using different additives (0.1\% Formic acid; $0.1 \%$ Acetic acid; $5 \mathrm{mM}$ Ammonium formate; $5 \mathrm{mM}$ Ammonium acetate). 
Table 2 - Optimized ESI ${ }^{+}$- MS/MS parameters and chromatographic retention times used for the multi-mycotoxin LC-MS/MS analysis of cereals and derived products.

\begin{tabular}{|c|c|c|c|c|c|c|c|c|c|}
\hline Analyte & $\begin{array}{l}\text { Precursor } \\
\text { ion }\end{array}$ & $\begin{array}{l}\text { DP } \\
(\mathbf{V})\end{array}$ & & $\begin{array}{l}\text { ansit } \\
(m / z)\end{array}$ & ion & $\begin{array}{l}\text { CE } \\
\text { (V) }\end{array}$ & $\begin{array}{c}\text { CXP } \\
(\mathbf{V})\end{array}$ & $\begin{array}{c}\text { Retention } \\
\text { time (min) }\end{array}$ & $\begin{array}{c}\text { Ion ratio } \\
\text { (RSD; \%) }\end{array}$ \\
\hline \multirow{2}{*}{$\left({ }^{13} C_{17}\right)-A F B 1$} & \multirow{2}{*}[\mathrm{M}+\mathrm{H}]{$^{+}$} & \multirow{2}{*}{86} & \multirow{2}{*}{330} & $\rightarrow$ & 301 & 35 & 22 & \multirow{2}{*}{8.0} & \multirow{2}{*}{$1.6(5.2)$} \\
\hline & & & & & 251 & 55 & 18 & & \\
\hline \multirow{2}{*}{ AFB1 } & \multirow{2}{*}[\mathrm{M}+\mathrm{H}]{$^{+}$} & \multirow{2}{*}{96} & \multirow{2}{*}{313} & & 285 & 33 & 22 & \multirow{2}{*}{8.0} & \multirow{2}{*}{$1.5(0.1)$} \\
\hline & & & & & 241 & 53 & 18 & & \\
\hline \multirow{2}{*}{ AFB2 } & \multirow{2}{*}[\mathrm{M}+\mathrm{H}]{$^{+}$} & \multirow{2}{*}{111} & \multirow{2}{*}{315} & & 287 & 37 & 22 & \multirow{2}{*}{7.5} & \multirow{2}{*}{$1.3(11.2)$} \\
\hline & & & & & 259 & 41 & 20 & & \\
\hline \multirow{2}{*}{$\left({ }^{13} C_{17}\right)$-AFG1 } & \multirow{2}{*}[\mathrm{M}+\mathrm{H}]{$^{+}$} & \multirow{2}{*}{81} & \multirow{2}{*}{346} & & 257 & 39 & 18 & \multirow{2}{*}{6.9} & $17(88)$ \\
\hline & & & & & 212 & 57 & 14 & & $1.1(8.8)$ \\
\hline FC1 & {$\left[\mathrm{M} \perp \mathrm{HI}^{+}\right.$} & 06 & 220 & & 243 & 39 & 18 & 60 & $13(105)$ \\
\hline AFGI & {$[\mathrm{M}+\mathrm{H}]$} & 90 & 329 & $\rightarrow$ & 311 & 31 & 24 & 0.9 & $1.3(10.5)$ \\
\hline AFG? & {$[\mathrm{M}+\mathrm{H}]^{+}$} & 01 & 331 & & 313 & 35 & 24 & & 17 (10 \\
\hline AFG2 & {$[\mathrm{M}+\mathrm{H}]^{-}$} & 91 & 331 & $\rightarrow$ & 245 & 43 & 18 & 0.3 & $1.1(10.2)$ \\
\hline CTV & {$[\mathrm{M}+\mathrm{H}]^{+}$} & 71 & 403 & $\rightarrow$ & 315 & 13 & 10 & 124 & $14(187)$ \\
\hline & & $/ 1$ & 403 & $\rightarrow$ & 139 & 33 & 10 & 12.4 & $1.4(18.1)$ \\
\hline d1-DON & {$[\mathrm{M}+\mathrm{H}]^{+}$} & 56 & 298 & & 249 & 15 & 18 & & $20(97)$ \\
\hline & & & 298 & & 203 & 23 & 14 & 3.4 & \\
\hline DON & {$[\mathrm{M}+\mathrm{H}]^{+}$} & 76 & 297 & $\rightarrow$ & 249 & 17 & 20 & 34 & $20(104)$ \\
\hline DON & {$[\mathbf{I} \mathbf{1}+\mathbf{H}]$} & 10 & 291 & & 203 & 23 & 16 & 3.4 & $2.0(10.4)$ \\
\hline 15AcDON & {$[\mathrm{M}+\mathrm{H}]^{+}$} & 81 & 339 & & 321 & 13 & 10 & 56 & $10(68)$ \\
\hline 15ACDUN & {$[\mathrm{M}+\mathrm{H}]$} & 81 & 339 & & 137 & 17 & 10 & 5.0 & $1.9(0.8)$ \\
\hline $34 \mathrm{cDON}$ & & 71 & 330 & & 231 & 17 & 18 & 57 & $18(58)$ \\
\hline 3ACDON & {$[\mathrm{M}+\mathrm{H}]^{\top}$} & 71 & 339 & & 203 & 23 & 16 & 5.7 & $1.8(5.8)$ \\
\hline D3G & {$\left[\mathrm{M}+\mathrm{NH}_{4}\right]^{+}$} & 41 & 476 & & 297 & 19 & 26 & 30 & $18(122)$ \\
\hline DSU & [IVI+NH4] & 41 & & $\rightarrow$ & 459 & 11 & 16 & 5.0 & $1.0(12.2)$ \\
\hline DOM & {$\left[\mathrm{M}+\mathrm{H}^{+}\right.$} & 66 & 281 & & 233 & 17 & 18 & 45 & $12(118)$ \\
\hline DUM & & 00 & 281 & $\rightarrow$ & 215 & 19 & 14 & 4.5 & $1.2(11.8)$ \\
\hline$\left({ }^{13} \mathrm{C}_{2}\right)-\mathrm{FB} 1$ & $\mathrm{CM}+\mathrm{H}^{+}$ & 106 & 756 & & 374 & 53 & 28 & 80 & $10(94)$ \\
\hline$\left(-C_{34}\right)-F B 1$ & {$[\mathrm{IN}+\mathrm{H}]$} & & 150 & $\rightarrow$ & 356 & 59 & 18 & 8.0 & $1.0(9.4)$ \\
\hline ED1 1 & {$[\mathrm{M}, \mathrm{H}]^{+}$} & 106 & 722 & $\rightarrow$ & 334 & 57 & 18 & 81 & 11 ( 6 6) \\
\hline FB1 & {$[\mathrm{M}+\mathrm{H}]^{\top}$} & 100 & 122 & $\rightarrow$ & 352 & 53 & 10 & 8.1 & $1.1(8.0)$ \\
\hline FR? & {$\left[\mathrm{M}+\mathrm{H}^{+}\right.$} & 06 & 706 & $\rightarrow$ & 336 & 51 & 10 & & \\
\hline FB2 & {$[\mathrm{M}+\mathrm{H}]^{\top}$} & 96 & 706 & $\rightarrow$ & 318 & 55 & 22 & 10.0 & $1.8(8.7)$ \\
\hline FB3 & {$[\mathrm{M}+\mathrm{H}]^{+}$} & 116 & 706 & $\rightarrow$ & 336 & 53 & 10 & 92 & $16(122)$ \\
\hline & & & 106 & $\rightarrow$ & 668 & 41 & 24 & 9.2 & \\
\hline HFB1 & {$\left[\mathrm{M}+\mathrm{H}^{+}\right.$} & 66 & 406 & & 388 & 25 & 12 & 66 & $14(83)$ \\
\hline & & & & $\rightarrow$ & 370 & 29 & 12 & & \\
\hline$\left({ }^{13} \mathrm{C}_{20}\right)$-OTA & {$[\mathrm{M}+\mathrm{H}]^{+}$} & 41 & 424 & & 250 & 35 & 18 & 127 & $11(73)$ \\
\hline & & & & $\rightarrow$ & 377 & 21 & 10 & 12.1 & $1.1(1.0)$ \\
\hline OTA & {$[\mathrm{M}+\mathrm{H}]^{+}$} & 61 & 404 & $\rightarrow$ & 239 & 35 & 18 & 127 & $12(160)$ \\
\hline & & & & $\rightarrow$ & 358 & 21 & 10 & & \\
\hline$\left({ }^{13} \mathrm{C}_{18}\right)-\mathrm{ZON}$ & {$[\mathrm{M}+\mathrm{H}]^{+}$} & 41 & 337 & $\rightarrow$ & 319 & 13 & 10 & 12.3 & $1.3(5.9)$ \\
\hline
\end{tabular}




\begin{tabular}{|c|c|c|c|c|c|c|c|c|}
\hline Analyte & $\begin{array}{l}\text { Precursor } \\
\text { ion }\end{array}$ & $\begin{array}{l}\text { DP } \\
(\mathbf{V})\end{array}$ & & $\begin{array}{l}\text { ransition } \\
(\mathrm{m} / \mathrm{z})\end{array}$ & $\begin{array}{l}\text { CE } \\
\text { (V) }\end{array}$ & $\begin{array}{c}\text { CXP } \\
(\mathbf{V})\end{array}$ & $\begin{array}{c}\text { Retention } \\
\text { time (min) }\end{array}$ & $\begin{array}{l}\text { Ion ratio } \\
\text { (RSD; \%) }\end{array}$ \\
\hline & & & & $\rightarrow \quad 301$ & 17 & 24 & & \\
\hline \multirow{2}{*}{ ZON } & \multirow{2}{*}[\mathrm{M}+\mathrm{H}]{$^{+}$} & \multirow{2}{*}{66} & \multirow{2}{*}{319} & $\rightarrow \quad 301$ & 15 & 10 & \multirow{2}{*}{12.3} & \multirow{2}{*}{$3.2(26.6)$} \\
\hline & & & & $\rightarrow \quad 283$ & 19 & 8 & & \\
\hline \multirow{2}{*}{$\alpha-Z O L$} & \multirow{2}{*}[\mathrm{M}+\mathrm{H}]{$^{+}$} & \multirow{2}{*}{56} & \multirow{2}{*}{321} & $\rightarrow \quad 303$ & 11 & 18 & \multirow{2}{*}{12.1} & \multirow{2}{*}{$1.2(13.0)$} \\
\hline & & & & $\rightarrow \quad 285$ & 17 & 24 & & \\
\hline
\end{tabular}

$\mathrm{DP}=$ declustering potential; $\mathrm{CE}=$ collision energy; $\mathrm{CXP}=$ collision cell exit potential; Ion ratio: quantifier/qualifier obtained through the validation experiments $(\mathrm{N}=270)$; RSD: relative standard deviation.

LOQs ranged from 0.5 to $1.2 \mu \mathrm{g} / \mathrm{kg}$ for aflatoxins, being higher for DON and its derivatives (up to $121 \mu \mathrm{g} / \mathrm{kg}$ for 15AcDON). Recoveries ranged from $91.4 \%$ ( $\alpha$-ZOL) to 116.6 $\%$ (FB2), considering all levels of fortification and using matrix matched curves and isotope internal standard, except for CTV for which no isotope standard was available. Precision was evaluated both as repeatability (r) and intermediate precision (p). $\mathrm{RSD}_{\mathrm{r}}$ ranged from $7.5 \%$ (FB2) to $15.6 \%(\mathrm{CTV})$, and $\mathrm{RSD}_{\mathrm{p}}$ from $10.4 \%(\mathrm{DON})$ to $27.8 \%(\alpha-\mathrm{ZOL})$, all within the acceptable range. Recoveries and precision obtained for each level of fortification are shown in Table S1 (Supplementary data).

Table 3 - Validation parameters obtained in five different concentration levels for maize meal.

\begin{tabular}{|c|c|c|c|c|c|c|c|}
\hline \multirow{3}{*}{$\begin{array}{c}\text { Mycotoxin } \\
\text { AFB1 }\end{array}$} & \multicolumn{2}{|c|}{ Matrix effect (RSD, \%) } & \multicolumn{5}{|c|}{ Internal calibration } \\
\hline & $\begin{array}{c}\text { External } \\
\text { calibration }\end{array}$ & $\begin{array}{c}\text { Internal } \\
\text { calibration }\end{array}$ & \multirow{2}{*}{$\begin{array}{c}\begin{array}{c}\text { Weighting } \\
\text { factor }\end{array} \\
1 / \mathrm{x}^{2}\end{array}$} & \multicolumn{2}{|c|}{$\begin{array}{c}\text { LOQ } \\
(\mu \mathrm{g} / \mathrm{kg})\end{array}$} & \multirow{2}{*}{$\begin{array}{l}\text { Recoveries } \\
(\text { RSD, \%) } \\
3(11.9)\end{array}$} & \multirow{2}{*}{$\begin{array}{c}\text { Intermediate } \\
\text { precision } \\
(\text { RSD, \%) } \\
93.0(23.6)\end{array}$} \\
\hline & $(16.7)$ & $(15.7)$ & & 1.2 & 109.3 & & \\
\hline AFB2 & $(14.1)$ & 121.7 & $1 / x^{2}$ & 0.7 & 104.8 & $8 \quad(12.0)$ & $100.9(22.4)$ \\
\hline AFG1 & $(23.4)$ & $(13.1)$ & $1 / x^{2}$ & 0.7 & 106.8 & $(9.2)$ & $96.2(22.3)$ \\
\hline AFG2 & $(12.7)$ & $107.5 \quad(10.6)$ & $1 / x^{2}$ & 0.5 & 104.4 & $4 \quad(11.4)$ & $96.1(22.8)$ \\
\hline CTV & $(19.6)$ & NA & $1 / \mathrm{x}^{2}$ & 16 & 111.3 & $3 \quad(15.6)$ & $96.9(23.7)$ \\
\hline DON & $(11.0)$ & $(14.2)$ & $1 / \mathrm{x}$ & 39 & 103.7 & $(9.7)$ & $99.9(10.9)$ \\
\hline 15AcDON & $(10.5)$ & $(11.8)$ & $1 / y$ & 121 & 110.9 & $9 \quad(10.9)$ & $98.9(16.5)$ \\
\hline 3AcDON & (9.8) & (9.8) & $1 / x$ & 77 & 109.6 & $(11.0)$ & $99.5(15.8)$ \\
\hline D3G* & (7.6) & (8.4) & Ordinary & 60 & 98.4 & $(15.1)$ & $85.8(20.9)$ \\
\hline DOM & $101.8 \quad(13.3)$ & $103.0 \quad(15.3)$ & $1 / x$ & 40 & 98.0 & $(12.3)$ & $91.6(15.9)$ \\
\hline FB1 & $114.6 \quad(14.2)$ & $(13.8)$ & $1 / x$ & 19 & 93.7 & (8.3) & $82.4(21.2)$ \\
\hline FB2 & (17.3) & (27.1) & $1 / \mathrm{x}^{2}$ & 8 & 116.1 & (7.5) & $99.3(20.6)$ \\
\hline
\end{tabular}




\begin{tabular}{|c|c|c|c|c|c|c|c|}
\hline \multirow{3}{*}{$\begin{array}{c}\text { Mycotoxin } \\
\text { FB3 }\end{array}$} & \multicolumn{2}{|c|}{ Matrix effect (RSD, \%) } & \multicolumn{5}{|c|}{ Internal calibration } \\
\hline & $\begin{array}{c}\text { External } \\
\text { calibration }\end{array}$ & $\begin{array}{c}\text { Internal } \\
\text { calibration }\end{array}$ & \multirow{2}{*}{$\begin{array}{c}\begin{array}{c}\text { Weighting } \\
\text { factor }\end{array} \\
1 / x\end{array}$} & \multicolumn{2}{|c|}{$\begin{array}{c}\text { LOQ } \\
(\mu \mathrm{g} / \mathrm{kg})\end{array}$} & \multirow{2}{*}{$\begin{array}{l}\text { Recoveries } \\
(\text { RSD, \%) } \\
6 \quad(12.0)\end{array}$} & \multirow{2}{*}{$\begin{array}{c}\text { Intermediate } \\
\text { precision } \\
(\text { RSD, \%) } \\
90.7(24.5)\end{array}$} \\
\hline & $117.6 \quad(20.4)$ & $(22.0)$ & & 32 & 105.6 & & \\
\hline HFB1 & $170.8 \quad(16.0)$ & $141.4 \quad(17.5)$ & $1 / x^{2}$ & 6 & 98.1 & $(12.1)$ & $87.7(20.1)$ \\
\hline OTA & $58.4 \quad(16.8)$ & $(12.1)$ & $1 / \mathrm{x}^{2}$ & 4 & 106.4 & $(9.8)$ & $92.6(21.9)$ \\
\hline ZON & $(12.0)$ & $(9.7)$ & $1 / y$ & 24 & 104.3 & $(9.9)$ & $96.4(14.5)$ \\
\hline$\alpha-Z O L *$ & $53.9 \quad(10.8)$ & $100.7 \quad(10.0)$ & Ordinary & 28 & 91.4 & $(7.8)$ & $85.8(27.8)$ \\
\hline
\end{tabular}

LOQ: limit of quantification; RSD: relative standard deviation; NA: isotope labeled internal standard not available; Matrix effect: six replicates; Recoveries: 3-6 replicates; Intermediate precision: triplicates, two different days; *Recoveries and intermediate precision: only two different fortification levels (LOQ and medium).

Validation results obtained for rice are shown in Table 4. Matrix effects were less pronounced for rice compared to maize meal, and although the use of isotope internal standard decreased the effect for most analytes, external calibration was considered satisfactory for all analytes $( \pm 10 \%)$, except AFB2 (Table 4). Analytical curves showed heteroscedastic behavior for all mycotoxins $\left(\mathrm{C}_{\text {calculated }}<\mathrm{C}_{\text {critical; } 5 ; 6}\right)$, with $1 / \mathrm{x}^{2}$ the best weighting factor found for seven of the analytes (Table 4); $\mathrm{R}^{2}$ were higher than 0.98 , regressions were significant $(\mathrm{p}<0.05)$, and there was no lack-of-fit. The lowest LOQs were also found for aflatoxins $(0.5$ to $1.6 \mu \mathrm{g} / \mathrm{kg})$ and the highest LOQ for $15 \mathrm{AcDON}(72 \mu \mathrm{g} / \mathrm{kg})$. Recoveries were considered acceptable for all analytes except HFB1 (55.2\%; n=3). Repeatability $\left(\mathrm{RSD}_{\mathrm{r}}\right)$ exceeded $20 \%$ for three analytes (up to $25.6 \%$ for HFB1), and $\mathrm{RSD}_{\mathrm{p}}$ were acceptable for all mycotoxins ( $\leq 25 \%$; $n=3-6$ each level; 2 days), except HFB1 (29.9\%). Complete recoveries and precision data obtained for rice are shown in Table S2 (Supplementary data). 
Table 4 - Validation parameters obtained in five different concentration levels for rice.

\begin{tabular}{|c|c|c|c|c|c|c|c|c|}
\hline \multirow{3}{*}{$\begin{array}{c}\text { Mycotoxin } \\
\text { AFB1 }\end{array}$} & \multicolumn{3}{|c|}{ Matrix effect (RSD, \%) } & \multicolumn{5}{|c|}{ Internal calibration } \\
\hline & $\begin{array}{c}\text { External } \\
\text { calibration }\end{array}$ & \multicolumn{2}{|c|}{$\begin{array}{c}\text { Internal } \\
\text { calibration }\end{array}$} & \multirow{2}{*}{$\begin{array}{c}\begin{array}{c}\text { Weighting } \\
\text { factor }\end{array} \\
1 / y\end{array}$} & \multicolumn{2}{|c|}{$\begin{array}{c}\text { LOQ } \\
(\mu \mathrm{g} / \mathrm{kg})\end{array}$} & \multirow{2}{*}{$\begin{array}{l}\text { Recoveries } \\
(\mathbf{R S D}, \%) \\
5 \quad(14.6)\end{array}$} & \multirow{2}{*}{$\begin{array}{c}\text { Intermediate } \\
\text { precision } \\
(\text { RSD, \%) } \\
91.5(20.5)\end{array}$} \\
\hline & $(14.3)$ & 97.3 & (13.3) & & 0.5 & 101.5 & & \\
\hline AFB2 & $78.1 \quad(10.0)$ & 86.7 & $(12.0)$ & $1 / x^{2}$ & 1.2 & 102.2 & $(13.7)$ & $92.4(17.4)$ \\
\hline AFG1 & $(12.2)$ & 91.9 & $(11.6)$ & $1 / y^{2}$ & 1.0 & 104.3 & $(14.6)$ & $93.3(19.8)$ \\
\hline AFG2 & $90.4 \quad(17.1)$ & 95.2 & (12.9) & $1 / \mathrm{x}^{2}$ & 1.6 & 108.5 & $(16.5)$ & $92.7(19.3)$ \\
\hline CTV & (13.5) & NA & NA & $1 / \mathrm{x}^{2}$ & 16 & 90.0 & $(15.3)$ & $86.1(19.7)$ \\
\hline DON & $91.8 \quad(12.4)$ & 95.5 & $(16.7)$ & $1 / x$ & 40 & 100.3 & $(18.9)$ & $98.5(20.1)$ \\
\hline 15AcDON & $96.5 \quad(10.4)$ & 95.2 & $(14.0)$ & $1 / x^{2}$ & 72 & 100.2 & $(19.0)$ & $94.9(19.2)$ \\
\hline 3AcDON & $(9.7)$ & 98.5 & $(15.2)$ & $1 / x^{2}$ & 48 & 100.7 & $(19.1)$ & $94.5(18.9)$ \\
\hline D3G* & (7.1) & 106.1 & (11.6) & $1 / y^{2}$ & 60 & 83.0 & $(17.0)$ & $84.6(23.3)$ \\
\hline DOM & 104.1 & 107.9 & (16.3) & $1 / x$ & 24 & 102.8 & $(17.7)$ & $96.4(18.4)$ \\
\hline FB1 & $100.8 \quad(13.9)$ & 96.5 & $(16.0)$ & $1 / x^{2}$ & 21 & 86.6 & $(20.3)$ & 85.9 (20.6) \\
\hline FB2 & (8.9) & 93.4 & $(18.5)$ & $1 / x^{2}$ & 12 & 85.7 & $(13.6)$ & 83.8 (16.7) \\
\hline FB3 & (14.3) & 92.5 & (15.5) & $1 / x$ & 24 & 92.2 & (18.6) & $87.8(21.5)$ \\
\hline HFB1 & $101.7 \quad(16.0)$ & 93.8 & $(17.2)$ & $1 / x$ & 8 & 55.2 & $(25.6)$ & $66.0(29.9)$ \\
\hline OTA & (14.1) & 98.5 & (14.2) & $1 / x$ & 3 & 88.1 & (17.3) & $87.3(19.0)$ \\
\hline ZON & $(16.0)$ & 101.6 & $(12.7)$ & $1 / y^{2}$ & 16 & 101.0 & $(12.2)$ & $94.5(15.0)$ \\
\hline$\alpha-Z O L *$ & $88.7 \quad(11.3)$ & 97.5 & (13.4) & $1 / y$ & 28 & 93.3 & $(22.4)$ & $82.6(20.4)$ \\
\hline
\end{tabular}

LOQ: limit of quantification; RSD: relative standard deviation; NA: isotope labeled internal standard not available; Matrix effect: six replicates; Recoveries: 3-6 replicates; Intermediate precision: triplicates, two different days; *Recoveries and intermediate precision: only two different fortification levels (LOQ and medium).

Table 5 shows the validation parameters obtained for wheat flour. When external calibration was used, signal suppression was observed for most compounds (up to 53\% for AFB2), and signal enhancement of almost $40 \%$ was observed for DOM. The use of isotope internal standard decreased the matrix effects in all cases, but was still important for AFB2 $(67.7 \%)$ and DOM (150.3\%). The analytical curves were homoscedastic for only D3G and $\alpha-$ $\mathrm{ZOL}$; for the heteroscedastic compounds the best weighting factors were either $1 / \mathrm{x}^{2}$ or $1 / \mathrm{x} . \mathrm{R}^{2}$ were higher than 0.98, regressions were significant, with no lack-of-fit. As for the other matrices, lowest LOQs were found for aflatoxins $(0.6$ to $1.6 \mu \mathrm{g} / \mathrm{kg})$, and the highest for the acetylated forms of DON (72 and $80 \mu \mathrm{g} / \mathrm{kg}$ ). Recoveries ranged from $80.1 \%$ (3AcDON) to 
$117.1 \%$ ( $\alpha$-ZOL). Repeatability was higher than $20 \%$ for only $15 \operatorname{AcDON}(21.1 \%)$ and intermediate precision was below $25 \%$ in all cases. Recoveries and precision obtained for each level of fortification in wheat flour are shown in Table S3 (Supplementary data).

Table 5 - Validation parameters obtained in five different concentration levels for wheat flour.

\begin{tabular}{|c|c|c|c|c|c|c|c|c|c|}
\hline \multirow{3}{*}{$\begin{array}{c}\text { Mycotoxin } \\
\text { AFB1 }\end{array}$} & \multicolumn{4}{|c|}{ Matrix effects (RSD, \%) } & \multicolumn{5}{|c|}{ Internal calibration } \\
\hline & \multicolumn{2}{|c|}{$\begin{array}{c}\text { External } \\
\text { calibration }\end{array}$} & \multicolumn{2}{|c|}{$\begin{array}{c}\text { Internal } \\
\text { calibration }\end{array}$} & \multirow{2}{*}{$\begin{array}{c}\begin{array}{c}\text { Weighting } \\
\text { factor }\end{array} \\
1 / \mathrm{x}^{2}\end{array}$} & \multicolumn{2}{|c|}{$\begin{array}{c}\text { LOQ } \\
(\mu \mathrm{g} / \mathrm{kg})\end{array}$} & \multirow{2}{*}{$\begin{array}{l}\begin{array}{c}\text { Recoveries } \\
\text { (RSD, \%) }\end{array} \\
9 \quad(9.4)\end{array}$} & \multirow{2}{*}{$\begin{array}{c}\begin{array}{c}\text { Intermediate } \\
\text { precision } \\
\text { (RSD, \%) }\end{array} \\
95.7(16.4)\end{array}$} \\
\hline & 61.2 & (18.7) & 89.0 & $(11.5)$ & & 0.6 & 103.9 & & \\
\hline AFB2 & 47.0 & $(18.7)$ & 67.7 & $(12.1)$ & $1 / x$ & 1.2 & 104.3 & $3 \quad(12.0)$ & $97.3(18.0)$ \\
\hline AFG1 & 62.3 & $(19.6)$ & 86.7 & $(11.3)$ & $1 / \mathrm{x}$ & 1.2 & 109.7 & $7 \quad(10.7)$ & $100.7(11.8)$ \\
\hline AFG2 & 60.9 & $(16.1)$ & 84.8 & $(11.4)$ & $1 / x^{2}$ & 1.6 & 104.4 & $4 \quad(9.8)$ & $95.4(15.8)$ \\
\hline CTV & 73.6 & (14.2) & NA & NA & $1 / \mathrm{x}^{2}$ & 12 & 110.9 & $9(12.1)$ & $100.0(18.1)$ \\
\hline DON & 108.6 & $(26.3)$ & 91.7 & $(13.2)$ & $1 / x$ & 40 & 114.0 & $0 \quad(9.5)$ & $112.5(13.5)$ \\
\hline 15AcDON & 76.5 & $(12.5)$ & 85.7 & $(14.0)$ & $1 / \mathrm{x}^{2}$ & 80 & 92.6 & $(21.1)$ & $84.2(20.7)$ \\
\hline 3AcDON & 77.0 & (14.7) & 84.1 & $(14.6)$ & $1 / x^{2}$ & 72 & 80.1 & $(19.4)$ & $77.5(16.2)$ \\
\hline D3G* & 121.5 & $(15.5)$ & 114.3 & (18.3) & ordinary & 15 & 102.5 & $5 \quad(15.6)$ & $95.9(14.5)$ \\
\hline DOM & 139.4 & (13.5) & 153,3 & (14.8) & $1 / x^{2}$ & 40 & 104.7 & $7 \quad$ (11.9) & $96.6(16.3)$ \\
\hline FB1 & 73.5 & (17.8) & 102.8 & (13.3) & $1 / x^{2}$ & 19 & 104.3 & 3 (14.3) & $98.8(19.0)$ \\
\hline FB2 & 51.5 & (20.2) & 71.3 & (12.9) & $1 / x$ & 8 & 113.3 & 3 (13.4) & $100.9(21.8)$ \\
\hline FB3 & 67.7 & (19.7) & 102.2 & (14.7) & $1 / x$ & 24 & 98.9 & (16.7) & $92.6(18.9)$ \\
\hline HFB1 & 90.0 & (19.1) & 121.5 & $(20.3)$ & $1 / x^{2}$ & 8 & 113.0 & (9.8) & $99.9(21.0)$ \\
\hline OTA & 66.5 & (19.4) & 98.4 & (13.2) & $1 / x$ & 3 & 111.2 & (7.5) & $103.8(15.5)$ \\
\hline ZON & 53.1 & (15.7) & 93.5 & $(9.3)$ & $1 / x$ & 16 & 107.5 & $(9.5)$ & $97.8(15.5)$ \\
\hline$\alpha-$ ZOL $^{*}$ & 60.0 & (13.3) & 111.4 & (14.4) & ordinary & 10 & 117.1 & $1 \quad(16.0)$ & $110.7(20.9)$ \\
\hline
\end{tabular}

LOQ: limit of quantification; RSD: relative standard deviation; NA:isotope labeled internal standard not available; Matrix effect: six replicates; Recoveries: 3-replicates; Intermediate precision: triplicates, two different days; *Recoveries and intermediate precision: only two different fortification levels (LOQ and medium).

Trueness of the validated method was evaluated through the analysis of maize multimycotoxin reference material, naturally contaminated with aflatoxins (total aflatoxin level reported, AFs), fumonisins (total fumonisin level reported, FBs), DON, OTA and ZON (Table 6). The results were within the reported uncertainty range for all mycotoxins, except for zearalenone, for which the level found $(238.1 \mu \mathrm{g} / \mathrm{kg})$ was slightly below the lower bound of the uncertainty range $(239.4 \mu \mathrm{g} / \mathrm{kg})$. Considering the standard deviation ranges also reported for the reference material, the results found were in the first range for fumonisins, in the second 
range for aflatoxins, deoxynivalenol and ochratoxin $\mathrm{A}$, and in the third range for zearalenone (Table 6).

Table 6 - Analysis of maize reference material for aflatoxins, fumonisins, deoxynivalenol, ochratoxin A e zearalenone.

\begin{tabular}{|c|c|c|c|}
\hline Mycotoxin & $\begin{array}{c}\text { Reported value } \\
\text { range }^{\mathrm{a}}\end{array}$ & SD range ${ }^{b}$ & $\begin{array}{l}\text { Measured value } \\
(\text { RSD }, \%)\end{array}$ \\
\hline AFs & $\begin{array}{c}22.1 \mu \mathrm{g} / \mathrm{kg} \\
14.4-29.8 \mu \mathrm{g} / \mathrm{kg}\end{array}$ & $18.4-25.8 / 14.7-29.5 / 11.0-33.2$ & $15.0 \mu \mathrm{g} / \mathrm{kg}(14.0)$ \\
\hline FBs & $\begin{array}{c}37.1 \mathrm{mg} / \mathrm{kg} \\
27.2-47.0 \mathrm{mg} / \mathrm{kg}\end{array}$ & $32.9-41.3 / 28.7-45.5 / 24.5-49.7$ & 39.7 mg/kg (6.8) \\
\hline DON & $\begin{array}{c}2.6 \mathrm{mg} / \mathrm{kg} \\
2.2-3.0 \mathrm{mg} / \mathrm{kg}\end{array}$ & $2.4-2.8 / 2.2-3.0 / 2.0-3.2$ & $2.2 \mathrm{mg} / \mathrm{kg}(3.6)$ \\
\hline OTA & $\begin{array}{c}4.0 \mu \mathrm{g} / \mathrm{kg} \\
0.5-7.5 \mu \mathrm{g} / \mathrm{kg}\end{array}$ & $2.3-5.7 / 0.6-7.4 / 0-9.1$ & $6.1 \mu \mathrm{g} / \mathrm{kg}(10.4)$ \\
\hline ZON & $\begin{array}{c}352.0 \mu \mathrm{g} / \mathrm{kg} \\
239.4-464.6 \mu \mathrm{g} / \mathrm{kg}\end{array}$ & $306-398 / 260-444 / 214-490$ & $238.1 \mu \mathrm{g} / \mathrm{kg}(10.0)$ \\
\hline
\end{tabular}

AFs: AFB1+AFB2+AFG1+AFG2; FBs: FB1+FB2+FB3; RSD: relative standard deviation; including uncertainty; ${ }^{\mathrm{b}} 1^{\text {st }}$ range $/ 2^{\text {nd }}$ range $/ 3^{\text {rd }}$ range.

Heterocedastic behavior was found in this study for all compounds for which the range of the calibration curves was wider (10 or 100xLOQ), but not for those with a narrow working range (5xLOQ; D3G and $\alpha-Z O L$ ), except rice. The matrix effect found for almost all analytes was expected, since the extraction procedure did not include any clean-up or dilution of the extracts. The use of stable isotope internal standard was essential to compensate these effects for maize meal and wheat flour, but may be less important when analyzing mycotoxins in rice. Matrix effect comparisons using stable isotope internal standard or external calibration have not been presented in studies (ASAM; RYCHLIK, 2007; HÄUBL et al., 2006; LIAO et al., 2013), except for Varga et al. (2012), who confirmed our findings for aflatoxins, fumonisins, DON, OTA and ZON in maize, in addition to the trichothecenes T2 and HT-2.

Overall, the LOQs found is this study were similar to those reported by Sulyok et al. (2007), Malachová et al. (2014), Liao et al. (2013), Varga et al. (2012) and Frenich et al. (2009) for cereals and derived products using LC-MS/MS. The limits obtained for DON, 3AcDON, $15 \mathrm{AcDON}$ and ZON, however, were much higher than those reported in the literature (0.7-12 $\mu \mathrm{g} / \mathrm{kg}$ ) (BOEVRE et al., 2012; FRENICH et al., 2009; (MALACHOVÁ et al., 2014; VARGA et al., 2012). Low values of LOQs were obtained through analysis of these mycotoxins in the negative polarization mode or using a method with the inclusion of a single class of mycotoxins (trichothecenes). The optimized extraction procedure met the performance criteria required for 
recovery $(80 \%-120 \%)$, repeatability (RSD <20\%), and intermediate precision (RSD <25\%) for most analytes evaluated.

\subsection{Preparation of hydrolyzed fumonisins}

In this study, the reaction time for hydrolysis of standards of fumonisins under $60^{\circ} \mathrm{C}$ and basic conditions $(2 \mathrm{M} \mathrm{KOH})$ was investigated. Hydrolysis efficiency was determined using quantification of both the remaining parental fumonisin standards (FB1, FB2 and FB3) and the expected formation of HFB1 (the only commercially available standard). At least $99 \%$ of the fumonisins were hydrolyzed at 0 time (RSD up to $1.3 \% ; n=3$ ), a situation that remained over time (15, 30, 60, 120 and $180 \mathrm{~min}$.), with a single exception (98.6\% of FB3 at $30 \mathrm{~min})$. Hence, the conditions chosen to be applied to maize samples was $60 \mathrm{~min} / 60^{\circ} \mathrm{C}$ in order to ensure complete hydrolysis in complex matrices. The quantification of HFB1 also showed that all FB1 was hydrolysed to HFB1.

The produced HFB2 and HFB3 were infused into the mass spectrometer and the analytedependent MS/MS parameters optimized. Transitions monitored for HFB2 and HFB3 were: HFB2: 390/372 (DP: 61 V; CE: 27 V; CXP: 12 V) and 390/336 (DP: 61 V; CE: 33 V; CXP: 20 V); HFB3:390/354 (DP: 51 V; CE: 27 V; CXP: 24 V) and 390/336 (DP: 51 V; CE: 31 V; CXP: $22 \mathrm{~V})$.

\subsection{Total fumonisins extraction procedure}

The hydrolysis efficiency $\left(2 \mathrm{M} \mathrm{KOH}\right.$ at $60^{\circ} \mathrm{C} / 60 \mathrm{~min}$ ) in maize products was confirmed by analyzing six replicates of the maize reference material, and comparing with samples where the $\mathrm{KOH}$ was replaced by water (non-hydrolyzed maize flour). In the non-hydrolyzed maize flour only the parental fumonisins were found (FB1, FB2 and FB3), while in the hydrolyzed maize flour just the hydrolyzed forms were found (HFB1, HFB2 and HFB3), proving the efficiency of the procedure for maize samples (Figure 3). Chromatograms of hydrolyzed and non-hydrolyzed naturally contaminated maize flour samples are shown in Figure 4. 


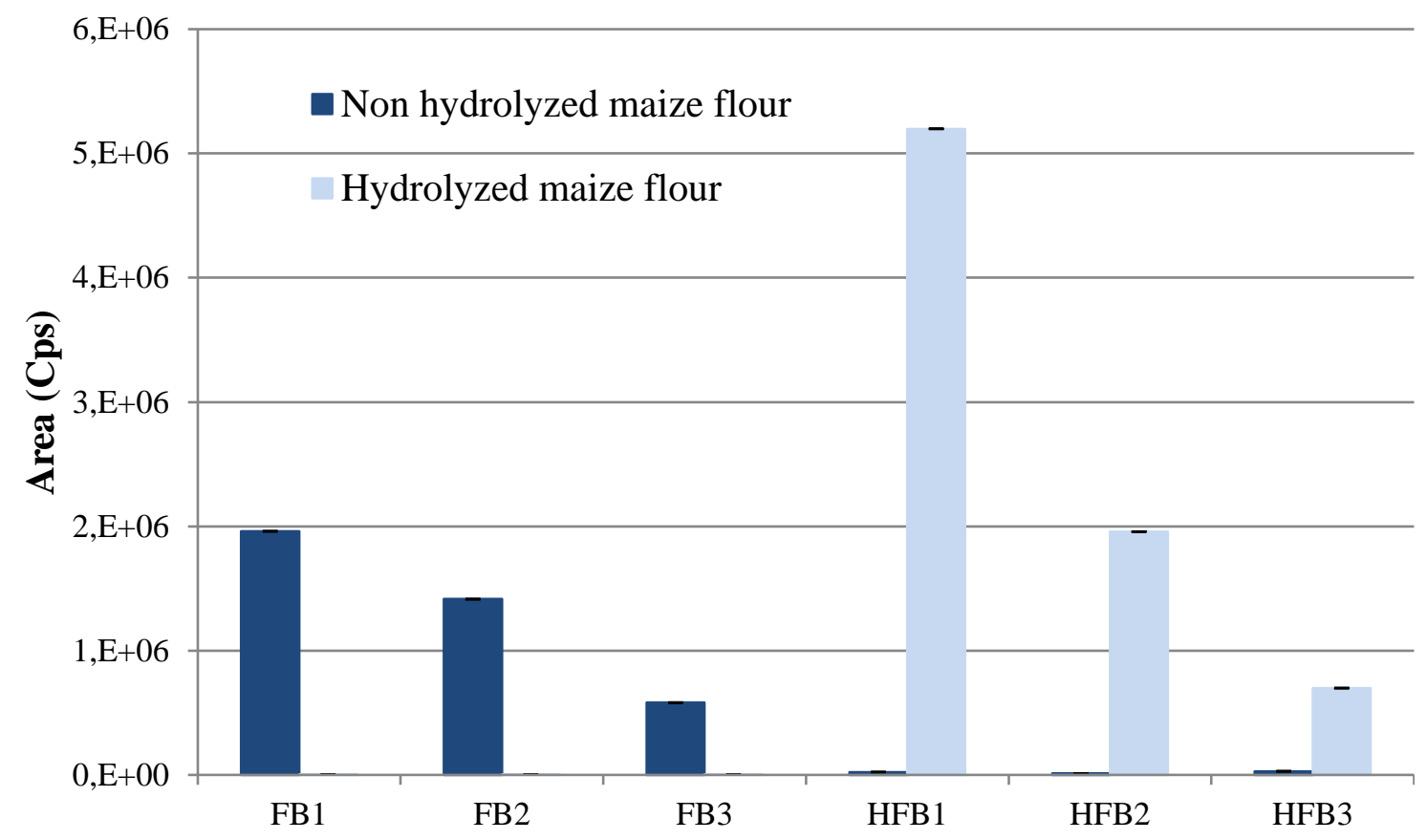

Figure 3 - LC-MS/MS analysis of maize flour naturally contaminated with fumonisins submitted or not to hydrolysis procedure $(n=6)$.

The absence of maize flour free of fumonisins made evaluation of the matrix effects for the hydrolyzed fumonisins impossible. As the hydrolyzed forms were more sensitive than the parental compounds, when the free forms found in the matrix were hydrolyzed, the levels were higher than the initial calibration point. Therefore, quantification was conducted using calibration curve made in the solvent $\left(\mathrm{MeOH}: \mathrm{H}_{2} \mathrm{O} ; 40: 60\right)$ and isotope internal calibration $\left({ }^{13} \mathrm{C}_{34}-\mathrm{FB} 1\right)$. Recoveries for HFB1, HFB2 and HFB3 were evaluated in six replicates fortified with the prepared standards (Section 2.5) at level of 1.2, 1.8 and $2.5 \mu \mathrm{g} / \mathrm{kg}$, respectively. Recoveries were $75.6 \%$ (RSD of 6.6\%) for HFB1, 108.0 (RSD of $10.6 \%$ ) for HFB2 and 74.9 $\%$ (RSD of $12.2 \%$ ) for HFB3. Falavigna et al. (2012) reported that both bound and hidden fumonisins can be cleaved under alkaline hydrolysis and, therefore, results obtained showed that this procedure may also be used to release these two forms from maize food products to enable the determination of the total fumonisin content. 


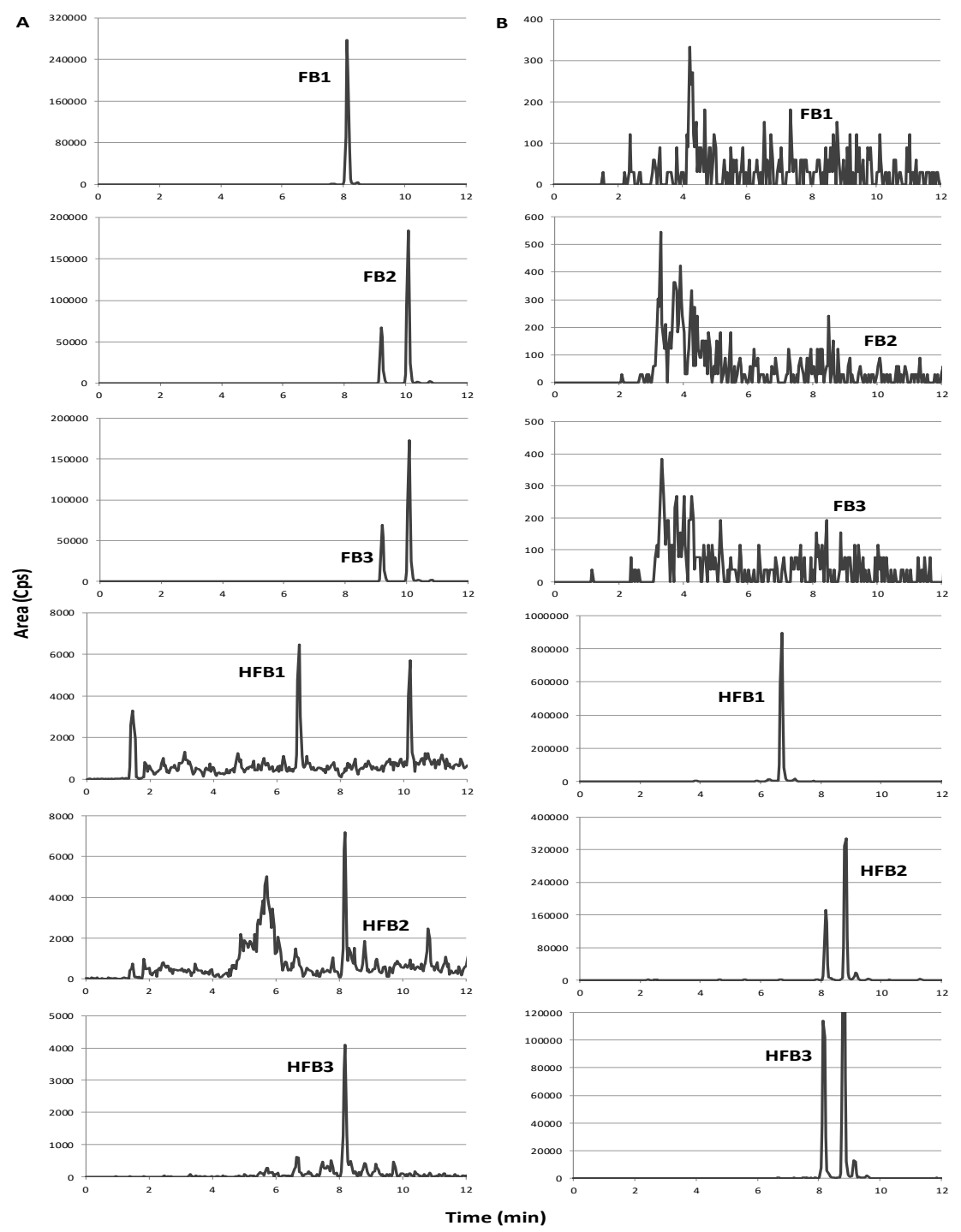

Figure 4 - LC-MS/MS chromatograms of naturally contaminated maize flour submitted to the total fumonisin extraction procedure. (A) non-hydrolyzed maize flour; (B) hydrolyzed maize flour.

\section{Conclusions}

Since the complete elimination of mycotoxins from the food supply is not feasible, it is critical that their occurrence in food be constantly monitored. Considering the high levels of cereal consumption worldwide and the prevalence of mycotoxins in these commodities and derived products, the development and validation of analytical methods are essential to determine dietary exposure to mycotoxins and to ensure the safety of consumers.

The use of acidified ACN as the extraction solvent proved to be suitable for the multimycotoxin method for wheat, maize and rice products, as well as a rapid and cost effective extraction procedure. The method developed for the simultaneous analysis of AFB1, AFB2, 
AFG1, AFG2, CTV, DON, 15AcDON, 3AcDON, D3G, DOM, FB1, FB2, FB3, HFB1, OTA, ZON and $\alpha-Z O L$ in maize, rice and wheat-derived products using LC-ESI ${ }^{+}-\mathrm{MS} / \mathrm{MS}$ was satisfactorily validated. Matrix effects were compensated using external calibration and matrix matched standard curves for rice, but to accurately determine mycotoxins in maize meal and wheat flour, the use of isotope internal standard was important. Hydrolyzed fumonisin standards were successfully prepared and total fumonisin content was obtained through an optimized procedure. To the best of our knowledge, this is the first study reporting determination of total fumonisin (free and bound forms) together with the determination of other mycotoxins.

\section{Supplementary data}

Table S1 - Recoveries (\%) and relative standard deviations (RSD; \%) obtained in five different concentration levels $(\mu \mathrm{g} / \mathrm{kg})$ for maize meal.

\begin{tabular}{ccccccccccccc}
\hline Mycotoxin & Range & \multicolumn{2}{c}{ Level 1 } & \multicolumn{2}{c}{ Level 2 } & \multicolumn{2}{c}{ Level 3 } & \multicolumn{2}{c}{ Level 4 } & \multicolumn{2}{c}{ Level 5 } \\
\hline AFB1 & $1.2-122$ & 109.7 & $(12.8)$ & 113.1 & $(7.4)$ & 107.8 & $(13.4)$ & 114.3 & $(15.2)$ & 102.4 & $(8.9)$ \\
AFB2 & $0.7-72$ & 108.1 & $(12.0)$ & 112.1 & $(10.3)$ & 97.8 & $(6.6)$ & 108.7 & $(14.9)$ & 98.0 & $(10.0)$ \\
AFG1 & $0.7-74$ & 116.1 & $(10.0)$ & 113.4 & $(8.5)$ & 101.3 & $(9.1)$ & 108.3 & $(7.1)$ & 101.9 & $(7.5)$ \\
AFG2 & $0.5-48$ & 113.9 & $(9.0)$ & 109.2 & $(10.8)$ & 101.4 & $(13.8)$ & 96.0 & $(4.2)$ & 102.6 & $(11.4)$ \\
CTV & $16-1602$ & 102.6 & $(12.7)$ & 106.5 & $(12.4)$ & 119.5 & $(13.4)$ & 115.7 & $(18.5)$ & 110.1 & $(19.8)$ \\
DON & $39-3911$ & 102.7 & $(8.1)$ & 111.3 & $(7.8)$ & 100.3 & $(9.7)$ & 106.2 & $(11.8)$ & 100.1 & $(9.1)$ \\
15AcDON & $121-1260$ & 114.8 & $(16.6)$ & 117.8 & $(7.1)$ & 106.0 & $(9.3)$ & 113.0 & $(8.6)$ & 103.6 & $(1.0)$ \\
3AcDON & $77-7719$ & 119.6 & $(11.4)$ & 106.8 & $(8.4)$ & 113.0 & $(11.9)$ & 103.2 & $(7.8)$ & 101.2 & $(5.0)$ \\
D3G* & $60-180$ & 95.1 & $(10.4)$ & - & - & 102.6 & $(19.8)$ & - & - & - & - \\
DOM & $40-120$ & 93.2 & $(13.7)$ & 103.5 & $(8.4)$ & 100.3 & $(18.4)$ & 91.2 & $(12.3)$ & 99.5 & $(8.8)$ \\
FB1 & $19-1952$ & 98.9 & $(9.0)$ & 93.3 & $(7.2)$ & 94.3 & $(10.4)$ & 90.5 & $(7.8)$ & 92.5 & $(7.2)$ \\
FB2 & $8-800$ & 111.8 & $(5.9)$ & 117.4 & $(5.9)$ & 119.0 & $(9.6)$ & 116.1 & $(13.3)$ & 118.6 & $(4.1)$ \\
FB3 & $32-96$ & 107.4 & $(11.6)$ & 102.1 & $(12.5)$ & 100.2 & $(14.1)$ & 106.5 & $(14.0)$ & 111.3 & $(11.2)$ \\
HFB1 & $6-18$ & 111.1 & $(16.1)$ & 96.8 & $(9.9)$ & 95.7 & $(9.7)$ & 94.6 & $(3.3)$ & 93.9 & $(10.7)$ \\
OTA & $4-402$ & 115.0 & $(10.1)$ & 109.4 & $(13.0)$ & 103.7 & $(9.1)$ & 101.3 & $(4.8)$ & 105.4 & $(11.1)$ \\
ZON & $24-2441$ & 102.6 & $(7.1)$ & 103.5 & $(11.5)$ & 96.1 & $(10.8)$ & 106.0 & $(11.3)$ & 113.3 & $(3.3)$ \\
$\boldsymbol{a - Z O L *}$ & $28-84$ & 95.7 & $(2.2)$ & - & - & 87.0 & $(9.9)$ & - & - & - & - \\
\hline Recoven
\end{tabular}

Recoveries: 3-6 replicates; *Recoveries and intermediate precision: only two different fortification levels (LOQ and medium). Levels of fortification: $\mathrm{AFB} 1=1.2 ; 2.4 ; 12.2 ; 60.8$ and $121.7 \mu \mathrm{g} / \mathrm{kg} ; \mathrm{AFB} 2=0.7 ; 1.4 ; 7.2 ; 35.9$ and $71.7 \mu \mathrm{g} / \mathrm{kg} ; \mathrm{AFG} 1=0.7 ; 1.5 ; 7.4 ; 36.8$ and $73.7 \mu \mathrm{g} / \mathrm{kg} ; \mathrm{AFG} 2=0.5 ; 1.0 ; 4.8 ; 24.1$ and $48.2 \mu \mathrm{g} / \mathrm{kg} ; \mathrm{CTV}=16 ; 32$; $160.2 ; 800.8$ and $1601.7 \mu \mathrm{g} / \mathrm{kg} ; \mathrm{DON}=39.1 ; 78.2 ; 391.1 ; 1955.3$ and $3910.7 \mu \mathrm{g} / \mathrm{kg} ; 15 \mathrm{AcDON}=120.6 ; 241.2 ;$ $1206 ; 6030.2$ and $12060.3 \mu \mathrm{g} / \mathrm{kg} ; 3 \mathrm{AcDON}=77.2 ; 154.4 ; 771.9 ; 3859.4$ and $7718.7 \mu \mathrm{g} / \mathrm{kg} ; \mathrm{D} 3 \mathrm{G}=60$ and 120 $\mu \mathrm{g} / \mathrm{kg} ; \mathrm{DOM}=39.9 ; 59.9 ; 79.8 ; 99.8$ and $119.7 \mu \mathrm{g} / \mathrm{kg} ; \mathrm{FB} 1=19.5 ; 39 ; 195.2 ; 976$ and $1952 \mu \mathrm{g} / \mathrm{kg} ; \mathrm{FB} 2=8 ; 16$; $80 ; 400 ; 800 \mu \mathrm{g} / \mathrm{kg} ; \mathrm{FB} 3=32 ; 48 ; 64 ; 80$ and $96 \mu \mathrm{g} / \mathrm{kg} ; \mathrm{HFB} 1=6 ; 9 ; 12 ; 15.1$ and $18.1 \mu \mathrm{g} / \mathrm{kg} ; \mathrm{OTA}=4 ; 8 ; 40.2$; 201 and $402.1 \mu \mathrm{g} / \mathrm{kg} ; \mathrm{ZON}=24.4 ; 48.8 ; 244.1 ; 1220.4$ and $2440.8 \mu \mathrm{g} / \mathrm{kg} ; \alpha-\mathrm{ZOL}=28$ and $56 \mu \mathrm{g} / \mathrm{kg}$. 
Table S2 - Recoveries (\%) and relative standard deviations (RSD; \%) obtained in five different concentration levels $(\mu \mathrm{g} / \mathrm{kg})$ for rice.

\begin{tabular}{ccccccccccccc}
\hline Mycotoxin & Range & \multicolumn{2}{c}{ Level 1 } & \multicolumn{2}{c}{ Level 2 } & \multicolumn{2}{c}{ Level 3 } & \multicolumn{2}{c}{ Level 4 } & \multicolumn{2}{c}{ Level 5 } \\
\hline AFB1 & $0.5-48$ & 99.3 & $(21.6)$ & 118.0 & $(9.7)$ & 94.0 & $(16.8)$ & 100.2 & $(11.2)$ & 97.9 & $(9.1)$ \\
AFB2 & $1.2-120$ & 115.0 & $(15.0)$ & 109.6 & $(9.8)$ & 94.0 & $(17.1)$ & 103.0 & $(14.3)$ & 99.5 & $(6.8)$ \\
AFG1 & $1.0-104$ & 118.4 & $(9.4)$ & 117.3 & $(9.9)$ & 90.5 & $(17.0)$ & 98.4 & $(14.1)$ & 103.7 & $(10.0)$ \\
AFG2 & $1.6-159$ & 118.1 & $(16.8)$ & 116.1 & $(19.7)$ & 103.5 & $(18.9)$ & 104.4 & $(12.8)$ & 102.1 & $(11.7)$ \\
CTV & $16-1602$ & 92.4 & $(15.9)$ & 79.9 & $(10.7)$ & 86.2 & $(18.2)$ & 90.9 & $(18.3)$ & 98.8 & $(10.2)$ \\
DON & $40-4000$ & 118.4 & $(13.2)$ & 104.2 & $(19.7)$ & 98.7 & $(18.5)$ & 95.8 & $(15.7)$ & 88.7 & $(17.4)$ \\
15AcDON & $72-7198$ & 118.3 & $(18.3)$ & 119.0 & $(11.8)$ & 100.4 & $(12.1)$ & 97.6 & $(15.3)$ & 83.1 & $(16.3)$ \\
3AcDON & $48-4800$ & 117.0 & $(7.2)$ & 118.0 & $(16.1)$ & 94.1 & $(11.6)$ & 95.4 & $(18.9)$ & 84.4 & $(15.2)$ \\
D3G* & $60-80$ & 93.0 & $(8.5)$ & - & - & 72.9 & $(15.9)$ & - & - & - & - \\
DOM & $24-71.4$ & 113.3 & $(13.1)$ & 104.1 & $(13.8)$ & 111.3 & $(13.5)$ & 102.3 & $(17.7)$ & 77.8 & $(12.1)$ \\
FB1 & $21-3200$ & 111.4 & $(18.2)$ & 92.7 & $(17.5)$ & 79.3 & $(11.7)$ & 81.5 & $(10.2)$ & 75.7 & $(15.5)$ \\
FB2 & $12-1200$ & 83.8 & $(7.2)$ & 92.6 & $(18.6)$ & 82.3 & $(11.3)$ & 85.6 & $(14.1)$ & 82.0 & $(11.7)$ \\
FB3 & $24-72$ & 103.6 & $(20.0)$ & 85.6 & $(10.9)$ & 100.2 & $(18.1)$ & 91.1 & $(17.2)$ & 76.0 & $(12.9)$ \\
HFB1 & $8-24$ & 76.9 & $(17.4)$ & 54.7 & $(6.0)$ & 52.8 & $(18.2)$ & 42.2 & $(10.1)$ & 49.3 & $(18.2)$ \\
OTA & $3-322$ & 77.7 & $(20.8)$ & 90.7 & $(18.3)$ & 73.6 & $(12.7)$ & 101.1 & $(11.0)$ & 91.8 & $(8.9)$ \\
ZON & $16-1598$ & 100.2 & $(5.4)$ & 106.8 & $(10.7)$ & 95.2 & $(16.6)$ & 102.2 & $(15.2)$ & 100.2 & $(10.6)$ \\
$\boldsymbol{\alpha - Z O L *}$ & $28-84$ & 77.4 & $(19.9)$ & - & - & 109.2 & $(8.9)$ & - & - & - & - \\
\hline Recovin
\end{tabular}

Recoveries: 3-6 replicates; *Recoveries and intermediate precision: only two different fortification levels (LOQ and medium). Levels of fortification: AFB1 $=0.5 ; 1.0 ; 4.8 ; 24.1$ and $48.2 \mu \mathrm{g} / \mathrm{kg} ; \mathrm{AFB} 2=1.2 ; 2.4 ; 12 ; 59.8$ and $119.6 \mu \mathrm{g} / \mathrm{kg} ; \mathrm{AFG} 1=1.0 ; 2.1 ; 10.4 ; 51.9$ and $103.7 \mu \mathrm{g} / \mathrm{kg} ; \mathrm{AFG} 2=1.6 ; 3.2 ; 15.9 ; 79.6$ and $159.2 \mu \mathrm{g} / \mathrm{kg} ; \mathrm{CTV}=$ $16 ; 32 ; 160.2 ; 800.8$ and $1601.7 \mu \mathrm{g} / \mathrm{kg} ; \mathrm{DON}=40 ; 79.9 ; 399.5 ; 1997 ; 6$ and $3995.2 \mu \mathrm{g} / \mathrm{kg} ; 15 \mathrm{AcDON}=72 ; 144$; $719.8 ; 3598.8$ and $7197.6 \mu \mathrm{g} / \mathrm{kg} ; 3 \mathrm{AcDON}=48 ; 96 ; 479.9 ; 2399.7$ and $4799.5 \mu \mathrm{g} / \mathrm{kg} ; \mathrm{D} 3 \mathrm{G}=60$ and $120 \mu \mathrm{g} / \mathrm{kg}$; $\mathrm{DOM}=23.8 ; 35.7 ; 47.6 ; 59.5$ and $71.4 \mu \mathrm{g} / \mathrm{kg} ; \mathrm{FB} 1=21.3 ; 42.7 ; 213.4 ; 1600$ and $3200 \mu \mathrm{g} / \mathrm{kg} ; \mathrm{FB} 2=12 ; 24 ; 120$; 600 and $1200 \mu \mathrm{g} / \mathrm{kg} ; \mathrm{FB} 3=24 ; 36 ; 48 ; 60$ and $72 \mu \mathrm{g} / \mathrm{kg} ; \mathrm{HFB} 1=8 ; 12 ; 16 ; 20$ and $23.9 \mu \mathrm{g} / \mathrm{kg} ; \mathrm{OTA}=3.2 ; 6.4$; $32.2 ; 160.8$ and $321.6 \mu \mathrm{g} / \mathrm{kg} ; \mathrm{ZON}=16 ; 32 ; 159.8 ; 798.8$ and $1597.6 \mu \mathrm{g} / \mathrm{kg} ; \alpha-\mathrm{ZOL}=28$ and $56 \mu \mathrm{g} / \mathrm{kg}$. 
Table S3 - Recoveries (\%) and relative standard deviations (RSD; \%) obtained in five different concentration levels $(\mu \mathrm{g} / \mathrm{kg})$ for wheat flour.

\begin{tabular}{ccccccccccccc}
\hline Mycotoxin & Range & \multicolumn{2}{c}{ Level 1 } & \multicolumn{3}{c}{ Level 2 } & \multicolumn{2}{c}{ Level 3 } & \multicolumn{2}{c}{ Level 4 } & \multicolumn{2}{c}{ Level 5 } \\
\hline AFB1 & $0.6-61$ & 113.7 & $(9.4)$ & 106.4 & $(13.5)$ & 104.7 & $(8.5)$ & 100.4 & $(5.5)$ & 99.0 & $(6.2)$ \\
AFB2 & $1.2-120$ & 104.1 & $(10.3)$ & 106.6 & $(14.6)$ & 98.5 & $(7.8)$ & 100.5 & $(6.4)$ & 111.0 & $(15.9)$ \\
AFG1 & $1.2-120$ & 114.8 & $(17.4)$ & 112.4 & $(11.6)$ & 109.6 & $(8.7)$ & 111.9 & $(9.7)$ & 103.5 & $(10.1)$ \\
AFG2 & $1.6-159$ & 111.2 & $(15.4)$ & 106.0 & $(7.9)$ & 107.6 & $(3.3)$ & 105.0 & $(4.6)$ & 94.0 & $(10.0)$ \\
CTV & $12-1204$ & 117.9 & $(13.6)$ & 112.5 & $(6.7)$ & 112.7 & $(11.6)$ & 100.8 & $(15.6)$ & 117.2 & $(5.6)$ \\
DON & $40-4016$ & 117.0 & $(9.6)$ & 108.1 & $(4.7)$ & 117.3 & $(6.9)$ & 117.7 & $(19.6)$ & 112.8 & $(7.9)$ \\
15AcDON & $80-8008$ & 119.2 & $(17.5)$ & 85.4 & $(8.9)$ & 74.3 & $(16.1)$ & 81.3 & $(17.7)$ & 77.9 & $(15.3)$ \\
3AcDON & $72-7224$ & 98.2 & $(16.8)$ & 84.8 & $(15.7)$ & 71.4 & $(16.3)$ & 81.6 & $(16.2)$ & 70.0 & $(19.4)$ \\
D3G* & $15-77$ & 89.5 & $(10.7)$ & - & - & 115.4 & $(5.8)$ & - & - & - & - \\
DOM & $40-120$ & 111.2 & $(14.4)$ & 102.1 & $(14.2)$ & 104.3 & $(12.6)$ & 103.1 & $(5.7)$ & 103.1 & $(13.4)$ \\
FB1 & $19-1952$ & 103.9 & $(16.7)$ & 115.8 & $(18.8)$ & 101.1 & $(10.0)$ & 100.9 & $(14.6)$ & 101.7 & $(10.2)$ \\
FB2 & $8-800$ & 112.8 & $(10.3)$ & 119.3 & $(14.4)$ & 112.8 & $(12.6)$ & 104.5 & $(16.9)$ & 118.0 & $(15.6)$ \\
FB3 & $24-72$ & 81.5 & $(3.2)$ & 110.1 & $(10.9)$ & 97.2 & $(10.3)$ & 88.3 & $(10.7)$ & 112.7 & $(18.9)$ \\
HFB1 & $8-24$ & 106.7 & $(5.5)$ & 112.2 & $(15.3)$ & 111.7 & $(9.0)$ & 115.4 & $(8.8)$ & 118.8 & $(11.9)$ \\
OTA & $3-322$ & 119.1 & $(5.9)$ & 114.6 & $(2.1)$ & 112.7 & $(5.6)$ & 102.9 & $(7.5)$ & 109.8 & $(8.1)$ \\
ZON & $16-1598$ & 103.0 & $(6.6)$ & 114.4 & $(9.2)$ & 106.5 & $(11.2)$ & 104.0 & $(7.9)$ & 108.0 & $(10.2)$ \\
a-ZOL* & $10-49$ & 117.1 & $(19.1)$ & - & - & 117.1 & $(16.7)$ & - & - & - & - \\
\hline Recovis
\end{tabular}

Recoveries: 3-6 replicates; *Recoveries and intermediate precision: only two different fortification levels (LOQ and medium). Levels of fortification: AFB1 $=0.6 ; 1.2 ; 6.1 ; 30.4$ and $60.8 \mu \mathrm{g} / \mathrm{kg} ; \mathrm{AFB} 2=1.2 ; 2.4 ; 12 ; 59.8$ and $119.6 \mu \mathrm{g} / \mathrm{kg} ; \mathrm{AFG} 1=1.2 ; 2.4 ; 12 ; 60$ and $120.1 \mu \mathrm{g} / \mathrm{kg} ; \mathrm{AFG} 2=1.6 ; 3.2 ; 15.9 ; 79.6$ and $159.2 \mu \mathrm{g} / \mathrm{kg} ; \mathrm{CTV}=12$; $24.1 ; 120.4 ; 602.1$ and $1204.2 \mu \mathrm{g} / \mathrm{kg} ; \mathrm{DON}=40.2 ; 80.3 ; 401.6 ; 2008.2$ and $4016.4 \mu \mathrm{g} / \mathrm{kg} ; 15 \mathrm{AcDON}=80.1 ; 160.2$; $800.8 ; 4004.0 ; 8008.1 \mu \mathrm{g} / \mathrm{kg} ; 3 \mathrm{AcDON}=72.2 ; 144.5 ; 722.4 ; 3612.0$ and $7223.9 \mu \mathrm{g} / \mathrm{kg} ; \mathrm{D} 3 \mathrm{G}=61.3$ and 131.4 $\mu \mathrm{g} / \mathrm{kg} ; \mathrm{DOM}=39.9 ; 59.9 ; 79.8 ; 99.8$ and $119.7 \mu \mathrm{g} / \mathrm{kg} ; \mathrm{FB} 1=19.5 ; 39 ; 195.2 ; 976$ and $1952 \mu \mathrm{g} / \mathrm{kg} ; \mathrm{FB} 2=8 ; 16$; $80 ; 400$ and $800 \mu \mathrm{g} / \mathrm{kg} ; \mathrm{FB} 3=24 ; 36 ; 48 ; 60$ and $72 \mu \mathrm{g} / \mathrm{kg} ; \mathrm{HFB} 1=8 ; 12 ; 16 ; 20$ and $23.9 \mu \mathrm{g} / \mathrm{kg} ;$ OTA= $3.2 ; 6.4$; $32.2 ; 160.8 ; 321.6 \mu \mathrm{g} / \mathrm{kg} ; \mathrm{ZON}=16 ; 32 ; 159.8 ; 798.8$ and $1597.6 \mu \mathrm{g} / \mathrm{kg} ; \alpha-\mathrm{ZOL}=39.2$ and $84 \mu \mathrm{g} / \mathrm{kg}$. 


\section{MYCOTOXINS IN CEREALS AND DERIVED PRODUCTS: OCCURRENCE AND PRELIMINARY RISK ASSESSMENT}

Patrícia Diniz Andrade, Tatiana Loureiro da Silva de Moura-Alves, Nathalya Evelyn Silva Araujo, Gabriel Moreira de Souza, Alessandra Page Brito, Eloisa Dutra Caldas.

\section{Introduction}

Mycotoxins are toxic fungi metabolites that can contaminate food before and/or after harvesting or even under post-harvest conditions (FRISVAD; THRANE; SAMSON, 2007; KUIPER-GOODMAN, 2004; PITT, 1996). Aflatoxins, fumonisins, ochratoxin A trichothecenes and zearalenone are among the classes of mycotoxins most relevant to human and animal health (CAST, 2003; NICHOLSON, 2004).

Aflatoxins (AFB1, AFB2, AFG1 and AFG2) are human liver carcinogens, with AFB1 being classified as a genotoxic compound by the International Agency for Research on Cancer (IARC, 1993). They are produced mainly by Aspergillus flavus and Aspergillus parasiticus and are found mainly in cereals and derived products, nuts, peanuts and dried fruits (ANDRADE; CALDAS, 2015; PITT; HOCKING, 2009; PITT et al., 2012). Since there is no safety threshold to aflatoxins exposure, it is recommended to be as low as reasonably achievable (CODEX ALIMENTARIUS, 1995).

Fumonisins are produced by Fusarium verticilliodes and Fusarium proliferatum endemic fungi in maize crops, being found mainly in maize and derived products (CALDAS; SILVA, 2007; MILLER, 1995; PITT, 2006). More than 50 types of fumonisins have been described, but group B fumonisins, especially FB1, FB2 and FB3, are the compounds of naturally occurrence most found in contaminated maize samples (BARTÓK et al., 2006; NELSON; DESJARDINS; PLATTNER, 1993; RHEEDER; MARASAS; VISMER, 2002). Human exposure to fumonisins has been associated with the development of esophageal and liver cancers, neural tube defects and cardiovascular diseases (MISSMER et al., 2006; SYDENHAM et al., 1995; UENO et al., 1997; WAES et al., 2005). Fumonisin B1 was classified as probable human carcinogen (IARC, 2002) and the FAO/WHO Joint Expert Committee on Food Additives (JECFA) established a Provisional Maximum Tolerable Daily Intake (PMTDI) of $2 \mu \mathrm{g} / \mathrm{kg}$ bw for FB1, FB2, FB3, alone or combined (JECFA, 2001). 
Ochratoxin A (OTA) is produced by Penicillium verrucosum and several species of Aspergillus, such as A. carbonarius and A. westerdijkiae, and has been found in cereal and derived products, mostly wheat flour based products (PITT; HOCKING, 2009; PITT, 2006). Additionally, exposure to OTA has also been related to consumption of beer, wine, cocoa and derived products, coffee and dried fruits (AISH et al., 2004). OTA is a nephrotoxic compound, classified as a possible human carcinogen (IARC, 1993), with a PMTDI of $0.1 \mu \mathrm{g} / \mathrm{kg}$ bw (JECFA, 2001).

Trichothecenes are a family of chemically related mycotoxins, with deoxynivalenol (DON) being the most relevant in the group. DON is produced by Fusarium graminearum, Fusarium culmorum and related species and can be found mostly in wheat, but also in maize, oatmeal and other small grains (BOEVRE et al., 2012; PITT; HOCKING, 2009; PITT, 2006; RASMUSSEN et al., 2012; VENDL et al., 2010) DON inhibits protein synthesis, and in high doses can cause abdominal pain, dizziness, headache, nausea and vomiting (COSTA et al., 2011; WALLE et al., 2010; PESTKA; SMOLINSKI, 2005; PESTKA, 2010; ROBBANABARNAT et al., 1987). The JECFA established a PMTDI of $1 \mu \mathrm{g} / \mathrm{kg}$ bw and an Acute Reference Dose (ARfD) of $8 \mu \mathrm{g} / \mathrm{kg}$ bw for DON and its acetylated derivatives, 3acetyldeoxynivalenol (3AcDON) and 15-acetyldeoxynivalenol (15AcDON) (JECFA, 2001, 2011).

Zearalenone $(\mathrm{ZON})$ is also produced by several Fusarium species, especially those reported for DON, and has been found in cereals, mainly maize and wheat (CAST, 2003; PITT, 2006). ZON is known to cause estrogenic syndrome in pigs, which may also happen in humans (SHERIF; SALAMA; ABDEL-WAHHAB, 2009). A PMTDI of $0.5 \mu \mathrm{g} / \mathrm{kg}$ bw was established for ZON (JECFA, 2000).

Acute cardiac beriberi was a prevalent disease in Asia for a long time, and was related to exposure to citreoviridin (CTV), a mycotoxin produced mainly by Penicillium citreonigrum (PITT; HOCKING, 2009; UENO, 1971; URAGUCHI, 1969). CVT has been found mostly in rice, and occasionally in maize, wheat, beans and peppers (ALMEIDA et al., 2012; PITT; HOCKING, 2009; ROSA et al., 2010; WICKLOW et al., 1988). In 2006, there was a beriberi outbreak in northern Brazil (Maranhão State), with 1207 cases and 40 deaths by the end of 2008 (PADILHA et al., 2011). P. citreonigrum was isolated from rice samples collected in the region and some were also contaminated with CTV (ROSA et al., 2010). Further, a case control study did not find any contaminated rice samples, however an association was found between beriberi cases and consumption of rice produced by the local population (LIMA et al., 2010). After this 
event, no oher studies were conducted to investigate the level of CVT in rice consumed in Brazil and its relation with beriberi.

This study aimed to evaluate the occurrence of aflatoxins, fumonisins, ochratoxin A, deoxynivalenol, zearalenone and citreoviridin in rice, maize and wheat products commercialized in Brazil, and to estimate the dietary exposure to these mycotoxins and the potential health risks arising from this exposure.

\section{Materials and methods}

\subsection{Samples}

A total of 196 samples of maize, rice and wheat-based food products were purchased at retail stores in Brasília (Federal District), from May 2015 to February 2016. Products collected weremaize starch $(n=6)$, degermed maize $(n=18)$, maize grits (canjiquinha; $n=3)$, breakfast cereal $(n=10)$, maize flour $(n=18)$, maize meal $(n=10)$, popcorn $(n=13)$, maize snacks $(n=18)$, maize pasta $(n=1)$, rice $(n=39)$, rice flour $(n=3)$, rice pasta $(n=2)$, crackers $(n=14)$, wheat snacks $(n=4)$, pasta $(n=30)$ and wheat flour $(n=7)$. At least $500 \mathrm{~g} /$ sample was collected, except for breakfast cereals, crackers and snacks (50 g minimum per sample). Cereals samples were quartered, ground (blender), homogenized, sieved (18 mesh) and stored in polyethylene bags at room temperature until analysis.

\subsection{Standards and reagents}

Standards of AFB1 (99.0\%), AFB2 (99.0\%), AFG1 (99.0\%), AFG2 (99.5\%) and d1DON (97.5\%) were purchased from Sigma-Aldrich (St. Louis, MO, USA). CTV (97.0\%) was from Enzo Life Sciences International Inc. (Farmingdale, NY, USA). 15AcDON (98.8\%), 3AcDON (99.4\%), D3G (96.0\%), DOM (98.0\%), DON (99.4\%), FB1 (97.6\%), FB2 (99.0\%), FB3 (98.5\%), HFB1 (98.4\%), ZON (99.4\%), $\alpha$-ZOL (98.7\%), $\left({ }^{13} \mathrm{C}_{17}\right)$-AFB1 $(99.0 \%),\left({ }^{13} \mathrm{C}_{17}\right)$ AFG1 (99.0\%), $\left({ }^{13} \mathrm{C}_{18}\right)$-ZON (99.2\%), $\left({ }^{13} \mathrm{C}_{20}\right)$-OTA (98.7\%) and $\left({ }^{13} \mathrm{C}_{34}\right)$-FB1 (97.8\%) were obtained from Biopure (Tulin, Áustria). HPLC-grade acetonitrile (ACN), ethyl acetate (AcOEt) and methanol $(\mathrm{MeOH})$ were purchased from Merck (Darmstadt, Germany); HPLC-grade toluene were obtained from Mallinckrodt Baker (Phillipsburg, USA); formic acid from SigmaAldrich (St. Louis, MO, USA); acetic acid from J.T Baker (Phillipsburg, USA); ammonium formate and ammonium acetate from Fluka (Buchs, Switzerland); anhydrous sodium sulphate, potassium hydroxide $(\mathrm{KOH})$ and hydrochloric acid $(\mathrm{HCl})$ from Vetec (Rio de Janeiro, Brazil); 
Ultrapure water was obtained through a Milli-Q purification system and the syringe filters used were Millex $^{\mathrm{TM}}$, both from Millipore (Millipore, Bedford, MA, USA).

\subsection{Multi-mycotoxin method}

Samples were analyzed using previously validated method (Chapter 2). Briefly, $5 \mathrm{~g}$ of the homogenized samples were weighted into a $50 \mathrm{~mL}$ falcon tube and $20 \mathrm{~mL}$ of $\mathrm{ACN}: \mathrm{H}_{2} \mathrm{O}$ (80:20; $0.1 \%$ formic acid) was added. Tubes were agitated for $20 \mathrm{~s}$ (vortex), extracted in the ultrasonic bath for $15 \mathrm{~min}$ and then centrifuged at $3500 \mathrm{rpm} / 10 \mathrm{~min} / 18^{\circ} \mathrm{C} .1 \mathrm{~mL}$ of supernatant was evaporated (Centrivap Vacuum Concentrator System - LABCONCO/Germany), redissolved in $1 \mathrm{~mL}$ methanol:water (40:60), filtered through a syringe filter $(0.45 \mu \mathrm{m})$ and injected in the LC-MS/MS. Three fortified samples (at the intermediate level) were included in each extraction batch for internal quality control. Rice and maize samples submitted to multimycotoxin method were analyzed using external calibration and matrix matched curves. Wheat samples were quantified using isotope labeled internal standards and matrix matched calibration curves. For that, $180 \mu \mathrm{L}$ of the extract was transferred to an insert and combined with $20 \mu \mathrm{L}$ of the internal standard working solutions.

\subsection{Total fumonisins analysis}

Total fumonisin were obtained through determination of free and bound/hidden fumonisins. Bound forms are fumonisins covalently bound to matrix constituents (starch or proteins) after a heat treatment. Hidden fumonisins are formed by a non-covalent interaction between the free forms and matrix constituents, without heat treatment. Both bound and hidden forms can be separated from matrix constituents after an alkaline hydrolysis. Therefore, maizebased products were extracted using the multi-mycotoxin method, the extract dried in the lyophilizer (Liobras/K105) and the residues submitted to hydrolysis to cleave non-extracted bound/hidden fumonisins present in the sample. $1 \mathrm{~g}$ of lyophilized sample was transferred to a $50 \mathrm{~mL}$ falcon tube, $10 \mathrm{~mL}$ of $\mathrm{KOH}(2 \mathrm{M})$ added under constant stirring (vortex) and the mixture allowed to react in a thermal bath $\left(60^{\circ} \mathrm{C}\right)$ under constant agitation, during $60 \mathrm{~min} .10 \mathrm{~mL}$ of acetonitrile was added, $\mathrm{pH}$ adjusted $(3.0 \pm 0.5)$, tubes were taken to sonication (15 min) and centrifugation $\left(3500 \mathrm{rpm} / 5 \mathrm{~min} / 12^{\circ} \mathrm{C}\right)$ and then stored in a freezer $\left(-18^{\circ} \mathrm{C}\right)$ for $12 \mathrm{~h}$. The liquid supernatant (organic phase) was passed through a funnel containing anhydrous sodium sulfate and the extract was completely evaporated under vacuum (Centrivap Vacuum Concentrator System - LABCONCO/Germany The residues were dissolved in $1 \mathrm{~mL} \mathrm{MeOH}: \mathrm{H}_{2} 0$ (40:60) 
andfiltered through a syringe filter $(0.45 \mu \mathrm{m}) .180 \mu \mathrm{L}$ of the extract was transferred to an insert, combined with $20 \mu \mathrm{L}$ of the internal standard working solution and then injected in the LCMS/MS. Samples were quantified using isotope labeled internal standards and neat solvent calibration curves. The hydrolyzed forms were expressed as the parental compound by applying the molar mass ratio. Total fumonisin (FB1, FB2 and FB3) was the sum of the free fumonisins determined in the multi-mycotoxin method and the bound/hidden fumonisins.

\subsection{LC-MS/MS conditions}

A Shimadzu LC system (Shimadzu, Kyoto, Japan) coupled to a 4000 Qtrap triplequadrupole mass spectrometer (Sciex, Framingham, MA, USA), fitted with a Turbo Ion Spray electrospray ionization (ESI) source was used for LC-MS/MS analysis. Chromatographic separation was performed at $40^{\circ} \mathrm{C}$, with a flow rate of $0.8 \mathrm{~mL} / \mathrm{min}$, using a Gemini $\mathrm{C} 18$ analytical column $(150 \times 4.6 \mathrm{~mm}, 5 \mu \mathrm{m})$ preceded by a C18 security guard cartridge $(4.0 \times 3.0$ mm, $5 \mu \mathrm{m}$ ), both from Phenomenex ${ }^{\circledR}$ (Torrance, CA, USA). Chromatographic and mass spectrometer parameters used were previously described method (ANDRADE et al., 2016; Chapter 2). ESI-MS/MS was done in the positive mode, using the multiple reaction monitoring (MRM), scanning two fragmentation reaction per analyte. Data acquisition and quantification were carried out using the software Analyst ${ }^{\circledR}$ (V 1.5.2).

\subsection{Food consumption data}

Brazilian consumption of maize, rice and wheat-based products were estimated from the raw data of the Pesquisa de Orçamento Familiar (POF) conducted by the Brazilian Institute of Geography and Statistics (IBGE), from July 2008 to June 2009. The 2008/2009 POF provided individual consumption data for 34003 individuals, aged 10 years or older, obtained in 2 non-consecutive days (food records). In addition, age and body weight were provided for each individual. Mean consumptions were estimated both for consumers (mean consumption among individuals that reported a certain food) and total population (all participants of the survey).

\subsection{Dietary risk assessment}

Total intake of mycotoxins was estimated according to FAO/WHO recommendation (FAO/WHO, 2005), as shown in equation 1. Intakes were obtained both for lower bound 
(considering samples below the LOQ as zero) and upper bound (considering samples below the LOQ as 0.5LOQ).

$$
\text { Total intake }=\sum \frac{(\text { consumption } \times \text { concentration })}{\text { body weight }}
$$

For chronic exposure, intakes were calculated using mean contamination levels found in products analyzed in this study and mean consumption data estimated from the 2008/2009 POF. Individual consumption for each food was obtained through the average of the two records provided; when only one record was provided, a zero was inputted to the second one. For DON acute exposure, intake was estimated using the 97.5 percentile of contamination and the 97.5 percentil of a distribution of individual consumption of the food that most impacted in the chronic exposure. For the remaining products, the mean of contamination and of consumption (total population) were used for the intake calculation (EFSA, 2011).

Risk characterization arising from mycotoxin exposure was conducted by comparing the total intakes estimated in this study with the respective PMTDI/ARfD (Equation 2). Intakes higher than the safety toxicological parameter may indicate a public health concern. Risk characterization was not performed for CVT as no toxicological parameter is currently available.

$$
\% P M T D I \text { or } A R f D=\frac{\text { Total intake }}{P M T D I \text { or } A R f D} \times 100
$$

\section{Results and discussion}

\subsection{Mycotoxins occurrence}

All 196 samples were analyzed using external standard method, and in addition, the wheat-based products and samples analyzed for bound/hidden fumonisins (maize-based products) were quantified using isotope labeled internal standards. As shown in Chapter 2, matrix effects were negligible for all mycotoxins in rice and for fumonisins in maize-based products, but had a greater impact for AFs, OTA and ZON in maize products. Internal quality controls $(n=3)$, included in each batch of extraction, were within the acceptable range for recoveries $\left(70-120 \%\right.$; $\left.\operatorname{RSD}_{\mathrm{r}}<20 \%\right)$, confirming that the method performed well during routine analysis.

Mycotoxins occurrence in the samples analyzed are shown in Table 1. Fumonisins (FB1, FB2 and/or FB3) were found in 90\% of all 97 maize-based samples analyzed (including breakfast cereals), FB2 being the most prevalent (80\%), followed by FB1 (77\%) and FB3 (34\%). Co-occcurence of FB1, FB2 and FB3 was observed in 20 samples, mainly maize meal 
$(\mathrm{n}=8)$. Fumonisins were found in all samples analyzed of maize flour, grits, meal, pasta and in popcorn. The highest mean levels (free form) were found in maize meal $(687.0 \pm 536.6 \mu \mathrm{g} / \mathrm{kg}$ ) and maize flour $(490.0 \pm 609.5 \mu \mathrm{g} / \mathrm{kg})$. HFB1 was found in maize flour, maize snack and popcorn $(10.3-22.6 \mu \mathrm{g} / \mathrm{kg})$ (Table 1$)$.

DON was found in all 55 wheat-based products analyzed, in addition to maize flour, snacks, grits and popcorn, and in two breakfast cereals, which was made of maize, rice and wheat flour (Table 1). Highest mean and maximum levels were found in crackers (560.7 and $916.1 \mu \mathrm{g} / \mathrm{kg}$, respectively). D3G was found in one pre-cooked maize flour $(99.6 \mu \mathrm{g} / \mathrm{kg})$ and in 18 wheat-based products, mainly crackers. $15 \mathrm{AcDON} / 3 \mathrm{AcDON}$ was found only in a precooked maize flour that also contained D3G and DON.

ZON was found in 46 wheat-based products, including all 14 cracker samples (mean of $60.7 \mu \mathrm{g} / \mathrm{kg}$ ), in addition to 3 maize flour and meal samples. $\alpha$-ZOL was found in only one sample (wheat snack) and OTA in two wheat pasta samples. CTV was found in 5 rice grain samples (1 parboiled and 4 polished), in one maize snack sample and in one cracker sample at very high level $(8640 \mu \mathrm{g} / \mathrm{kg})$. AFB1 and AFG2 were found in only two samples (rice pasta and maize snack). AFB2, AFG1 and DOM were not found in any samples. Examples of chromatograms obtained from contaminated samples are shown in Figure 1.

Levels of AFs, fumonisins, DON, OTA and ZON found in samples analyzed did not exceed the established maximum limit (ML) set by Brazilian authorities (BRASIL, 2011), except for a whole wheat pasta contaminated at $205.6 \mu \mathrm{g} / \mathrm{kg}(\mathrm{ML}=200 \mu \mathrm{g} / \mathrm{kg})$. In general, there is a low prevalence of mycotoxins occurrence in rice samples analyzed in Brazil, although the occurrence of AFs, OTA, DON, ZON and CTV has been reported (ALMEIDA et al., 2012; CARVALHO et al., 2010; DORS; BIERHALS; BADIALE-FURLONG, 2011; NUNES et al., 2003; ROSA et al., 2010). Levels of CTV found in two polished rice samples (704.0 and 3472.0 $\mu \mathrm{g} / \mathrm{kg}$ ) were much higher than the levels previously found in samples collected in the region of the beriberi outbreak in Brazil (12-254 $\mu \mathrm{g} / \mathrm{kg}$ ) (ROSA et al., 2010).

High prevalence of free fumonisins in maize-based samples collect in Brazil was expected, as previously shown other authors, although the levels differ among the studies. For example, mean fumonisins levels found in the present study for maize meal was $687 \mu \mathrm{g} / \mathrm{kg}$ (FB1, FB2, FB3), while Caldas et al. (2007) found $3.32 \mathrm{mg} / \mathrm{kg}$ (FB1 and FB2), Bordin et al. $476 \mu \mathrm{g} / \mathrm{kg}$ (FB1) and Martins et al. $297 \mu \mathrm{g} / \mathrm{kg}$ (FB1 and FB2). Occurrence of DON and ZON in wheat and wheat-based products in Brazil has also been frequently reported (ALMEIDA et al., 2016; CALORI-DOMINGUES et al., 2016; SAVI et al., 2014). 
Table 1 - Mycotoxins occurrence in maize, wheat, and rice product samples. Number of positive samples/Mean of positive samples (range), $\mu$ g/kg. No samples were contaminated with AFB2, AFG1 and DOM

\begin{tabular}{|c|c|c|c|c|c|c|c|c|c|c|c|c|c|c|}
\hline Products & $\mathbf{N}$ & FB1 & FB2 & FB3 & HFB1 & DON & D3G & 15AcDON & ZON & $\alpha-Z O L$ & OTA & CTV & AFB1 & AFG2 \\
\hline Maize flour & 18 & $\begin{array}{c}15 / 537.7 \\
(23.4-2051.2)\end{array}$ & $\begin{array}{c}17 / 34.8 \\
(11.9-85.3)\end{array}$ & $\begin{array}{c}4 / 43.9 \\
(27.2-66.8)\end{array}$ & $1 / 22.6$ & $1 / 956.0$ & $1 / 99.6$ & $1 / 245.2$ & $\begin{array}{c}2 / 78.2 \\
(77.6-78.8)\end{array}$ & $<\mathrm{LOQ}$ & $<\mathrm{LOQ}$ & $<\mathrm{LOQ}$ & $<\mathrm{LOQ}$ & $<\mathrm{LOQ}$ \\
\hline Degermed maize & 18 & $\begin{array}{c}10 / 225.8 \\
(17.3-757.7)\end{array}$ & $\begin{array}{c}13 / 30.4 \\
(7.5-127.3)\end{array}$ & $\begin{array}{c}4 / 58.9 \\
(29.4-123.4)\end{array}$ & $<\mathrm{LOQ}$ & $<\mathrm{LOQ}$ & $<\mathrm{LOQ}$ & $<$ LOQ & $1 / 83.6$ & $<\mathrm{LOQ}$ & $<\mathrm{LOQ}$ & $<\mathrm{LOQ}$ & $<\mathrm{LOQ}$ & $<\mathrm{LOQ}$ \\
\hline Maize snacks & 18 & $\begin{array}{c}13 / 37.3 \\
(18.0-71.1)\end{array}$ & $\begin{array}{c}9 / 13.0 \\
(8.0-20.1)\end{array}$ & $\begin{array}{c}4 / 42.3 \\
(30.4-71.0)\end{array}$ & $1 / 30.2$ & $\begin{array}{c}2 / 57.6 \\
(55.2-60.0)\end{array}$ & $<\mathrm{LOQ}$ & $<\mathrm{LOQ}$ & $<$ LOQ & $<\mathrm{LOQ}$ & $<\mathrm{LOQ}$ & $1 / 544$ & $<$ LOQ & $1 / 0.7$ \\
\hline Popcorn & 13 & $\begin{array}{c}13 / 167.9 \\
(22.2-539.8)\end{array}$ & $\begin{array}{c}12 / 37.7 \\
(12.3-151.5)\end{array}$ & $\begin{array}{c}6 / 93.6 \\
(27.9-190.0)\end{array}$ & $1 / 10.3$ & $1 / 102.8$ & $<\mathrm{LOQ}$ & $<$ LOQ & $<\mathrm{LOQ}$ & $<$ LOQ & $<\mathrm{LOQ}$ & $<$ LOQ & $<\mathrm{LOQ}$ & $<\mathrm{LOQ}$ \\
\hline Maize meal & 10 & $\begin{array}{c}10 / 550.5 \\
(76.6-2051.2)\end{array}$ & $\begin{array}{c}10 / 80.2 \\
(13.6-135.0)\end{array}$ & $\begin{array}{c}8 / 70.4 \\
(40.2-104.1)\end{array}$ & $<\mathrm{LOQ}$ & $<\mathrm{LOQ}$ & $<\mathrm{LOQ}$ & $<$ LOQ & $1 / 62.8$ & $<\mathrm{LOQ}$ & $<\mathrm{LOQ}$ & $<\mathrm{LOQ}$ & $<\mathrm{LOQ}$ & $<\mathrm{LOQ}$ \\
\hline Maize starch & 6 & $<\mathrm{LOQ}$ & $<\mathrm{LOQ}$ & $1 / 94.3$ & $<\mathrm{LOQ}$ & $<$ LOQ & $<$ LOQ & $<$ LOQ & $<\mathrm{LOQ}$ & $<$ LOQ & $<\mathrm{LOQ}$ & $<$ LOQ & $<$ LOQ & $<\mathrm{LOQ}$ \\
\hline Maize grits & 3 & $\begin{array}{c}3 / 53.1 \\
(31.4-73.4)\end{array}$ & $1 / 25.9$ & $1 / 110.3$ & $<\mathrm{LOQ}$ & $1 / 135.2$ & $<\mathrm{LOQ}$ & $<\mathrm{LOQ}$ & $<\mathrm{LOQ}$ & $<\mathrm{LOQ}$ & $<\mathrm{LOQ}$ & $<$ LOQ & $<$ LOQ & $<\mathrm{LOQ}$ \\
\hline Maize pasta & 1 & $<\mathrm{LOQ}$ & $1 / 28.4$ & $<\mathrm{LOQ}$ & $<\mathrm{LOQ}$ & $<\mathrm{LOQ}$ & $<\mathrm{LOQ}$ & $<\mathrm{LOQ}$ & $<\mathrm{LOQ}$ & $<\mathrm{LOQ}$ & $<\mathrm{LOQ}$ & $<\mathrm{LOQ}$ & $<\mathrm{LOQ}$ & $<\mathrm{LOQ}$ \\
\hline Breakfast cereals & 10 & $\begin{array}{c}3 / 150.4 \\
(50.3-326.8)\end{array}$ & $\begin{array}{c}7 / 20.5 \\
(7.9-34.7)\end{array}$ & $1 / 80.3$ & $<\mathrm{LOQ}$ & $\begin{array}{c}2 / 116.0 \\
(107.2-124.8)\end{array}$ & $<\mathrm{LOQ}$ & $<\mathrm{LOQ}$ & $<\mathrm{LOQ}$ & $<\mathrm{LOQ}$ & $<\mathrm{LOQ}$ & $<\mathrm{LOQ}$ & $<$ LOQ & $<\mathrm{LOQ}$ \\
\hline Wheat pasta & 30 & $\begin{array}{c}4 / 39.7 \\
(22.8-67.6)\end{array}$ & $\begin{array}{c}3 / 30.2 \\
(14.0-62.4)\end{array}$ & $<\mathrm{LOQ}$ & $<\mathrm{LOQ}$ & $\begin{array}{c}30 / 366.2 \\
(84.0-860.8)\end{array}$ & $\begin{array}{c}3 / 102.0 \\
(54.8-138.8)\end{array}$ & $<\mathrm{LOQ}$ & $\begin{array}{c}22 / 55.0 \\
(18.8-205.6)\end{array}$ & $<\mathrm{LOQ}$ & $\begin{array}{c}2 / 5.3 \\
(5.3-5.3)\end{array}$ & $<\mathrm{LOQ}$ & $<\mathrm{LOQ}$ & $<\mathrm{LOQ}$ \\
\hline Crackers & 14 & $<\mathrm{LOQ}$ & $<\mathrm{LOQ}$ & $<\mathrm{LOQ}$ & $<\mathrm{LOQ}$ & $\begin{array}{c}14 / 560.7 \\
(139.4-916.1)\end{array}$ & $\begin{array}{c}12 / 145.2 \\
(60.4-335.2)\end{array}$ & $<\mathrm{LOQ}$ & $\begin{array}{c}14 / 60.7 \\
(26.5-117.6)\end{array}$ & $<\mathrm{LOQ}$ & $<\mathrm{LOQ}$ & $1 / 8640$ & $<\mathrm{LOQ}$ & $<\mathrm{LOQ}$ \\
\hline Wheat flour & 7 & $<\mathrm{LOQ}$ & $<\mathrm{LOQ}$ & $<\mathrm{LOQ}$ & $<\mathrm{LOQ}$ & $\begin{array}{c}7 / 256.4 \\
(79.7-597.5)\end{array}$ & $1 / 183.6$ & $<$ LOQ & $\begin{array}{c}6 / 49.6 \\
(17.4-79.2)\end{array}$ & $<\mathrm{LOQ}$ & $<\mathrm{LOQ}$ & $<\mathrm{LOQ}$ & $<\mathrm{LOQ}$ & $<\mathrm{LOQ}$ \\
\hline Wheat snacks & 4 & $<\mathrm{LOQ}$ & $<\mathrm{LOQ}$ & $<$ LOQ & $<\mathrm{LOQ}$ & $\begin{array}{c}4 / 372.6 \\
(278.6-476.5)\end{array}$ & $\begin{array}{c}2 / 74.8 \\
(68.4-81.2)\end{array}$ & $<$ LOQ & $\begin{array}{c}4 / 71.3 \\
(36.6-102.8)\end{array}$ & $1 / 149.2$ & $<\mathrm{LOQ}$ & $<\mathrm{LOQ}$ & $<\mathrm{LOQ}$ & $<\mathrm{LOQ}$ \\
\hline Rice & 39 & $<\mathrm{LOQ}$ & $<\mathrm{LOQ}$ & $<\mathrm{LOQ}$ & $<\mathrm{LOQ}$ & $<\mathrm{LOQ}$ & $<\mathrm{LOQ}$ & $<\mathrm{LOQ}$ & $<\mathrm{LOQ}$ & $<\mathrm{LOQ}$ & $<\mathrm{LOQ}$ & $\begin{array}{c}5 / 849.4 \\
(19.8-3472)\end{array}$ & $<\mathrm{LOQ}$ & $<\mathrm{LOQ}$ \\
\hline Rice flour & 3 & $<\mathrm{LOQ}$ & $<\mathrm{LOQ}$ & $<\mathrm{LOQ}$ & $<\mathrm{LOQ}$ & $<\mathrm{LOQ}$ & $<\mathrm{LOQ}$ & $<\mathrm{LOQ}$ & $<\mathrm{LOQ}$ & $<\mathrm{LOQ}$ & $<\mathrm{LOQ}$ & $<\mathrm{LOQ}$ & $<\mathrm{LOQ}$ & $<\mathrm{LOQ}$ \\
\hline Rice pasta & 2 & $<\mathrm{LOQ}$ & $<\mathrm{LOQ}$ & $<\mathrm{LOQ}$ & $<\mathrm{LOQ}$ & $<\mathrm{LOQ}$ & $<\mathrm{LOQ}$ & $<\mathrm{LOQ}$ & $<\mathrm{LOQ}$ & $<\mathrm{LOQ}$ & $<\mathrm{LOQ}$ & $<\mathrm{LOQ}$ & $1 / 0.6$ & $<\mathrm{LOQ}$ \\
\hline
\end{tabular}

$15 \mathrm{AcDON}=120.6 \mu \mathrm{g} / \mathrm{kg} ; 3 \mathrm{AcDON}=77.2 \mu \mathrm{g} / \mathrm{kg} ; \mathrm{D} 3 \mathrm{G}=60 \mu \mathrm{g} / \mathrm{kg} ; \mathrm{DOM}=39.9 \mu \mathrm{g} / \mathrm{kg} ; \mathrm{FB} 1=19.5 \mu \mathrm{g} / \mathrm{kg} ; \mathrm{FB} 2=8 \mu \mathrm{g} / \mathrm{kg} ; \mathrm{FB} 3=32 \mu \mathrm{g} / \mathrm{kg} ; \mathrm{HFB} 1=6 \mu \mathrm{g} / \mathrm{kg} ; \mathrm{OTA}=4 \mu \mathrm{g} / \mathrm{kg} ; \mathrm{ZON}=24.4 \mu \mathrm{g} / \mathrm{kg} ; \alpha-\mathrm{ZOL}=28 \mu \mathrm{g} / \mathrm{kg}$. LOQs for wheat flour and derived products: AFB1=0.6 $\mu \mathrm{g} / \mathrm{kg} ; \mathrm{AFB} 2=1.2 \mu \mathrm{g} / \mathrm{kg} ; \mathrm{AFG} 1=1.2 \mu \mathrm{g} / \mathrm{kg} ; \mathrm{AFG} 2=1.6 \mu \mathrm{g} / \mathrm{kg} ; \mathrm{CTV}=12 \mu \mathrm{g} / \mathrm{kg} ; \mathrm{DON}=40.2 \mu \mathrm{g} / \mathrm{kg} ; 15 \mathrm{AcDON}=80.1 \mu \mathrm{g} / \mathrm{kg} ; 3 \mathrm{AcDON}=72.2 \mu \mathrm{g} / \mathrm{kg} ; \mathrm{D} 3 \mathrm{G}=61.3 \mu \mathrm{g} / \mathrm{kg}$; 
$\mathrm{DOM}=39.9 \mu \mathrm{g} / \mathrm{kg} ; \mathrm{FB} 1=19.5 \mu \mathrm{g} / \mathrm{kg} ; \mathrm{FB} 2=8 \mu \mathrm{g} / \mathrm{kg} ; \mathrm{FB} 3=24 \mu \mathrm{g} / \mathrm{kg} ; \mathrm{HFB} 1=8 \mu \mathrm{g} / \mathrm{kg} ; \mathrm{OTA}=3.2 \mu \mathrm{g} / \mathrm{kg} ; \mathrm{ZON}=16 \mu \mathrm{g} / \mathrm{kg} ; \alpha-\mathrm{ZOL}=39.2 \mu \mathrm{g} / \mathrm{kg}$. LOQs for rice and derived products: AFB1= $0.5 \mu \mathrm{g} / \mathrm{kg} ; \mathrm{AFB} 2=1.2 \mu \mathrm{g} / \mathrm{kg}$; $\mathrm{AFG} 1=1.0 \mu \mathrm{g} / \mathrm{kg} ; \mathrm{AFG} 2=1.6 \mu \mathrm{g} / \mathrm{kg} ; \mathrm{CTV}=16 \mu \mathrm{g} / \mathrm{kg} ; \mathrm{DON}=40 \mu \mathrm{g} / \mathrm{kg} ; 15 \mathrm{AcDON}=72 \mu \mathrm{g} / \mathrm{kg} ; 3 \mathrm{AcDON}=48 \mu \mathrm{g} / \mathrm{kg} ; \mathrm{D} 3 \mathrm{G}=60 \mu \mathrm{g} / \mathrm{kg} ; \mathrm{DOM}=23.8 \mu \mathrm{g} / \mathrm{kg} ; \mathrm{FB} 1=21.3 \mu \mathrm{g} / \mathrm{kg} ; \mathrm{FB} 2=12 \mu \mathrm{g} / \mathrm{kg} ; \mathrm{FB} 3=24 \mu \mathrm{g} / \mathrm{kg} ; \mathrm{HFB} 1=8$ $\mu \mathrm{g} / \mathrm{kg} ; \mathrm{OTA}=3.2 \mu \mathrm{g} / \mathrm{kg} ; \mathrm{ZON}=16 \mu \mathrm{g} / \mathrm{kg} ; \alpha-\mathrm{ZOL}=28 \mu \mathrm{g} / \mathrm{kg}$.

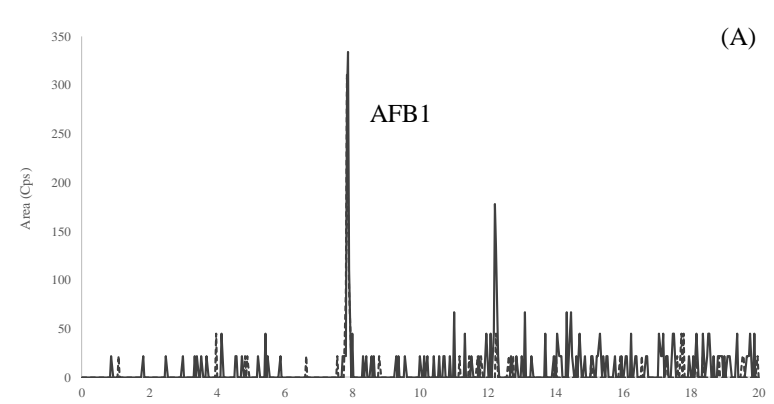

Time (nim)

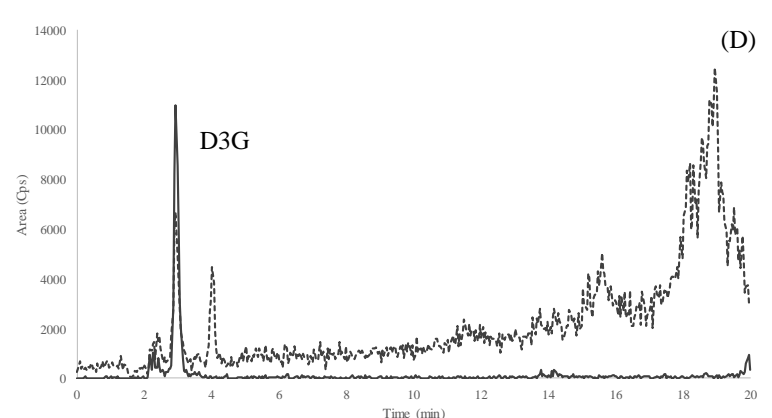

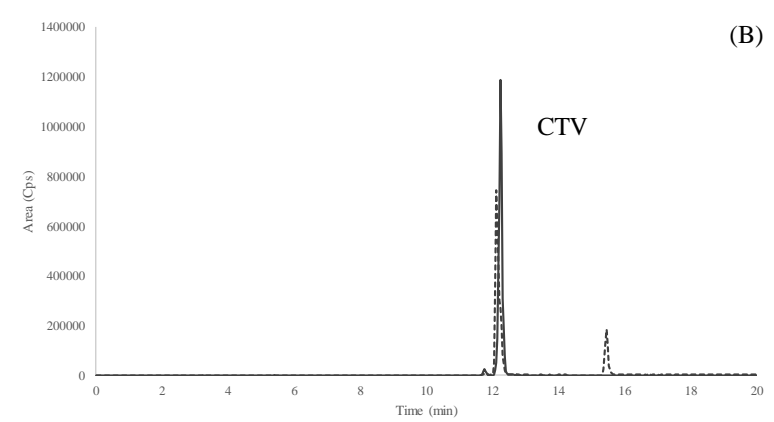
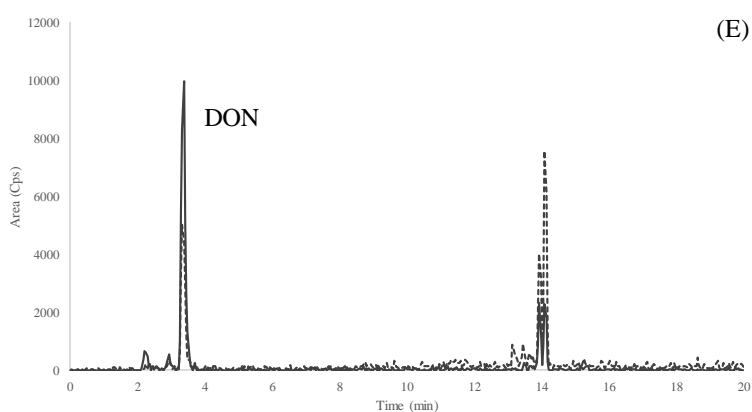
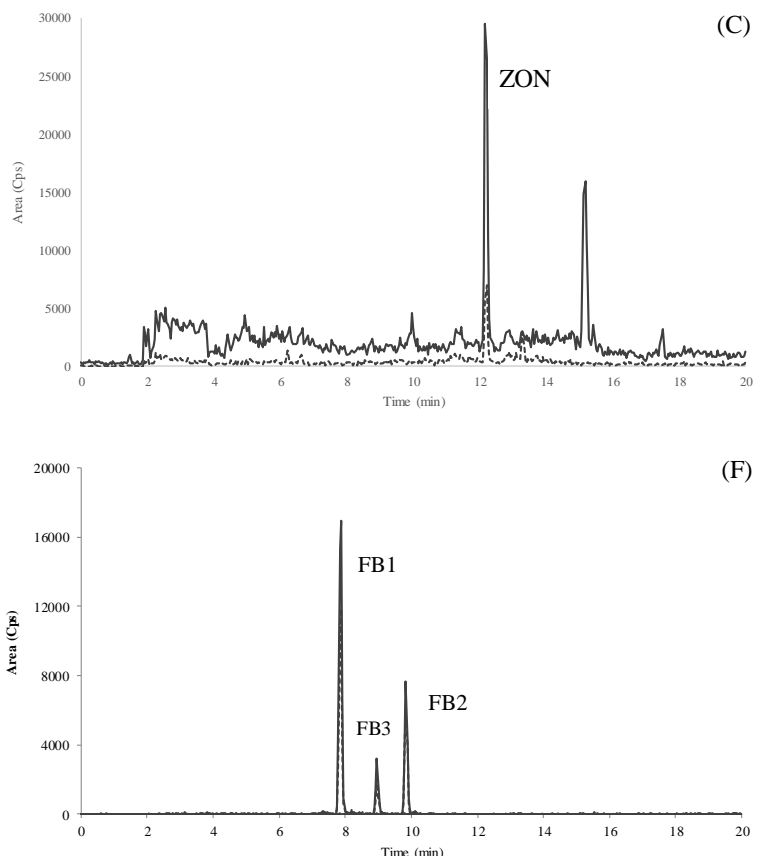

Figure 1- LC-MS/MS chromatograms of naturally contaminated samples. (A) rice pasta, AFB1=0.6 $\mu \mathrm{g} / \mathrm{kg}$; $(\mathrm{B}) \mathrm{cracker}, \mathrm{CTV}=8640 \mu \mathrm{g} / \mathrm{kg}$; $(\mathrm{C})$ snacks, ZON=102.8 $\mu \mathrm{g} / \mathrm{kg}$; (D) pasta, D3G=54.8 $\mu \mathrm{g} / \mathrm{kg}$; (E) wheat flour, DON=326.4 $\mu \mathrm{g} / \mathrm{kg}$; (F) maize meal, total fumonisins $633.3 \mu \mathrm{g} / \mathrm{kg}$. 


\subsection{Total fumonisins}

Mean levels of total fumonisins are shown in Table 2 and expressed as the sum of free and bound/hidden fumonisins. Free fumonisins were determined after the multi-mycotoxin extraction procedure and bound/hidden fumonisins were obtained after alkaline hydrolysis. Bound/hidden forms were found in all maize-based samples, even in those without quantifiable amounts of the free forms. Considering the samples contaminated with the free forms $(\mathrm{n}=88 / 97)$, bound/hidden forms represented, on average, $24.9 \%$ of total fumonisins concentration in maize pasta, $15.8 \%$ of breakfast cereals, $10.9 \%$ of maize snacks and $9.7 \%$ of degermed maize. These results are expected since these products are submitted to thermal treatment and susceptible to the formation of bound fumonisins.

Table 2 - Total fumonisins (free + bound/hidden, FB1+FB2+FB3) in maize-based products, and $\%$ of bound/hidden*.

\begin{tabular}{ccc}
\hline Products & $\begin{array}{c}\text { Total fumonisins } \\
\text { Mean (range), } \boldsymbol{\mu g} / \mathbf{k g}\end{array}$ & $\begin{array}{c}\text { Mean \% } \\
\text { bound/hidden }\end{array}$ \\
\hline Maize pasta & 37.8 & 24.9 \\
Breakfast cereals & $71.3(\mathrm{nd}-333.8)$ & 15.8 \\
Maize snacks & $46.9(5.5-119.5)$ & 10.9 \\
Degermed maize & $164.3(2.7-1016.8)$ & 9.7 \\
Maize flour & $495.8(14.8-2077.8)$ & 4.1 \\
Maize starch & $18.8(2.9-97.7)$ & 3.5 \\
Popcorn & $251.6(60.6-805.1)$ & 3.1 \\
Maize grits & $101.7(57.6-144.4)$ & 2.7 \\
Maize meal & $697.6(101.9-2077.8$ & 2.1 \\
\hline
\end{tabular}

*only samples containing free fumonisins were considered.

A recent study published in Brazil showed that hidden fumonisins (not covalently bound to maize components) in maize grain corresponded to 1.5-3.8 times the concentration of free fumonisins (FB1 and FB2) (OLIVEIRA et al., 2015), much higher than what was found in the present study for degermed maize and maize grits (up to 0.7). Levels of bound/hidden fumonisins found was also lower for other maize products such as breakfast cereals, pasta and snacks than reported in the literature ((DALL'ASTA et al., 2008, 2009c; PARK et al., 2004). Our results showed that bound/hidden fumonisins represented, at most, $73.3 \%$ of the free forms concentration, while those other studies showed that occurrence of bound/hidden forms were at least the same found for free forms. 


\subsection{Food consumption and dietary risk assessment}

Dietary risk assessment was carried out for DON, fumonisins and ZON in maize-based and wheat-based products. The remaining mycotoxins and food products were not included in the exposure estimation because of the low prevalence of contamination. Food in which a mycotoxin was not found in any sample was also not considered in the intake estimation (e.g., fumonisins in crackers or DON in maize meal; Table 1).

A summary of consumption data estimated for the foods relevant to this work, estimated from the 2008/2009 POF is shown in Table 3. A total of 34004 people participated on the survey, with a total of 66903 records for the relevant foods. The age of the participants ranged from 10 to 104 years (mean of $36.6 \pm 18.4)$ and body weight from 19 to $150 \mathrm{~kg}(65.6 \pm 15.6$ $\mathrm{kg})$.

Table 3 - Consumption of maize, rice and wheat-based products obtained from 2008/2009 POF, estimated both for chronic exposure and acute exposure (g/bw day).

\begin{tabular}{cccc}
\hline \multirow{2}{*}{ Products } & \multicolumn{2}{c}{ Chronic exposure $^{\mathbf{a}}$} & $\begin{array}{c}\text { Acute } \\
\text { exposure }\end{array}$ \\
\cline { 2 - 4 } & Consumers $^{\mathbf{b}}$ & Total population $^{\mathbf{c}}$ & $\mathbf{9 7 . 5} \%$ \\
\hline Pasta & 1.88 & 0.61 & 10.24 \\
Maize starch & 1.44 & 0 & 13.2 \\
Maize grits & 1.43 & 0.01 & 14.01 \\
Maize meal & 1.34 & 0.2 & 7.35 \\
Bread & 1.15 & 0.84 & 3.86 \\
Snacks & 0.96 & 0.04 & 4.58 \\
Degermed maize & 0.69 & 0.01 & 4.86 \\
Crackers & 0.45 & 0.1 & 3.46 \\
Maize flour & 0.38 & 0 & 1.67 \\
Breakfast cereals & 0.3 & 0 & 1.67 \\
Popcorn & 0.27 & 0.01 & 1.61 \\
\hline
\end{tabular}

andividual consumption was obtained through the average of the two records, of the same person, in two different days; ${ }^{b}$ mean consumption among individuals that reported a type food; ${ }^{c}$ all participants of the survey.

For chronic exposure, mean consumption was estimated for consumers (mean consumption among the individuals that reported a certain food) and total population (all participants of the survey). Pasta had the highest mean consumption for consumers $(\sim 2 \mathrm{~g} / \mathrm{kg}$ bw/day), and bread the highest consumption for the total population $(0.84 \mathrm{~g} / \mathrm{bw}$ day). For acute exposure, 97.5 percentile of consumption was estimated for consumers only (Table 3). 
Chronic exposure was evaluated for DON, fumonisins and ZON and acute exposure just for DON, the only mycotoxin with an ARfD. Previous studies have shown that D3G can be cleaved to the original form (DON) by intestinal bacteria (BERTHILLER et al., 2011; NAGL et al., 2012) and that the acetylated derivatives (15AcDON and $3 \mathrm{AcDON})$ can also contributed to total toxicity due to DON exposure (JECFA, 2011). Thus, the mean level of contamination of D3G, 3AcDON/15AcDON were converted to DON (molar mass ratio) and added to the DON levels for the estimation of dietary exposure to DON.

It was assumed that consumption of pasta reported in the POF was wheat pasta, as it is the most consumed in the country. Consumption of snacks did not specify the cereal used, and it was considered to be either of wheat or maize. Contamination on wheat flour was used to estimate mycotoxin exposure from the consumption of bread, considering that wheat flour accounts for $66.5 \%$ of bread composition (ARAÚJO; GUERRA, 2007; FISBERG; VILLAR, 2002; PINHEIRO et al., 2004).

Chronic intakes estimated for DON from the consumption of maize and wheat-based products are shown in Table 4. Total intakes ranged from 0.29 (LB; total population) to 1.071 $\mu \mathrm{g} / \mathrm{kg}$ bw day (UB; consumers). Pasta was the product that most contributed to total intake (60.8-71.3\%), followed by bread (10.2-26.0\%) and snacks (1.1-9.7\%). The great contribution of pasta to total intake was due both to its high level of contamination $(338.9-346.5 \mu \mathrm{g} / \mathrm{kg}$ ) and consumption (about $2 \mathrm{~g} / \mathrm{kg}$ bw/day, in average). Chronic intakes represented up to $31 \%$ of the PMTDI stablished for DON (1 $\mu \mathrm{g} / \mathrm{kg}$ bw) for the total population and up to $107 \%$ for consumers. Acute exposure to DON is shown in Table 5. Total intakes ranged from 9.33 (LB) to $9.34 \mu \mathrm{g} / \mathrm{kg}$ bw day (UB), with pasta contributing to up $99 \%$ of the intake (LB). Intakes estimated to acute exposure represented $117 \%$ of the ARfD set for DON ( $8 \mu \mathrm{g} / \mathrm{kg} \mathrm{bw}$ ), both for the lower and upper bounds.

Dietary exposure to DON was evaluated in two studies in southern Brazil through the consumption of bread and pasta using data found in wheat samples (transformed to equivalent contamination in wheat-based products) and consumption data obtained through food questionnaires (SANTOS et al., 2011, 2013). In the first study, wheat grain samples collected during 2006, 2007 and 2008 seasons showed a DON mean level of $321.6 \mu \mathrm{g} / \mathrm{kg}$, with a mean exposure though the consumption of bread and pasta of $0.308 \mu \mathrm{g} / \mathrm{kg}$ bw day $(30.8 \%$ of the PMTDI). The second study used contamination data found in wheat samples collected during 2008 and 2009 seasons, which was much higher $(1894.9 \mu \mathrm{g} / \mathrm{kg}$ bw day), leading to an exposure that represented $113 \%$ of the PMTDI, similar to what was found in the present study. 
Table 4 - Chronic dietary exposure assessment of deoxynivalenol from the consumption of maize and wheat-based products.

\begin{tabular}{|c|c|c|c|c|c|c|}
\hline \multirow{3}{*}{ Products } & \multirow{2}{*}{\multicolumn{2}{|c|}{ Contamination $(\mu \mathrm{g} / \mathrm{kg})$}} & \multicolumn{4}{|c|}{ Intake $(\mu \mathrm{g} / \mathrm{kg}$ bw day $)$} \\
\hline & & & \multicolumn{2}{|c|}{ Consumers $^{\mathrm{a}}$} & \multicolumn{2}{|c|}{ Total population ${ }^{b}$} \\
\hline & LB & UB & LB & UB & LB & UB \\
\hline Pasta & 338.9 & 346.5 & 0.637 & 0.651 & 0.207 & 0.211 \\
\hline Bread & 84.9 & 95.0 & 0.098 & 0.109 & 0.071 & 0.080 \\
\hline Crackers & 80.9 & 101.6 & 0.036 & 0.046 & 0.008 & 0.010 \\
\hline Snacks & 77.4 & 108.0 & 0.074 & 0.104 & 0.003 & 0.004 \\
\hline Maize flour & 68.7 & 155.8 & 0.026 & 0.059 & 0.0 & 0.0 \\
\hline Maize grits & 45.1 & 58.1 & 0.064 & 0.083 & 0.0 & 0.001 \\
\hline Breakfast cereals & 23.2 & 38.8 & 0.007 & 0.012 & 0.0 & 0.0 \\
\hline \multirow[t]{3}{*}{ Popcorn } & 7.9 & 25.9 & 0.002 & 0.007 & 0.0 & 0.0 \\
\hline & & intake & 0.945 & 1.071 & 0.290 & 0.306 \\
\hline & PMTDI $(1 \mu$ & w day) & 94 & 107 & 29 & 31 \\
\hline
\end{tabular}

LB: lower bound; UB: upper bound; PMTDI: provisional maximum tolerable daily intake; ${ }^{a}$ mean consumption among individuals that reported a type food; ball participants of the survey.

Table 5 - Acute dietary exposure assessment of deoxynivalenol from the consumption of maize and wheat-based products.

\begin{tabular}{lcc}
\hline \multirow{2}{*}{ Products } & Contamination $(\boldsymbol{\mu g} / \mathbf{k g})$ & Intake $(\boldsymbol{\mu g} / \mathbf{k g}$ bw day $)$ \\
\cline { 2 - 3 } & \multicolumn{2}{c}{ Lower-upper bound } \\
\hline Pasta & $903.0-903.0$ & $9.25-9.25$ \\
Bread & $84.9-95.0$ & $0.071-0.08$ \\
Crackers & $80.9-101.6$ & $0.008-0.01$ \\
Snacks & $77.4-108.0$ & $0.003-0.004$ \\
Maize flour & $68.7-155.8$ & $0.0-0.0$ \\
Breakfast cereals & $23.2-38.8$ & $0.0-0.0$ \\
Maize grits & $45.1-58.1$ & $0.0-0.001$ \\
Popcorn & $7.9-25.9$ & $0.0-0.0$ \\
\hline & Total intake & $9.33-9.34$ \\
& \% ARfD $(\mathbf{8} \boldsymbol{\mu g} / \mathbf{k g ~ b w ~ d a y ) ~}$ & $117-117$ \\
\hline
\end{tabular}

ARfD: acute reference dose.

Table 6 shows the intakes estimated for total fumonisins (free and bound/hidden forms). Total intakes ranged from 0.15 (LB; total population) to $1.7 \mu \mathrm{g} / \mathrm{kg}$ bw day (UB; consumers). For total population, maize meal contributed the most for total intake (83.4-92.1\%), followed by pasta $(3.5-11.9 \%)$ and popcorn $(1.5-1.7 \%)$. For consumers, maize meal was also the food that most contributed for total intake (55.2-60.3\%), followed by maize flour (11.4-12.2\%), 
maize grits (9.4-9.7\%) and popcorn (4.1-4.4\%). Fumonisin intakes represented up to $8 \%$ of the PMTDI $(2.0 \mu \mathrm{g} / \mathrm{kg} \mathrm{bw})$ for total population and up to $85 \%$ for consumers.

Table 6 - Chronic dietary exposure assessment of total fumonisins from the consumption of maize and wheat based products.

\begin{tabular}{|c|c|c|c|c|c|c|}
\hline \multirow{3}{*}{ Products } & \multirow{2}{*}{\multicolumn{2}{|c|}{ Contamination $(\mu \mathrm{g} / \mathrm{kg})$}} & \multicolumn{4}{|c|}{ Intake $(\mu \mathrm{g} / \mathrm{kg}$ bw day $)$} \\
\hline & & & \multicolumn{2}{|c|}{ Consumers $^{\mathrm{a}}$} & \multicolumn{2}{|c|}{ Total population ${ }^{b}$} \\
\hline & $\mathbf{L B}$ & UB & LB & UB & LB & UB \\
\hline Maize meal & 697.6 & 700.8 & 0.935 & 0.939 & 0.140 & 0.140 \\
\hline Maize flour & 495.8 & 510.1 & 0.188 & 0.194 & 0.0 & 0.0 \\
\hline Popcorn & 251.2 & 260.1 & 0.068 & 0.070 & 0.003 & 0.003 \\
\hline Degermed maize & 164.3 & 182.1 & 0.113 & 0.126 & 0.002 & 0.002 \\
\hline Maize grits & 101.7 & 115.0 & 0.145 & 0.164 & 0.001 & 0.001 \\
\hline Breakfast cereals & 68.0 & 90.2 & 0.020 & 0.027 & 0.0 & 0.0 \\
\hline Snacks & 38.4 & 57.0 & 0.037 & 0.055 & 0.002 & 0.002 \\
\hline Maize starch & 18.8 & 45.7 & 0.027 & 0.066 & 0.0 & 0.0 \\
\hline \multirow[t]{3}{*}{ Pasta } & 8.7 & 32.9 & 0.016 & 0.062 & 0.005 & 0.020 \\
\hline & & tal intake & 1.5 & 1.7 & 0.15 & 0.17 \\
\hline & PMTDI (2 & bw day) & 77 & 85 & 8 & 8 \\
\hline
\end{tabular}

LB: lower bound; UB: upper bound; PMTDI: provisional maximum tolerable daily intake; ${ }^{a}$ mean consumption among individuals that reported a type food; ball participants of the survey.

Fumonisins intakes estimated for the Brazilian total population were similar to those calculated by Bordin et al. (2014) and Martins et al. (2012), who found intakes representing 3 and 6\% of the PMTDI, respectively. Bordin et al. (2014), analyzed just FB1 in corn products $(103.5-476.6 \mu \mathrm{g} / \mathrm{kg}$; mean level) and estimated food consumption through application of food questionnaires. Samples collected by Martins et al. (2012) were analyzed for FB1 and FB2 (457 $\mu \mathrm{g} / \mathrm{kg}$; mean level of maize-based products) and food consumption obtained from the 2008/2009 POF. Previously work conducted by Caldas, Silva. (2007) using the data from 2003/2004 POF also showed that maize meal was the main contributor to fumonisins exposure for the Brazilian population (74\% of total intake), although the intakes were much higher, representing $24.1 \%$ of the PMTDI for total population and $355 \%$ for consumers. The lower intakes found in the present study compared to the work by Caldas and Silva is probably due to the establishment of MLs by Brazilian authorities in 2011 (BRASIL, 2011). For example, mean level of fumonisin contamination in maize meal dropped from $3320 \mu \mathrm{g} / \mathrm{kg}$ (CALDAS; SILVA, 2007 ) to $697.6 \mu \mathrm{g} / \mathrm{kg}$ in the present study ( $\mathrm{ML}=2500 \mu \mathrm{g} / \mathrm{kg}$, since 2014). 
Total intakes estimated for ZON ranged from 0.04 (LB; total population) to $0.18 \mu \mathrm{g} / \mathrm{kg}$ (UB; consumers) (Table 7). Products that most contributed to total intake for consumers were pasta (40.4-49.6\%), crackers (14.9-19.7\%), bread (10.3-10.9\%) and snacks (9.0-11.9\%). For total population, higher intakes were due to consumption of pasta (49.7-54.1\%), bread (26.8$28.5 \%)$, crackers (12.5-14.7\%) and maize meal (3.0-7.1\%). ZON intakes represented up to $10 \%$ of the PMTDI $(0.5 \mu \mathrm{g} / \mathrm{kg} \mathrm{bw})$ for the total population and up to $37 \%$ for consumers. Recently, ZON exposure was also evaluated for the Brazilian population through the consumption of pasta and bakery products (BOL et al., 2016). Intake estimated represented $12.6 \%$ of the PMTDI, almost 4 times lower than the estimated in this work, probably due to the fact that maize-based products were not included in the estimation and processing factors were applied to the levels of ZON in wheat flour (75-95\% reduction of ZON during preparation of pasta and bakery products).

Table 7 - Chronic dietary exposure assessment of zearalenone from the consumption of maize and wheat based products.

\begin{tabular}{|c|c|c|c|c|c|c|}
\hline \multirow{3}{*}{ Products } & \multirow{2}{*}{\multicolumn{2}{|c|}{ Contamination $(\mu \mathrm{g} / \mathrm{kg})$}} & \multicolumn{4}{|c|}{ Intake $(\mu \mathrm{g} / \mathrm{kg}$ bw day $)$} \\
\hline & & & \multicolumn{2}{|c|}{ Consumers $^{\mathrm{a}}$} & \multicolumn{2}{|c|}{ Total population $^{b}$} \\
\hline & $\mathbf{L B}$ & $\mathbf{U B}$ & LB & UB & LB & UB \\
\hline Pasta & 36.7 & 39.4 & 0.069 & 0.074 & 0.022 & 0.024 \\
\hline Bread & 13.2 & 16.4 & 0.015 & 0.019 & 0.011 & 0.014 \\
\hline Crackers & 60.7 & 60.7 & 0.027 & 0.027 & 0.006 & 0.006 \\
\hline Degermed maize & 4.6 & 16.0 & 0.003 & 0.011 & 0.0 & 0.0 \\
\hline Maize flour & 8.7 & 19.4 & 0.003 & 0.007 & 0.0 & 0.0 \\
\hline Maize meal & 6.3 & 17.1 & 0.008 & 0.023 & 0.001 & 0.003 \\
\hline \multirow[t]{3}{*}{ Snacks } & 13.0 & 22.8 & 0.012 & 0.022 & 0.001 & 0.001 \\
\hline & \multicolumn{2}{|c|}{ Total intake } & 0.14 & 0.18 & 0.04 & 0.05 \\
\hline & \multicolumn{2}{|c|}{$\%$ PMTDI (0.5 $\mu \mathrm{g} / \mathrm{kg}$ bw day) } & 28 & 37 & 8 & 10 \\
\hline
\end{tabular}

LB: lower bound; UB: upper bound; PMTDI: provisional maximum tolerable daily intake; amean consumption among individuals that reported a type food; ${ }^{b}$ all participants of the survey.

Intakes estimated in this study for fumonisins, DON and ZON may be overestimated as they did not consider the effect of processing factors on mycotoxin contamination. For example, the great contributor for both DON and ZON intakes was pasta, a food that undergoes further preparations steps before consumption. Farahany and Jinap (2011) estimated that the reduction of DON contamination in pasta due to cooking was up to $35 \%$ and, if this factor was used here, the intakes estimated for DON would not surpass the PMTDI and ARfD stablished for this compound. On the other hand, not all types of food that could be contaminated with these 
mycotoxins were included in the intakes estimation. For instance, fumonisins, DON and ZON have been found in beer samples analyzed and, therefore, could contribute to total micotxins intakes (BAUER et al., 2016; BELTRÁN et al., 2013; RODRÍGUEZ-CARRASCO et al., 2015).

In this study, only two cereal samples were contaminated with aflatoxins, one maize snack sample containing AFG2 and one rice pasta containing AFB1 (0.6-0.7 $\mu \mathrm{g} / \mathrm{kg})$, a low incidence compared to other studies. A high occurrence of aflatoxins was found in rice samples (37\%) analyzed in Brazil, with rice accounting for up to 98\% of AFs intake for total population (ANDRADE et al., 2013). Andrade and Caldas (2015) showed that $12.7 \%$ of all raw samples of maize, rice, wheat and sorghum analyzed worldwide were contaminated with at least one aflatoxin. The dietary exposure conducted in the study using GEMS/Food Cluster diets indicated a potential health risk for consumers of all clusters evaluated (different parts of the world).

\section{Conclusion}

The high prevalence of fumonisins (maize-based products), DON and ZON (wheatbased products) were shown in samples collected in the Federal District. Levels of CTV found in samples of crackers, maize snacks and rice were considerably high, although with a low prevalence. Bound/hidden fumonisins were found in all maize-based samples, but contributed the most to the total fumonisins concentration in samples submitted to thermal treatment such as maize pasta, breakfast cereals and maize snacks.

The preliminary dietary risk assessment conducted is this study indicates a health concern for consumers of maize and wheat products for DON, both for chronic and acute exposures (Intake > PMTDI). Fumonisins and ZON exposures did not exceeded the stablished PMTDIs neither for total population nor for consumers, and do not indicate a health concern. Samples that most contributed to the total intakes were maize meal (fumonisins) and pasta (DON and ZON). It is important to note that the impact of food preparation on mycotoxins concentration was not taking into account in this study and, considering that maize meal and pasta were the products that most contributed to the estimated intakes, any level of reduction obtained through processing could have an impact on the dietary risk assessment.

Although just one sample analyzed was above the ML stablished by Brazilian Government, any level of mycotoxin contamination in cereals and cereals-based products have an important impact in the total exposure due to the high consumption of these products. Thus, 
the occurrence of mycotoxins in cereals and cereals-based products should be continuously monitored and the processing factors for food preparation should be determined in order to refine the estimated dietary risk assessment. 


\section{CONCLUSÕES FINAIS}

A avaliação dos dados mundiais de contaminação de arroz, milho, trigo e sorgo por aflatoxinas, obtidos a partir da literatura existente bem como do banco de dados do GEMS/Food, revelou um panorama de elevada incidência de AFs nos cereais comercializados internacionalmente. $\mathrm{O}$ arroz foi um dos cereais com maior número de amostras positivas, além de apresentar também os maiores índices de contaminação por AFs. A avaliação da exposição às AFs pela dieta indicou risco à saúde para as populações de todas as regiões do mundo (todos os clusters), e em especial aquelas que têm o arroz como base na alimentação, o que é o caso do Brasil. Estes resultados demonstram a importância do monitoramento constante da presença de contaminantes em cereais e, considerando sua participação na dieta da população mundial, reafirmam a necessidade de ações que mantenham o nível de AFs o mais baixo possível.

É importante destacar que o risco da exposição deve ser continuamente reduzido, mas a segurança alimentar (disponibilidade de alimentos) deve ser garantida. Entre as ações que impactam na redução da contaminação de cereais por AFs podemos ressaltar a elaboração e divulgação de Código de Práticas, bem como o estabelecimento de limites máximos. Pelos resultados apresentados, as ações de controle devem ser priorizadas para as commodities arroz, milho e trigo.

Foi possível estabelecer e validar um método multi-micotoxinas para análise de aflatoxinas (AFB1, AFB2, AFG1 e AFG2), CTV, DON, 15AcDON, 3AcDON, D3G, DOM, fumonisinas (FB1, FB2, FB3 e HFB1), OTA, ZON e $\alpha$-ZOL em arroz e derivados, produtos de milho e produtos de trigo, utilizando calibração interna isotópica e LC-MS/MS. O método utilizado é de fácil implementação, pois não utiliza etapas de purificação, o que reduz o tempo e o custo de análise. O efeito de matriz foi pronunciado para algumas micotoxinas em produtos de milho e trigo, o que foi solucionado pela utilização da calibração interna isotópica.

A determinação das fumonisinas totais foi obtida pela soma das formas livres determinadas pelo método multi-micotoxinas com as formas ligadas/ocultadas avaliadas após a hidrólise em meio alcalino dos produtos de milho. O método utilizado se baseou na conversão das formas ligadas/ocultas nas formas hidrolisadas (HFB1, HFB2 e HFB3) pela ação do KOH, seguido de extração sólido líquido com purificação à baixa temperatura e análise por LCMS/MS. A eficiência da hidrólise foi determinada com sucesso, tanto para a produção dos padrões analíticos das fumonisinas hidrolisadas, quanto na hidrólise de farinha de milho naturalmente contaminadas por fumonisinas. 
A análise das amostras coletadas no Distrito Federal demonstrou alta incidência de contaminação nos produtos avaliados, principalmente pela presença de fumonisinas nos produtos de milho e DON e ZON nos produtos de trigo. A presença de CTV em amostras de arroz, salgadinhos de milho e bolachas salgadas (trigo) em níveis altos de contaminação, mostra a necessidade da inclusão desta micotoxina em ações de monitoramento, especialmente após o surto de beribéri ocorrido no norte do Brasil. As fumonisinas ligadas/ocultas foram encontradas em todas as amostras de produtos de milho avaliadas, mesmo naquelas que não estavam contaminadas pelas formas livres. As formas ligadas/ocultas tiveram maior contribuição para o valor de contaminação das fumonisinas totais nas amostras que foram submetidas a tratamentos térmicos, como massas, cereais matinais e salgadinhos.

De maneira geral, as ingestões de DON, fumonisinas e ZON estimadas neste estudo para a população total não demontraram situação de risco, entretanto, as estimativas realizadas para DON em consumidores de produtos de milho e trigo mostraram um cenário de potencial risco à saúde, tanto para a exposição crônica, quanto para a aguda. É importante ressaltar que, neste estudo de avaliação preliminar da exposição, não foram considerados os fatores de processamento e, portanto, as ingestões podem estar superestimadas. Sendo assim, considerando a importância dos cereais para a dieta brasileira, é de extrema importância o contínuo monitoramento da presença de micotoxinas nesses produtos, uma vez que qualquer nível de contaminação pode causar grande impacto na exposição. Além disso, para que as estimativas de exposição sejam cada vez mais realistas é fundamental que fatores de processamento sejam estimados, principalmente para os produtos como fubá e massas alimentícias, alimentos que mais impactaram nas ingestões calculadas neste estudo. 


\section{REFERÊNCIAS}

ABBAS, H. K. et al. Effect of cleaning, milling, and baking on deoxynivalenol in wheat. Applied and Environmental Microbiology , v. 50 , n. 2 , p. 482-486, 1985.

AFOLABI, C. G. et al. Effect of Sorting on Incidence and Occurrence of Fumonisins and Fusarium verticillioides on Maize from Nigeria. Journal of Food Protection, v. 8, p. 17682035, 2006.

AISH, J. L. et al. Ochratoxin A. In: MAGAN, N.; OLSEN, M. (Eds.). Mycotoxins in food detection and control. Cambridge, England: Woodhead Publishing Limited, 2004. p. 307338 .

ALMEIDA, A. P. DE et al. Occurrence of deoxynivalenol in wheat flour, instant noodle and biscuits commercialised in Brazil. Food Additives \& Contaminants: Part B, p. 1-5, 2016.

ALMEIDA, M. I. et al. Co-occurrence of aflatoxins $B_{1}, B_{2}, G_{1}$ and $G_{2}$, ochratoxin A, zearalenone, deoxynivalenol, and citreoviridin in rice in Brazil. Food additives \& contaminants: Part A, v. 29, n. 4, p. 694-703, 2012.

ALMEIDA, M. I. D. Método para determinação de citreoviridina em amostras de arroz e suas frações de beneficiamento (quirera, casco e farelo). Revista de Ciências da Vida, v. 28, p. 147-149, 2008.

AMARAL, K. A. S. et al. Aflatoxinas em produtos à base de milho comercializados no Brasil e riscos para a saúde humana. Aflatoxins in corn-based food products traded in Brazil and risks to human health, v. 26, n. 2, p. 336-342, 2006.

ANDRADE, P. D. et al. Aflatoxins in food products consumed in Brazil: a preliminary dietary risk assessment. Food Additives \& Contaminants: Part A, v. 30, n. 1, p. 127-136, 2013.

ANDRADE, P. D.; CALDAS, E. D. Aflatoxins in cereals: worldwide occurrence and dietary risk assessment. World Mycotoxin Journal, v. 8, n. 4, p. 415-431, 2015.

APSIM. AFLOMAN Programm. Disponível em: <http://www.apsim.info/afloman>. Acesso em: 17 jul. 2016.

ARAÚJO, M. O. D.; GUERRA, T. M. M. Alimentos per capta. 3. ed. Natal: Editora da UFRN, 2007.

ASAM, S.; RYCHLIK, M. Studies on accuracy of trichothecene multitoxin analysis using stable isotope dilution assays. Mycotoxin Research, v. 23, n. 4, p. 191-198, 2007.

BARTÓK, T. et al. Detection of new fumonisin mycotoxins and fumonisin-like compounds by reversed-phase high-performance liquid chromatography/electrospray ionization ion trap mass spectrometry. Rapid Communications in Mass Spectrometry, v. 20, n. 16, p. 2447 2462, 2006.

BATTILANI, P. et al. Logistic Regression Modeling of Cropping Systems To Predict Fumonisin Contamination in Maize. Journal of Agricultural and Food Chemistry, v. 56, n. 21, p. 10433-10438, 12 nov. 2008.

BATUMAN, V. Fifty years of Balkan endemic nephropathy: daunting questions, elusive answers. Kidney International, v. 69, n. 4, p. 644, 2006.

BAYMAN, P.; BAKER, J. Ochratoxins: A global perspective. Mycopathologia, v. 162, n. 3, p. 215-223, 2006.

BECKER-ALGERI, T. A. et al. Thermal treatments and their effects on the fumonisin B1 level 
in rice.Food Control, v. 34, p. 488-493.

BEDARD, L. L.; MASSEY, T. E. Aflatoxin B1-induced DNA damage and its repair. Cancer Letters, v. 241, n. 2, p. 174-183, 2006.

BELTRÁN, E. et al. Development of sensitive and rapid analytical methodology for food analysis of 18 mycotoxins included in a total diet study. Analytica Chimica Acta, v. 783, p. 39-48, 2013.

BENNETT, R. A.; ESSIGMANN, J. M.; WOGAN, G. N. Excretion of an Aflatoxin-Guanine Adduct in the Urine of Aflatoxin Entreated Rats. Cancer Research, v. 41, n. 2, p. 650-654, 1981.

BERTHILLER, F. et al. Masked mycotoxins: Determination of a deoxynivalenol glucoside in artificially and naturally contaminated wheat by liquid chromatography-tandem mass spectrometry. Journal of Agricultural and Food Chemistry, v. 53, n. 9, p. 3421-3425, 2005.

BERTHILLER, F. et al. Liquid chromatography coupled to tandem mass spectrometry (LCMS/MS) determination of phase II metabolites of the mycotoxin zearalenone in the model plant Arabidopsis thaliana. Food additives and contaminants, v. 23, n. 11, p. 1194-200, 2006.

BERTHILLER, F. et al. Chromatographic methods for the simultaneous determination of mycotoxins and their conjugates in cereals. International Journal of Food Microbiology, v. 119, n. 1-2, p. 33-37, 2007.

BERTHILLER, F. et al. Formation, determination and significance of masked and other conjugated mycotoxins. Analytical and Bioanalytical Chemistry, v. 395, n. 5, p. $1243-$ 1252, 2009.

BERTHILLER, F. et al. Hydrolytic fate of deoxynivalenol-3-glucoside during digestion. Toxicology Letters, v. 206, n. 3, p. 264-267, 2011.

BERTHILlER, F. et al. Masked mycotoxins: A review. Molecular Nutrition and Food Research, v. 57, n. 1, p. 165-186, 2013.

BITTNER, A.; CRAMER, B.; HUMPF, H. U. Matrix binding of ochratoxin a during roasting. Journal of Agricultural and Food Chemistry, v. 61, n. 51, p. 12737-12743, 2013.

BOEVRE, M. et al. Development and validation of an LC-MS/MS method for the simultaneous determination of deoxynivalenol, zearalenone, T-2-toxin and some masked metabolites in different cereals and cereal-derived food. Food Additives \& Contaminants: Part A, v. 29, n. 5 , p. 819-835, 2012.

BOL, E. K. et al. Estimated exposure to zearalenone, ochratoxin A and aflatoxin B1 through the consume of bakery products and pasta considering effects of food processing. Food and Chemical Toxicology, v. 89, p. 85-91, 2016.

BORDIN, K. et al. Assessment of dietary intake of fumonisin B1 in São Paulo, Brazil. Food Chemistry, v. 155, p. 174-178, 15 jul. 2014.

BRASIL. Guia alimentar para a população brasileira. Guia alimentar para a população, p. 210, 2008.

BRASIL. Ministério da Saúde. Resolução nº 7, de 18 de fevereiro de 2011 da ANVISA. Aprova o Regulamento Técnico Sobre Limites Máximos Tolerados (LMT) para micotoxinas em alimentos. Diário Oficial da União - D.O.U., de 22 de fevereiro de 2011 
BRASIL. Ministério da Saúde. Agência Nacional de Vigilância Sanitária. Resolução -RDC n ${ }^{\circ}$ 274 de 15 de outubro de 2002. Aprova o regulamento técnico sobre limites máximos de aflatoxinas admissíveis no leite, no amendoim e no milho. Diário Oficial da União D.O.U., de 16 de outubro de 2002.

BRASIL. Ministério da Saúde. Agência Nacional de Vigilância Sanitária. Resolução - RDC $\mathrm{N}^{\mathrm{o}}$ 59, de 26 de dezembro de 2013. Diário Oficial da União - D.O.U., de 30 de dezembro de 2013, 2013.

BRERA, C. et al. Effect of Industrial Processing on the Distribution of Fumonisin B1 in Dry Milling Corn Fractions. Journal of Food Protection, v. 6, p. 1092-1308, 2004.

BRERA, C. et al. Effect of Industrial Processing on the Distribution of Aflatoxins and Zearalenone in Corn-Milling Fractions. Journal of Agricultural and Food Chemistry, v. 54, n. 14, p. 5014-5019, 2006.

BRERA, C. et al. Mycotoxins. In: PICÓ, Y. (Ed.). Comprehensive Analytical Chemistry. 1. ed. Amsterdam, The Netherlands. 2008. p. 363-427.

BRETZ, M. et al. Thermal Degradation of the Fusarium Mycotoxin Deoxynivalenol. Journal of Agricultural and Food Chemistry, v. 54, n. 17, p. 6445-6451, 2006.

BRYŁA, M. et al. Free and hidden fumonisins in various fractions of maize dry milled under model conditions. LWT - Food Science and Technology, v. 64, n. 1, p. 171-176, 2015.

BULLERMAN, L. B.; BIANCHINI, A. Stability of mycotoxins during food processing. International Journal of Food Microbiology, v. 119, n. 1, p. 140-146, 2007.

CALDAS, E. D.; SILVA, A. C. S. Mycotoxins in corn-based food products consumed in Brazil: An exposure assessment for fumonisins. Journal of Agricultural and Food Chemistry, v. 55, n. 19, p. 7974-7980, 2007.

CAMPONE, L.; PICCINELLI, A. L.; RASTRELLI, L. Dispersive liquid-liquid microextraction combined with high-performance liquid chromatography-tandem mass spectrometry for the identification and the accurate quantification by isotope dilution assay of Ochratoxin A in wine samples. Analytical and Bioanalytical Chemistry, v. 399, n. 3, p. 1279-1286, 2011.

CALORI-DOMINGUES, M. A. et al. Co-occurrence and distribution of deoxynivalenol, nivalenol and zearalenone in wheat from Brazil. Food Additives \& Contaminants: Part B, v. 9, n. 2, p. 142-151, 2016.

CAPRIOTTI, A. L. et al. Multiclass mycotoxin analysis in food, environmental and biological matrices with chromatography/mass spectrometry. Mass Spectrometry Reviews, v. 31, n. 4, p. 466-503, 2012.

CAPRIOTTI, A. L. et al. Development and validation of a liquid chromatography/atmospheric pressure photoionization-tandem mass spectrometric method for the analysis of mycotoxins subjected to commission regulation (EC) No. 1881/2006 in cereals. Journal of Chromatography A, v. 1217, p. 6044-6051, 2010.

CARVALHO, R. A. DE et al. Incidencia de fungos toxigênicos e aflatoxinas em arroz. Ciência e Agrotecnologia, v. 34, n. 4, p. 946-952, ago. 2010.

CAST. Council for Agricultural Science and Technology . Mycotoxins: Risks in Plant, Animal, and Human Systems. Ames, Iowa - USA: Council for Agricultural Science and Technology, n.139, p. 199, 2003.

CASTELLS, M. et al. Reduction of Aflatoxins by Extrusion-Cooking of Rice Meal. Journal 
of Food Science, v. 71, n. 7, p. C369-C377, 2006.

CASTELLS, M. et al. Distribution of total aflatoxins in milled fractions of hulled rice. Journal of Agricultural and Food Chemistry, v. 55, n. 7, p. 2760-2764, 2007.

CASTELLS, M. et al. Distribution of fumonisins and aflatoxins in corn fractions during industrial cornflake processing. International Journal of Food Microbiology, v. 123, n. 1, p. 81-87, 2008.

CASTELO, M. M. et al. Loss of Fuminosin B1 in Extruded and Baked Corn-Based Foods with Sugars. Journal of Food Science, v. 66, n. 3, p. 416-421, 2001.

CASTELO, M. M.; SUMNER, S. S.; BULLERMAN, L. B. Stability of Fumonisins in Thermally Processed Corn Products. Journal of Food Protection, v. 8, p. 929-1086, 1998.

CASTRO, M. F. P. M. et al. Fumonisins in Brazilian corn-based foods for infant consumption. Food Additives and Contaminants, v. 21, n. 7, p. 693-699, 2004.

CAVALIERE, C. et al. Development of a multiresidue method for analysis of major Fusarium mycotoxins in corn meal using liquid chromatography/tandem mass spectrometry. Rapid Communications in Mass Spectrometry, v. 19, n. 14, p. 2085-2093, 2005.

CAWOOD, M. E. Isolation of the fumonisin mycotoxins: A quantitative approach. Journal of Agricultural and Food Chemistry, v. 39, n. 11, p. 1958-1962, 1991.

CAZZANIGA, D. et al. Mycotoxins inactivation by extrusion cooking of corn flour. Letters in Applied Microbiology, v. 33, n. 2, p. 144-147, 2001.

CETIN, Y.; BULLERMAN, L. B. Evaluation of Reduced Toxicity of Zearalenone by Extrusion Processing As Measured by the MTT Cell Proliferation Assay. Journal of Agricultural and Food Chemistry, v. 53, n. 16, p. 6558-6563, 2005.

CHAYTOR, A. C. et al. Effects of chronic exposure of diets with reduced concentrations of aflatoxin and deoxynivalenol on growth and immune status of pigs. Journal of Animal Science, v. 89, n. 1, p. 124-135, 2011.

CIRLINI, M.; DALL'ASTA, C.; GALAVERNA, G. Hyphenated chromatographic techniques for structural characterization and determination of masked mycotoxins. Journal of Chromatography A, v. 1255, p. 145-152, 2012.

CNNPA. Comissão Nacional de Normas e Padrões para Alimentos. Resolução n`34 [Internet]. Brasil: 1977. Disponível em: http://portal.anvisa.gov.br/wps/wcm/connect/ 41eccf00474580fd8d18dd3fbc4c6735/CNNPA+n\%C2\%BA+34\%2C+de+1976.pdf?MOD =AJP ERES. Acesso em 17 de julho de 2016.

CODEX ALIMENTARIUS. Codex general stadard for contaminants and toxins in food and feed. CODEX STAN 193-195. Disponível em: <http://www.fao.org/fileadmin/user_upload/livestockgov/documents/1_CXS_193e.pdf>. Acesso em 16 de julho de 2016.

CODEX ALIMENTARIUS. Code of practice for the prevention and reduction of mycotoxin contamination in cereals, including annexes on ochratoxin a, zearalenone, fumonisins and tricothecenes. CAC/RCP 51-2003 2003. Disponível em: <http://www.fao.org/fao-whocodexalimentarius/sh-proxy/ar/?lnk=1\&url=https $\% 25$

3A\%252F\%252Fworkspace.fao.org\%252Fsites $\% 252$ Fcodex $\% 252 \mathrm{FStandards} \% 252 \mathrm{FCAC}$

\%2BRCP\%2B51-2003\%252FCXP_051e.pdf>. Acesso em 16 de julho de 2016.

CODEX ALIMENTARIUS. Discussion paper on aflatoxins in cereals - CX/CF 13/7/18 2013. Rome, Italy. Disponível em: <ftp://ftp.fao.org/codex/meetings/cccf/cccf7/ cf07_18e.pdf>. 
Acesso em 16 de julho de 2016.

CODEX ALIMENTARIUS. Discussion paper on the possible revision of the Code of Practice for the Prevention and Reduction of Mycotoxin Contamination in Cereals - CX/CF 14/8/14 2014. Rome, Italy. Disponível em: <ftp://ftp.fao.org/codex/ meetings/cccf/cccf8/cf08_14e.pdf>. Acesso em 16 jul. 2016.

COSTA, A. N. et al. An analysis of the phosphoproteome of immune cell lines exposed to the immunomodulatory mycotoxin deoxynivalenol. Biochimica et Biophysica Acta - Proteins and Proteomics, v. 1814, n. 7, p. 850-857, 2011.

CRAMER, B.; KÖNIGS, M.; HUMPF, H.-U. Identification and in vitro cytotoxicity of ochratoxin A degradation products formed during coffee roasting. Journal of agricultural and food chemistry, v. 56, n. 14, p. 5673, 2008.

DAENICKE, S. et al. Effects of deoxynivalenol (DON) and related compounds on bovine peripheral blood mononuclear cells (PBMC) in vitro and in vivo. Mycotoxin Research, $v$. 27, n. 1, p. 49-55, 2011.

DALL'ASTA, C. et al. A LC/MS/MS method for the simultaneous quantification of free and masked fumonisins in maize and maize-based products. World Mycotoxin Journal, v. 1, n. 3, p. 237-246, 2008.

DALL'ASTA, C. et al. Difficulties in fumonisin determination: The issue of hidden fumonisins. Analytical and Bioanalytical Chemistry, v. 395, n. 5, p. 1335-1345, 2009a.

DALL'ASTA, C. et al. Free and bound fumonisins in gluten-free food products. Molecular Nutrition and Food Research, v. 53, n. 4, p. 492-499, 2009b.

DATTA, S. C.; GHOSH, J. J. Production and purification ofPenicillium citreoviride toxin and its effect on tpp-dependent liver transketolase. Folia Microbiologica, v. 26, n. 5, p. 408412, 1981.

DE LA CAMPA, R.; MILLER, J. D.; HENDRICKS, K. Fumonisin in tortillas produced in small-scale facilities and effect of traditional masa production methods on this mycotoxin. Journal of Agricultural and Food Chemistry, v. 52, n. 14, p. 4432-4437, 2004.

DESPHANDE, S. S. The Science of Toxicology. Handbook of Food Toxicology, p. 8-16, 2002.

DING, X.; LICHTI, K.; STAUDINGER, J. L. The mycoestrogen zearalenone induces CYP3A through activation of the pregnane $\mathrm{X}$ receptor. Toxicological sciences : an official journal of the Society of Toxicology, v. 91, n. 2, p. 448-55, 2006.

DOMBRINK-KURTZMAN, M. A. et al. Effect of nixtamalization (alkaline cooking) on fumonisin-contaminated corn for production of masa and tortillas. Journal of Agricultural and Food Chemistry, v. 48, n. 11, p. 5781-5787, 2000.

DORS, G.; BIERHALS, V. DA S.; BADIALE-FURLONG, E. Parboiled rice: chemical composition and the occurrence of mycotoxins. Ciência e Tecnologia de Alimentos, v. 31, n.1, p. 172-177, 2011.

EATON, D. L.; GALLAGHER, E. Mechanism of aflatoxin carcinogenesis. Annual Review of Pharmacology Toxicology, v.34, p. 135-172, 1994.

EC. Commission regulation. EC $\mathrm{n}^{\circ} 1881 / 2006$ of 19 December 2006 - Setting maximum levels for certain contaminants in foodstuffs. Official Journal of the European Union, 2006.

EFSA. European Food Safety Authority. Opinion of the scientific committee on a request from 
EFSA related to a harmonized approach for risk assessment of substances which are both genotoxic and carcinogenic. The EFSA Journal. 282: 31 p. 2005.

EFSA. European Food Safety Authority. Guidance of EFSA - Use of the EFSA Comprehensive European Food Consumption Database in Exposure Assessment. The EFSA Journal, v. 9, n.3, p. 2097, 2011.

EL-BANNA, A. A.; PITT, J. I.; LEISTNER, L. Production of Mycotoxins by Penicillium Species. Systematic and Applied Microbiology, v. 10, n. 1, p. 42-46, 1987.

EL-SHARKAWAY, S. H. et al. Microbial transformation of zearalenone to a zearalenone sulfate. Applied and Environmental Microbiology, v. 57, n. 2, p. 549-552, 1991.

EL-SHARKAWY, S.; ABUL-HAJJ, Y. Microbial Transformation of Zearalenone, I. Formation of Zearalenone-4-O- $\beta$-glucoside. Journal of Natural Products, v. 50, n. 3, p. 520-521, 1987.

ERIKSEN, G. S. et al. Transformation of Trichothecenes in Ileal Digesta and Faeces from Pigs. Archiv für Tierernaehrung, v. 56, n. 4, p. 263-274, 2002.

ERIKSEN, G. S.; PETTERSSON, H.; LUNDH, T. Comparative cytotoxicity of deoxynivalenol, nivalenol, their acetylated derivatives and de-epoxy metabolites. Food and Chemical Toxicology, v. 42, n. 4, p. 619-624, 2004.

FALAVIGNA, C. et al. Masked fumonisins in processed food: co-occurrence of hidden and bound forms and their stability under digestive conditions. WORLD MYCOTOXIN JOURNAL, v. 5, n. 3, p. 325-334, 2012.

FAO/WHO. Food and Agricultural Organization and World Health Organization. Dietary exposure assessment of chemicals in food: report of a joint FAO/WHO consultation. Annapolis: 2005. Disponível em: http://whqlibdoc:Who.int/publications/2008/ 97892415597470 _eng.pdf. Acesso em 16 de julho de 2016.

FAO/WHO. Food and Agricultural Organization and World Health Organization. Evaluation of certain food additives and contaminants: seventy-fourth report of the Joint FAO/WHO Expert Committee on Food Additives. WHO technical report series; no. 966, 2011.

FAO/WHO. Food and Agricultural Organization and World Health Organization. Report of the eighth session of the Codex Committee on Contaminants in foods. Geneva, Switzerland. 2014. Disponível em: <ftp://ftp.fao.org/codex/Reports/Reports_2014 /REP14 _CFe.pdf>. Acesso em 16 de julho de 2016.

FAO. FAOSTAT - Statistics division of the Food and Agriculture Organization of the United Nations 2014. Disponível em: <http://faostat.fao.org/site/291/default.aspx>. Acesso em 22 junho de 2014.

FARAHANY, E. M.; JINAP, S. Influence of noodle processing (industrial protocol) on deoxynivalenol. Food Control, v. 22, n. 11, p. 1765-1769, 2011.

FINK-GREMMELS, J.; MALEKINEJAD, H. Clinical effects and biochemical mechanisms associated with exposure to the mycoestrogen zearalenone. Animal Feed Science and Technology, v. 137, n. 3, p. 326-341, 2007.

FIRRAO, G. et al. Prediction of milled maize fumonisin contamination by multispectral image analysis. Journal of Cereal Science, v. 52, n. 2, p. 327-330, 2010.

FISBERG, R. M.; VILLAR, B. S. Manual de Receitas e Medidas Caseiras para Cálculo de Inquéritos alimentares: Manual elaborado para auxiliar o processamento de dados de inquéritos alimentares. 1. ed. São Paulo: Editora Signus, 2002. 
FOLEY, D. C. Systemic infection of corn by fusarium-moniliforme. Phytopathology, v. 52, n. 9, p. 870, 1962.

FORSELL, J. H. et al. Comparison of acute toxicities of deoxynivalenol (vomitoxin) and 15acetyldeoxynivalenol in the B6C3F1 mouse. Food and Chemical Toxicology, v. 25, n. 2, p. 155-162, fev. 1987.

FRENICH, A. G. et al. Simple and high-throughput method for the multimycotoxin analysis in cereals and related foods by ultra-high performance liquid chromatography / tandem mass spectrometry. Food Chemistry, v. 117, n. 4, p. 705-712, 2009.

FRISVAD, J. et al. Fumonisin B-2 production by Aspergillus niger. Jounal of Agricultural and Food Chemistry, v. 55, n. 23, p. 9727-9732, 2007.

FRISVAD, J. C.; THRANE, U.; SAMSON, R. A. Mycotoxin producers. In: DIJKSTERHUIS, J. SAMSON, R. A. (Ed.). . Food Mycology: A Multifaceted Approach to Fungi and Food. New York: CRC Press, 2007. p. 135-160.

GARCIA, D. et al. Predicting mycotoxins in foods: A review. Food Microbiology, v. 26, n. 8, p. 757-769, 2009.

GAREIS, M. et al. Cleavage of Zearalenone-Glycoside, a "Masked" Mycotoxin, during Digestion in Swine. Journal of Veterinary Medicine, Series B, v. 37, n. 1-10, p. 236-240, 1990.

GELDERBLOM, W. C. et al. Fumonisins--novel mycotoxins with cancer-promoting activity produced by Fusarium moniliforme. Appl. Envir. Microbiol., v. 54, n. 7, p. 1806-1811, 1988.

GELDERBLOM, W. C. . et al. Interaction of fumonisin B1 and aflatoxin B1 in a short-term carcinogenesis model in rat liver. Toxicology, v. 171, n. 2, p. 161-173, 2002.

GELDERBLOM, W. C. A. et al. Structure-activity relationships of fumonisins in short-term carcinogenesis and cytotoxicity assays. Food and Chemical Toxicology, v. 31, n. 6, p. 407414, 1993.

GIROLAMO, A. et al. Use of liquid chromatography-high-resolution mass spectrometry for isolation and characterization of hydrolyzed fumonisins and relevant analysis in maize-based products. Journal of Mass Spectrometry, v. 49, n. 4, p. 297-305, 2014.

GOSETTI, F. et al. Signal suppression/enhancement in high-performance liquid chromatography tandem mass spectrometry. Journal of Chromatography A, v. 1217, n. 25, p. 3929-3937, 2010.

GRATZ, S. W.; DUNCAN, G.; RICHARDSON, A. J. The Human Fecal Microbiota Metabolizes Deoxynivalenol and Deoxynivalenol-3-Glucoside and May Be Responsible for Urinary Deepoxy-Deoxynivalenol. Applied and Environmental Microbiology , v. 79 , n. 6 , p. 1821-1825, 2013.

GREENHALGH, R. et al. Synthesis, characterization, and occurrence in bread and cereal products of an isomer of 4-deoxynivalenol (vomitoxin). Journal of Agricultural and Food Chemistry, v. 32, n. 6, p. 1416-1420, 1984.

GROLLMAN, A. P. et al. Aristolochic acid and the etiology of endemic (Balkan) nephropathy. Proceedings of the National Academy of Sciences of the United States of America, v. 104, n. 29, p. 12129, 2007.

GROSS-STEINMEYER, K.; EATON, D. L. Dietary modulation of the biotransformation and genotoxicity of aflatoxin B1. Toxicology, v. 299, n. 2, p. 69-79, 2012. 
GROVE, J. F. Phytotoxic compounds produced by Fusarium equiseti. Part 7. Reactions and rearrangement of the 7-hydroxy-12\{,\}13-epoxytrichothec-9-en-8-one skeleton. J. Chem. Soc.\{,\} Perkin Trans. 1, n. 0, p. 1731-1736, 1985.

GURSOY-YUZUGULLU, O. et al. Aflatoxin genotoxicity is associated with a defective DNA damage response bypassing p53 activation. Liver International, v. 31, n. 4, p. 561-571, 2011.

HÄUBL, G. et al. Characterization and application of isotope-substituted (13C15)deoxynivalenol (DON) as an internal standard for the determination of DON. Food Additives and Contaminants, v. 23, n. 11, p. 1187-1193, 2006a.

HÄUBL, G. et al. Suitability of a fully 13C isotope labeled internal standard for the determination of the mycotoxin deoxynivalenol by LC-MS/MS without clean up. Analytical and Bioanalytical Chemistry, v. 384, n. 3, p. 692-696, 2006 b.

HEWITT, T. C. et al. Occurrence of zearalenone in fresh corn and corn products collected from local Hispanic markets in San Diego County, CA. Food Control, v. 26, n. 2, p. 300-304, 2012.

HOOKER, D. C.; SCHAAFSMA, A. W.; TAMBURIC-ILINCIC, L. Using Weather Variables Pre- and Post-heading to Predict Deoxynivalenol Content in Winter Wheat. Plant Disease, v. 86, n. 6, p. 611-619, 2002.

HOPMANS, E. C.; MURPHY, P. A. Detection of fumonisins B1, B2, and B3 and hydrolyzed fumonisin B1 in corn-containing foods. Journal of Agricultural and Food Chemistry, v. 41, n. 10, p. 1655-1658, 1993.

HOWARD, P. C. et al. Formation of N-(carboxymethyl)fumonisin B-1, following the reaction of fumonisin B-1 with reducing sugars. Journal of Agricultural and Food Chemistry, v. 46, n. 9, p. 3546-3557, 1998.

HUMPF, H. U.; VOSS, K. A. Effects of thermal food processing on the chemical structure and toxicity of fumonisin mycotoxins. Molecular Nutrition and Food Research, v. 48, n. 4, p. 255-269, 2004.

HWANG, J.-H.; LEE, K.-G. Reduction of aflatoxin B1 contamination in wheat by various cooking treatments. Food Chemistry, v. 98, n. 1, p. 71-75, 2006.

IARC. Monographs on the evaluation of carcinogenic risks to humans - Some naturally occurring substances: food items and constituents, heterocyclic aromatic amines and mycotoxins. Lyon, France: World Health Organization, v. 56 1993. Disponível em: <http://monographs.iarc.fr/ENG/Monographs/vol56/mono56.pdf>. Acesso em 13 de julho de 2016.

IARC. Monographs on the evaluation of carcinogenic risks to humans - Some traditional herbal medicines, some mycotoxins, naphthalene and styrene. Lyon, França: World Health Organiztion, $\quad$ v. 2002. D2, Disponível em: <http://monographs.iarc.fr/ENG/Monographs/vol82/mono82.pdf>.

IPCS. International Programme on Chemical Safety . Environmental Health Criteria 240 Principles and methods for the Risk Assessment on Chemicals in Food. WHO Press:2009. Disponível em: http://www.who.int/ipcs/publications/ehc/en/index.html. Acesso em 13 de julho de 2016.

JACKSON, L.; JABLONSKI, J. Fumonisins. In: MAGAN, N.; OLSEN, M. (Eds.). Mycotoxins in food. Cambridge, England: Woodhead Publishing Limited, 2004. p. 367- 
405.

JACKSON, L. S. et al. Effects of Baking and Frying on the Fumonisin B 1 Content of CornBased Foods. Journal of Agricultural and Food Chemistry, v. 45, n. 12, p. 4800-4805, 1997.

JACKSON, L. S. et al. Reduction of Fumonisin B 1 in Corn Grits by Twin-Screw Extrusion. Journal of Food Science, v. 76, n. 6, p. T150-T155, 2011.

JARDIM, A. N. O.; CALDAS, E. D. Exposição humana a substâncias químicas potencialmente tóxicas na dieta e os riscos para saúde. Química Nova, v. 32, n. 7, p. 1898-1909, 2009.

JECFA. Joint FAO/WHO expert committee on food additives - evaluation of certain food additives and contaminants: forty-ninth report of the join FAO/WHO expert committee on food additives. Geneva: WHO technical report series; n. 884, 1999.

JECFA. Joint FAO/WHO Expert Commttee on Food Additives - Evaluation of certain food additives and contaminants: fifty-third report of the Joint FAO/WHO Expert Committee on Food Additives. Geneva, Switzerland: WHO technical report series.; n. 896, 2000.

JECFA. Joint FAO/WHO Expert Commttee on Food Additives - Evaluation of certain mycotoxins in food: fifty-sixth report of the Joint FAO/WHO Expert Committee on Food Additives. Geneva: WHO technical report series; n. 906, 2002.

JECFA. Joint FAO/WHO Expert Commttee on Food Additives - Evaluation of certain food contaminants: sixty-fourth report of the Joint FAO/WHO Expert Committee on Food Additives. Geneva: WHO technical report series; n. 930, 2006.

JECFA. Joint FAO/WHO Expert Commttee on Food Additives - Evaluation of certain contaminants in food: seventy-second report of the Joint FAO/WHO Expert Committee on Food Additives. Geneva: WHO technical report series; n.959, 2011.

JOHANSSON, A. S. et al. Predicting aflatoxin and fumonisin in shelled corn lots using poorquality grade components. Journal of AOAC International, v. 89, n. 2, p. 433, 2006.

KABAK, B. Determination of aflatoxins and ochratoxin A in retail cereal products from Turkey by high performance liquid chromatography with fluorescence detection. Food Control, v. 28, n. 1, p. 1-6, 2012.

KAMIMURA, H. Conversion of zearalenone to zearalenone glycoside by Rhizopus sp. Applied and Environmental Microbiology , v. 52 , n. 3 , p. 515-519, 1986.

KATTA, S. K. et al. Effect of temperature and screw speed on stability of fumonisin B1 in extrusion-cooked corn grits. Cereal Chemistry, v. 76, n. 1, p. 16-20, 1999.

KAWASHIMA, L. M.; VALENTE SOARES, L. M. Incidência de fumonisina B1, aflatoxinas B1, B2, G1 e G2, ocratoxina A e zearalenona em produtos de milho. Ciência e Tecnologia de Alimentos, v. 26, n. 3, p. 516-521, 2006.

KIM, E.-K.; SCOTT, P. M.; LAU, B. P.-Y. Hidden fumonisin in corn flakes. Food additives and contaminants, v. 20, n. 2, p. 161, 2003.

KLICH, M. A.; THOMAS, S. H.; MELLON, J. E. Field Studies on the Mode of Entry of Aspergillus flavus into Cotton Seeds. Mycologia, v. 76, n. 4, p. 665, 1984.

KOTSONIS, F. N.; BURDOCK, G. A. Food Toxicology. In: KLAASSEN, C. D. (Ed.). Casarett and Doull's Toxicology - The basic science of poisons. 7. ed. New York: McGraw-Hill Medical Publishing Division, 2008. p. 1191-1236.

KRSKA, R. et al. Determination of molar absorptivity coefficients for major type-B 
trichothecenes and certification of calibrators for deoxynivalenol and nivalenol. Analytical and Bioanalytical Chemistry, v.388, p. 1215-1226, 2007.

KUIPER-GOODMAN, T. Risk assessment and risk management of mycotoxins in food. In: MAGAN, N. E OLSEN, M. (Ed.). Mycotoxins in food - Detection and control. Cambrige - England: Woodheah Publishing Limited, 2004. p. 3-31.

KUNIHOLM, M. H. et al. Aflatoxin Exposure and Viral Hepatitis in the Etiology of Liver Cirrhosis in The Gambia, West Africa. Environmental Health Perspectives, v. 116, n. 11, p. 1553-1557, 2008.

LANCOVA, K. et al. Transfer of Fusarium mycotoxins and "masked" deoxynivalenol (deoxynivalenol-3-glucoside) from field barley through malt to beer. Food Additives \& Contaminants: Part A, v. 25, n. 6, p. 732-744, 2008.

LATTANZIO, V. M. T. et al. Development and in-house validation of a robust and sensitive solid-phase extraction liquid chromatography/tandem mass spectrometry method for the quantitative determination of aflatoxins B1, B2, G 1, G2, ochratoxin A, deoxynivalenol, zearalenone, T-2 and. Rapid Communications in Mass Spectrometry, v. 25, n. 13, p. 1869-1880, 2011.

LIAO, C. et al. Multi-mycotoxin Analysis of Finished Grain and Nut Products Using HighPerformance Liquid Chromatography - Triple-Quadrupole Mass Spectrometry. Journal of Agricultural and Food Chemistry, v. 61, p. 4771-4782, 2013.

LILLEHOJ, E. B. et al. Aflatoxin-producing Fungi in Preharvest Corn: Inoculum Source in Insects and Soils1. Journal of Environment Quality, v. 9, n. 4, p. 691, 1980.

LIMA, H. C. A. V. et al. Outbreak of beriberi in the state of Maranhão, Brazil: revisiting the mycotoxin aetiologic hypothesis. Tropical Doctor , v. 40 , n. 2, p. 95-97, 1 abr. 2010.

LIU, J. et al. Ochratoxin A induces oxidative DNA damage and G1 phase arrest in human peripheral blood mononuclear cells in vitro \&. Toxicology Letters, v. 211, n. 2, p. 164-171, 2012.

LOGRIECO, A. et al. Toxigenic Fusarium Species and Mycotoxins Associated with Maize Ear Rot in Europe. Plant Pathology, v. 108, n. 7, p. 597-609, 2002.

LU, Y. et al. Characterization of Fumonisin B1-Glucose Reaction Kinetics and Products. Journal of Agricultural and Food Chemistry, v. 50, n. 16, p. 4726-4733, 2002.

MACHINSKI JUNIOR, M.; SOARES, L. M. Fumonisins B1 and B2 in Brazilian corn-based food products. Food Addit Contam, v. 17, n. 10, p. 875-879, 2000.

MAGAN, N.; ALDRED, D. Why do fungi produce mycotoxins? In: DIJKSTERHUIS, J.; SAMSON, R. A. (Eds.). Food Mycology - A multifaceted approach to fungi and food. New York: CRC Press, 2007. p. 121-134.

MAIORANO, A. et al. A dynamic risk assessment model (FUMAgrain) of fumonisin synthesis by Fusarium verticillioides in maize grain in Italy. Crop Protection, v. 28, n. 3, p. 243-256, 2009.

MALACHOVÁ, A. et al. Optimization and validation of a quantitative liquid chromatographytandem mass spectrometric method covering 295 bacterial and fungal metabolites including all regulated mycotoxins in four model food matrices. Journal of Chromatography A, v. 1362, p. 145-156, 2014.

MAPA. Ministério da Pecuária, Agricultura e Abastecimento. Manual of Analytical Quality 
Assurance. Brasília: Ministério da Pecuária, Agricultura e Abastecimento, 2011.

MARIN, S. et al. Effect of water activity and temperature on growth and fumonisin B1 and B2 production by Fusarium proliferatum and F. moniliforme on maize grain. Letters in Applied Microbiology, v. 21, n. 5, p. 298-301, 1995.

MARTINS, F. A. et al. Daily intake estimates of fumonisins in corn-based food products in the population of Parana, Brazil. Food Control, v. 26, n. 2, p. 614-618, 2012.

MATUSZEWSKI, B. K.; CONSTANZER, M. L.; CHAVEZ-ENG, C. M. Strategies for the Assessment of Matrix Effect in Quantitative Bioanalytical Methods Based on HPLCMS/MS. J. Pharm. Biomed. Anal.. Anal. Chem, v. 18, n. 705, p. 347-357, 1998.

MEDEIROS, F. et al. Biological control of mycotoxin-producing molds. Ciencia E Agrotecnologia, v. 36, n. 5, p. 483-497, 2012.

MERRILL, A. et al. Sphingolipid metabolism: Roles in signal transduction and disruption by fumonisins. Environmental Health Perspectives, v. 109, p. 283-289, 2001.

MILLER, J. D. Fungi and mycotoxins in grain: Implications for stored product research. Journal of Stored Products Research, v. 31, n. 1, p. 1-16, 1995.

MISSMER, S. A. et al. Exposure to Fumonisins and the Occurrence of Neural Tube Defects along the Texas-Mexico Border. Environmental Health Perspectives, v. 114, n. 2, p. $237-$ 241, 2006.

NAGL, V. et al. Metabolism of the masked mycotoxin deoxynivalenol-3-glucoside in rats. Toxicology Letters, v. 213, n. 3, p. 367-373, 2012.

NEAGU, C. et al. Effects of industrial cleaning on wheat microbial burden and deoxynivalenol levels. Environmental Engineering and Management Journal, v. 11, n. 10, p. 1857$1863,2012$.

NELSON, P. E.; DESJARDINS, A. E.; PLATTNER, R. D. Fumonisins, Mycotoxins Produced by Fusarium Species: Biology, Chemistry, and Significance. Annual Review of Phytopathology, v. 31, p. 233-252, 1993.

NGFA. National Grain and Feed Association. FDA Regulatory Guidance for Mycotoxins - A Guide for Grain Elevators, Feed Manufacturers, Grain Processors and Exporters: National Grain and Feed Association, 2011.

NICHOLSON, P. Rapid detection of mycotoxigenic fungi in plants. In: MAGAN, N.; OLSEN, M. (Eds.). Mycotoxins in food - Detection and control. Cambridge, England: Woodhead Publishing Limited, 2004. p. 111-136.

NUNES, I. L. et al. Arroz comercializado na região sul do Brasil: aspectos micotoxicológicos e microscópicos. Ciência e Tecnologia de Alimentos, v. 23, n. 2, p. 190-194, 2003.

O'BRIEN, E.; DIETRICH, D. Ochratoxin A: The continuing enigma. Critical Reviews in Toxicology, v. 35, n. 1, p. 33-60, 2005.

OBANOS, A. P.; CERAIN, E. L.; GONZÁLEZ-PEÑAS, A. Influence of roasting and brew preparation on the ochratoxin A content in coffee infusion. Food Additives and Contaminants, v. 22, n. 5, p. 463-471, 2005.

OLIVEIRA, A. DE Q.; SOARES, L. M. V.; SAWAZAKI, E. Survey of deoxynivalenol, diacetoxyscirpenol, and $\mathrm{t} 2$ toxin in popcorn hybrids planted in the state of são paulo and in popcorn commercialized in the city of campinas, SP. Ciência e Tecnologia de Alimentos, v. 21, n. 3, p. 330-333, 2001. 
OLIVEIRA, M. S. et al. Free and hidden fumonisins in Brazilian raw maize samples. Food Control, v. 53, p. 217-221, 2015.

PADILHA, E. M. . et al. Perfil epidemiológico do beribéri notificado de2006 a 2008 no Estado do Maranhão, Brasil. Caderno de Saúde Pública, v. 449-459, n. 27, 2011.

PARK, J. W. et al. Analysis of heat-processed corn foods for fumonisins and bound fumonisins. Food Additives \& Contaminants, v. 21, n. 12, p. 1168-1178, 2004.

PARK, J. W.; KIM, Y.-B. Effect of pressure cooking on aflatoxin B1 in rice. Journal of agricultural and food chemistry, v. 54, n. 6, p. 2431, 2006.

PESTKA, J. J. Deoxynivalenol: mechanisms of action, human exposure, and toxicological relevance. Archives of Toxicology, v. 84, n. 9, p. 663-679, 2010.

PESTKA, J. J.; SMOLINSKI, A. T. Deoxynivalenol: Toxicology and Potential Effects on Humans. Journal of Toxicology and Environmental Health, Part B, v. 8, n. 1, p. 39-69, 142005.

PFOHL-LESZKOWICZ, A. Ochratoxin A and aristolochic acid involvement in nephropathies and associated urothelial tract tumours. Arhiv za higijenu rada i toksikologiju, v. 60, n. 4, p. 465, 2009.

PIETRI, A.; ZANETTI, M.; BERTUZZI, T. Distribution of aflatoxins and fumonisins in drymilled maize fractions. Food Additives and Contaminants - Part A, v. 26, n. 3, p. 372380, 2009.

PINHEIRO, A. B. V. et al. Tabela para avaliação de consumo alimentar em medidas caseiras. 5. ed. São Paulo: Editora Atheneu, 2004.

PITT, J. I. What are mycotoxins? Australian Mycotoxin Newsletter, v. 7, n. 1, 1996.

PITT, J. I. Fungal ecology and the occurrence of mycotoxins. In: NJAPAU, H.; TRUJILLO, S. (Eds.). Mycotoxins and Phycotoxins: Advances in Determination, Toxicology and Exposure Management. The Netherlands: Wageningen Academic Publishers, 2006. p. 3341.

PITT, J. I. et al. IMPROVING PUBLIC HEALTH THROUGH MYCOTOXIN CONTROL. Lyon - France: International Agency for Research on Cancer, 2012.

PITT, J. I.; HOCKING, A. D. Fungi and Food Spoilage. 3. ed. New York: Springer Science + Business Media, 2009.

PITT, J. I.; TANIWAKI, M. H.; COLE, M. B. Mycotoxin production in major crops as influenced by growing, harvesting, storage and processing, with emphasis on the achievement of Food Safety Objectives. Food Control, v. 32, n. 1, p. 205-215, 2013.

PLASENCIA, J.; MIROCHA, C. J. Isolation and characterization of zearalenone sulfate produced by Fusarium spp. Applied and Environmental Microbiology , v. 57 , n. 1, p. 146-150, 1 jan. 1991.

POPPENBERGER, B. et al. Detoxification of the Fusarium Mycotoxin Deoxynivalenol by a UDP-glucosyltransferase from Arabidopsis thaliana. Journal of Biological Chemistry, v. 278, n. 48, p. 47905-47914, 2003.

POPPENBERGER, B. et al. Heterologous Expression of Arabidopsis UDPGlucosyltransferases in Saccharomyces cerevisiae for Production of Zearalenone-4-OGlucoside. Applied and Environmental Microbiology , v. 72 , n. 6 , p. 4404-4410, 2006.

PRANDINI, A. et al. Review of predictive models for Fusarium head blight and related 
mycotoxin contamination in wheat. Food and Chemical Toxicology, v. 47, n. 5, p. 927931, 2009.

QUEIROZ, V. A. V. et al. Occurrence of fumonisins and zearalenone in maize stored in family farm in Minas Gerais, Brazil. Food Control, v. 28, n. 1, p. 83-86, 2012.

RASMUSSEN, P. H. et al. Occurrence of different trichothecenes and deoxynivalenol- 3- $\beta$-Dglucoside in naturally and artificially contaminated Danish cereal grains and whole maize plants. Mycotoxin Research, v. 28, n. 3, p. 181-190, 2012.

REID, L. M. et al. Interaction of Fusarium graminearum and F. moniliforme in Maize Ears: Disease Progress, Fungal Biomass, and Mycotoxin Accumulation. Phytopathology, v. 89, n. 11, p. 1028, 1999.

RHEEDER, J. P.; MARASAS, W. F. O.; VISMER, H. F. Production of Fumonisin Analogs by Fusarium Species. Applied and Environmental Microbiology, v. 68, n. 5, p. 2101, 2002.

ROBBANA-BARNAT, $S$. et al. Protein synthesis inhibition and cardiac lesions associated with deoxynivalenol ingestion in mice. Food Additives \& Contaminants, v. 4, n. 1, p. 49-56, 1987.

ROCHA, M. W.; RESCK, I. S.; CALDAS, E. D. Purification and full characterisation of citreoviridin produced by Penicillium citreonigrum in yeast extract sucrose (YES) medium. Food Additives \& Contaminants: Part A, v. 32, n. 4, p. 584-595, 2015.

ROSA, C. A. R. et al. Production of citreoviridin by Penicillium citreonigrum strains associated with rice consumption and beriberi cases in the Maranhão State, Brazil. Food additives \& contaminants: Part A, v. 27, n. 2, p. 241, 2010.

RUBERT, J.; SOLER, C.; MAÑES, J. Evaluation of matrix solid-phase dispersion (MSPD) extraction for multi-mycotoxin determination in different flours using LC-MS/MS. Talanta, v. 85, n. 1, p. 206-215, 2011.

RYCHLIK, M. et al. Proposal of a comprehensive definition of modified and other forms of mycotoxins including "masked" mycotoxins. Mycotoxin Research, v. 30, n. 4, p. 197-205, 2014.

RYCHLIK, M.; ASAM, S. Stable isotope dilution assays in mycotoxin analysis. Analytical and Bioanalytical Chemistry, v. 390, n. 2, p. 617-628, 2008.

SANTOS, J. S. et al. Monitoramento e nível de ingestão de desoxinivalenol por trigo Monitoring and ingestion of deoxynivalenol by wheat. Semina: Ciências Agrárias, v. 32, n. 4, p. 1439-1450, 2011.

SANTOS, J. S. et al. Natural occurrence of deoxynivalenol in wheat from Paraná State, Brazil and estimated daily intake by wheat products. Food Chemistry, v. 138, p. 90-95, 2013.

SAVI, G. D. et al. Mycoflora and deoxynivalenol in whole wheat grains (Triticum aestivum L.) from Southern Brazil. Food Additives \& Contaminants: Part B, v. 7, n. 3, p. 232-237, 2014.

SCHAAFSMA, A. W.; HOOKER, D. C. Climatic models to predict occurrence of Fusarium toxins in wheat and maize. International Journal of Food Microbiology, v. 119, n. 1-2, p. 116-125, 2007.

SCOTT, P. M.; LAWRENCE, G. A. Stability and problems in recovery of fumonisins added to corn-based foods. Journal of AOAC International, v. 77, n. 2, p. 541-545, 1994.

SCUDAMORE, K. A.; BANKS, J. N.; GUY, R. C. E. Fate of ochratoxin A in the processing 
of whole wheat grain during extrusion. Food Additives and Contaminants, v. 21, n. 5, p. 488-497, 2004.

SCUDAMORE, K. A.; PATEL, S. Fusarium mycotoxins in milling streams from the commercial milling of maize imported to the UK, and relevance to current legislation. Food Additives and Contaminants - Part A, v. 26, n. 5, p. 744-753, 2009.

SCUDAMORE, K.; BANKS, J.; MACDONALD, S. J. Fate of ochratoxin A in the processing of whole wheat grains during milling and bread production. Food Additivves and Contaminants, v. 20, n. 12, p. 1153-1163, 2003.

SCUDAMORE, K.; PATEL, S. The fate of deoxynivalenol and fumonisins in wheat and maize during commercial breakfast cereal production. World Mycotoxin Journal, v. 1, n. 4, p. 437-448, 2008.

SEEFELDER, W.; HARTL, M.; HUMPF, H.-U. Determination of N-(Carboxymethyl) fumonisin B1 in Corn Products by Liquid Chromatography/Electrospray Ionization-Mass Spectrometry. Journal of Agricultural and Food Chemistry, v. 49, n. 5, p. 2146-2151, 2001.

SEEFELDER, W.; KNECHT, A.; HUMPF, H. U. Bound fumonisin B1: Analysis of fumonisinB1 glyco and amino acid conjugates by liquid chromatography-electrospray ionizationtandem mass spectrometry. Journal of Agricultural and Food Chemistry, v. 51, n. 18, p. 5567-5573, 2003.

SEKIYAMA, B. L. et al. Aflatoxins, ochratoxin A and zearalenone in maize-based food products. Brazilian Journal of Microbiology, v. 36, n. 3, p. 289-294, set. 2005.

SHERIF, S. O.; SALAMA, E. E.; ABDEL-WAHHAB, M. A. Mycotoxins and child health: The need for health risk assessment. International Journal of Hygiene and Environmental Health, v. 212, n. 4, p. 347-368, 2009.

SHIER, W. T. et al. Biological consequences of fumonisins. Bulletin of the Institute for Comprehensive Agricultural Sciences, v. 8, p. 67-74, 2000.

SIWELA, A. H. et al. Decontamination of aflatoxin-contaminated maize by dehulling. Journal of the Science of Food and Agriculture, v. 85, n. 15, p. 2535-2538, 2005.

SORENSEN, L.; ELBAK, T. Determination of mycotoxins in bovine milk by liquid chromatography tandem mass spectrometry. Journal of Chromatography B, v. 820, n. 2, p. 183-196, 2005.

STUBBLEFIELD, R. D.; GREER, J. I.; SHOTWELL, O. L. Liquid chromatographic method for determination of citreoviridin in corn and rice. Journal - Association of Official Analytical Chemists, v. 71, n. 4, p. 721-724, 1988.

SUBIRADE, I. Fate of ochratoxin A during breadmaking. Food additives and contaminants, v. 13 Suppl, p. 25-26, 1996.

SULYOK, M. et al. Development and validation of a liquid chromatography/tandem mass spectrometric method for the determination of 39 mycotoxins in wheat and maize. Rapid Communications in Mass Spectrometry, v. 20, n. 18, p. 2649-2659, 2006.

SULYOK, M.; KRSKA, R.; SCHUHMACHER, R. A liquid chromatography / tandem mass spectrometric multi-mycotoxin method for the quantification of 87 analytes and its application to semi-quantitative screening of moldy food samples. Analytical and Bioanalytical Chemistry, v. 389, n. 5, p. 1505-1523, 2007.

SYDENHAM, E. W. et al. Potential of alkaline hydrolysis for the removal of fumonisins from 
contaminated corn. Journal of Agricultural and Food Chemistry, v. 43, n. 5, p. 11981201, 1995.

TANIWAKI, M. H.; IAMANAKA, B. T.; SILVA, N. Fungos deterioradores de alimentos: Ocorrência e detecção. Campinas - São Paulo: Instituto de Tecnologia de Alimentos (ITAL), 2013.

TATU, C. et al. The etiology of Balkan endemic nephropathy: Still more questions than answers. Environmental Health Perspectives, v. 106, n. 11, p. 689-700, 1998.

THURNHAM, D. I. Thiamin/Beriberi. In: CABALLERO, B. (Ed.). Guide to nutritional supplements. Oxford: Elsevier, 2009. p.381-389.

TKACHUK, R. et al. Removal by specific-gravity table of tombstone kernels and associated trichothecenes from wheat infected with fusarium head blight. Cereal Chemistry, v. 68, n. 4, p. 428-431, 1991.

TRAN, S. T.; SMITH, T. K.; GIRGIS, G. N. A survey of free and conjugated deoxynivalenol in the 2008 corn crop in Ontario, Canada. Journal of the Science of Food and Agriculture, v. 92, n. 1, p. 37-41, 2012.

TURNER, N. W.; SUBRAHMANYAM, S.; PILETSKY, S. A. Analytical methods for determination of mycotoxins: A review. Analytica Chimica Acta, v. 632, n. 2, p. 168-180, 2009.

UENO, Y. Production of Citreoviridin, a Neurotoxic Mycotoxin of Penicillium Citreo-Viride Biourge. In: PURCHASE, I. F. H. (Ed.). Symposium on Mycotoxins in Human Health: London: Palgrave Macmillan UK, 1971. p. 115-132.

UENO, Y. Temperature-dependent production of citreoviridin, a neurotoxin of Penicillium citreo-viride Biourge. The Japanese journal of experimental medicine, v. 42, n. 2, p. 107 114, 1972.

UENO, Y. et al. Fumonisins as a possible contributory risk factor for primary liver cancer: A 3 -year study of corn harvested in Haimen, China, by HPLC and ELISA. Food and Chemical Toxicology, v. 35, n. 12, p. 1143-1150, 1997.

URAGUCHI, K. Mycotoxic origin of cardiac beriberi. Journal of Stored Products Research, v. 5, n. 3, p. 227-236, 1969.

USFDA. U.S. Food and Drug Administration - Guidance for Industry: Action levels for poisonous or deleterious substances in human food and animal feed. U.S. Food and Drug Administration, 2000.

VAN DER FELS-KLERX, H. et al. Development of a European system for identification of emerging mycotoxins in wheat supply chains. World Mycotoxin Journal, v. 2, n. 2, p. 119$127,2009$.

VAN DER FELS-KLERX, H. J. et al. Mycotoxin contamination of cereal grain commodities in relation to climate in North West Europe. Food Additives and Contaminants - Part A, v. 29, n. 10, p. 1581-1592, 2012.

VAN DER WESTHUIZEN, L. et al. Optimising sorting and washing of home-grown maize to reduce fumonisin contamination under laboratory-controlled conditions. Food Control, v. 22, n. 3, p. 396-400, 2011.

VANARA, F.; REYNERI, A.; BLANDINO, M. Fate of fumonisin B.sub.1 in the processing of whole maize kernels during dry-milling. Food Control, v. 20, n. 3, p. 235, 2009. 
VARGA, E. et al. Stable isotope dilution assay for the accurate determination of mycotoxins in maize by UHPLC-MS/MS. Analytical and Bioanalytical Chemistry, v. 402, n. 9, p. 26752686, 2012.

VENDL, O. et al. Occurrence of free and conjugated Fusarium mycotoxins in cereal-based food. Food additives and contaminants: Part A, v. 27, n. 8, p. 1148-52, 2010.

VIDAL, A. et al. The fate of deoxynivalenol and ochratoxin A during the breadmaking process, effects of sourdough use and bran content. Food and Chemical Toxicology, v. 68, p. 5360, 2014.

VISCONTI, A. Fumonisins in Maize Genotypes Grown in Various Geographic Areas. Fumonisins in Food, v. 392, p. 193-204, 1996.

VISCONTI, A. et al. Reduction of deoxynivalenol during durum wheat processing and spaghetti cooking. Toxicology Letters, v. 153, n. 1, p. 181-189, 2004.

VISHWANATH, V. et al. Simultaneous determination of 186 fungal and bacterial metabolites in indoor matrices by liquid chromatography/tandem mass spectrometry. Analytical and Bioanalytical Chemistry, v. 395, n. 5, p. 1355-1372, 2009.

VOSS, K. A. et al. Fate of fumonisins during the production of fried tortilla chips. Journal of Agricultural and Food Chemistry, v. 49, n. 6, p. 3120-3126, 2001.

VOSS, K. A. et al. Reproductive and Sphingolipid Metabolic Effects of Fumonisin B 1 and its Alkaline Hydrolysis Product in LM/Bc Mice: Hydrolyzed Fumonisin B 1 Did Not Cause Neural Tube Defects. Toxicological Sciences, v. 112, n. 2, p. 459-467, 2009.

VOSS, K. A.; SNOOK, M. E. Stability of the mycotoxin deoxynivalenol (DON) during the production of flour-based foods and wheat flake cereal. Food Additives and Contaminants: Part A, v. 27, n. 12, p. 1694-1700, 2010.

WAES, J. G. et al. Maternal Fumonisin Exposure and Risk for Neural Tube Defects : Mechanisms in an In Vivo Mouse Model. Birth Defects Research Part a-Clinical and Molecular Teratology, v. 497, p. 487-497, 2005.

WALLE, J. VAN DE et al. Deoxynivalenol affects in vitro intestinal epithelial cell barrier integrity through inhibition of protein synthesis. Toxicology and Applied Pharmacology, v. 245, n. 3, p. 291-298, 2010.

WANG, E. et al. Inhibition of sphingolipid biosynthesis by fumonisins. Implications for diseases associated with Fusarium moniliforme. The Journal of biological chemistry, $v$. 266, n. 22, p. 14486, 1991.

WARTH, B. et al. Quantitation of Mycotoxins in Food and Feed from Burkina Faso and Mozambique Using a Modern LC-MS/MS Multitoxin Method. Journal of Agricultural and Food Chemistry, v. 60, n. 36, 2012.

WICKLOW, D. T. et al. Citreoviridin levels in Eupenicillium ochrosalmoneum-infested maize kernels at harvest. Applied and Environmental Microbiology, v. 54, n. 5, p. 1096-1098, 1988.

WICKLOW, D. T.; COLE, R. J. Citreoviridin in Standing Corn Infested by Eupenicillium ochrosalmoneum. Mycologia, v. 76, n. 5, p. 959-961, 1984.

WILK-ZASADNA, I.; MINTA, M. Developmental toxicity of Ochratoxin A in rat embryo midbrain micromass cultures. International journal of molecular sciences, v. 10, n. 1, p. 37-49, 272009. 
WILLIAMS, J. H. et al. Human aflatoxicosis in developing countries: a review of toxicology, exposure, potential health consequences, and interventions. American Journal Of Clinical Nutrition, v. 80, n. 5, p. 1106-1122, 2004.

WOO, L. L. et al. Aflatoxin B 1-DNA adduct formation and mutagenicity in livers of neonatal male and female B6C3F1 mice. Toxicological Sciences, v. 122, n. 1, p. 38-44, 2011.

YOUNG, J. C.; BLACKWELL, B. A.; APSIMON, J. W. Alkaline degradation of the mycotoxin 4-deoxynivalenol. Tetrahedron Letters, v. 27, n. 9, p. 1019-1022, 1986.

YUMBE-GUEVARA, B. E.; IMOTO, T.; YOSHIZAWA, T. Effects of heating procedures on deoxynivalenol, nivalenol and zearalenone levels in naturally contaminated barley and wheat. Food Additives \& Contaminants, v. 20, n. 12, p. 1132-1140, 12003.

ZACHARIASOVA, M. et al. Deoxynivalenol oligoglycosides: New "masked” fusarium toxins occurring in malt, beer, and breadstuff. Journal of Agricultural and Food Chemistry, v. 60, n. 36, p. 9280-9291, 2012. 
ANEXO I 


\section{Author's copy \\ provided for non-commercial and educational use only}

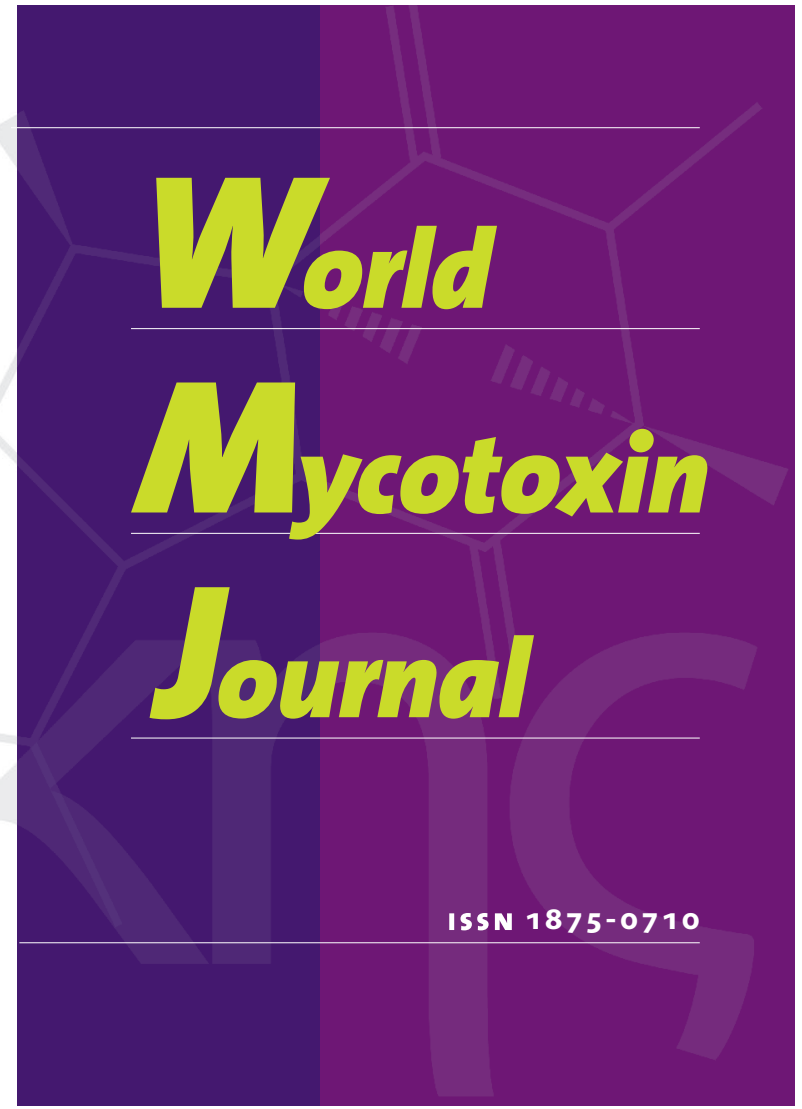

No material published in World Mycotoxin Journal may be reproduced without first obtaining written permission from the publisher.

The author may send or transmit individual copies of this PDF of the article, to colleagues upon their specific request provided no fee is charged, and furtherprovided that there is no systematic distribution of the manuscript, e.g. posting on a listserve, website or automated delivery. However posting the article on a secure network, not accessible to the public, is permitted.

For other purposes, e.g. publication on his/her own website, the author must use an author-created version of his/her article, provided acknowledgement is given to the original source of publication and a link is inserted to the published article on the

World Mycotoxin Journal website by referring to the DOI of the article.

For additional information

please visit

www.WorldMycotoxinJournal.org. 
Editor-in-chief: Hans P. van Egmond, RIKILT Wageningen UR, Business unit Contaminants \& Toxins, the Netherlands

\title{
Section editors
}

- -omics

- feed, toxicology

- toxicology

- pre-harvest

- post-harvest

- analysis

- food, human health, analysis

- economy, regulatory issues

- industrial challenges and solutions

\author{
Deepak Bhatnagar, USDA, USA \\ Johanna Fink-Gremmels, Utrecht University, the Netherlands \\ Isabelle P. Oswald, INRA, France \\ Alain Pittet, Nestlé Research Center, Switzerland \\ Naresh Magan, Cranfield University, United Kingdom \\ Paola Battilani, Università Cattolica del Sacro Cuore, Italy \\ Sarah de Saeger, Ghent University, Belgium \\ Gordon S. Shephard, University of Stellenbosch, South Africa \\ Felicia Wu, Michigan State University, USA
}

\section{Editors}

Paula Alvito, National Institute of Health, Portugal; Diána Bánáti, ILSI Europe, Belgium; Lei Bao, ACSIQ, China P.R.; Franz Berthiller, BOKU, Austria; Catherine Bessy, FAO, Italy; Wayne L. Bryden, University of Queensland, Australia; Pedro A. Burdaspal, Centro Nacional de Alimentación, Spain; Jeffrey W. Cary, USDA, USA; Sofia N. Chulze, Universidad Nacional de Rio Cuarto, Argentina; Mari Eskola , EFSA; Piotr Goliński, Poznań University of Life Sciences, Poland; Tetsuhisa Goto, Shinshu University, Japan (retired); Clare Hazel, RHM Technology, United Kingdom; Rudolf Krska, University of Natural Resources and Life Sciences, Vienna, Austria; Antonio F. Logrieco, Institute of Sciences of Food Production, Italy; Rebeca López-García, Logre International, Mexico; Chris Maragos, USDA, USA; Monica Olsen, National Food Administration, Sweden; Roland Poms, MoniQA Association, Austria; James J. Pestka, Michigan State University, USA; Michael Rychlik, Technical University München, Germany; Helen Schurz Rogers, CDC/ NCEH/DEEHS, USA; Hamide Z. Şenyuva, FoodLife International Ltd., Turkey; Joseph R. Shebuski, Cargill Corporate, USA; Trevor K. Smith, University of Guelph, Canada; Martien Spanjer, VWA, the Netherlands; Jörg Stroka, European Commission, IRMM; János Varga, University of Szeged, Hungary; Frans Verstraete, European Commission, DG Health and Consumer Protection; Cees Waalwijk, Plant Research International, the Netherlands; Thomas B. Whitaker, USDA, USA; Christopher P. Wild, IARC, WHO

Founding editor: Daniel Barug, Bastiaanse Communication, the Netherlands

\section{Publication information}

World Mycotoxin Journal: ISSN 1875-0710 (paper edition); ISSN 1875-0796 (online edition)

Subscription to 'World Mycotoxin Journal' (4 issues per year) is either on institutional (campus) basis or on personal basis. Subscriptions can be online only, printed copy, or both. Prices are available upon request from the publisher or from the journal's website (www.WorldMycotoxinJournal.org). Subscriptions are accepted on a prepaid basis only and are entered on a calendar year basis. Subscriptions will be renewed automatically unless a notification of cancelation has been received before the 1 of December. Issues are sent by standard mail. Claims for missing issues should be made within six months of the date of dispatch.

Further information about the journal is available through the website www.WorldMycotoxinJournal.org.

\section{Paper submission}

http://mc.manuscriptcentral.com/wmj

\section{Editorial office}

\section{Bastiaanse . Communicátion \\ Leading in life science communication}

P.O. Box 179

3720 AD Bilthoven

The Netherlands editorial@WorldMycotoxinJournal.org

Tel: +31302294247

Fax: +31 302252910

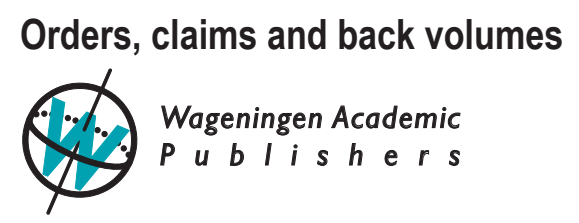

\author{
P.O. Box 220 \\ 6700 AE Wageningen \\ The Netherlands \\ subscription@WorldMycotoxinJournal.org \\ Tel: +31317476516 \\ Fax: +31317453417
}




\title{
Aflatoxins in cereals: worldwide occurrence and dietary risk assessment
}

\author{
P.D. Andrade and E.D. Caldas" \\ DF,Brazil; eloisa@unb.br \\ Received: 20 October 2014 / Accepted: 4 February 2015 \\ (c) 2015 Wageningen Academic Publishers
}

Laboratory of Toxicology, Faculty of Health Sciences, University of Brasília, Campus Darci Ribeiro, 70910-900, Brasília,

\section{RESEARCH ARTICLE}

\begin{abstract}
The worldwide occurrence of aflatoxins $\left(\mathrm{AFB}_{1}, \mathrm{AFB}_{2}, \mathrm{AFG}_{1}, \mathrm{AFG}_{2}\right)$, genotoxic mycotoxins, in raw maize, rice, sorghum and wheat samples collected since the year 2000 was evaluated using published data and occurrence data from the GEMS/Food database (https://extranet.who.int/gemsfood). Dietary risk assessments were conducted using GEMS/Food total aflatoxin occurrence and food consumption data obtained from the 17 Cluster Diets. Risk characterisation arising from aflatoxin exposure was conducted using both cancer risk and margin of exposure (MOE) approaches. A total of 89 publications were retrieved from the literature, reporting data related to 18,097 samples, of which $37.6 \%$ were positive for at least one aflatoxin. The total upper bound (UB) mean for all samples analysed was $13.6 \mu \mathrm{g} / \mathrm{kg}$, and was higher for rice $(24.6 \mu \mathrm{g} / \mathrm{kg})$ and sorghum $(25.9 \mu \mathrm{g} / \mathrm{kg})$. Of data related to the analysis of 4,536 samples reported to GEMS/Food database, $12.7 \%$ were positive for at least one aflatoxin. The total UB mean was $1.9 \mu \mathrm{g} / \mathrm{kg}$, and was higher for rice $(2.4 \mu \mathrm{g} / \mathrm{kg})$ and maize $(1.6 \mu \mathrm{g} / \mathrm{kg})$. Total intakes ranged from $3.0 \mathrm{ng} / \mathrm{kg} \mathrm{bw} /$ day (Cluster C11) to $17.1 \mathrm{ng} / \mathrm{kg}$ bw/day (Cluster C09). On average, the consumption of rice contributed to $41.6 \%$ of the total aflatoxin intake in all clusters, followed by wheat (35.4\%), maize (21.2\%) and sorghum (1.8\%). The lowest cancer risk was found in cluster C11 (0.057 cancers/year $/ 10^{5}$ individuals), and the highest in cluster C09 (0.467 cancers/year $/ 10^{5}$ individuals). MOE ranged from 56 (C11) to 10 (C09), indicating a potential risk to consumers. These results highlight the need for continuous action by health authorities to decrease aflatoxin contamination in cereals, as they are staple foods in diets worldwide. These actions include the enforcement of code of practices at the national level and the establishment of maximum contamination levels by the Codex System.
\end{abstract}

Keywords: aflatoxins, cereal diets, dietary exposure, carcinogenicity, risks

\section{Introduction}

Cereals are staple foods in diets around the world. Wheat is the main cereal consumed in America and Asia accounting, respectively, for 14.1 and $24.3 \%$ of the total calorie intake in these regions. Rice is the main contributor to the total energy intake in Asia (28.5\%) and wheat and maize contribute equally (30\%) in Africa (FAO, 2014). The contamination of cereals with aflatoxins $B_{1}, B_{2}, G_{1}$ and $G_{2}\left(\mathrm{AFB}_{1}, \mathrm{AFB}_{2}, \mathrm{AFG}_{1}\right.$ and $\left.\mathrm{AFG}_{2}\right)$ has been reported worldwide. Mean concentrations in positive maize samples in Argentina and Uganda were, respectively, $35.8 \mu \mathrm{g} / \mathrm{kg}$ (total aflatoxins; 264/3,192 samples) (Garrido et al., 2012), and $19.5 \mu \mathrm{g} / \mathrm{kg}$ (total aflatoxins; 296/390 samples) (Kaaya and Kyamuhangire, 2006). The mean level of aflatoxins found in rice from Pakistan was $11.2 \mu \mathrm{g} / \mathrm{kg}$ (total aflatoxins;
185/413 samples) (Iqbal et al., 2012), while in South Korea it was only $1.7 \mu \mathrm{g} / \mathrm{kg}$ (total aflatoxins; 6/160 samples) (Ok et al., 2014). In Nigeria, 55\% of the 168 sorghum samples were contaminated with $\mathrm{AFB}_{1}$ with levels up to $1,164 \mu \mathrm{g} / \mathrm{kg}$ (Hussaini et al., 2009), while in Turkey wheat samples reached levels up to $643.5 \mu \mathrm{g} / \mathrm{kg}$ (total aflatoxins; $24 / 41$ samples) (Giray et al., 2007).

Aflatoxins are human liver carcinogens, with $\mathrm{AFB}_{1}$ shown to be genotoxic (IARC, 1993); as such, exposure should be as low as reasonably achievable (CAC, 1995). The complete elimination of aflatoxins from the food supply, however, is not possible, and worldwide strategies are needed to control and manage contamination (CAC, 2003). Aspergillus flavus and Aspergillus parasiticus infection and aflatoxin production in cereals are influenced by several 
environmental factors such as temperature, humidity, insect damage and drought (Miraglia et al., 2009). Furthermore, aflatoxins can also be produced after harvesting the grain (Pitt et al., 2013), mainly during storage.

Several countries have established regulatory limits to control the presence of aflatoxins in cereals, including Brazil (Anvisa, 2011), European Union (EC, 2006), and the United States (USFDA, 2000). Internationally, maximum levels (ML) for aflatoxins in cereals are currently under discussion at the Codex Committee on Contaminants in Foods (FAO/WHO, 2014). Given the difficulty of eliminating aflatoxins from the food chain and considering the worldwide consumption of cereals, dietary risk assessments for aflatoxins are essential to help government authorities and the Codex Alimentarius to take actions aimed at reducing risk while still ensuring the food security.

In the context of food safety, risk assessment is a fourstep conceptual framework that aims to estimate the risk of occurrence of adverse health effects after exposure to chemicals present in food. The hazard identification step is designed to identify the nature of the adverse health effects caused by human exposure to the contaminant, and the aim of the hazard characterisation step is to establish a quantitative relationship between exposure and the incidence of adverse effects. In the exposure assessment step the likely intake of contaminants through the diet is estimated, taking into account the concentration of the chemical in food, as well as consumption patterns. The risk characterisation step finalises the process, providing an estimation of the probability of occurrence of health outcomes in a population under defined exposure conditions (IPCS, 2009).

Dietary exposure assessments for aflatoxins have been conducted worldwide. In most studies, cereals accounted for over $90 \%$ of the total intake (Andrade et al., 2013; Ding et al., 2012; Li et al., 2014; Park et al., 2004; Yazdanpanah et al., 2013). Risk characterisation for aflatoxins has been conducted using two different approaches. The first, developed by the FAO/WHO Joint Expert Committee on Food Additives (JECFA), estimates the cancer risk for a given population considering the incidence of the hepatitis $\mathrm{B}$ virus ( $\mathrm{HBsAg}^{+}$individuals) and the carcinogenic potency of aflatoxins, which was defined for HBV carriers and noncarriers (FAO/WHO, 1998). More recently, the margin of exposure (MOE) approach has been used by the European Food Safety Authority (EFSA) and was recommended by JECFA to evaluate compounds that are both carcinogenic and genotoxic (EFSA, 2005; FAO/WHO, 2006). The MOE is the ratio of a toxicological threshold obtained from animal studies and the estimated human exposure (IPCS, 2009).

This study aimed to evaluate the current scenario on aflatoxin contamination in raw maize, rice, sorghum and wheat commercialised worldwide, and to estimate the dietary exposure to aflatoxins and the potential health risks arising from this exposure. The first draft of this paper was the basis for the preparation of the Discussion Paper on Aflatoxins in Cereals presented at the $8^{\text {th }}$ Session of the Codex Committee on Contaminants in Food (CX/CF 14/8/15; CAC, 2014a).

\section{Materials and methods}

\section{Aflatoxins occurrence: data obtained from the literature}

Occurrence data on aflatoxins in raw maize, rice, sorghum and wheat were obtained from published studies related to samples collected from 2000 to 2014. The search was conducted in the Web of Science database and Google Scholar in September 2012, July 2013, and May 2014, using the following keywords: 'mycotoxin' and 'aflatoxin' alone, or in combination with 'maize,' 'rice,' 'sorghum' and 'wheat', using the logical operator AND. Papers related to samples that were inoculated with mycotoxin producing fungi in the laboratory were excluded. Only peer review papers were considered in the search, written in English or in other languages.

For each crop, the mean values estimated for all studies were calculated by weighting the reported mean of each study by the number of samples analysed in that study. When only the median value was reported in the study, this value was used to estimate the weighted mean. When only the concentration range was reported, the midrange was used in the calculation. The lower bound of the total mean (LB) was estimated considering samples below the limit of detection (LOD) or below the limit of quantification (LOQ) as zero. The upper bound (UB) was obtained considering samples below LOD or below LOQ as $1 / 2 \mathrm{LOD}$ or $1 / 2 \mathrm{LOQ}$. Whenever the LOD or LOQ of the method used in the study were not reported, limits found in other studies that used a similar analytical method were used in the calculation of the UB mean. When both LOD and LOQ were reported, the latter was used in the estimation.

\section{Aflatoxins occurrence: data from the GEMS/Food database}

The Global Environment Monitoring System/Food Contamination Monitoring and Assessment Programme (GEMS/Food) compile surveillance and monitoring data on food contamination submitted by national government authorities. In July 2013, the JECFA issued a specific public call for data on aflatoxin contamination in cereals, to be submitted to GEMS/Food (https://extranet.who. int/gemsfood). Data on total aflatoxin $\left(\mathrm{AFB}_{1}+\mathrm{AFB}_{2}+\right.$ $\mathrm{AFG}_{1}+\mathrm{AFG}_{2}$ ) in raw maize, rice, sorghum and wheat were extracted from the GEMS/Food database using an ADS WHO partner login, and exported to MS Excel (Microsoft, 
Redmond, WA, USA) spreadsheets. Data were obtained for all WHO regions and countries, with the sampling period starting in 2000. Data were extracted on October 21, 2013 and on July 02, 2014.

The informed food codes (WHO food identifier, WHO food code and local food identifier) were used to identify processed commodities, which were not included in this study. Rice samples that included inedible portions (husk) or that were submitted to heat treatment (cooked) prior to analysis were also excluded. When the portion analysed was not mentioned, it was assumed that the analysis was performed in the cereal edible portion. Information regarding analytical quality assurance was also obtained from the GEMS/Food database.

For some samples, there were up to six entries in the database (individual aflatoxins, sum of $\mathrm{AFB}_{1}$ and $\mathrm{AFB}_{2}$, and total aflatoxins), but only the total aflatoxins value was considered. When the total aflatoxins value was not included, it was estimated from the individual aflatoxin values. When values reported were below LOQ or LOD, they were considered as 0 or $1 / 2 \mathrm{LOQ} / \mathrm{LOD}$ in the LB or UB estimations of the means, respectively. When both LOD and LOQ were reported, $1 / 2$ LOQ was used. Where LOD or LOQ was not reported, the value informed for other samples from the same laboratory or country was used.

\section{Consumption of cereals: data from the 17 GEMS/Food Consumption Cluster Diets}

The Food and Agriculture Organization of the United Nations (FAO) compiles country-level data on the production and trade of food commodities, producing food balance sheets that provide data on the overall per capita supply of commodities within countries (FAO, 2014). GEMS/Food uses the FAO Food Supply Utilisation Account data to determine the food consumption patterns that are used in chronic dietary risk assessments conducted at the international level by FAO/WHO scientific panels, including the JECFA. The 17 GEMS/Food cluster diets were elaborated based on FAO Food Supply Utilisation Account data from 2002 to 2007 for 179 countries. Clusters were formed according to their consumption system profiles (combination of different food products and local factors such as availability, seasonality and socio-cultural habits) using statistical methods (Sy et al., 2013). The average data were weighted by the population size to determine the average $\mathrm{kg} /$ person/cluster over a 5 year period. The countries included in each Cluster are shown in Figure 1. Body weight (bw) is $60 \mathrm{~kg}$ for all clusters, except cluster 09 (55 kg).

\section{Dietary risk assessment}

Total chronic intake of aflatoxins through the consumption of rice, maize, wheat and sorghum for each of the GEMS/ Food Cluster Diets was estimated using the International Estimated Daily Intake (IEDI) 17 Cluster diets template, developed by the Dutch National Institute for Public Health and the Environment, in cooperation with the WHO, to conduct dietary intake by the FAO/WHO Joint Meeting on Pesticide Residues (FAO/WHO, 2013).

The IEDI 17 Cluster diets template estimates the dietary intake of aflatoxins, according to FAO/WHO recommendation (FAO/WHO, 2005), as shown in Equation 1:

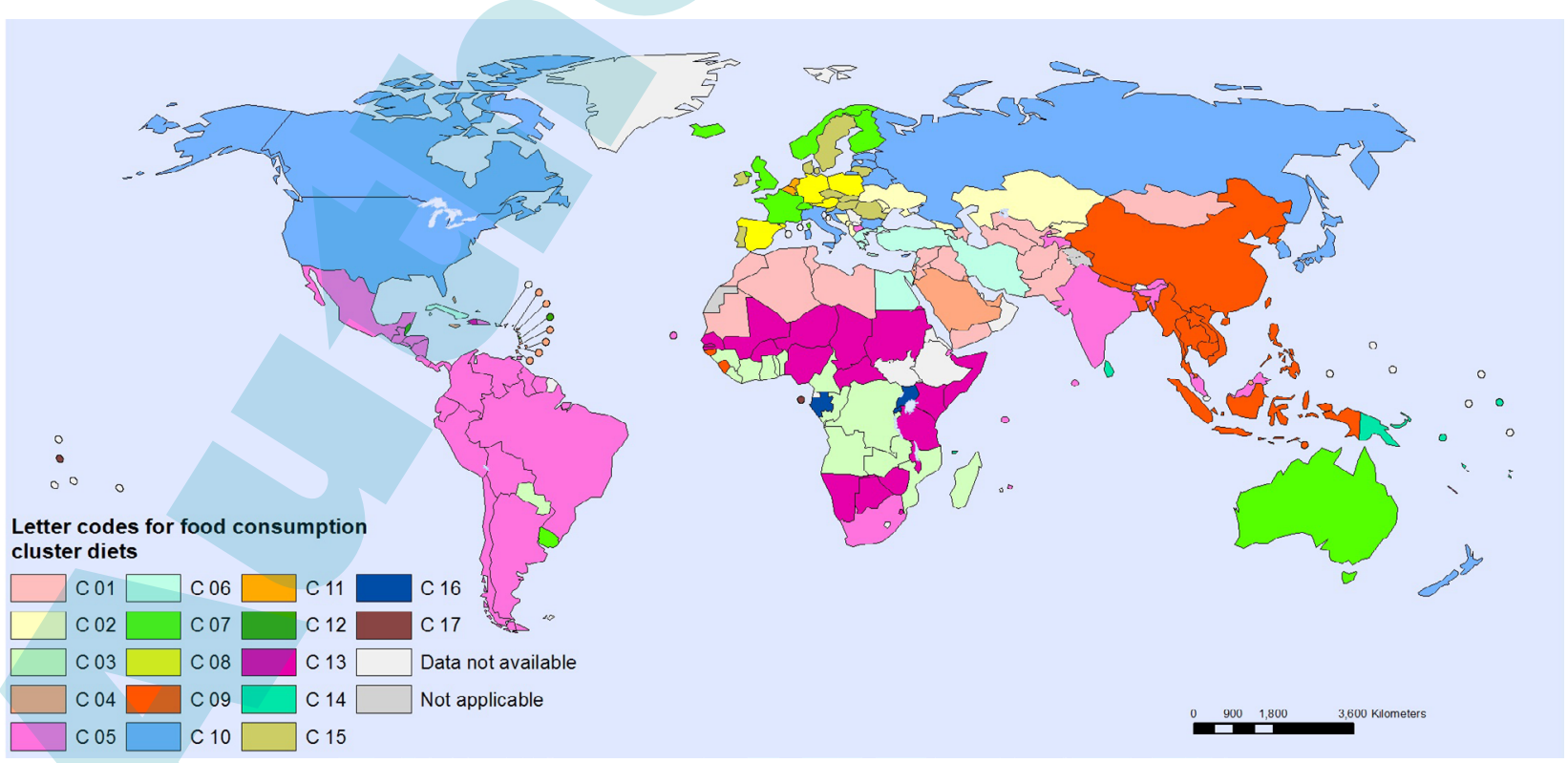

Figure 1.17 GEMS/Food Consumption Cluster Diets (WHO, 2014). 
Total intake $=\sum \frac{(\text { consumption } \times \text { concentration })}{\text { body weight }}$

The Cluster diet consumption figures used in the intake estimation includes processed food. For maize, it includes flour, oil, beer, germ and starch; for rice, it includes polished and husked rice, flour, oil, beverages and starch; for sorghum, it includes beer and flour; and for wheat, it includes whole meal, flour, beverages, pasta, bread, starch, gluten, and mixed grain. The concentration used in the intake estimations was obtained from samples submitted to the GEMS/Food database (UB mean concentration).

Risk characterisation arising from aflatoxin exposure was conducted using both the cancer risk (FAO/WHO, 1998) and MOE approaches (EFSA, 2005). The cancer risk for each cluster was calculated by multiplying the carcinogenic potency $\left(\mathrm{P}_{\text {cancer }}\right)$ by the total intake of AFs (Equation 2). The $\mathrm{P}_{\text {cancer }}$ considers both the carcinogenic potency of AFs for individuals with hepatitis $\mathrm{B}$ virus $\left(\mathrm{PHBsAg}^{+}=0.3\right.$ cancers $/$ year/100,000 individuals/ng aflatoxin/bw/day) and for noninfected individuals ( $\mathrm{PHBsAg}^{-}=0.01$ cancers $/$ year $/ 100,000$ individuals/ng aflatoxin/bw/day), as well as the percentage of carriers $\left(\mathrm{HBsAg}^{+}\right)$and non-carriers $\left(\mathrm{HBsAg}^{-}\right)$of hepatitis $B$ virus in the population (Equation 3$)$. The worldwide prevalence of chronic hepatitis $B$ virus infection among adults published by CDC (2014) was used to estimate the prevalence of hepatitis $\mathrm{B}$ virus $\left(\mathrm{HBsAg}^{+}\right)$for each cluster.
Cancer risk $=P_{\text {cancer }} \times$ total intake

$P_{\text {cancer }}=\left(P H B s A g^{+} \times \%\right.$ pop $\left.\cdot H B s A g^{+}\right)+\left(P H B s A g^{-} \times \%\right.$ pop $\left.\cdot H B s A g^{-}\right)$

The MOE was given by the ratio between the benchmark dose level that caused a $10 \%$ increase in cancer incidence in rodents $(\mathrm{BMDL} 10=170 \mathrm{ng} / \mathrm{kg} \mathrm{bw} /$ day; 95\% lower confidence limit) (EFSA, 2007) and the total intake (Equation 4). MOE values lower than 10,000 may indicate a public health concern (EFSA, 2005).

$$
M O E=B M D L 10 / \text { total intake }
$$

\section{Results}

\section{Aflatoxins occurrence: data from the literature}

A total of 89 publications reporting data on aflatoxins contamination in raw cereal samples collected since 2000 were retrieved from the literature. The first such study was published in 2003, and the highest numbers of papers were found in 2011 and 2012 (15 and 14 papers, respectively). A summary of the published studies, grouped by continent, is shown in Table 1. Data covers samples collected in a wide range of countries. Most papers concerned maize $(n=47)$ and rice $(n=39)$, and 18 studies analysed two or more cereals of interest to this study. The majority of papers

Table 1. Summary of published data on aflatoxins in cereal samples collected from 2000 onwards.

\begin{tabular}{|c|c|c|}
\hline Country & Cereal $^{1}$ & Reference \\
\hline \multicolumn{3}{|l|}{ African continent } \\
\hline Algeria & W & Riba et al., 2010 \\
\hline Benin and Togo & M & Egal et al., 2005 \\
\hline Burkina Faso & M & Probst et al., 2014; Warth et al., 2012 \\
\hline Cameroon & M & Abia et al., 2013; Probst et al., 2014 \\
\hline Egypt & M & Nogaim et al., 2011 \\
\hline Ethiopia & S & Chala et al., 2014; Probst et al., 2014 \\
\hline Kenya & $M, W$ & Daniel et al., 2011; Muthomi et al., 2008; Mwihia et al. 2008; Probst et al., 2014 \\
\hline Ivory Coast & $M, R$ & Probst et al., 2014; Sangare-Tigori et al., 2006 \\
\hline Lesotho & M & Mohale et al., 2013; Probst et al., 2007 \\
\hline Malawi & S & Matumba et al., 2011; Probst et al., 2014 \\
\hline Morocco & W & Zinedine et al., 2006 \\
\hline Mozambique & M & Probst et al., 2014; Warth et al., 2012 \\
\hline Nigeria & $M, R, S, W$ & $\begin{array}{l}\text { Adejumo et al., 2013; Ayejuyo et al., 2011; Bandyopadhyay et al., 2007; Bankole and Mabekoje, } \\
\text { 2004; Hussaini et al., 2009; Makun et al., } 2011\end{array}$ \\
\hline South Africa & M & Chilaka et al., 2012; Shephard et al., 2013 \\
\hline Tanzania & M & Kimanya et al., 2008; Probst et al., 2014 \\
\hline Tunisia & $M, R, S, W$ & Ghali et al., 2008, 2009, 2010; Oueslati et al., 2012 \\
\hline Uganda & M & Kaaya and Kyamuhangire, 2006; Probst et al., 2014 \\
\hline Zambia & M & Mukanga et al., 2010; Probst et al., 2014 \\
\hline $\begin{array}{l}\text { D. Republic of Congo, Ghana, } \\
\text { Mali, Rwanda, Senegal, } \\
\text { Sierra-Leone, Somalia, } \\
\text { Zimbabwe }\end{array}$ & M & Probst et al., 2014 \\
\hline
\end{tabular}


Table 1. Continued.

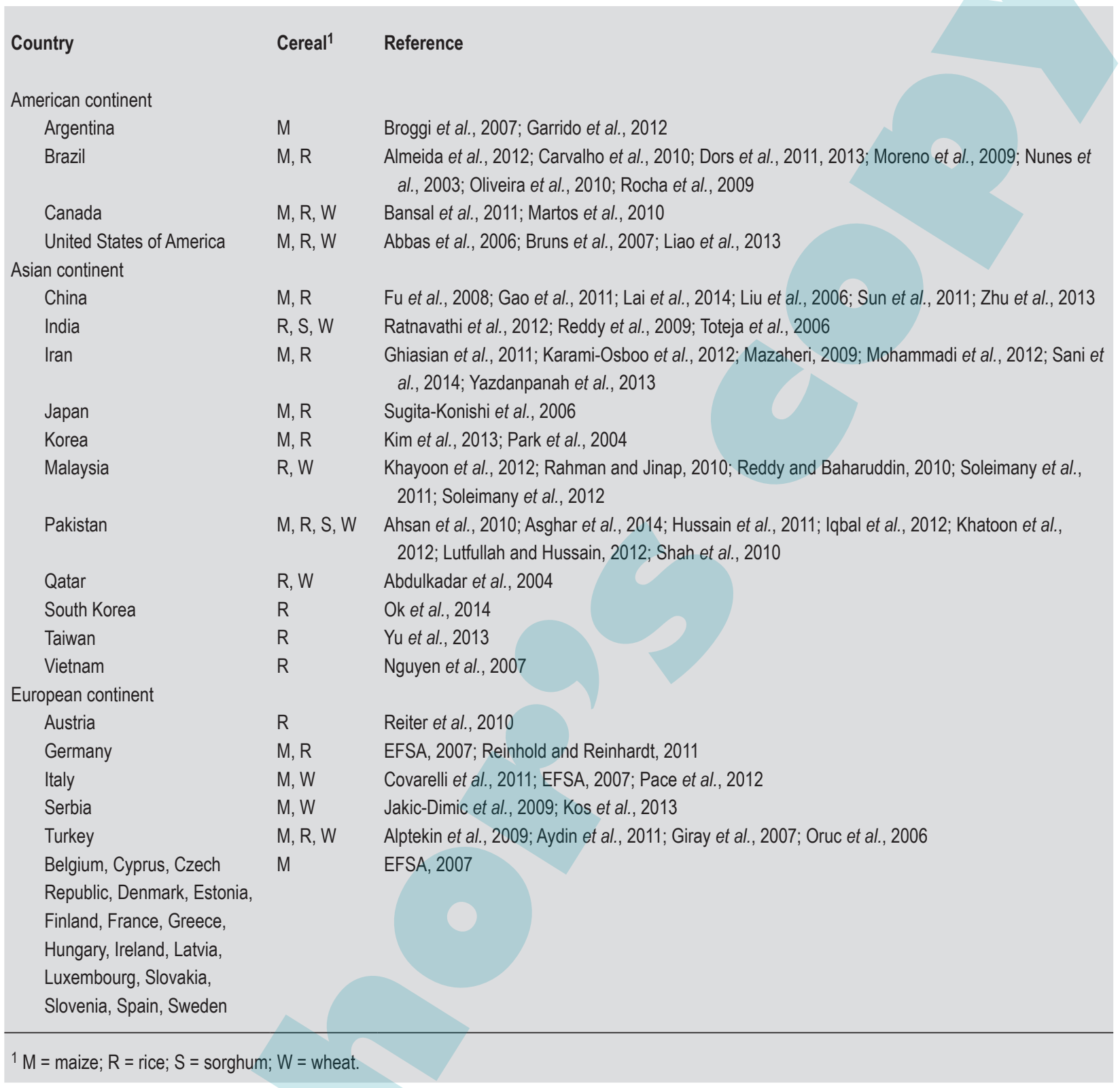

(56) reported method validation data. One study reported that the laboratory participated in proficiency testing, two in interlaboratory studies, and one reported the use of certified reference material for method validation. Thirty papers did not provide any analytical quality assurance information. Even though quality assurance information was not available in some studies, all data were included in the dataset in order to describe the occurrence scenario.

Table 2 summarises the published data on aflatoxin levels in cereals. A total of 18,097 samples were analysed in the studies, with maize accounting for $54.3 \%$ of the samples ( 9,819 samples), followed by rice (21.1\%). About $41 \%$ of the samples were collected in Asia, of which $39.2 \%$ were rice samples. Maize was the main cereal analysed in American countries, accounting for $85.6 \%$ of the samples for the region. Most of the analysed wheat samples were from Asian countries (72.1\%). Sorghum was only analysed in samples from African and Asian countries.

Considering all samples analysed in the studies, 37.6\% were positive for at least one aflatoxin (Table 2). Sorghum had the highest incidence of positive samples (68.9\%), followed by rice $(52.3 \%)$. Contaminated rice, sorghum and wheat samples were mostly from Asia (about 80\%), while $40 \%$ of contaminated maize came from Africa. There was no positive wheat sample reported in the American continent and the lowest incidence of aflatoxins for the other commodities was also found in this continent. 
Table 2. Worldwide occurrence of total aflatoxin in cereals obtained from published literature (samples collected from 2000 onwards).

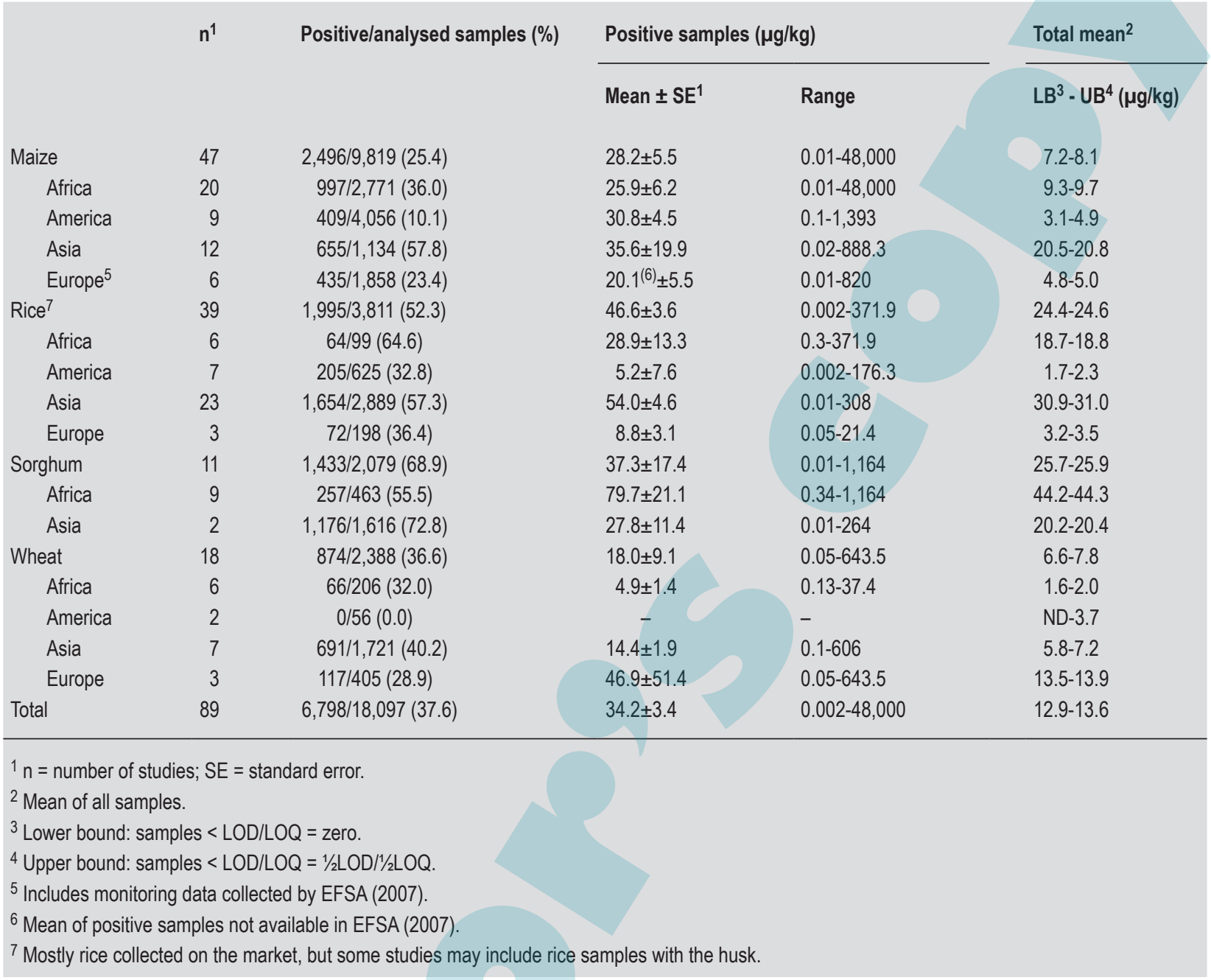

The mean aflatoxin level found in positive samples, considering all cereals, was $34.2 \pm 3.4 \mu \mathrm{g} / \mathrm{kg}$, with rice samples having the highest mean among the grains analysed $(46.6 \pm 3.6 \mu \mathrm{g} / \mathrm{kg})$. The highest aflatoxin level $(48,000 \mu \mathrm{g} / \mathrm{kg})$ was found in a sample collected in Kenya (Daniel et al., 2011). Samples of maize and rice analysed from Asia had the highest mean of positive samples $(35.6 \mu \mathrm{g} / \mathrm{kg}$ and 54.0 $\mu \mathrm{g} / \mathrm{kg}$, respectively), while Africa showed the highest mean level of contamination in sorghum $(79.7 \mu \mathrm{g} / \mathrm{kg})$, and Europe in wheat $(46.9 \mu \mathrm{g} / \mathrm{kg})$. The total UB mean of all samples analysed was $13.6 \mu \mathrm{g} / \mathrm{kg}$. Sorghum samples had the highest total mean, with similar lower and UB levels (25.7 and $25.9 \mu \mathrm{g} / \mathrm{kg})$.

\section{Aflatoxins occurrence: data from the GEMS/Food database}

Figure 2 shows the countries that submitted data on aflatoxins in raw maize, rice, sorghum and wheat to the GEMS/Food database, related to 4,536 samples collected since the year 2000. Singapore submitted the largest dataset
(1,028 samples), followed by Canada (967), the Republic of Korea (392), Germany (387), and Brazil (377). Most maize samples came from the USA (27.9\%), rice from Singapore (27.8\%), sorghum from Republic of Korea (85.5\%) and wheat from Canada (81.5\%). On average, 324 samples were collected for analysis each year, most of which in 2005 and 2011 (32\% of all samples). The smallest number of samples was obtained in $2000(0.9 \%)$, and 2004 (0.6\%).

The GEMS/Food dataset was comprised mainly of samples collected by random sampling (78.5\% of the samples), and $20.0 \%$ by target sampling. For $1.5 \%$ of the samples, the sampling method was not informed. Information on portions analysed was not available for 21 samples, none of which were contaminated with aflatoxins. Regarding analytical quality assurance of the laboratory, the GEMS/ Food system allows one of four options to be checked: officially accredited methodology, internal quality assurance, proficiency testing, and unknown. For most of the samples (53.3\%) officially accredited methodologies were used; for $19.3 \%$ the laboratory had internal quality 


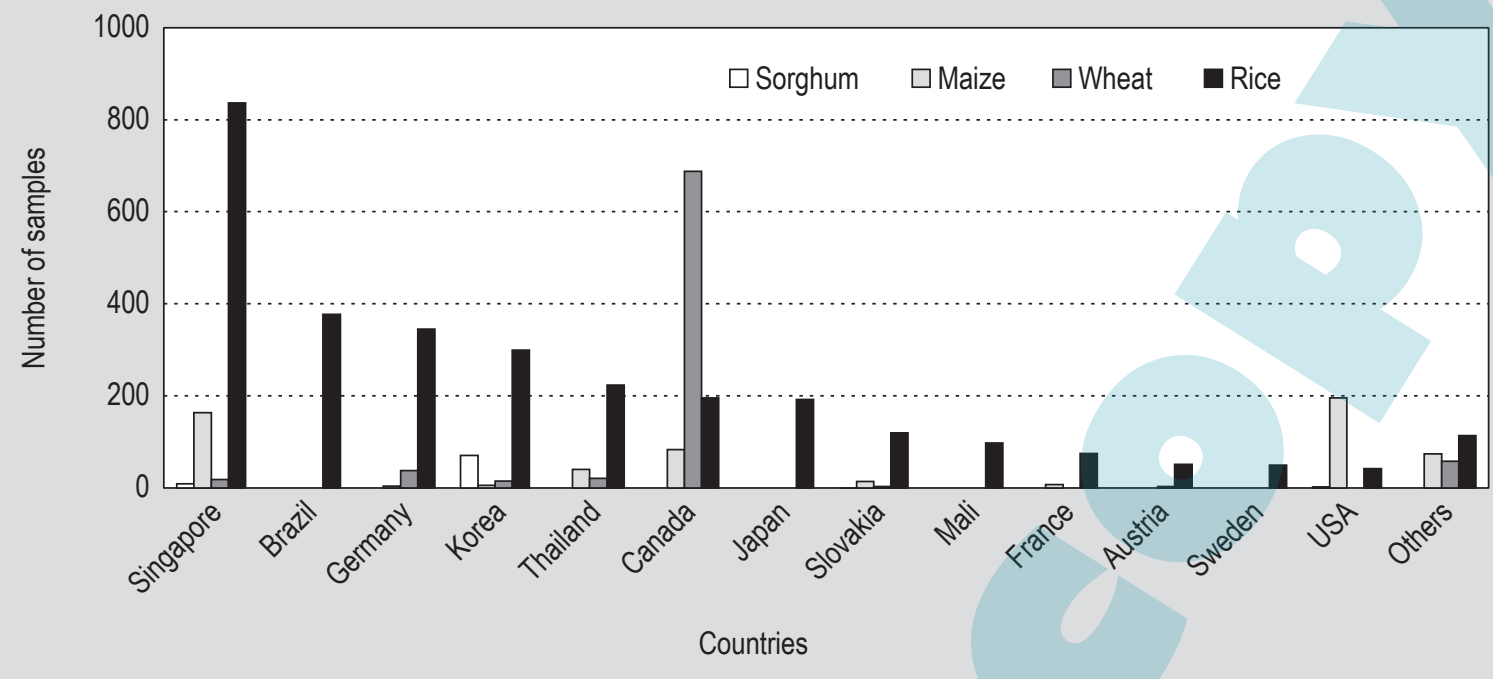

Figure 2. Number of samples submitted to the GEMS/Food database on aflatoxin in maize, rice, sorghum and wheat by country.

assurance, and for $17.9 \%$ the laboratory participated in proficiency testing. This information was unknown or was not provided for the remaining samples (9.5\%). All samples were kept in the dataset, even those analysed by laboratories that have not provided quality assurance information.

Table 3 summarises the data submitted to GEMS/Food, grouped by continent. Considering all samples analysed, $12.7 \%$ were positive for aflatoxins, with a mean of $10.7 \pm 35.3$ $\mu \mathrm{g} / \mathrm{kg}$. Total LB and UB means were, respectively, $1.4 \mu \mathrm{g} /$ $\mathrm{kg}$ and $1.9 \mu \mathrm{g} / \mathrm{kg}$. Rice was the commodity with the largest number of records in the database $(66.6 \%)$, and with the highest incidence of positive samples (17.7\%), including the highest aflatoxin level (347 $\mu \mathrm{g} / \mathrm{kg}$ in a Mali sample). Rice also had the highest LB and UB values (1.9 and 2.4 $\mu \mathrm{g} / \mathrm{kg}$, respectively). Wheat was the cereal with the lowest incidence and levels of aflatoxins (Table 3).

\section{Consumption of cereals: data from the 17 GEMS/Food Cluster Diets}

Consumption data for maize, rice, sorghum and wheat (including processed products) for the 17 clusters are summarised in Figure 3. Wheat is the cereal most consumed worldwide (daily mean of $205.8 \mathrm{~g} /$ person), and the most consumed in 11 of the 17 clusters, including C01, C02, and C06 (mainly countries in Northern Africa and Asia; Figure 1). Rice is the second cereal most consumed (91.3 $\mathrm{g} /$ person/day), and the main cereal consumed in clusters C05, C09, and C14 (mostly South American and Asian countries; Figure 1). Maize (mean of $48.9 \mathrm{~g} /$ person/day) is the main cereal consumed in clusters C03, C13, and C16 (mostly African countries; Figure 1). The mean worldwide consumption of sorghum is $11 \mathrm{~g} /$ person/day, with the highest consumption in clusters C13 (89.2 g/person/day), and C16 (35.4 g/person/day).

\section{Dietary risk assessment of aflatoxins using GEMS/Food data}

The UB total intakes of aflatoxins through the consumption of maize, rice, sorghum and wheat ranged from $3.0 \mathrm{ng} / \mathrm{kg}$ bw/day (Cluster C11) to $17.1 \mathrm{ng} / \mathrm{kg}$ bw/day (Cluster C09) (Table 4). LB intakes varied from 0.7 to $12.1 \mathrm{ng} / \mathrm{kg} \mathrm{bw} /$ day (data not shown). As the concentration for each cereal in the intake calculation was constant (UB mean concentration for each crop; Table 3), only the consumption pattern had an impact on the total aflatoxin intake among the clusters.

On average, the consumption of rice contributed to $41.6 \%$ of the total intake in all clusters, followed by wheat (35.4\%), maize $(21.2 \%)$ and sorghum (1.8\%). Figure 4 shows the impact of each cereal in total intake for each cluster. The highest impact of rice was mainly due to the highest contamination level $(2.4 \mu \mathrm{g} / \mathrm{kg})$, while for wheat, high consumption was the parameter that most affected intake, as the concentration was low $(0.6 \mu \mathrm{g} / \mathrm{kg})$. The consumption of rice contributed from 46.8 to $89.1 \%$ to total intake for eight clusters, including C05, C09, C14 and C17 (mostly Asian countries; Figure 1). Wheat consumption contributed the most to intake in seven clusters (42.9 to $71.3 \%$; including $\mathrm{C} 02$, C07 and C11). Maize was the main contributor to total intake for clusters C13 and C16 (42.4-59.4\%; mostly African countries; Figure 1). The contribution of sorghum to total intake reached a maximum of $13.4 \%$ in C13 (Figure 4).

Risk characterisation from the exposure to aflatoxins was estimated using the cancer risk and MOE approaches, and the results are shown in Table 4. The lowest cancer risk was found in cluster C11 (0.057 cancers/ year/ $10^{5}$ individuals) and the highest in cluster C09 (0.467 cancers/year/10 individuals). MOE ranged from 56 (C11) to 10 (C09). 
Table 3. GEMS/Food data on aflatoxins in cereals grouped by continent.

\begin{tabular}{|c|c|c|c|c|}
\hline & \multirow{2}{*}{$\begin{array}{l}\text { Positive/analysed } \\
\text { samples (\%) }\end{array}$} & \multicolumn{2}{|c|}{ Positive samples $(\mu \mathrm{g} / \mathrm{kg})^{1}$} & Total mean ${ }^{2}$ \\
\hline & & Mean \pm SD & Range & $\mathrm{LB}^{3}-\mathrm{UB}^{4}(\mu \mathrm{g} / \mathrm{kg})$ \\
\hline Maize ${ }^{5}$ & $33 / 588(5.6)$ & $13.0 \pm 18.7$ & $0.2-93.1$ & $0.7-1.6$ \\
\hline America & $20 / 279(7.2)$ & $18.3 \pm 22.2$ & $1.7-93.1$ & $1.3-2.3$ \\
\hline Asia & $9 / 224(4.0)$ & $5.9 \pm 6.3$ & $0.2-14.8$ & $0.2-0.6$ \\
\hline Europe & $4 / 85(4.7)$ & $2.1 \pm 1.4$ & $1.0-3.3$ & $0.1-1.8$ \\
\hline Rice & $536 / 3,021(17.7)$ & $10.6 \pm 36.3$ & $0.002-347$ & $1.9-2.4$ \\
\hline Africa & $84 / 98(85.7)$ & $41 \pm 71.3$ & $0.2-347$ & $35.1-35.2$ \\
\hline America & 223/615 (36.3) & $8.8 \pm 28.7$ & $0.002-272.2$ & $3.2-3.5$ \\
\hline Asia & $66 / 1,553(4.2)$ & $0.4 \pm 0.4$ & $0.02-2.5$ & $0.02-0.5$ \\
\hline Europe & $163 / 755(21.6)$ & $1.5 \pm 2.5$ & $0.04-17.0$ & $0.3-1.0$ \\
\hline Sorghum & $4 / 83(4.8)$ & $8.6 \pm 5.4$ & $0.6-12.0$ & $0.4-0.6$ \\
\hline America & $2 / 2(100.0)$ & $12 \pm 0.07$ & $11.9-12.0$ & 12.0 \\
\hline Asia & $2 / 80(2.5)$ & $5.2 \pm 6.4$ & $0.6-9.7$ & $0.1-0.3$ \\
\hline Europe & $0 / 1(0.0)$ & ND & ND & ND-0.08 \\
\hline Wheat & $3 / 844(0.4)$ & $1.0 \pm 0.7$ & $0.1-1.4$ & $0.003-0.6$ \\
\hline America & $0 / 688(0.0)$ & ND & ND & ND-0.5 \\
\hline Asia & $0 / 54(0.0)$ & ND & ND & ND-0.5 \\
\hline Europe & $3 / 102(2.9)$ & $1.0 \pm 0.7$ & $0.1-1.4$ & $0.03-1.4$ \\
\hline Total & $576 / 4,536(12.7)$ & $10.7 \pm 35.3$ & $0.002-347$ & $1.4-1.9$ \\
\hline
\end{tabular}

${ }^{1} \mathrm{ND}=$ not detected; $\mathrm{SD}=$ standard deviation .

2 Total mean = mean of all samples.

${ }^{3}$ Lower bound: samples $<$ LOD/LOQ $=$ zero.

${ }^{4}$ Upper bound: samples $<\mathrm{LOD} / \mathrm{LOQ}=1 / 2 \mathrm{LOD} / 1 / 2 \mathrm{LOQ}$

${ }^{5}$ Africa: samples from Mali; America: samples from Brazil, Canada and USA; Asia: samples from Japan, Philippines, Republic of Korea, Singapore, Thailand; Europe: samples from Austria, Belgium, Cyprus, Czech Republic, France, Germany, Greece, Ireland, Italy, Latvia, Portugal, Slovakia, Slovenia, Spain and Sweden.

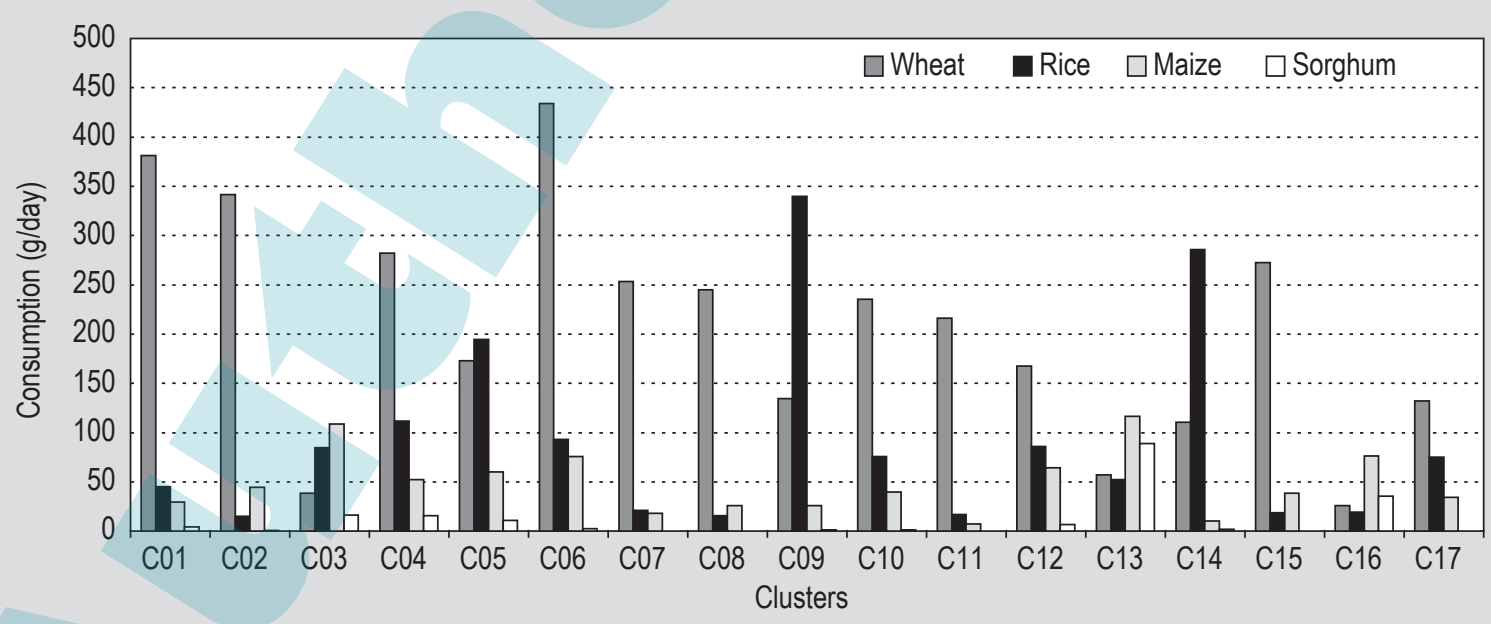

Figure 3. Consumption of maize, rice, sorghum and wheat for the 17 Cluster diets, including consumption of processed cereals (WHO, 2014). For Clusters, see Figure 1. 
Table 4. Upper bound of the aflatoxin intake, cancer risk and margin of exposure through the consumption of maize, rice, wheat and sorghum for GEMS/Food Clusters $\mathrm{C} 01$ to $\mathrm{C} 17$ (ng/kg bw/day).

\begin{tabular}{|c|c|c|c|c|c|c|c|c|c|c|c|c|c|c|c|c|c|c|}
\hline & $\begin{array}{l}\text { Aflatoxins } \\
(\mu \mathrm{g} / \mathrm{kg})\end{array}$ & $\mathrm{C} 01$ & $\mathrm{CO} 2$ & $\mathrm{CO} 3$ & $\mathrm{CO} 4$ & $\mathrm{C} 05$ & $\mathrm{C} 06$ & $\mathrm{CO} 7$ & $\mathrm{CO8}$ & C09 & $\mathrm{C} 10$ & $\mathrm{C} 11$ & $\mathrm{C} 12$ & $\mathrm{C} 13$ & C14 & C15 & $\mathrm{C} 16$ & C17 \\
\hline $\mathrm{HBsAg}^{+}$ & & $3 \%$ & $6 \%$ & $8 \%$ & $3 \%$ & $3 \%$ & $3 \%$ & $3 \%$ & $3 \%$ & $6 \%$ & $3 \%$ & $3 \%$ & $6 \%$ & $8 \%$ & $6 \%$ & $3 \%$ & $8 \%$ & $6 \%$ \\
\hline Rice & 2.4 & 1.8 & 0.6 & 3.4 & 4.5 & 7.8 & 3.7 & 0.8 & 0.6 & 14.8 & 3.0 & 0.7 & 3.4 & 2.1 & 11.4 & 0.7 & 0.8 & 3.0 \\
\hline Maize & 1.6 & 0.8 & 1.2 & 2.9 & 1.4 & 1.6 & 2.0 & 0.5 & 0.7 & 0.8 & 1.1 & 0.2 & 1.7 & 3.1 & 0.3 & 1.0 & 2.0 & 0.9 \\
\hline Wheat & 0.6 & 3.8 & 3.4 & 0.4 & 2.8 & 1.7 & 4.3 & 2.5 & 2.4 & 1.5 & 2.4 & 2.2 & 1.7 & 0.6 & 1.1 & 2.7 & 0.3 & 1.3 \\
\hline Sorghum & 0.6 & 0.04 & 0.001 & 0.2 & 0.2 & 0.1 & 0.03 & 0.0 & 0.0 & 0.0 & 0.01 & 0.0 & 0.07 & 0.9 & 0.02 & 0.0 & 0.4 & 0.0 \\
\hline Total & 1.9 & 6.5 & 5.2 & 6.8 & 8.8 & 11.2 & 10.1 & 3.9 & 3.8 & 17.1 & 6.4 & 3.0 & 6.9 & 6.7 & 12.8 & 4.5 & 3.4 & 5.2 \\
\hline Cancer risk ${ }^{1}$ & & 0.121 & 0.143 & 0.227 & 0.165 & 0.21 & 0.189 & 0.072 & 0.071 & 0.467 & 0.121 & 0.057 & 0.189 & 0.222 & 0.352 & 0.084 & 0.114 & 0.144 \\
\hline $\mathrm{MOE}^{2}$ & & 26.3 & 32.6 & 24.8 & 19.2 & 15.1 & 16.8 & 44.0 & 44.9 & 10.0 & 26.4 & 56.0 & 24.6 & 25.5 & 13.2 & 37.8 & 49.4 & 32.4 \\
\hline
\end{tabular}

${ }^{1}$ Cancers/year/ $10^{5}$ individuals, estimated according to FAO/WHO (1998).

${ }^{2}$ Based on a BMDL 10 in rodents of $170 \mathrm{ng} / \mathrm{kg}$ bw/day (EFSA, 2007).

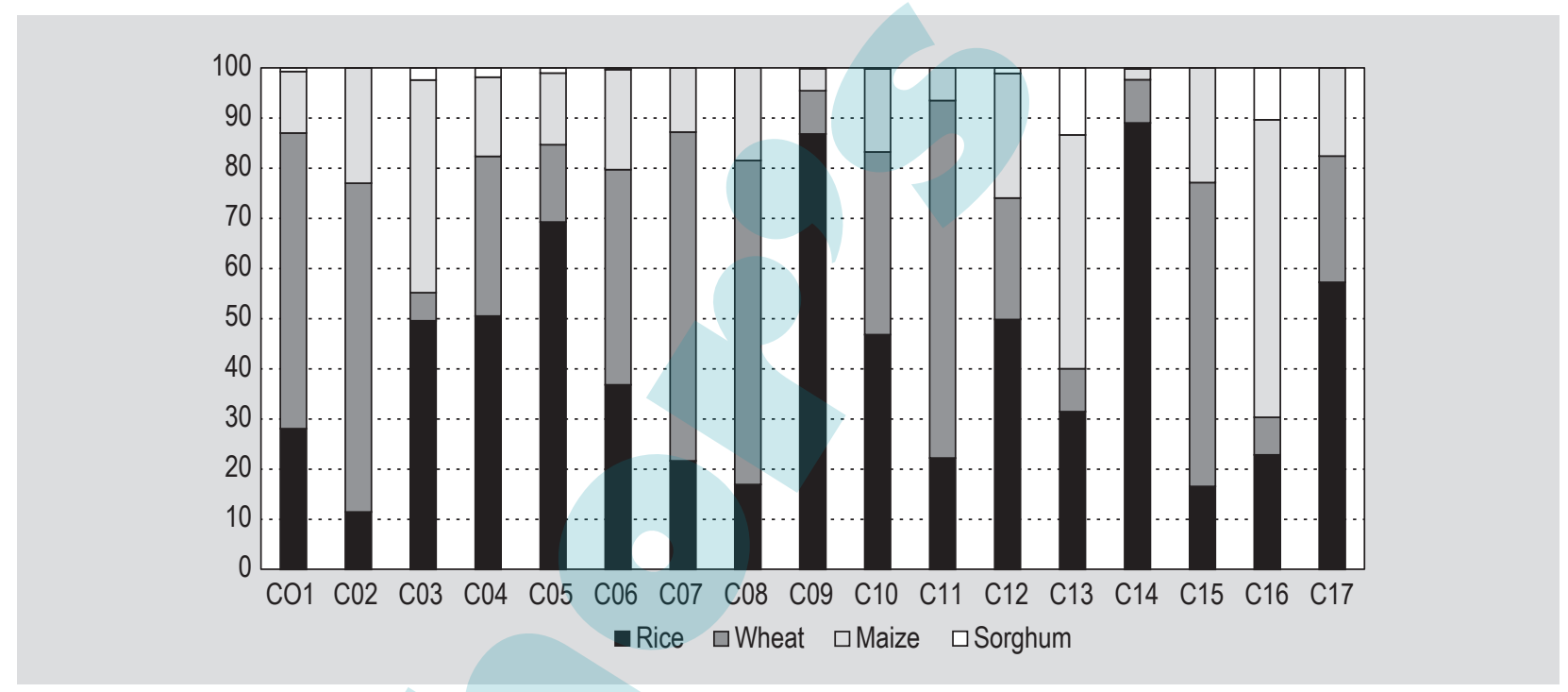

Figure 4. Impact of maize, rice, sorghum and wheat on the total aflatoxin intake for each cluster. For Clusters, see Figure 1.

\section{Discussion}

In this study, we reported data on aflatoxin contamination in maize, rice, wheat and sorghum grains obtained from the published literature and the GEMS/Food database. Literature data concerned samples collected in 64 countries; data from the GEMS/Food were submitted by 24 countries. No data on samples collected in Oceania countries were available in either dataset. Aflatoxin contamination data were mostly available for maize (54.2\% of all samples analysed in the studies), while most of the data submitted to GEMS/Food were related to rice (66.6\%). The interest in sorghum was lower in the literature in comparison with the other cereals, and the data provided to GEMS/Food were also very limited (83 samples), and did not include samples collected in African countries, the highest consumers of sorghum worldwide. This dataset will probably increase in the next few years as a FAO/WHO project on mycotoxins in sorghum is being conducted, with samples collected in the four largest producing/exporting countries of this commodity (Burkina Faso, Ethiopia, Mali, and the Sudan) (CAC, 2012). Under this project, up to February 2014, a total of 20,908 of sorghum samples have been analysed, with $3.1 \%$ of samples positive for mycotoxins, mainly aflatoxins, fumonisins, and sterigmatocystin (CAC, 2014b). Data reported in the literature may include some monitoring data submitted to the GEMS/Food database, however it was not possible to trace it back. Nevertheless, the dietary risk assessment was conducted using only the GEMS/ Food dataset. 
With the exception of rice samples from Africa and American continents, the incidence of aflatoxins and the concentration were higher in the published data than in the GEMS/Food database, probably due to sampling differences in the two data sources. Research studies normally do not follow strict sampling plans, and may include samples involved in outbreaks of mycotoxin contamination, not reflecting the general scenario of a specific region or country. This was the case of a survey conducted in Kenya, where some samples were collected in households of patients involved in the aflatoxicosis outbreak (Daniel et al., 2011). On the other hand, the data provided to the GEMS/Food by national authorities were mostly collected under monitoring programs (non-target sampling) and are more representative of mycotoxin contamination in a given country.

In general, higher incidence and concentration calculated from the literature lead to higher aflatoxin mean levels (for positive samples and for all samples) compared to GEMS/ Food data. On the other hand, mean levels calculated from published data may be overestimated, as in some studies only the concentration range was reported, and the midrange was used in the estimation (Matumba et al., 2011; Ratnavathi et al., 2012; Reddy et al., 2009; Reiter et al., 2010; Riba et al., 2010). The exclusion of the study that reported the highest value of aflatoxin contamination (maize sample $-48,000 \mu \mathrm{g} / \mathrm{kg}$ ) did not have a significant impact on the mean values for this cereal.

UB and LB of total means did not differ greatly in both datasets, which show that LOQs and or LODs of the methods used for analysis were low. The method LOQs for aflatoxins in the published studies ranged from $0.03 \mu \mathrm{g} / \mathrm{kg}$ (high-performance liquid chromatography with fluorescence detection) (Reinhold and Reinhardt, 2011; Yazdanpanah et al., 2013) to $4 \mu \mathrm{g} / \mathrm{kg}$ (thin layer chromatography) (Garrido et al., 2012). Method LOQs provided to GEMS/Food were in the range of $0.05-8.7 \mu \mathrm{g} / \mathrm{kg}$, although method description was not available in the database. It is important to emphasise that the uncertainties of the UB and LB estimations made using literature or GEMS/Food data could not be assessed due to the limitation of the information provided in both cases.

In this study, we used the UB mean concentration for each crop derived from all the data provided to GEMS/Food to estimate the total exposure. This is justifiable as the crops produced in one region may be in the international trade and consumed elsewhere. With the concentration level for each cereal remaining constant, only the consumption pattern had an effect on the total aflatoxin intake in each cluster. In four of the five clusters that showed the highest intake ( 8.8 to $17.1 \mathrm{ng} / \mathrm{kg} \mathrm{bw} /$ day), rice was the cereal that most contributed to the total intake, indicating the importance of controlling fungi infection and aflatoxin levels in this commodity.

Various studies published in the literature have estimated the dietary intake of aflatoxins (Table 5). In Malaysia (C05), the total UB intake of $58.0 \mathrm{ng} / \mathrm{kg}$ bw/day (from the consumption 38 foods, both raw and processed) (Chin et al., 2012) was much higher than the intake for cluster C05 estimated in this study ( $11.2 \mathrm{ng} / \mathrm{kg}$ bw/day). On the other hand, the UB intake estimated for the total Brazilian population, also included in cluster $\mathrm{C} 05$, was considerably lower (6.8 ng/kg bw/day) (Andrade et al., 2013), with rice contributing to $97.1 \%$ of the total intake.

The intakes obtained for $\mathrm{C} 06, \mathrm{C} 07, \mathrm{C} 09$ and $\mathrm{C} 10$ in this study were higher than the intakes found in countries belonging to these clusters. For example, the intake in France (C07), estimated through consumption of 212 foods (including rice and wheat products), was $0.9 \mathrm{ng} / \mathrm{kg} \mathrm{bw} /$ day (Sirot et al., 2013) while in China (C09) the intake of individual commodities reached $5.8 \mathrm{ng} / \mathrm{kg}$ bw/day (rice) (Ding et al., 2012), as shown in Table 5. Most studies considered cereals in the intake estimations, but focused mainly on processed products, unlike the present study in which only contamination data on the raw commodity were considered. A case in point is the assessment performed in Japan, which only considered cooked rice (Sakuma et al., 2013). Intakes found in the present study were also higher than the most recent risk assessment conducted by JECFA (Bendford et al., 2010; FAO/WHO, 2008) (0.4-3.7 ng/kg bw/day), using the previous GEMS/Food Consumption Cluster Diets (13 Clusters). The only cereal considered in the JECFA assessment was maize (including processed products), in addition to peanuts, oilseeds, cocoa products, dried fruits, peanut oil, spices, tree nuts, dried figs, butter of Karité, and other nuts.

Chronic dietary risk characterisation for aflatoxins from the consumption of cereals was conducted in this study using two available approaches. One limitation to the cancer risk approach estimate is related to the prevalence rates of the hepatitis B virus, which were derived from the prevalence map made by the CDC (2014), and agreement with the GEMS/Cluster was not always possible. For example, Brazil (C05), Canada and the United States of America (C10) are considered by $\mathrm{CDC}$ as countries with low prevalence of hepatitis B virus $\left(<2 \% \mathrm{HBsAg}^{+}\right)$. In this paper, a prevalence rate of $3 \% \mathrm{HBsAg}^{+}$was used for $\mathrm{C} 05$ and $\mathrm{C} 10$, as they include countries with low-intermediate prevalence of hepatitis B virus $\left(2-4 \% \mathrm{HBsAg}^{+}\right)$. Estimation made by the Brazilian Ministry of Health indicates that actual prevalence in the country is $0.37 \%$ (Brasil, 2010).

The total exposure to aflatoxins and the risk estimates shown in this paper may be overestimated, as they do not consider the impact of cereal processing on aflatoxin levels, 
Table 5. Dietary exposure and risk characterisation for aflatoxins estimated in the present study using GEMS/Food occurrence data and assessments reported in other studies.

\begin{tabular}{|c|c|c|c|c|}
\hline Country & Food analysed & Intake $^{1}$ & Cancer risk $^{2}$ & MOE $^{3}$ \\
\hline Present work ${ }^{4}$ & Maize, rice, sorghum and wheat & $3.0-17.1$ & $0.057-0.467$ & $56-10$ \\
\hline Africa - C03/C13 (Shephard, 2008) 5 & $\begin{array}{l}\text { Beer, groundnuts, kenkey, maize, millet, peanut } \\
\text { butter, rice, sorghum and yam chips }\end{array}$ & $1.4-850$ & $0.1-70.1$ & $121.4-0.2$ \\
\hline Brazil - C05 (Andrade et al., 2013) $)^{6}$ & $\begin{array}{l}\text { Brazil nuts, maize products, other nuts, peanuts, } \\
\text { peanut products and rice }\end{array}$ & $6.6-6.8$ & $0.0731-0.0753$ & $25.8-25.0$ \\
\hline China - C09 (Ding et al., 2012) $)^{7}$ & $\begin{array}{l}\text { Maize and derived products, peanuts, peanut oil } \\
\text { and rice }\end{array}$ & $0.11-5.8$ & $0.003-0.2$ & $24.7-0.5$ \\
\hline China - C09 (Li et al., 2014) & $\begin{array}{l}\text { Edible oils, maize, oats and other coarse grains, } \\
\text { peanuts, rice, soybean and wheat }{ }^{8}\end{array}$ & 8.3 & -9 & - \\
\hline France - C07 (Sirot et al., 2013) $)^{10}$ & 212 foods $s^{11}$ & 0.9 & 0.011 & - \\
\hline Iran - C06 (Yazdanpanah et al., 2013) & $\begin{array}{l}\text { Bread, peanuts, puffed maize snack, rice and } \\
\text { wheat flour }\end{array}$ & 3.6 & - & - \\
\hline Japan -C10 (Sakuma et al., 2013) ${ }^{12}$ & Cooked rice & 1.2 & 0.0021 & 209 \\
\hline Japan - C10 (Sugita-Konishi et al., 2010) ${ }^{13}$ & 24 foods $^{14}$ & $0.003-0.004$ & $0.00004-0.00005$ & - \\
\hline Malaysia - C05 (Chin et al., 2012) ${ }^{15}$ & 38 foods (raw and processed) ${ }^{16}$ & $28.8-58.0$ & $0.72-1.45$ & - \\
\hline New Zealand - C10 (Cressey and Reeve, 2013) ${ }^{17}$ & $\begin{array}{l}\text { Dried fruits, maize and derived products, peanut } \\
\text { and derived products, snacks, spices, tree nuts } \\
\text { and derived products }\end{array}$ & $\begin{array}{l}0.09^{18} \\
0.12^{19}\end{array}$ & $\begin{array}{l}0.0015-0.0019^{18} \\
0.0018-0.0022^{19}\end{array}$ & - \\
\hline Republic of Korea - C10 (Park et al., 2004) $)^{20}$ & $\begin{array}{l}\text { Barley and its products, maize and its products, } \\
\text { meju and rice }\end{array}$ & $1.2-5.8$ & - & - \\
\hline Worldwide - 13 Cluster Diets (FAO/WHO, 2008) & $\begin{array}{l}\text { Butter of Karité, cocoa products, dried figs, dried } \\
\text { fruits, groundnuts, maize, oilseeds, other nuts, } \\
\text { peanut oil, spices and tree nuts }\end{array}$ & $0.4-3.7$ & - & - \\
\hline 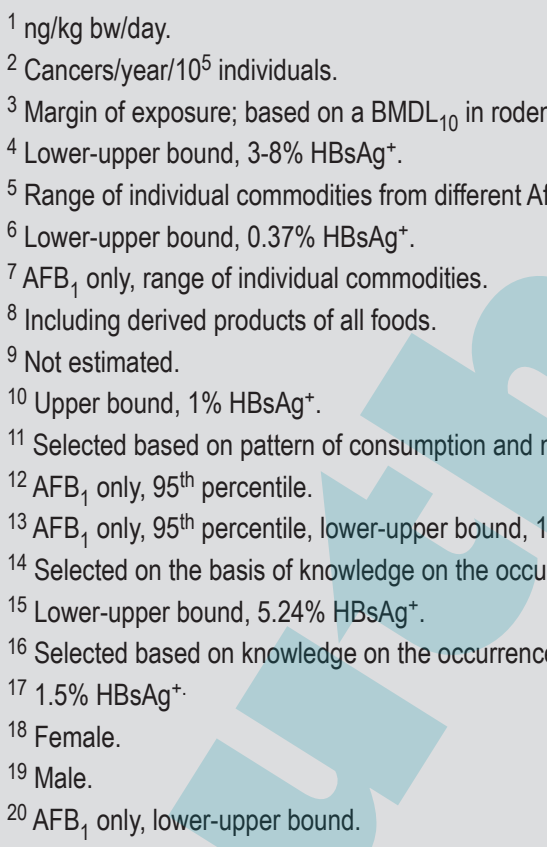 & $\begin{array}{l}\text { t of } 170 \mathrm{ng} / \mathrm{kg} \text { bw/day, except for China and Japan } \\
\text { rican countries, } 25 \% \mathrm{HBsAg}^{+} \text {. } \\
\text { nain } \mathrm{known} \text { contributors to aflatoxins exposure - inc } \\
\text { r HBsAg }{ }^{+} \text {. } \\
\text { rence of AFs - includes rice and wheat. } \\
\text { of AFs - type of food not informed. }\end{array}$ & $40 \mathrm{ng} / \mathrm{kg}$ bw/day & eat products. & \\
\hline
\end{tabular}

such as sorting, milling and cooking (Castells et al., 2007; Hussain and Luttfullah, 2009; Hwang and Lee, 2006; Park and Kim, 2006; Pearson et al., 2004; Siwela et al., 2005). On the other hand, no other sources of aflatoxin exposure were considered, such as peanuts and oil seeds, which were shown to contribute significantly to the total exposure estimated by the JECFA for the 13 Cluster Diets (FAO/ WHO, 2008; Benford et al., 2010). 
This work clearly showed that aflatoxin in rice is a major concern due to its high concentration and consumption patterns in certain regions of the world. Currently, the Codex ML for aflatoxins are only established for almonds, Brazil nuts, hazelnuts, peanuts, pistachios, and dried figs (CAC, 1995), food commodities whose average consumption is much lower than for cereals (maximum of $18.8 \mathrm{~g} /$ person/ day for peanuts in C13; WHO, 2014). The establishment of a ML for rice would remove the most contaminated samples from the market and would have a significant impact on exposure in various regions of the world. For example, if a hypothetical ML of aflatoxins in rice were set at $40 \mu \mathrm{g} / \mathrm{kg}$, the cancer risk would decrease by up to $48 \%$ in comparison with a no limit situation. At MLs of 20 and $10 \mu \mathrm{g} / \mathrm{kg}$, the risk would be reduced by up to $63 \%$. Lower limits would not have a significant impact on cancer risk for all clusters, except C09 and C14 (Asian countries), for which a ML of $1 \mu \mathrm{g} / \mathrm{kg}$ would decrease the risk by 76 and $77.8 \%$, respectively. This lower level, however, would have a significant impact on the food supply (about 20\% of the samples rejected), when compared with the higher MLs (up to $4 \%$ of the samples rejected).

The dietary risk assessment of aflatoxins in cereals conducted in this study used incidence data provided to the GEMS/Food up to July 2014, in response to a public call made by the JECFA and requested by the $7^{\text {th }}$ Session of the CCCF (REP13/CF) to support the discussion on aflatoxins in cereals at the international level. However, only 24 countries responded to this call, yielding a database which is not representative of every region of the world. For example, no rice data were available for China, a country with a high rice consumption rate and that is part of Cluster C09, which had the highest total intake of aflatoxins. In spite of these limitations, the information provided in this paper is of most relevance as it shows rice as a major driver of mycotoxin exposure in most clusters. Furthermore, the study clearly indicates the need for additional data on aflatoxin contamination in cereals, mainly from countries for which these data are lacking, in support of a more sound risk assessment, and the establishment of ML by the Codex Alimentarius.

\section{Conclusions}

Occurrence data summarised in the present study showed that raw cereals are frequently contaminated with aflatoxins, a genotoxic mycotoxin. Rice was one of the most contaminated cereals, and presented the highest concentration in both literature and GEMS/Food datasets. The dietary risk assessment conducted in this paper indicated a health concern for all 17 GEMS/Food Clusters $(\mathrm{MOE}<50)$, with the consumption of rice, wheat and/or maize as the main contributors to aflatoxin intake. Even if the impact of cereal processing on contamination levels had been considered, the MOE would still be much lower than that considered of low health concern for genotoxic compounds such as aflatoxins (>10,000).

Since cereals are staple foods worldwide, and the elimination of aflatoxins from the food supply is not possible, they should be constantly monitored and actions taken to maintain concentration as low as possible. Actions aimed at lowering the risk of aflatoxin exposure, while still ensuring the food supply, include the enforcement of codes of practices and the establishment of ML. Therefore, considering the results of this study, priority should be given to actions focusing on rice, wheat and maize.

\section{Acknowledgments}

The authors would like to acknowledge Dr. Philippe Verger from the WHO for all the support given with the GEMS/Food database, and the Brazilian Codex Group for Contaminants in Food for the suggestions given during the preparation of the draft document. We also would like to thank the financial support provided by the National Council of Scientific and Technological Development (CNPq) and the Coordination for the Improvement of Higher Education Personnel (CAPES) for supporting P.D. Andrade with a PhD scholarship.

\section{References}

Abbas, H.K., Cartwright, R.D., Xie, W.P. and Shier, W.T., 2006. Aflatoxin and fumonisin contamination of corn (maize, Zea mays) hybrids in Arkansas. Crop Protection 25: 1-9.

Abdulkadar, A.H.W., Al-Ali, A.A., Al-Kildi, A.M. and Al-Jedah, J.H., 2004. Mycotoxins in food products available in Qatar. Food Control 15: 543-548.

Abia, W.A., Warth, B., Sulyok, M., Krska, R., Tchana, A.N., Njobeh, P.B., Dutton, M.F. and Moundipa, P.F., 2013. Determination of multi-mycotoxin occurrence in cereals, nuts and their products in Cameroon by liquid chromatography tandem mass spectrometry (LC-MS/MS). Food Control 31: 438-453.

Adejumo, O., Atanda, O., Raiola, A., Somorin, Y., Bandyopadhyay, R. and Ritieni, A., 2013. Correlation between aflatoxin M-1 content of breast milk, dietary exposure to aflatoxin B-1 and socioeconomic status of lactating mothers in Ogun State, Nigeria. Food and Chemical Toxicology 56: 171-177.

Ahsan, S., Bhatti, I.A., Asi, M.R., Bhatti, H.N. and Sheikh, M.A., 2010. Occurrence of aflatoxins in maize grains from central areas of Punjab, Pakistan. International Journal of Agriculture and Biology 12: 571-575.

Almeida, M.I., Almeida, N.G., Carvalho, K.L., Gonçalves, G.A.A., Silva, C.N., Santos, E.A., Garcia, J.C. and Vargas, E.A., 2012. Co-occurrence of aflatoxins $B_{1}, B_{2}, G_{1}$ and $G_{2}$, ochratoxin $A$, zearalenone, deoxynivalenol, and citreoviridin in rice in Brazil. Food Additives and Contaminants Part A 29: 694-703.

Alptekin, Y., Duman, A.D. and Akkaya, M.R., 2009. identification of fungal genus and detection of aflatoxin level in second crop corn grain. Journal of Animal and Veterinary Advances 8: 1777-1779. 
Andrade, P.D., Homen de Mello, M., Franca, J. and Caldas, E.D., 2013. Aflatoxins in food products consumed in Brazil: a preliminary dietary risk assessment. Food Additives and Contaminants:Part A 30: 127-136.

Asghar, M.A., Iqbal, J., Ahmed, A. and Khan, M.A., 2014. Occurrence of aflatoxins contamination in brown rice from Pakistan. Iranian Journal of Public Health 43: 291-299.

Aydin, A., Aksu, H. and Gunsen, U., 2011. Mycotoxin levels and incidence of mould in Turkish rice. Environmental Monitoring and Assessment 178: 271-280.

Ayejuyo, O.O., Olowu, R.A., Agbaje, T.O., Atamenwan, M. and Osundiya, M.O., 2011. Enzyme-linked immunosorbent assay (Elisa) of aflatoxin $B_{1}$ in groundnut and cereal grains in Lagos, Nigeria. Research Journal of Chemical Sciences 1(8): 1-5.

Bandyopadhyay, R., Kumar, M. and Leslie., J.F., 2007. Relative severity of aflatoxin contamination of cereal crops in West Africa. Food Additives and Contaminants 24: 1109-1114.

Bankole, S.A. and Mabekoje, O.O., 2004. Occurrence of aflatoxins and fumonisins in preharvest maize from south-western Nigeria. Food Additives and Contaminants 21: 251-255.

Bansal, J., Pantazopoulos, P., Tam, J., Cavlovic, P., Kwong, K., Turcotte, A.M., Lau, B.P.Y. and Scott, P.M., 2011. Surveys of rice sold in Canada for aflatoxins, ochratoxin A and fumonisins. Food Additives and Contaminants Part A 28: 767-774.

Benford, D., Leblanc, J.C. and Setzer, R.W., 2010. Application of the margin of exposure (MoE) approach to substances in food that are genotoxic and carcinogenic: example: aflatoxin $\mathrm{B}_{1}\left(\mathrm{AFB}_{1}\right)$. Food and Chemical Toxicology 48: S34-S41.

Brasil, 2010. Estudo de prevalência de base populacional das infecções pelos vírus das hepatites $\mathrm{A}, \mathrm{B}$ E C nas capitais do Brasil. Universidade de Pernambuco, Recife, Brazil. Available at: http://tinyurl.com/ ne7892n.

Brazilian Health Surveillance Agency (Anvisa), 2011. Resolução no. 7, de 18 de fevereiro de 2011. Anvisa, Brasília, Brazil.

Broggi, L.E., Pacin, A.M., Gasparovic, A., Sacchi, C., Rothermel, A., Gallay, A. and Resnik, S., 2007. Natural occurrence of aflatoxins, deoxynivalenol, fumonisins and zearalelone in maize from Entre Ríos Province, Argentina. Mycotoxin Research 23: 59-64.

Bruns, H.A., Abbas, H.K., Mascagni, H.J., Cartwright, R.D. and Allen, F., 2007. Evaluation of short-season corn hybrids in the mid-south USA. Crop Management 6. DOI: http://dx.doi.org/10.1094/CM2007-1005-01-RS.

Carvalho, R.A., Batista, L.R., Prado, G., Oliveira, B.R. and Silva, D.M., 2010. Incidence of toxigenic fungi and aflatoxins in rice. Ciência e Agrotecnologia 34: 946-952.

Castells, M., Ramos, A.J., Sanchis, V. and Marin, S., 2007. Distribution of total aflatoxins in milled fractions of hulled rice. Journal of Agricultural and Food Chemistry 55: 2760-2764.

Centers for Disease Control and Prevention (CDC), 2014. Yellow book - prevalence of chronic hepatitis b virus infection among adults 2014. Available at: http://tinyurl.com/nso32kz.

Chala, A., Taye, W., Ayalew, A., Krska, R., Sulyok, M. and Logrieco, A., 2014. Multimycotoxin analysis of sorghum (Sorghum bicolor L. Moench) and finger millet (Eleusine coracana L. Garten) from Ethiopia. Food Control 45: 29-35.
Chilaka, C.A., Kock, S., Phoku, J.Z., Mwanza, M., Egbuta, M.A. and Dutton, M.F., 2012. Fungal and mycotoxin contamination of South African commercial maize. Journal of Food Agriculture and Environment 10: 296-303.

Chin, C.K., Abdullah, A. and Sugita-Konishi, Y., 2012. Dietary intake of aflatoxins in the adult Malaysian population - an assessment of risk. Food Additives and Contaminants Part B 5: 286-294.

Codex Alimentarius Commission (CAC), 1995. Codex general standard for contaminants and toxins in food and feed - Codex Standard 193-1995. Available at: http://tinyurl.com/mpkehpr.

Codex Alimentarius Commission (CAC), 2003. Code of practice for the prevention and reduction of mycotoxin contamination in cereals, including annexes on ochratoxin a, zearalenone, fumonisins and tricothecenes - CAC/RCP 51-2003. Available at: http://www. codexalimentarius.org/download/standards/406/CXP_051e.pdf.

Codex Alimentarius Commission (CAC), 2012. Sixth session of the joint FAO/WHO food standards programme - Codex committee on contaminants in foods - matters of interest arising from FAO and WHO - Capacity building activities relevant to the work of the Codex Committee on Contaminants in Foods - CX/CF 12/6/5Add.1. Available at: http://tinyurl.com/prdl5sv.

Codex Alimentarius Commission (CAC), 2014a. Eighth session of the joint FAO/WHO food standards programme - Codex committee on contaminants in foods - discussion paper on aflatoxins in cereals CX/CF 14/8/15. Available at: http://tinyurl.com/nnejcha.

Codex Alimentarius Commission (CAC), 2014b. Eighth session of the joint FAO/WHO food standards programme - codex committee on contaminants in foods - matters of interest arising from FAO and WHO (including JECFA) - CX/CF 14/8/3. Available at: http:// tinyurl.com $/ \mathrm{p} 46 \mathrm{~g} 9 \mathrm{k} 6$.

Covarelli, L., Beccari, G. and Salvi, S., 2011. Infection by mycotoxigenic fungal species and mycotoxin contamination of maize grain in Umbria, Central Italy. Food and Chemical Toxicology 49: 2365-2369.

Cressey, P.J. and Reeve, J., 2013. Dietary exposure and risk assessment for aflatoxins in New Zealand. World Mycotoxin Journal 6: 427-437. Daniel, J.H., Lewis, L.W., Redwood, Y.A., Kieszak, S., Breiman, R.F., Flanders, W.D., Bell, C., Mwihia, J., Ogana, G., Likimani, S., Straetemans, M. and McGeehin, M.A., 2011. Comprehensive assessment of maize aflatoxin levels in Eastern Kenya, 2005-2007. Environmental Health Perspectives 119: 1794-1799.

Ding, X., Li, P., Bai, Y. and Zhou, H., 2012. Aflatoxin $B_{1}$ in post-harvest peanuts and dietary risk in China. Food Control 23: 143-148.

Dors, G.C., Bierhals, V.S. and Badiale-Furlong, E., 2011. Parboiled rice: chemical composition and the occurrence of mycotoxins. Ciência e Tecnologia de Alimentos 31: 172-177.

Dors, G.C., Caldas, S.S., Hackbart, H.C.S., Primel, E.G., Fagundes, C.A.A. and Badiale-Furlong, E., 2013. Fungicides and the effects of mycotoxins on milling fractions of irrigated rice. Journal of Agricultural and Food Chemistry 61: 1985-1990.

Egal, S., Hounsa, A., Gong, Y.Y., Turner, P.C., Wild, C.P., Hall, A.J., Hell, K. and Cardwell, K.F., 2005. Dietary exposure to aflatoxin from maize and groundnut in young children from Benin and Togo, West Africa. International Journal of Food Microbiology 104: 215-224. 
European Commission (EC), 2006. Commission regulation (EC) no 1881/2006 of 19 December 2006 - setting maximum levels for certain contaminants in foodstuffs. Official Journal of the European Union L364: 5-24.

European Food Safety Authority (EFSA), 2005. Opinion of the scientific committee on a request from EFSA related to a harmonized approach for risk assessment of substances which are both genotoxic and carcinogenic. EFSA Journal 282: 1-31.

European Food Safety Authority (EFSA), 2007. Opinion of the scientific panel on contaminants in the food chain on a request from the commission related to the potential increase of consumer health risk by a possible increase of the existing maximum levels for aflatoxins in almonds, hazelnuts and pistachios and derived products. EFSA Journal 446: 1-127.

Food and Agriculture Organization of the United Nations (FAO), 2014. FAOSTAT - Statistics division of the Food and Agriculture Organization of the United Nations 2014. Available at: http://faostat. fao.org/site/291/default.aspx.

Food and Agriculture Organization of the United Nations/World Health Organization (FAO/WHO), 1998. Joint FAO/WHO expert committee on food additives - evaluation of certain food additives and contaminants: forty-ninth report of the joint FAO/WHO expert committee on food additives. Available at: http://tinyurl.com/ pgrz8uq.

Food and Agriculture Organization of the United Nations/World Health Organization (FAO/WHO), 2005. Dietary exposure assessment of chemicals in food: report of a joint FAO/WHO consultation. May 2-6, 2005. Annapolis, MA, USA. Available at: http://tinyurl.com/q6hxjjv.

Food and Agriculture Organization of the United Nations/World Health Organization (FAO/WHO), 2006. Evaluation of certain food contaminants - sixty-fourth report of the joint FAO/WHO expert committee on food. Available at: http://tinyurl.com/3ab7mc.

Food and Agriculture Organization of the United Nations/World Health Organization (FAO/WHO), 2008. Safety evaluation of certain food additives and contaminants - prepared by the sixty-eighth meeting of the joint $\mathrm{FAO} / \mathrm{WHO}$ expert committee on food additives (JECFA). Available at: http://tinyurl.com/lgxhdsn.

Food and Agriculture Organization of the United Nations/World Health Organization (FAO/WHO), 2013. Joint FAO/WHO meeting on pesticide residues - acceptable daily intakes, acute reference doses, short-term and long-term dietary intakes, recommended maximum residue limits and supervised trials median residue values recorded by the 2013 meeting. Available at: http://tinyurl. com/p6dynuk.

Food and Agriculture Organization of the United Nations/World Health Organization (FAO/WHO), 2014. Report of the eighth session of the Codex Committee on Contaminants in foods. Available at: http://tinyurl.com/lzqn82k.

Fu, Z., Huang, X. and Min. S., 2008. Rapid determination of aflatoxins in corn and peanuts. Journal of Chromatography A 1209: 271-274.

Gao, X., Yin, S., Zhang, H., Han, C., Zhao, X. and Ji, R., 2011. Aflatoxin contamination of corn samples collected from six regions of China. Wei Sheng Yan Jiu 40: 46-49.
Garrido, C.E., Pezzani, C.H. and Pacin, A., 2012. Mycotoxins occurrence in Argentina's maize (Zea mays L.), from 1999 to 2010. Food Control 25: 660-665.

Ghali, R., Belouaer, I., Hdiri, S., Ghorbel, H., Maaroufi, K. and Hedilli, A., 2009. Simultaneous HPLC determination of aflatoxins $B_{1}, B_{2}$, $G_{1}$ and $G_{2}$ in Tunisian sorghum and pistachios. Journal of Food Composition and Analysis 22: 751-755.

Ghali, R., Hmaissia-Khlifa, K., Ghorbel, H., Maaroufi, K. and Hedili, A., 2008. Incidence of aflatoxins, ochratoxin A and zearalenone in Tunisian foods. Food Control 19: 921-924.

Ghali, R., Khlifa, K.H., Ghorbel, H., Maaroufi, K. and Hedilli, A., 2010. Aflatoxin determination in commonly consumed foods in Tunisia. Journal of the Science of Food and Agriculture 90: 2347-2351.

Ghiasian, S.A., Shephard, G.S. and Yazdanpanah, H., 2011. Natural occurrence of aflatoxins from maize in Iran. Mycopathologia 172: 153-160.

Giray, B., Girgin, G., Engin, A., Aydin, B.S. and Sahin, G., 2007. Aflatoxin levels in wheat samples consumed in some regions of Turkey. Food Control 18: 23-29.

Hussain, A. and Luttfullah, G., 2009. Reduction of aflatoxin $B_{1}$ and ochratoxin A levels in polished Basmati rice (Oryza sativa Linn.) by different cooking methods. Journal of the Chemical Society of Pakistan 31: 911-915.

Hussain, A., Ali, J. and Ullah, S., 2011. Studies on contamination level of aflatoxins in Pakistani tice. Journal of the Chemical Society of Pakistan 33: 481-484.

Hussaini, A.M., Timothy, A.G., Olufunmilayo, H.A., Ezekiel, A.S. and Godwin, H.O., 2009. Fungi and some mycotoxins found in mouldy sorghum in Niger State, Nigeria. World Journal of Agricultural Sciences 5: 5-17.

Hwang, J.H. and Lee, K.G., 2006. Reduction of aflatoxin $B_{1}$ contamination in wheat by various cooking treatments. Food Chemistry 98: 71-75.

International Agency for Research on Cancer (IARC), 1993. Some naturally occurring substances: food items and constituents, heterocyclic aromatic amines and mycotoxins. IARC Monographs on the evaluation of carcinogenic risks to humans. Vol. 56. IARC, Lyon, France.

International Programme on Chemical Safety (IPCS), 2009. Environmental health criteria 240 - principles and methods for the risk assessment on chemicals in food. Available at: http://tinyurl. com/pscgglx.

Iqbal, S.Z., Asi, M.R., Ariño, A., Akram, N. and Zuber, M., 2012. Aflatoxin contamination in different fractions of rice from Pakistan and estimation of dietary intakes. Mycotoxin Research 28: 175-180.

Jakic-Dimic, D., Nesic, K. and Petrovic, M., 2009. Contamination of cereals with aflatoxins, metabolites of fungi Aspergillus flavus. Biotechnology in Animal Husbandry 25: 1203-1208.

Kaaya, A.N. and Kyamuhangire, W., 2006. The effect of storage time and agroecological zone on mould incidence and aflatoxin contamination of maize from traders in Uganda. International Journal of Food Microbiology 110: 217-223.

Karami-Osboo, R., Mirabolfathy, M,. Kamran, R., Shetab-Boushehri, M. and Sarkari, S., 2012. Aflatoxin $B_{1}$ in maize harvested over 3 years in Iran. Food Control 23: 271-274. 
Khatoon, S., Hanif, N.Q., Tahira, I., Sultana, N., Sultana, K. and Ayub, N., 2012. Natural occurrence of aflatoxins, zearalenone and trichothecenes in maize grown in Pakistan. Pakistan Journal of Botany 44: 231-236.

Khayoon, W.S., Saad, B., Lee, T.P. and Salleh, B., 2012. High performance liquid chromatographic determination of aflatoxins in chilli, peanut and rice using silica based monolithic column. Food Chemistry 133: 489-496.

Kim, D.M., Lee, N., Kim, S.M., Chung, S.H., Kim, M., Han, S.B. and Chun, H.S., 2013. Occurrence of aflatoxin and aflatoxigenic Aspergillus species in Corn Harvested in Korea. Journal of the Korean Society for Applied Biological Chemistry 56: 221-225.

Kimanya, M.E., Meulenaer, B., Tiisekwa, B., Ndomondo-Sigonda, M., Devlieghere, F., Van Camp, J. and Kolsteren, P., 2008. Co-occurrence of fumonisins with aflatoxins in home-stored maize for human consumption in rural villages of Tanzania. Food Additives and Contaminants Part A 25: 1353-1364.

Kos, J., Mastilovic, J., Hajnal, E.J. and Saric, B., 2013. Natural occurrence of aflatoxins in maize harvested in Serbia during 2009-2012. Food Control 34: 31-34.

Lai, X.W., Sun, D.L., Ruan, C.Q., Zhang, H. and Liu, C.L., 2014. Rapid analysis of aflatoxins $B_{1}, B_{2}$, and ochratoxin $A$ in rice samples using dispersive liquid-liquid microextraction combined with HPLC. Journal of Separation Science 37: 92-98.

Li, R., Wang, X., Zhou, T., Yang, D., Wang, Q. and Zhou, Y., 2014. Occurrence of four mycotoxins in cereal and oil products in Yangtze Delta region of China and their food safety risks. Food Control 35: $117-122$.

Liao, C.D., Wong, J.W., Zhang, K., Hayward, D.G., Lee, N.S. and Trucksess, M.W., 2013. Multi-mycotoxin analysis of finished grain and nut products using high-performance liquid chromatographytriple-quadrupole mass spectrometry. Journal of Agricultural and Food Chemistry 61: 4771-4782.

Liu, Z., Gao, J. and Yu, J., 2006. Aflatoxins in stored maize and rice grains in Liaoning Province, China. Journal of Stored Products Research 42: 468-479.

Lutfullah, G. and Hussain, A., 2012. Studies on contamination level of aflatoxins in some cereals and beans of Pakistan. Food Control 23: 32-36.

Makun, H.A., Dutton, M.F., Njobeh, P.B., Mwanza, M. and Kabiru A.Y., 2011. Natural multi-occurrence of mycotoxins in rice from Niger State, Nigeria. Mycotoxin Research 27: 97-104.

Martos, P.A., Thompson, W. and Diaz., G.J., 2010. Multiresidue mycotoxin analysis in wheat, barley, oats, rye and maize grain by high-performance liquid chromatography-tandem mass spectrometry. World Mycotoxin Journal 3: 205-223.

Matumba, L., Monjerezi, M., Khonga, E.B. and Lakudzala, D.D., 2011. Aflatoxins in sorghum, sorghum malt and traditional opaque beer in southern Malawi. Food Control 22: 266-268.

Mazaheri, M., 2009. Determination of aflatoxins in imported rice to Iran. Food and Chemical Toxicology 47: 2064-2066.
Miraglia, M., Marvin, H.J.P., Kleter, G.A., Battilani, P., Brera, C., Coni, E., Cubadda, F., Croci, L., Santis, B., Dekkers, S., Filippi, L.R., Hutjes, W.A., Noordam, M.Y., Pisante, M., Piva, G., Prandini, A., Toti, L., Van den Born, G.J. and Vespermann, A., 2009. Climate change and food safety: an emerging issue with special focus on Europe. Food and Chemical Toxicology 47: 1009-1021.

Mohale, S., Medina, A., Rodríguez, A., Sulyok, M. and Magan, N., 2013. Mycotoxigenic fungi and mycotoxins associated with stored maize from different regions of Lesotho. Mycotoxin Research 29: 209-219.

Mohammadi, M., Mohebbi, G.H., Hajeb, P., Akbarzadeh, S. and Shojaee, I., 2012. Aflatoxins in rice imported to Bushehr, a southern port of Iran. American-Eurasian Journal of Toxicological Sciences 4: 31-35.

Moreno, E.C., Garcia, G.T., Ono, M.A., Vizoni, E., Kawamura, O., Hirooka, E.Y. and Ono, E.Y.S., 2009. Co-occurrence of mycotoxins in corn samples from the Northern region of Parana State, Brazil. Food Chemistry 116: 220-226.

Mukanga, M., Derera, J., Tongoona, P. and Laing, M.D., 2010. A survey of pre-harvest ear rot diseases of maize and associated mycotoxins in South and Central Zambia. International Journal of Food Microbiology 141: 213-221

Muthomi, J.W., Ndung'u, J.K., Gathumbi, J.K., Mutitu, E.W. and Wagacha. J.M., 2008. The occurrence of Fusarium species and mycotoxins in Kenyan wheat. Crop Protection 27: 1215-1219.

Mwihia, J.T., Straetmans, M., Ibrahim, A., Njau, J., Muhenje, O., Guracha, A., Gikundi, S., Mutonga, D., Tetteh, C., Likimani, S., Breiman, R.F., Njenga, K. and Lewis, L., 2008. Aflatoxin levels in locally grown maize from Makueni District, Kenya. East African Medical Journal 85: 311-317.

Nguyen, M.T., Tozovanu, M., Tran, T.L. and Pfohl-Leszkowicz, A., 2007. Occurrence of aflatoxin $B_{1}$, citrinin and ochratoxin $A$ in rice in five provinces of the central region of Vietnam. Food Chemistry 105: 42-47.

Nogaim, Q.A., Amra, H.A. and Bakr, A.A., 2011. Natural occurrence of mycotoxins in corn grains and some corn products. Pakistan Journal of Life and Social Sciences 9: 1-6.

Nunes, I.L., Magagnin, G., Bertolin, T.E. and Badiale-Furlong, E., 2003. Rice comercialized in southern Brazil: micotoxicological and microscopic aspects. Ciência e Tecnologia de Alimentos 23: 190-194.

Ok, H.E., Kim, D.M., Kim, D., Chung, S.H., Chung, M.S., Park, K.H. and Chun, H.S., 2014. Mycobiota and natural occurrence of aflatoxin, deoxynivalenol, nivalenol and zearalenone in rice freshly harvested in South Korea. Food Control 37: 284-291.

Oliveira, T.R., Barana, A.C., Jaccound-Filho, D.S. and Neto, F.F., 2010. Contamination evaluation for total aflatoxins and zearalenone in varieties of Landraces Maize (Zea mays L.) through ELISA immunoenzymatic method. Revista Brasileira de Tecnologia Agroindustrial 4: 179-185.

Oruc, H.H., Cengiz, M. and Kalkanli, O., 2006. Comparison of aflatoxin and fumonisin levels in maize grown in Turkey and imported from the USA. Animal Feed Science and Technology 128: 337-341.

Oueslati, S., Romero-González R., Lasram, S., Frenich, A.G. and Vidal. J.L., 2012. Multi-mycotoxin determination in cereals and derived products marketed in Tunisia using ultra-high performance liquid chromatography coupled to triple quadrupole mass spectrometry. Food and Chemical Toxicology 50: 2376-2381. 
Pace, R., Menga, V., Vita, V., Franchino, C., Dattoli, M.A. and Fares, C., 2012. Durum and common wheat imports into Puglia during 2010: mycotoxins and grain-quality monitoring. Italian Journal of Food Science 24: 388-395.

Park, J.W. and Kim, Y.B., 2006. Effect of pressure cooking on aflatoxin $B_{1}$ in rice. Journal of Agricultural and Food Chemistry 54: 2431-2435.

Park, J.W., Kim, E.K. and Kim, Y.B., 2004. Estimation of the daily exposure of Koreans to aflatoxin $\mathrm{B}_{1}$ through food consumption. Food Additives and Contaminants 21: 70-75.

Pearson, T.C., Wicklow, D.T. and Pasikatan. M.C., 2004. Reduction of aflatoxin and fumonisin contamination in yellow corn by high-speed dual-wavelength sorting. Cereal Chemistry 81: 490-498.

Pitt, J.I., Taniwaki M.H. and Cole, M.B., 2013. Mycotoxin production in major crops as influenced by growing, harvesting, storage and processing, with emphasis on the achievement of food safety objectives. Food Control 32: 205-215.

Probst, C., Bandyopadhyay, R. and Cotty, P.J., 2014. Diversity of aflatoxin-producing fungi and their impact on food safety in subSaharan Africa. International Journal of Food Microbiology 174: 113-122.

Probst, C., Njapau, H. and Cotty, P.J., 2007. Outbreak of an acute aflatoxicosis in Kenya in 2004: Identification of the causal agent. Applied and Environmental Microbiology 73: 2762-2764.

Rahman, A. and Jinap, S., 2010. Validation of the procedure for the simultaneous determination of aflatoxins ochratoxin A and zearalenone in cereals using HPLC-FLD. Food Additives and Contaminants Part A 27: 1683-1693.

Ratnavathi, C.V., Komala, V.V., Kumar, B.S.V., Das, I.K. and Patil, J.V., 2012. Natural occurrence of aflatoxin $B_{1}$ in sorghum grown in different geographical regions of India. Journal of the Science of Food and Agriculture 92: 2416-2420.

Reddy, K.R.N. and Baharuddin, S., 2010. A preliminary study on the occurrence of Aspergillus ssp. and aflatoxin $\mathrm{B}_{1}$ in imported wheat and barley in Penang, Malaysia. Mycotoxin Research 26: 267-271.

Reddy, K.R.N., Reddy, C.S. and Muralidharan, K., 2009. Detection of Aspergillus spp. and aflatoxin $\mathrm{B}_{1}$ in rice in India. Food Microbiology 26: 27-31.

Reinhold, L. and Reinhardt, K., 2011. Mycotoxins in foods in Lower Saxony (Germany): results of official control analyses performed in 2009. Mycotoxin Research 27: 137-143.

Reiter, E.V., Vouk, F., Boehm, J. and Razzazi-Fazeli, E., 2010. Aflatoxins in rice - a limited survey of products marketed in Austria. Food Control 21: 988-991.

Riba, A., Bouras, N., Mokrane, S., Mathieu, F., Lebrihi, A. and Sabaou, N., 2010. Aspergillus section Flavi and aflatoxins in Algerian wheat and derived products. Food and Chemical Toxicology 48: 2772-2777.

Rocha, L.O., Nakai, V.K., Braghini, R., Reis, T.A., Kobashigawa, E. and Corrêa, B., 2009. Mycoflora and co-occurrence of fumonisins and aflatoxins in freshly harvested corn in different regions of Brazil. International Journal of Molecular Sciences10: 5090-5103.

Sakuma, H., Watanabe, Y., Furusawa, H., Yoshinari, T., Akashi, H., Kawakami, H., Saito, S. and Sugita-Konishi, Y., 2013. Estimated dietary exposure to mycotoxins after taking into account the cooking of staple foods in Japan. Toxins 5: 1032-1042.
Sangare-Tigori, B., Moukha, S., Kouadio, H.J., Betbeder, A.M., Dano, D.S. and Creppy, E.E., 2006. Co-occurrence of aflatoxin $B_{1}$, fumonisin $\mathrm{B}_{1}$, ochratoxin $\mathrm{A}$ and zearalenone in cereals and peanuts from Côte d'Ivoire. Food Additives and Contaminants 23: 1000-1007.

Sani, A.M., Azizi, E.G., Salehi, E.A. and Rahimi, K., 2014. Reduction of aflatoxin in rice by different cooking methods. Toxicology and Industrial Health 30: 546-550.

Shah, H.U., Simpson, T.J., Alam, S., Khattak, K.F. and Perveen, S., 2010. Mould incidence and mycotoxin contamination in maize kernels from Swat Valley, North West Frontier Province of Pakistan. Food and Chemical Toxicology 48: 1111-1116.

Shephard, G.S., 2008. Risk assessment of aflatoxins in food in Africa. Food Additives and Contaminants: Part A 25: 1246-1256.

Shephard, G.S., Burger, H.M., Gambacorta, L., Krska, R., Powers, S.P., Rheeder, J.P., Solfrizzo, M., Sulyok, M., Visconti, A., Warth, B. and Van der Westhuizen, L., 2013. Mycological analysis and multimycotoxins in maize from rural subsistence farmers in the former Transkei, South Africa. Journal of Agricultural and Food Chemistry 61: 8232-8240.

Sirot, V., Fremy, J.M. and Leblanc, J.C., 2013. Dietary exposure to mycotoxins and health risk assessment in the second French total diet study. Food and Chemical Toxicology 52: 1-11.

Siwela, A.H., Siwela, M., Matindi, G., Dube, S. and Nziramasanga, N., 2005. Decontamination of aflatoxin-contaminated maize by dehulling. Journal of the Science of Food and Agriculture 85: 2535-2538.

Soleimany, F., Jinap, S., Faridah, A. and Khatib, A., 2012. A UPLCMS/MS for simultaneous determination of aflatoxins, ochratoxin A, zearalenone, DON, fumonisins, T-2 toxin and HT-2 toxin, in cereals. Food Control 25: 647-653.

Soleimany, F., Jinap, S., Rahmani, A. and Khatib A., 2011. Simultaneous detection of 12 mycotoxins in cereals using RP-HPLC-PDA-FLD with PHRED and a post-column derivatization system. Food Additives and Contaminants Part A 28: 494-501.

Sugita-Konishi, Y., Nakajima, M., Tabata, S., Ishikuro, E., Tanaka, T., Norizuki, H., Itoh, Y., Aoyama, K., Fujita, K., Kai, S. and Kumagai, S., 2006. Occurrence of aflatoxins, ochratoxin A, and fumonisins in retail foods in Japan. Journal of Food Protection 69: 1365-1370.

Sugita-Konishi, Y., Sato, T., Saito, S., Nakajima, M., Tabata, S., Tanaka, T., Norizuki, H., Itoh, Y., Kai, S., Sugiyama, K., Kamata, Y., Yoshiike, N. and Kumagai, S., 2010. Exposure to aflatoxins in Japan: risk assessment for aflatoxin $\mathrm{B}_{1}$. Food Additives and Contaminants: Part A 27: 365-372.

Sun, G., Wang, S., Hu, X., Su, J., Zhang, Y., Xie, Y., Zhang, H., Tang, L. and Wang, J. S., 2011. Co-contamination of aflatoxin $B_{1}$ and fumonisin $B_{1}$ in food and human dietary exposure in three areas of China. Food Additives and Contaminants Part A 28: 461-470.

Sy, M.M., Feinberg, M., Verger, P., Barre, T., Clemencon, S. and Crepet, A., 2013. New approach for the assessment of cluster diets. Food and Chemical Toxicology 52: 180-187.

Toteja, G.S., Mukherjee, A., Diwakar, S., Singh, P., Saxena, B.N., Sinha, K.K., Sinha, A.K., Kumar, N., Nagaraja, K.V., Bai, G., Prasad, C.A.K., Vanchinathan, S., Roy, R. and Parkar, S., 2006. Aflatoxin $\mathrm{B}_{1}$ contamination in wheat grain samples collected from different geographical regions of India: a multicenter study. Journal of Food Protection 69: 1463-1467. 
US Food and Drug Administration (USFDA), 2000. Guidance for industry: action levels for poisonous or deleterious substances in human food and animal feed. Available at: http://tinyurl.com/ m6dgula.

Warth, B., Parich, A., Atehnkeng, J., Bandyopadhyay, R., Schuhmacher, R., Sulyok, M. and Krska, R., 2012. Quantitation of mycotoxins in food and feed from Burkina Faso and Mozambique using a modern LC-MS/MS multitoxin method. Journal of Agricultural and Food Chemistry 60: 9352-9366.

World Health Organization (WHO), 2014. GEMS/Food Consumption Cluster Diets 2014 Available at: http://www.who.int/nutrition/ landscape_analysis/nlis_gem_food/en.

Yazdanpanah, H., Zarghi, A., Shafaati, A.R., Foroutan, S.M., AboulFathi, F., Khoddam, A., Nazari, F. and Shaki, F., 2013. Analysis of aflatoxin $B_{1}$ in Iranian foods using HPLC and a monolithic column and estimation of its dietary intake. Iranian Journal of Pharmaceutical Research 12: 83-89.
Yu, F.Y., Gribas, A.V., Vdovenko, M.M. and Sakharov, I.Y., 2013. Development of ultrasensitive direct chemiluminescent enzyme immunoassay for determination of aflatoxin $B_{1}$ in food products. Talanta 107: 25-29.

Zhu, Z., Liu, G., Chen, Y. and Cheng, J., 2013. Assessment of aflatoxins in pigmented rice using a validated immunoaffinity column method with fluorescence HPLC. Journal of Food Composition and Analysis 31: 252-258.

Zinedine, A., Brera, C., Elakhdari, S., Catano, C., Debegnach, F., Angelini, S., Santis, B., Faid, M., Benlemlih, M., Minardi, V. and Miraglia, M., 2006. Natural occurrence of mycotoxins in cereals and spices commercialized in Morocco. Food Control 17: 868-874. 


$$
y
$$

